\title{
Economic, social and biological attributes of two marine reserves within New Zealand
}

By

Ursula A. Rojas Nazar

\author{
A thesis submitted to \\ Victoria University of Wellington \\ In fulfilment of the requirements for the degree of \\ Doctor of Philosophy in Marine Biology.
}

2013

VICTORIA UNIVERSITY OF WELLINGTON

Te Whare Wānanga o te Ūpoko o te Ika a Māui

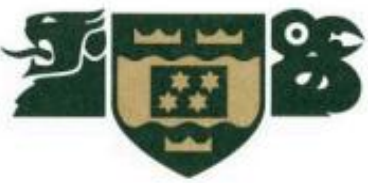


This thesis was conducted under the supervision of:

Dr James J Bell (Primary Supervisor)

Victoria University of Wellington

Wellington, New Zealand

Dr Jonathan PA Gardner (Co-Supervisor)

Victoria University of Wellington

Wellington, New Zealand

And

Dr Ross Cullen (Co-Supervisor)

Lincoln University

Christchurch, New Zealand 


\section{Abstract}

Marine Reserves (MRs) are amongst the most common tools used for marine conservation around the world. New Zealand (NZ) has 34 MRs protecting approximately 7.6\% of NZ's territorial seas. In NZ the main purpose of MRs is to allow scientific research to be conducted in the absence of human disturbance. The establishment of MRs around the country produces different biological, social and economic effects in the surrounding communities. However, the majority of previous MR studies have evaluated the biological effects of protection and not the social and economic effects. This thesis investigates how established MRs are performing in terms of social, economic, social and biological goals and contributing to society's well-being within New Zealand. For this research I conducted research at two MRs. The Taputeranga MR (TMR) was established in 2008, and is the newest MR established in New Zealand. It is located in the Wellington region, on the Wellington south coast, and extends from Princess Bay to Quarry Bay, protecting $8.54 \mathrm{~km}^{2}$ of coastal waters. Kapiti MR (KMR), which is one of the oldest MRs in New Zealand, was established in 1992 in the Wellington region, approximately $50 \mathrm{~km}$ north of Wellington city. It is located on the Kapiti coast in front of Paraparaumu beach. The KMR covers $20.90 \mathrm{~km}^{2}$ of coastal water, divided into two parts; the largest part is $17.50 \mathrm{~km}^{2}$ and the smaller part is $3.4 \mathrm{~km}^{2}$.

In this thesis I am starting to explore the financial cost of the MRs (chapter 2), where I attempted to estimate all of the costs required to establish a MR. The Taputeranga MR was used as a case study along with an analysis of the management costs for four other MRs. I aimed to find predictor variables across these five MRs to explain differences in their management cost. In addition, I also estimated the displacement cost to fishermen. Results showed that the Taputeranga's pre-establishment process cost approximately NZ $\$ 508,000$, and the establishment process cost approximately NZ \$ 354,000. In addition, the average management cost across five MRs per year was around NZ $\$ 63,000$ year $^{-1}$. With respect to the predictor variables, the Akaike Information Criterion (AICc) analysis showed that MR size best explains cost, where small MRs are more expensive to maintain than big MRs. The displacement cost was estimated as NZ \$22,000 approximately per vessel. 
I also researched and examined the social impacts of MRs (chapter 3). The aim of this chapter was to explore the human dimensions of the TMR and KMR and a hypothetical MR as a control area. I used a series of questionnaires with five main groups affected by the establishment of the MRs. Results showed that of the people who conducted activities close to the TMR and KMR, nobody selected either area specifically because there was a MR in the vicinity. With respect to MR knowledge, the majority of people at both MRs and at the hypothetical MR believed they knew what a MR was, however, nobody could provide a correct description of the main reasons for MR designation in New Zealand. Most groups surveyed at KMR indicated that its establishment had not personally affected them. At TMR, all groups believed they had experienced direct (personal) and indirect problems since the establishment of the MR. At the hypothetical MR, the majority of respondents perceived that its establishment would not cause any personal or family problems. I found that respondents at both MRs and the hypothetical MR believed that MRs are a good tool for protecting the environment.

I also develop a framework to understand and estimate MR goods and services by using the Millennium Ecosystem Assessment framework (chapter 4). The aim of this study was to identify and determine use and non-use values of the Taputeranga MR and Kapiti MR. At KMR and TMR I identified eight main value-categories: (1) Commercial fishing benefits from MR, (2) Nature-based tourism, (3) Education, (4) Research, (5) Public recreation, (6) Recreational fishing benefit from MR, (7) Ecosystem health, and (8) Existence - Bequest value. The existence-bequest values (non-use values) were estimated based on the public's willingness to pay (WTP) and found to have a mean value of NZ \$61.54 at the TMR and NZ $\$ 31.45$ at the KMR per household/year.

After being exploring cost of MRs, social effects of MRs and MR goods and services, I researched the biological effects of MRs. For this I examined the effect of MRs on rock lobster (Jasus edwardsii) biomass and abundance (chapter 5). I investigated how rock lobsters (RLs) (Jasus edwardsii) have responded to the protection afforded by the TMR and KMR by comparing rock lobster Catch Per Unit Effort (CPUE) between reserve and nonreserve areas. The average CPUE was higher inside both MRs than outside. Also bigger RLs were caught inside both MRs'. In addition, the TMR catches were twice as high compared with historical catches, and the KMR compared with historical catches were 1.93 times higher. 
By integrating all these different chapters and methodologies I have been able to provide insights that will help in the future of conservation of MRs, by improving the level of information for better decision-making, improving the communication between decisionmakers and stakeholders and to build better relationships between researchers and nonextractive users of MRs. Moreover, I provide recommendations that could be useful to include within the current Marine Protected Area Policy and potentially improve it. These recommendations also attempt to minimize the time and costs involved in MRs from the preestablishment stages, by creating effective and formal alliances between different groups of stakeholders. 


\section{Dedicated to my son Sebastian, my loved Cristian, my mother and father}

\section{Acknowledgments}

First of all I would like to thank my supervisors James Bell, Jonathan Gardner and Ross Cullen for giving me the opportunity to conduct this research and for their valuable and critical assessment and advice through the course of my study. Through our long conversations they helped me become a dedicated researcher with an ability to think critically

I would like to thank all the people that in one way or another helped me to achieve my targets in this research. I am particularly grateful to my son Sebastian, and my partner Cristian, as well as the newest family members Maty and Cony, for constantly supporting me and for their patience. I really love them, and without their support my time in New Zealand would have been very difficult. Many thanks for believing in me, I truly appreciate that.

Also important has been the support of all those friends and colleagues that have helped make my thesis better with their ideas, logistic support and conversations that made my thesis and my life in New Zealand so much better, I would like to thanks Fernanda, Agnes, Mike M-Y., Cesario, Simona Sandra, Tyler, Tim, Keko, Andrea, Marita, Marce \& Cristian, Pauli, Paul M., Alejandro, Ceviche, Sonja, Poncho, Colin R., Andrew C., Alejandra P., Alejandra Mc., Alix, John, Michael G.

I am also grateful to the crawfishing crew: Michael Meredyth-Young, Don Nelson, Hawea Tomoana, Seba, Cristian \& Matias C., Simona, Cesario, Ian, Alejandro, Pauli, Henrieta, Teresa, Alejandra, Hayden, Katja, Tim, Daniela, Tyler, Fernanda, Leana, Luke, Smrutica, Rodney, Graham, Katia, Flyn, Shane P.

Ewa K. for helping with the English and the questionnaire design; Peter H. for promoting this study between locals, Nicky F., Phoebe A., Mathew N. for their help with the questionnaire as interviewers.

I also acknowledge the support of public organizations, businesses, services and clubs at national and community level who enabled me to get alongside and fully understand the 
social, political, and economic significance of marine reserves: Daryl Sykes and The New Zealand Rock Lobster Industry Council Ltd; Debbie F., Helen K. and Peter S. (DOC); NIWA, Forest and Bird; Island Bay, Paraparaumu and Waikanae Public libraries; the Bowling Club Island Bay; Kapiti Underwater Club; Raumati Fishing club; Waikanae Fishing club; Owhiro Bay School; Island Bay School; Houghton Valley School; Raumati Beach School; St Francis de Sales School; Paraparaumu Beach School; Paraparaumu College, Kapiti College, Te Ra School, Tawa School, Wellington Girls College, Berhampore School, Evans Bay Intermediate, Karori Normal School, Karori West Normal School, Kelburn Normal School, Lyall Bay School, Raroa Normal Intermediate, Ridway School, South Wellington Intermediate, Miramar Christian School, St Mark's Church School, St Theresa's School; Island Bay divers; Splash Gordon Diving shop; Dive Kapiti (Ben) and Kapiti Tours and Zoe S (EMR).

I want to thank the VUW Staff, for constantly supporting me as student and person. Special thanks to Patricia S., Shona D.S., Marry M., Sandra T., Paul M., Magdalen S., Jan S. and Maria G. for their patience and always being willing to help and assist the Chilenos.

I wish to thank those agencies that have funded my studies as well as my research the CONYCTYT-Chile, Department of Conservation (DOC) - New Zealand. I am also thankful to Victoria University of Wellington and Victoria University Coastal Ecology Laboratory (VUCEL) for letting me be part of their community. I acknowledge the English EPP scholarship and the submission scholarship that provided me with the financial support necessary.

Finally, I would like to thanks to my family in Chile. Despite the geographical distance your on-going love and support has sustained me through this research endeavour. Los amo mucho con todo mi corazón! 


\section{Thesis outputs}

Ursula Rojas-Nazar, Jonathan Gardner, Ross Cullen, and James Bell. 2009. Local perceptions of and satisfaction levels for the Taputeranga Marine Reserve, Wellington, New Zealand. New Zealand Marine Society, Annual conference in Auckland, September 2009. Poster

Ursula Rojas-Nazar, Jonathan Gardner, Ross Cullen, Matthew Nitschke, Nicky Fitzgibbon, Phoebe Argyle, and James Bell. 2010. Current social status of two marine reserves in New Zealand: marine reserve knowledge, perceptions, satisfaction levels and attitudes. New Zealand Marine Society, Annual conference in Wellington

Ursula Rojas-Nazar, Jonathan Gardner, and James Bell. 2011.Marine Reserve effects on Catch Per Unit Effort (CPUE) of rock lobster (Jasus edwardsii). 25th International Congress for Conservation Biology, Auckland, New Zealand. December, 2011. Poster

Ursula Rojas-Nazar, Ross Cullen, Jonathan Gardner and James Bell. 2011. Estimating the value of two Marine Reserves in New Zealand via public 'willingness to pay'. 25th International Congress for Conservation Biology, Auckland, New Zealand. December, 2011. Oral Presentation 


\section{Table of Contents}

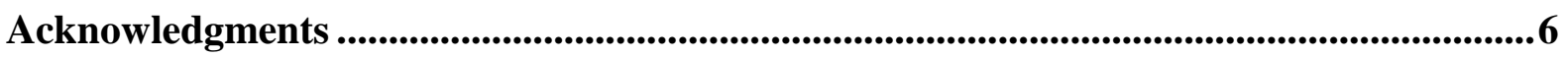

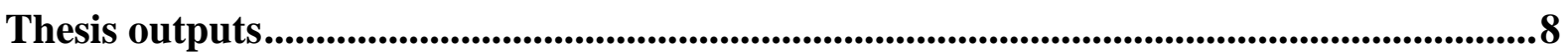

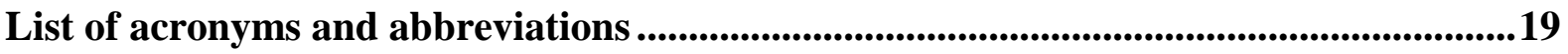

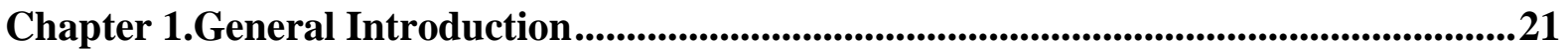

Chapter 2. Estimating the cost of marine reserve establishment and management in

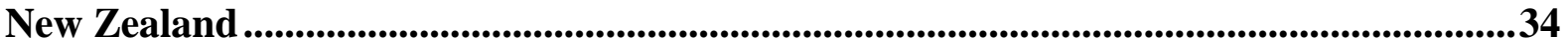

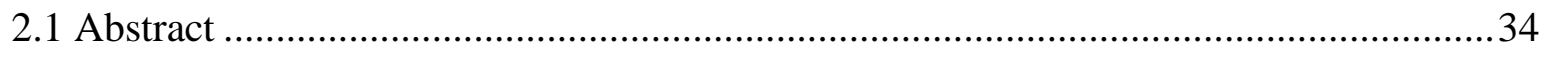

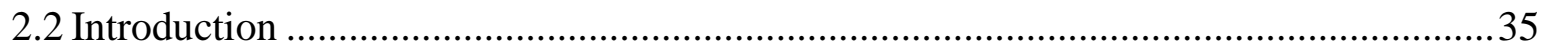

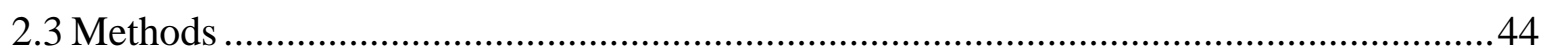

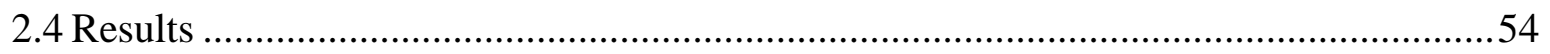

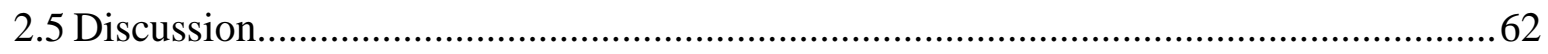

Chapter 3.The social impacts of two marine reserves: the perceptions of users and the

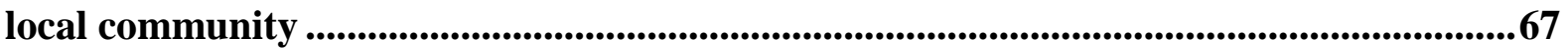

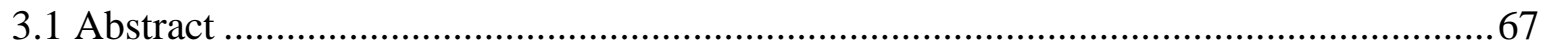

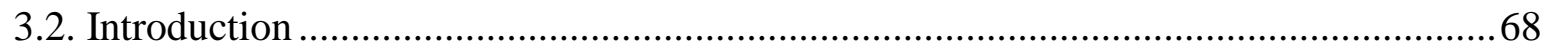

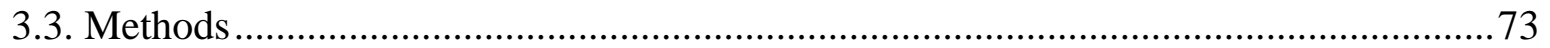

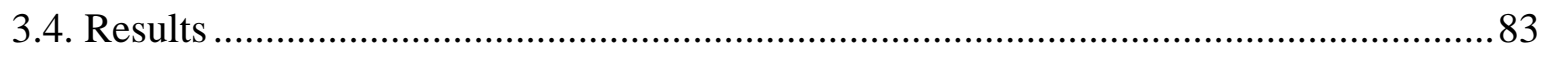

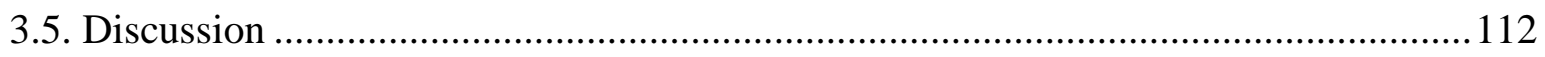

Chapter 4.Understanding the use and non-use values of no-take marine protected areas: case studies from the Taputeranga and Kapiti Marine Reserves..................................119

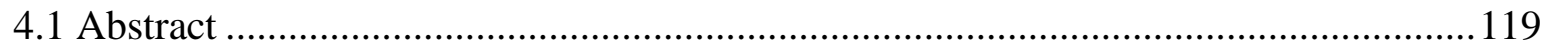

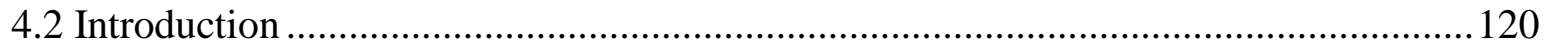

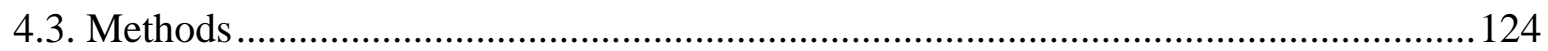

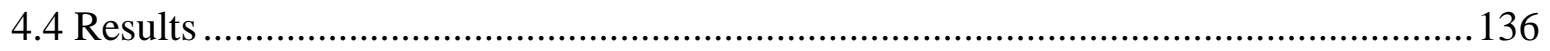

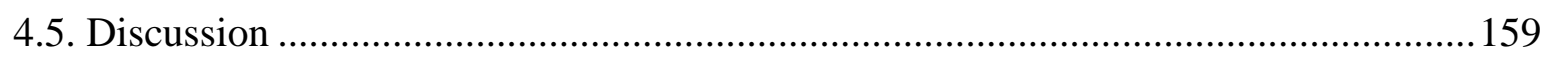

Chapter 5. No-take areas: protection effects on rock lobster (Jasus edwardsii) populations.............................................................................................................................................................. 165 


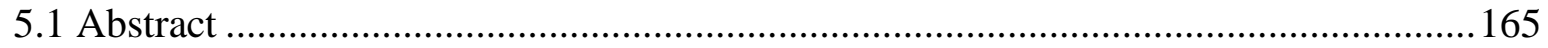

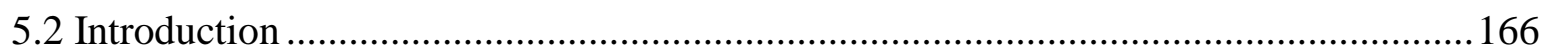

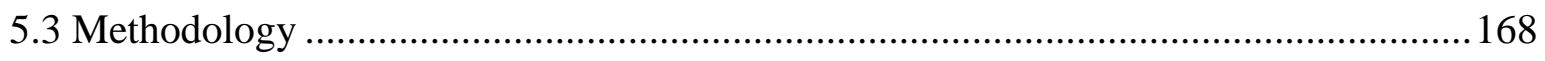

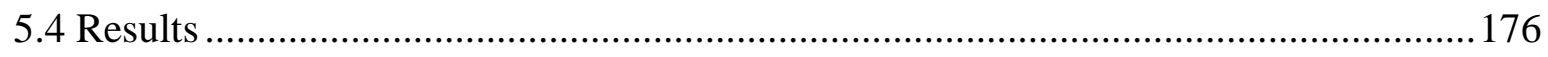

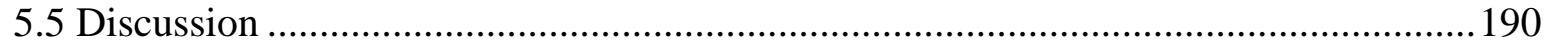

Chapter 6.General Discussion........................................................................................................197

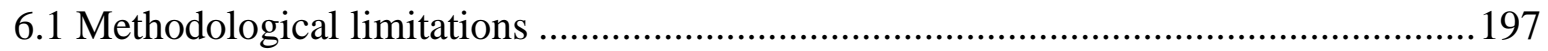

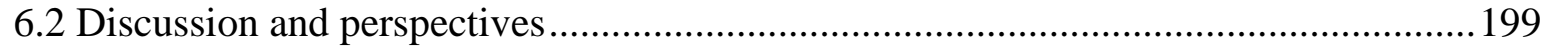

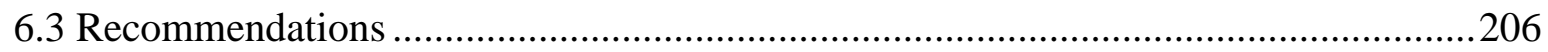

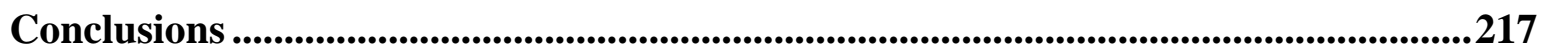

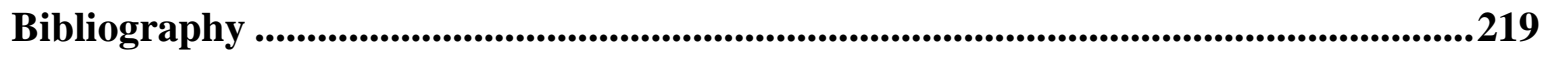




\section{List of Figures}

Figure 2.1a: Marine reserve boundaries proposed during the establishment process. Image from the Royal Forest and Bird Protection Society of New Zealand files. Different colours showing different years proposed.

Figure 2.1b: Current marine reserve boundaries. Image from Department of Conservation webpage.

Figure 2.2: Location of study sites in five regions of New Zealand. (a) Taputeranga Marine Reserve, (b) Kapiti Marine Reserve, (c) Tonga Island Marine Reserve, (d) $\mathrm{Te}$ Tapuwae o Rongokako Marine Reserve (RMR) and (e) Tapuae Marine Reserve. .....46

Figure 2.3: Marine reserve costs framework used in this study to determine and calculate preestablishment, establishment, management and displacement costs.

Figure 2.4: Scatter plots of management costs (NZ dollars \$) and the marine reserve size (hectares) (marine reserve $\mathrm{N}=5$ ). In the top plots are years (a) 2008/2009, (b) 2009/2010, scatter plots below are years (c) 2010/2011 and (d) average cost across years. .58

Figure 2.5: Scatter plots of management costs (NZ dollars \$) and the marine reserve age (marine reserve $\mathrm{N}=5$ ). In the top plots are years (a) 2008/2009, (b) 2009/2010, scatter plots below are years (c) 2010/2011 and (d) average cost across years.

Figure 2.6: Scatter plots of management costs (NZ dollars \$) and the marine reserve access (from 1-low access to 5-high access) (marine reserve $\mathrm{N}=5$ ). In the top plots are years (a) 2008/2009, (b) 2009/2010, scatter plots below are years (c) 2010/2011 and (d) average cost across years.

Figure 2.7: Scatter plots of management costs (NZ dollars \$) and the human population near to the marine reserve (from 1-low population to 5-high population) (marine reserve $\mathrm{N}=5$ ). In the top plots are years (a) 2008/2009, (b) 2009/2010, scatter plots below are years (c) 2010/2011 and (d) average cost across years.

Figure 2.8: Displacement of rock lobster fishermen due to the Taputeranga MR (TMR) establishment (yellow dotted lines). The yellow solid lines along the coast show the current reef fishing areas by the rock lobster fishermen.

Figure 3.1: Map showing the study sites in Wellington region, New Zealand. Two marine reserves, Kapiti (a), and Taputeranga (c), and the hypothetical marine reserve located at Plimmerton (b). Location of the hypothetical marine reserve at Plimmerton (d)....75

Figure 3.2 The main marine reserve goals perceived by respondents in this study. Responses were grouped into five main categories. Each category was split into sub-categories 89

Figure 3.3: Each graph shows all the activities considered in this study. Each bar represents relative frequency as a percentage per activity per marine reserve, at Kapiti Marine Reserve (a), Taputeranga Marine Reserve (b) and Plimmerton as the hypothetical marine reserve (c). The black colour represents those activities considered by respondents as permitted, while the proportion of people considering an activity prohibited in the marine reserve is shown in white, and grey bars show which 
respondents were unsure if the activity is prohibited or permitted in the marine reserve.

Figure 3.4: Current activities conducted by users in the marine reserves, plus the hypothetical marine reserve (Plimmerton area). Responses are calculated as relative frequency as a percentage per activity per marine reserve.

Figure 3.5: Percentage of respondents answering the question 'Has the establishment of the Kapiti/Taputeranga MR had a negative impact on you or your family?' K: Kapiti; T: Taputeranga; LB: Local business; LR: Local residents; RDFs: Recreational fishers and divers; V: Visitors; CF: Commercial fishermen.

Figure 3.6: Responses to the question at both MRs: 'Are you aware of any other problems that have arisen after the establishment the Kapiti/Taputeranga MR?' The third graph shows the percentage of people from the hypothetical marine reserve in relation to personal/familiar problems and other problems that could arise if the marine reserve is established.

Figure 3.7: Perceived benefits of marine reserves in Taputeranga and Kapiti Marine Reserves (a), and at the hypothetical marine reserve (b). The scale is from zero (negative impacts) to five (very beneficial). Errors bars represent standard deviations............ 101

Figure 3.8: Changes perceived per group in terms of flora and fauna since the Kapiti (a) and Taputeranga (b) MRs were established................................................................. 102

Figure 3.9: Perceived changes in human uses since the designation of the Kapiti (a) and Taputeranga (b) MRs. ................................................................................. 103

Figure 3.10: Expected changes in flora and fauna, and human uses in the hypothetical marine reserve if it were established 104

Figure 3.11: General attitudes toward Kapiti (a) and Taputeranga (b) marine reserve from the word association question. K: Kapiti; T: Taputeranga; LB: Local business; LR: Local residents; RDFs: Recreational fishers and divers; Vs: Visitors; CF: Commercial fishermen.

Figure 3.12: Responses concerning general attitudes regarding the environmental consequences toward potential marine reserve disestablishment at both marine reserves Kapiti (a), Taputeranga (b) and Hypothetical marine reserve (c). K: Kapiti; T: Taputeranga; LB: Local business; LR: Local residents; RDFs: Recreational fishers and divers; V: Visitors; CF: Commercial fishermen.

Figure 3.13: Responses to the hypothetical implications of future marine reserve environments if the Kapiti (a), Taputeranga (b) marine reserves and the Hypothetical marine reserve (c) were disestablished.

Figure 4.1: Sample locations according to distance from the marine reserve. (1) Closest to the MR; (2) middle distance areas from the MR; (3) those areas farthest away from the MR.

Figure 4.2: Total economic value of Taputeranga and Kapiti Marine Reserves. Option value and Bequest values were combined as they represent similar values in this case. .... 139

Figure 4.3: Projected Rock lobster biomass for Taputeranga and Kapiti Marine Reserves. The estimation was projected until 2050 by using information on harvest rates provided by commercial fishers. 
Figure 4.4: The diagram shows the Experiencing Marine Reserves (EMR) programme used in the Wellington region, which currently includes TMR. The time invested in Process 1 is variable and depends on each school. This diagram only shows the content time, and does not include non-content time that is approximately $40-60$ hours. Noncontent time is everything related to the organization and preparation of material for the EMR programme. 145

Figure 4.5: Proportion of respondents willing to pay a new environmental levy proposed for this study. 151

Figure 4.6: Main reasons provided by respondents from TMR and KMR for declining to contribute to a new annual environmental levy proposed in this study. Numbers on the $x$ axis are coded as follows: (1) I support the idea, but I cannot afford to pay based on my financial circumstances. (2) I pay income tax and GST and am opposed to any additional payments to central government. (3) I believe the marine reserve is already well managed. (4) I believe the government should seek funding from alternative sources. (5) I do not believe that paying such an amount will result in improved conservation of the marine reserve. (6) Only people who will receive direct benefits from the existence of the marine reserve should pay for the fund. (7) Conservation is not an important issue for me. (8) I do not believe if I give my money to a government fund, it will be used for that purpose.

Figure 4.7: Responses (and \pm SD) on how respondents would like the funds that are collected by an environmental levy to be used. Black bars represent Taputeranga MR and white bars represent Kapiti MR. 158

Figure 5.1: Maps showing the two marine reserves and study sites at each marine reserve used as in Wellington region, New Zealand. (a) Taputeranga MR: PH: Palmer Head, HBO: Houghton Bay Outside, HBI: Houghton Bay Inside, TI: Taputeranga Island, TSR: The Sirens Rock, WOB: Western side Owhiro Bay, RR: Red Rocks and SH: Sinclair Head. (b) Kapiti MR: HWO: Hole in the wall outside; HWI: Hole in the wall inside; ON: Onepoto; TO: Te Oneroa; TPI: Trig Point inside; TPO: Trig Point outside; KP: Kaiwharawhara Point; WP: West Point.

Figure 5.2: Statistical areas for rock lobster fishing in New Zealand CRA 4 (Fig. 5.2a). Statistical zones for rock lobster fishing in the Wellington region. The 915 area corresponds to the Wellington south coast, and the 934 area corresponds to the Kapiti Coast (Fig. 5.2b). 170

Figure 5.3: Total CPUE (kg rock lobster per pot lift; sex and seasons pooled) in Wellington south coast (statistical area 915) and Kapiti coast (statistical area 934) from 1989 to 2010. The asterisk (*) is showing no data were reported in those years (1997 and 2003) for Kapiti coast. Red arrow indicates the year that quota was introduced for RLs.

Figure 5.4: Rock lobster pots used in this study. The escape gaps are based on Ministry of Primary Industries regulations: 'Square or rectangular pots must have at least 2 escape gaps/or apertures (other than the mouth) in opposite faces of the pot. Each aperture shall not be less than $80 \%$ of the height or length of the face of the pot in which the apertures are contained. Each aperture shall have an inside dimension of not less than 54 mm x 200 mm.' (Ministry of Fisheries, 2011). 
Figure 5.5: Types of measures to determine population structure. (a, b) Tail width, between the tips of the primary spines of the 2nd segment of the tail. (c) Tail length, along the underside in a straight line just before of the rear of the calcified bar on the first segment to the tip of the middle fan of the tail. (d) Carapace width, across the carapace in the widest part of it. (e) Carapace length, from the antennal platform to the dorsal posterior margin of the carapace along the midline. Figures a $\&$ b taken from Ministry of Fisheries, the rest were made by own.

Figure 5.6: Rock lobster pictures. (a) Female rock lobster carrying eggs. Females have small pincers on the rear pair of legs, plus pleopods are in paired form on each side of the underside of female tails. (b) Male rock lobster. Male's pleopods are in single form in the tails. 175

Figure 5.7: Mean CPUE (kg rock lobster per pot lift; males and females pooled) in three different seasons from 2010 to 2012 ... 178

Figure 5.8: Mean Catch Per Unit Effort (CPUE) expressed as $\mathrm{kg}$ per pot lifted between different sites among season from Summer 2010 to Summer 2010. (a) Summer 2010, (b) Winter 2010, (c) Spring 2010, (d) Summer 2011, (e) Winter 2011, (f) Spring 2011 and (g) Summer 2012. The sites outside the reserve were (from East to West on the Wellington south coast) PH: Palmer Head, HBO: Houghton Bay Outside, HBI: Houghton Bay Inside, TI: Taputeranga Island, TSR: The Sirens Rock, WOB: Western side Owhiro Bay RR: Red Rocks and SH: Sinclair Head. 179

Figure 5.9: Mean Catch Per Unit Effort (CPUE) expressed as $\mathrm{kg}$ per pot lifted between different sites among season from Winter 2010 to Summer 2010. (a) Winter 2010, (b) Summer 2011, (c) Winter 2011, (d) Spring 2011 and (e) Summer 2012. The sites outside of the reserve were (from the south to the north of Kapiti Island), WP: West Point, KP: Kaiwharawhara Point, TPO: Trig Point outside and HWO: Hole in the wall outside. The four sites inside the reserve were: TPI: Trig Point inside, TO: Te Oneroa, ON: Onepoto and HWI: Hole in the wall inside. 180

Figure 5.10: Mean CPUE (kg rock lobster per pot lift; males and females pooled) in three different seasons from 2010 to 2012. The graph shows the catch inside and outside of Kapiti Marine Reserve. 181

Figure 5.11: Mean Catch Per Unit Effort (CPUE) expressed as $\mathrm{kg}$ per pot lifted between different seasons from 1989 to 2005. (a) Comparison between mean CPUE between area 915 (Wellington South coast) and data from Taputeranga MR inside/outside. (b) Comparison between mean CPUE between area 934 (Kapiti coast) and data from Kapiti MR inside/outside. The 915/934 data were pooled between years and separated between season. Data from this study were separated between inside and outside of the reserve, and then separated per season. 183

Figure 5.12: Box plots for rock lobster caught inside and outside Taputeranga and Kapiti Marine Reserves respectively (male and female data were pooled). Box plots show the median interquartile range (box) for carapace width $(\mathrm{mm})$ between different seasons and years. (a) Taputeranga Marine Reserve and (b) Kapiti Marine Reserve. 186

Figure 5.13: The box plots for rock lobster caught inside and outside of Taputeranga and Kapiti Marine Reserve, respectively (males and females data were pooled). Box plots 
show the median interquartile range (box) for tail width $(\mathrm{mm})$ between different season and years. (a) Taputeranga Marine Reserve and (b) Kapiti Marine Reserve. 186

Figure 5.14: Size frequency histograms (\% frequency) for male and female rock lobsters surveyed on the Wellington south coast and Kapiti Island within and outside Taputeranga and Kapiti MRs. Figures from a-d show male data, and from e-h are the female data. The measures are carapace length, carapace width, tail length and tail width. Vertical red lines are the minimum legal sizes equivalent to $54 \mathrm{~mm}$ TW for males and $60 \mathrm{~mm}$ TW for females. 188

Figure 5.15: Weight frequency histograms (\% frequency) for male (a) and female (b) rock lobsters surveyed at Wellington south coast and Kapiti Island within and outside Taputeranga and Kapiti MR. The measure is weight of rock lobster caught. Vertical red lines are the minimum legal sizes for either sex.

Figure 6.1: MPA Policy Implementation Plan. (a) Stage one: Preparation for implementation, (b) Stage two: Strategic analysis, (c) Stage three: Development of an MPA network and, (d) Stage four: Monitoring and evaluation. (Figure from the MPA Policy \&

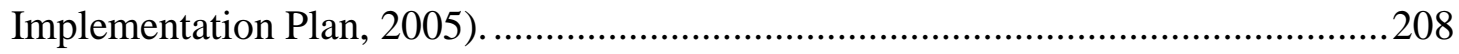

Figure 6.2a: Schematic including a new set of recommendations related to the establishment, management and on-going monitoring of marine reserves in New Zealand. The figure describes Phase I.

Figure 6.2b: Schematic including a new set of recommendations related to the establishment, management and on-going monitoring of marine reserves in New Zealand. The figure describes Phase II.

Figure 6.2c: Schematic including a new set of recommendations related to the establishment, management and on-going monitoring of marine reserves in New Zealand. The figure describes Phase III

Figure 6.2d: Schematic including a new set of recommendations related to the establishment, management and on-going monitoring of marine reserves in New Zealand. The figure describes Phase IV.

Figure 6.2e: Schematic including a new set of recommendations related to the establishment, management and on-going monitoring of marine reserves in New Zealand. The figure describes Phase V. 


\section{List of Tables}

Table 2.1: Marine reserve attributes and socioeconomic factors analysed as independent variables at five marine reserves. Size is expressed as hectares, age in years. Access is ranked from low (1) to high (5). Human population is ranked from low (1) to high (5).

Table 2.2: Pre-establishment costs used in the Taputeranga Marine Reserve from 1991 until the opening ceremony in 2008. Costs are inflation adjusted to 2012. DOC: Department of Conservation; F\&B: Royal Forest and Bird Protection Society of New Zealand; SCMRC: South Coast Marine Reserve Coalition. (*) Conservative cost with true cost in the range $-10 \% ;+30 \%$ of the listed cost. .............................................55

Table 2.3: Taputeranga Marine Reserve establishment cost. All values are adjusted to 2012

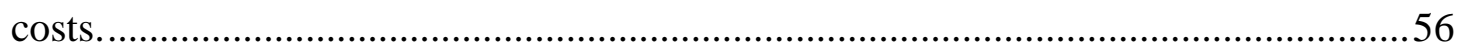

Table 2.4: Management costs from three consecutive years at five marine reserves in New Zealand. .56

Table 2.5: Marginal test using Distell analysis performed using average cost per marine reserve across years. Size is the variable that explains the greatest variation in the cost data $(12 \%)$ of all variables analysed (bold).

Table 2.6: Overall best results from AICc analysis by using average cost per marine reserve across years. The best results are shown in bold.

Table 2.7: Pearson correlation (r) and Spearman rank correlation (rho) between four variables size, age, access and human population, and the cost of management of five MRs in New Zealand in three years 2008/2009, 2009/2010 and 2010/2011.

Table 2.8: Displacement costs for rock lobster fishers associated with the establishment of the Taputeranga Marine Reserve. Annual cost and total cost from 2008 to 2011. Values are in New Zealand dollars

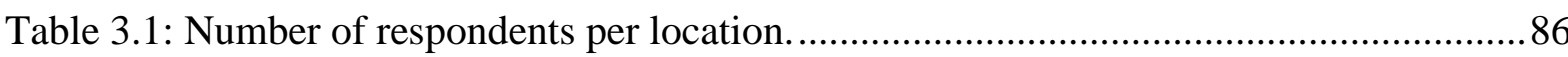

Table 3.2: Breakdown of respondents' answers with respect to 'marine conservation issues' and 'support for marine reserve establishment'. Responses are per marine reserve and per group in each marine reserve. Responses are expressed as a percentage.

Table 3.3: Mean respondents' perceptions of marine reserves regarding important features of marine reserves perceived by them. Each statement contains standard errors (SE). Responses are per group in each marine reserve including the hypothetical marine reserve (Plimmerton). Statistical comparisons (p-value) within Kapiti MR's groups and within Taputeranga MR's groups are shown in the column after Kapiti visitors. Statistical comparisons ( $\mathrm{p}$-value) between both marine reserves groups and the hypothetical reserve is in the last column in the table. LB: Local business; LR: Local residents; RDFs: Recreational fishers and divers; V: Visitors; CF: Commercial fishermen.

Table 3.4: Breakdown of mean respondents' satisfaction levels in each statement and standard errors (SE). Responses are per group in each marine reserve including the hypothetical marine reserve (Plimmerton). Statistical comparison ( $\mathrm{p}$-value) between 
Kapiti and Taputeranga marine reserves are shown in the column after Kapiti visitors. Statistic comparison ( $p$-value) between both marine reserves and the hypothetical reserve is shown in the last column in the table. LB: Local business; LR: Local residents RDFs: Recreational fishers and divers; V: Visitors; CF: Commercial fishermen. 108

Table 4.1: Activities conducted in the Taputeranga and Kapiti Marine Reserves by five dive shops. Dive shop numbers 1 and 2 corresponding to the dive shops close to the TMR; numbers 3 and 4 are the shops located in between TMR and KMR; and number 5 is the dive shop located closest to KMR. T: Activity conducted at Taputeranga Marine Reserve, K: Activity conducted at Kapiti Marine Reserve. (Wreck dive on the frigate HMNZS Wellington - F69 was sunk in 2005 to increase tourism in the area prior to the TMR establishment).

Table 4.2: The amount of diving in a year per dive activity for each dive shop. The number of dives was calculated based on good weather conditions.

Table 4.3: Sample and population socio-demographics characteristics. 150

Table 4.4: Descriptive statistics of willingness to pay (NZ\$) amount at both marine reserves. 152

Table 4.5: Breakdown of respondents' socio-demographics and their WTP (Yes/No) and WTP amount (NZ\$) and standard errors (SE). Asterisks show cases where it was not possible to calculate SE due to low numbers of respondents. 153

Table 4.6: Breakdown of respondents' awareness and their WTP (Yes/No) and WTP amount (NZ\$) and standard errors (SE). Asterisks show cases where was not impossible to calculate SE due to low number of respondents. 154

Table 4.7: Comparison between socio-demographic data for my sample and the three areas analysed: suburb, city (Wellington City and Kapiti Coast) and Wellington Region. 155

Table 4.8: Variables influencing willingness to pay an environmental levy (Yes/No) at Taputeranga and Kapiti MRs.

Table 4.9: Variables influencing WTP amount responses at Taputeranga and Kapiti MRs. 156

Table 5.1: Catch Per Unit Effort (CPUE) comparison between seasons and inside/outside in each MR (Taputeranga and Kapiti). Comparisons were made using a Two-way ANOVA ( $\mathrm{p}=0.05)$, where seasons and inside/outside were considered as fixed factors.

Table 5.2: PERMANOVA results between data source origin (origin; two levels: commercial and data collected in this study), and 'Season' (with three levels were Summer, Winter and Spring). Data from inside and outside were run independently. The analysis was based on similarity matrices calculated using Bray-Curtis coefficients. NP: Number of permutations.

Table 5.3: Pair-wise comparisons between research and historical commercial catch data for three seasons (Summer, Winter, and Spring) Data from inside and outside each MR were analysed separately. NP: Number of permutations.

Table 5.4: Average size for carapace length, carapace width, tail length, tail width and weight for rock lobsters caught inside and outside of Taputeranga and Kapiti MR (mean \pm s.e.). 
Table 5.5: Two-tailed $t$-test for a comparison of morphometric indices between lobsters from inside and outside two MRs. Significant results are shown in bold........................... 185 


\section{List of acronyms and abbreviations}

AIC: Akaike Information Criterion

BPAs: Benthic Protected Areas

CBD: Convention for Biological Diversity

CF: Commercial Fishermen

CPUE: Catch Per Unit Effort

CVM: Contingent Valuation Method

DOC: Department of Conservation

EGS: Ecosystem goods and services

ES: Ecosystem Services

EEZ: Exclusive Economic Zone

EMR: Experiencing Marine Reserves

F\&B: The Royal Forest and Bird Protection Society of New Zealand

GDP: Gross Domestic Product

GNP: Gross National Product

KMR: Kapiti Marine Reserve

LBs: Local Businesses

LRs: Local Residents

MEA: Millennium Ecosystem Assessment

MoF: Ministry of Fisheries

MPAs: Marine Protected Areas

MRs: Marine Reserves

NIMBY: Not In My Back Yard

NIWA: National Institute of Water and Atmospheric Research 
NZ: New Zealand

NZBS: New Zealand Biodiversity Strategy

NZRLIC: New Zealand Rock Lobster Industry Council

QMA: Quota management area

RDFs: Recreational Fishermen and Divers

RL: Rock lobsters

RLP: Rock lobster pots

RR: Response rates

SCMRC: South Coast Marine Reserve Coalition

SE: Standard error

SMP: Saba Marine Park

TEV: Total economic value

TMR: Taputeranga Marine Reserve

V: Visitors

VUW: Victoria University of Wellington

WCC: Wellington City Council

WSSD: World Summit on Sustainable Development

WTP: Willingness to Pay

WWF-NZ: World Wildlife Fund - New Zealand 


\section{Chapter 1.General Introduction}

\section{The importance of coastal environments and problems associated with their management}

Coastal environments provide considerable ecosystem goods and services (EGS) to humans including food, recreational opportunities and coastal protection, as well as having aesthetic and cultural benefits (Moberg and Folke, 1999). Goods and services can be defined as 'the direct and indirect benefits that people obtain from ecosystems' (Costanza et al., 1997). The wide range of factors that are contributing to the global reuction in biodiversity can also affect ecosystem functioning and the generation of EGS. In coastal marine systems activities such as fishing, aquaculture, coastal zone construction, terrestrial run-off (e.g. from mining and farming), eutrophication, the introduction of exotic species, and climate change, are major threats to biodiversity (NRC, 2001; Jenkins, 2003; Leslie et al., 2003; Restrepo et al., 2006, McDiarmid et al., 2012). As a result of the negative impacts caused by these activities, declines have been observed in numerous marine animal populations (e.g. Hutching, 2000; Myers and Worm, 2003), many habitats have suffered extensive damage and in some cases destroyed (Pauly et al., 1998, Pandolfi et al., 2003; Balmford et al., 2004). At present, human populations and coastal settlements continue to grow, thereby increasing the use of EGS, which is likely to continue into the future.

\section{Marine Protected Areas \& Marine Reserves: a potential solution to protect marine biodiversity}

Marine Protected Areas (MPAs) have been used as a solution to protect marine biodiversity, to enhance or protect some EGS, to improve the management of marine resources and also for the preservation of areas for the purpose of scientific research (such as in New Zealand). MPA is a general term that includes different types of conservation approaches, which include totally no-take, like Marine Reserves (MRs) in New Zealand, and/or partially open areas such as multiple use marine protected areas. In many cases MPAs have been proposed to contribute to the long-term sustainability and survival of ecosystems (Castilla, 1986; Moreno and Rubilar, 1997). Such protected areas are an important component of ecosystembased ocean conservation and management (NRC, 2001), and it is important to designate 
protected areas that represent different ecosystems where basic ecological processes occur (Castilla, 1976; Soulé, 1991; Moritz \& Faith, 1998; NRC, 2001).

Effective MPAs can contribute to: (1) conservation of essential habitats and populations; (2) ecosystem protection; (3) recovery of over-fished species or those at risk of extinction by biomass export to the areas outside the ,MPA via migration (Roberts et al., 2001; Pauly et al., 2002; Gell and Roberts, 2003; Halpern, 2003; Balmford et al., 2004; Hilborn et al., 2004), density-dependent dispersal and larval export (Sumaila, 1998; Conrad, 1999; Hannesson, 2002; Armstrong, 2007); (4) sustainable resource use; (5) education, recreation and culture; and (6) the generation of an environment in which research can be conducted without major anthropogenic influences (Castilla, 1976; NRC, 2001; Shipp, 2003).

Spalding et al (2008) estimated that there are 5,045 MPAs around the world, which represents less than $1 \%$ of the world's oceans. An international agreement currently exists between countries (193 countries), where signatories' committed: “By 2020, at least 17 per cent of terrestrial and inland water areas, and 10 per cent of coastal and marine areas, especially areas of particular importance for biodiversity and ecosystem services, are conserved through effectively and equitably managed, ecologically representative and well connected systems of protected areas and other effective area-based conservation measures, and integrated into the wider landscapes and seascapes" (CBD, 2010). Decisions to close critical habitats will have many effects on the users of these environments, including both social and economic effects.

\section{Social and economic evaluation of Marine Protected Areas}

It is important to evaluate the consequences of different management decisions, and it is not enough to know that ecosystem services are valuable, we need to know just how valuable they are, and how their value is affected by different forms of protection and management, and how the value changes over time. It has often been argued that a major reason for the failure to conserve natural ecosystems is because we do not realise how valuable they are (Barbier et al., 1994; Perrings et al., 1995; Swanson, 1995; Patterson and Cole, 1999; Tacchoni, 2000; Nunes et al., 2003; Mendonca et al., 2003; Kettunen, 2006, Beaumont, et al., 2008). Many people still have shared views about common resources, for example on 'The tragedy of the commons' published by Hardin (1968), where he showed the problematic to 
manage and control shared resources (such as marine). Hardin showed how this problematic, normaly finish in a tragedy, due to people acting induvidualy and rationally according to each self's interest, without considering the value of shared resources. Economic evaluation can be a powerful tool for conserving important ecosystem services (nationally and local level), as it offers a way to compare diverse benefits and costs associated with ecosystems by attempting to measure and express them in a common denominator, typically a monetary unit. This enables the contributions that ecosystems provide to economic activity through goods and services to be identified, quantified and enables the promotion of efficient strategies for biodiversity conservation (Pagiola et al., 2004; Brauer et al., 2006; Beaumont et al., 2008). The majority of the literature on ecosystem goods and services has tended to focus on terrestrial environments (Beaumont et al., 2007). Balmford et al. (2004) calculated the worldwide cost of a global MPA network; they estimated that conserving 20-30\% of the world's seas might cost between U.S. \$6 billion and U.S. \$23 billion annually to run (values adjusted for 2012). However, this study ignored potential gains from improved fisheries and tourism and other likely social gains. It is likely that the estimates from Balmford et al. are not comprehensive enough for decision making, because if we want to ensure suitable environmental decisions are made, it is essential to include all social, economic and environmental impacts generated by the establishment of MPAs, including both short and long term impacts and increases or decreases in value (Daily et al., 2000).

\section{Marine reserves and other types of marine protected areas in New Zealand}

In New Zealand, the first MR, Cape Rodney-Okakari Point Marine Reserve (better known as Goat Island or Leigh Marine Reserve), was designated in November 1975 (Enderby and Enderby, 2006), and now there are 34 MRs protecting approximately 7.6\% of New Zealand's territorial seas. MRs are established under the Marine Reserve Act (1971), which is 'An act to provide for the setting up and management of areas of the sea and foreshore as marine reserves for the purpose of preserving them in their natural state as the habitat of marine life for scientific study.' Therefore MRs in NZ have been established for the principal purpose of being able to conduct scientific research in the absence of anthropogenic pressure (primarily fishing), while the main reason MRs are used in other countries are to protect marine biodiversity and support fisheries (Bohnsack and Ault, 1996; Dayton et al., 2000; Russ and Alcala, 2004; Lester et al., 2009). It is important to highlight that a MR Bill was introduced to 
Parliament on $7^{\text {th }}$ June 2002, which was expected to replace the MR Act mainly because the current MR Act is limited to preserving areas for scientific study, preventing other goals being achieved such as those laid out in the New Zealand Biodiversity Strategy (NZBS).

There are also other types of marine protection in New Zealand which are listed in table 1.1.

Table 1.1: Marine protected areas (MPAs) in New Zealand

\begin{tabular}{|c|c|}
\hline MPA & Description \\
\hline Mataitai Reserves & $\begin{array}{l}\text { Permanent areas where people can take marine resources, in keeping } \\
\text { with local sustainable management practices. However, commercial } \\
\text { fishing is not permitted. }\end{array}$ \\
\hline Taipure & $\begin{array}{l}\text { Special area for Maori culture (local Iwi or hapu). The goal of this area } \\
\text { is protection for food, spiritual or cultural gain, with ancestral } \\
\text { management. In these areas commercial fishing is allowed. }\end{array}$ \\
\hline $\begin{array}{l}\text { Areas of significant } \\
\text { conservation value }\end{array}$ & $\begin{array}{l}\text { Specific coastal marine areas regulated by Regional and Unitary } \\
\text { Councils. These areas have specific rules and methods to ensure that } \\
\text { these areas are not adversely affected. }\end{array}$ \\
\hline $\begin{array}{l}\text { Wildlife sanctuaries \& } \\
\text { refuges }\end{array}$ & $\begin{array}{l}\text { Specific and defined geographic areas for protection of particular } \\
\text { species. }\end{array}$ \\
\hline $\begin{array}{l}\text { Marine mammal } \\
\text { sanctuaries }\end{array}$ & $\begin{array}{l}\text { Refuges for marine mammals in NZ fisheries waters under the Marine } \\
\text { Mammals Protection Act 1978. The most common marine species } \\
\text { protected are dolphins, whales, seals and sea lions. In these areas } \\
\text { fishing activities are regulated and restricted. In some sanctuaries fishing } \\
\text { activities are completely prohibited. The Department of Conservation is } \\
\text { responsible for these sanctuaries. }\end{array}$ \\
\hline
\end{tabular}

Marine parks This is a more flexible conservation tool although, in NZ legislation, thre is no definition for marine parks. Marine parks have a mixture of rules and regulations based around fisheries and conservation.

Benthic Protected Areas To prevent all trawling and dredging in specific areas within the Exclusive Economic Zone (EEZ), in order to protect the seabed environment; this includes seamounts, underwater mountains and active hydrothermal vents. With this new conservation tool, the New Zealand government argues it has protected $32 \%$ of its EEZ (Ministry of Fisheries, 2009), and the government considers this conservation measure is a 'step towards meeting objectives in the New Zealand Biodiversity Strategy and ensuring that pristine areas of ocean sea-bed are maintained for posterity' (Ministry of Primary Industries, 2007). 
The New Zealand Government through the implementation of NZBS (2000) aimed to establish a network of Marine Protected Areas to protect a full range of marine habitats and ecosystems and effectively conserve marine biodiversity. Goals included having $10 \%$ of the marine environment in a network of MPAs by the past 2010 (DOC, 2008). Therefore, with the benthic protected areas the New Zealand Government claims that the conservation goal has been reached (see table 1.1). However, this conservation tool is only protecting deep seabed habitats and communities, leaving apart all habitats and communities in shallow waters.

\section{Marine reserve ecosystem services: 'Valuing marine resources and marine reserves' a case study of the Wellington South Coast}

Ecosystem goods and services can be defined as the direct and indirect benefits that people obtain from ecosystems, such as freshwater filtration and allocation, soil maintenance, erosion and flood control, and the role the environment plays in the maintenance of food resources (Costanza et al., 1997; Carter, 2006); it also includes nonmaterial benefits such as spiritual or aesthetic benefits (MEA, 2005). Ecosystem goods and services enhance human well-being, and contribute to the balance between different physical and biological processes, for example, carbon storage, food production, tourism and recreation. The Millennium Ecosystem Assessment (MEA) (2005) reported that $60 \%$ of ecosystems worldwide have been degraded or are being used in an unsustainable manner. MEA classified EGS into four categories; provisioning, regulation, supporting and cultural services. Provisioning services include food and water; regulating services include regulation of floods, drought, land degradation, and disease; supporting services include soil formation and nutrient cycling; and cultural services include recreational, spiritual, religious and other nonmaterial benefits. Any changes in these services may affect human well-being.

In the majority of cases EGS are irreplaceable, and in other cases are very difficult to provide artificially (Carter, 2006). It is widely recognised that there are major threats to the sustainability and integrity of EGS (U.S. Commission Ocean Policy, 2004; Costanza \& Kubiszewski, 2012; Egoh et al., 2012). Most of the threats result from human activity, for example, commercial fishing, oil and gas production, shipping, tourism and other traditional 
and developing industries. Nevertheless, all these activities are vital for economic growth and the welfare of populations (Wallmo and Edwards, 2008). Because of these problems, researchers have been trying to determine and quantify EGS at a global scale, and determine their value; they have also been trying to evaluate the negative impacts of processes that are impacting EGS (for example, see Costanza et al., 1997; Millennium Ecosystem Assessment, 2005).

Despite all of the research in the last few years in marine conservation fields, the information available regarding marine EGS is very limited, also the progress in this area is insufficient to counter continuing pressures and demands on the world's resources (Voora and Thrift, 2010). In addition, in recent years researchers have realised that there are other important factors that are further contributing to the decline in EGS, particularly climate change and excessive nutrient loading (MEA, 2005). For these reasons is important to continue assessing and collecting more information about the changes, effects and potential solutions for conserving and protecting EGS.

Since Costanza et al (1997), most of the studies that have focused on EGS valuation have been conducted at the global scale, so there is not much information at the local scale (e.g. regional scales). However, it is very important to determine the value of EGS from local to global scales, as well as to take account of the cost of asset depletion, pollution, introduced species, and physical damage caused to marine environments. It is also important to determine the value of leisure activities (e.g. recreational fishing, diving, and sunbathing) (Wallmo and Edwards, 2008) to facilitate an assessment of the total value of ecosystems at the local and global scale, and to determine how much the environment provides to each country (e.g. Genuine Progress Indicator, Gross Domestic Product).

Despite the environment having an intrinsic value, it is very important to understand and evaluate the utility of protected areas in terms of conserving EGS, in order to understand how much protected areas are saving and supporting (or not) human well-being. This valuation could be provided in the same monetary terms that government agencies use. Adequately valuing EGS can help decision-makers better manage natural environments so they can continue providing valuable services (Voora and Thrift, 2010).

Tourism is a major component of the New Zealand economy, where MPAs and more specifically MRs are important destinations for tourists, for example Cape Rodney - Okakari Point MR attracts over 350,000 snorkelers, divers, sightseers and marine scientists each year 
(F\&B, 2010). In 2012, the tourism industry contributed $\$ 6.2$ billion directly to GDP, or 3.3\% to New Zealand's total GDP. The indirect value to industries supporting tourism generated an additional $\$ 9.7$ billion from tourism (Ministry of Tourism, 2013). Although currently New Zealand has 34 MRs protecting approximately $7.6 \%$ of New Zealand's territorial seas (DOC, 2009), it's not clear how much of this $\$ 6.2$ billion comes from MR-related activities. Even less clear is how much EGS from MRs are contributing to the country's local and national economies. New Zealand has lacks knowledge of the value of its ecosystem goods and services, particularly in marine environments. This undervaluation is reflected in the smaller proportion of marine environments being protected compared to terrestrial protected areas, which represent more than $30 \%$ of the total land (McAlpine and Wotton, 2009). McAlpine and Wotton (2009) reported that there have been very few studies on EGS in New Zealand, in addition, there is scarcity of data to support such studies, making it more difficult to conduct an EGS valuation.

\section{The costs of establishing a Marine Reserve in New Zealand}

During 2002 in Johannesburg, at the World Summit on Sustainable Development (WSSD), 190 different countries agreed to increase the global coverage of MPAs, with the aim of creating a worldwide network by 2012 (Balmford et al., 2005, Gravestock et al., 2008). This agreement included developing interdisciplinary science collaborations. Some of the recomendations from the WSSD were to encourage more research, development and implementation of conservation programmes, monitoring systems and promote more accessibility to funds for long-term research. The outcomes also aimed to develop biological, economic and financial indicators for conservation (Balmford et al., 2005). In order to achieve all these goals proposed during the WSSD, it is necessary to have an extensive knowledge about the monetary cost of this wide ranging research (biological and socioeconomic), as well as the cost of developing and maintaining MPAs. Currently, this is very difficult because there is not enough information available to calculate what the MPA establishment and management costs are (Gravestock et al., 2008) on a global or local scale.

Knowing the real costs of establishment and effective (effectiveness should be specific defined depending on each MPA' goals) MPA management is essential for government agencies and organisations that are working and investing in conservation. They need to be able to calculate and include in their national and international budgets the true costs involved 
in MPA designation and management. Insufficient investment is likely to produce 'paper MPAs'. Paper MPAs means to those MPAs which are established by legislation, but it are not functioning as it should, then with insufficient and/or ineffective management, and result in the further degradation of the biodiversity where the MPAs are established (Wilkie et al., 2001). Therefore, it would be better to calculate the spending on current MPAs first, and then evaluate if the available budgets can covering the current expenditure, before creating more MPAs just to reach the 2012 goal from the WSSD.

\section{Marine reserve establishment: social effects in New Zealand}

Marine Reserves are one of the most widely used conservation tool used in New Zealand, and although MR establishment can produce different effects on the surrounding human communities in different countries, this has not been studied in New Zealand. These effects may be positive or negative, direct or indirect. Several authors (e.g., Halpern and Warner 2002; Fraschetti et al., 2005; McClanahan et al., 2008; Camargo et al., 2009) have concluded that social effects, such as environmental perceptions and behaviour, have not received the same attention as biological effects (such as Roberts and Polunin, 1991; Roberts and Hawkins, 2000; Goñi et al., 2001; NRC, 2001; Fraschetti et al., 2002; Gell and Roberts, 2002; Russ, 2002; Gerber et al., 2003; Goñi et al., 2001, 2006; Follesa et al., 2007; Follesa et al., 2008). This paucity of information has left an important gap in marine conservation knowledge, because social information is important for developing better and more effective conservation policies. In order to evaluate MR effectiveness, it is important to consider all effects (positive and negative) from the past to the present to prevent future social impacts, (e.g., Halpern and Warner 2002; Fraschetti et al., 2005; McClanahan et al., 2008; Camargo et al., 2009). In New Zealand, and more widely across the world, government agencies and research institutions have not yet fully considered social effects of MR establishment to the same degree that biological evaluations and monitoring have been considered.

There is little information on the social and economic effects of the MRs. Wolfenden et al. (1994) assessed community reactions to a marine reserve proposal at Te Whanganui A-Hei MR because the communities were divided into two main groups: one actively supporting the proposal, and another group actively opposing it. After the Te Whanganui A-Hei MR establishment, Craw and Cocklin (1997) assessed the social impacts. In 2003, Taylor and Buckenham assessed some of the social impacts of three MRs: Cape Rodney-Okakari Point 
MR, Tonga Island MR, and Pohatu MR. These three studies come to similar conclusions, and suggested that the consultation process was not as participative as it should have been. Therefore to establish a MR needs more work with the different community groups, such as Maori, fishers, and local business, with the aim of increasing the level of public engagement and/or consultation.

In 2008, Hunt, conducted an Economic Impact Analysis of the Cape Rodney Okakari Point (Leigh) Marine Reserve in the Rodney District. This report was focused on visitors to the reserve, ignoring other groups such as recreational/commercial fishermen and people who live in the area surrounding the MR. Hunt (2008) found that the majority of day visitors (54\%) only visited the area because of the Cape Rodney Okakari Point (Leigh) Marine Reserve.

Through a better understanding of the social effects of MPA and MR designation are very important in order to better improving relationships between conservation actions and human well-being (Camargo et al., 2009). This will make marine conservation more effective, because ultimately MPA success will depend on users and stakeholder actions (Gelcich et al., 2005a, b; Gelcich et al., 2008).

\section{Marine reserve effects beyond it boundaries}

Many marine resources have faced high rates of exploitation (Hutchings and Myers, 1994; Myers et al., 1997; Pauly et al., 2002); for example, Northeast Atlantic cod (Gadus morhua) (Sumalia and Amstrong, 2006) and the American lobster (Homarus americanus) whose abundances have dramatically declined (Buchsbaum et al., 2005). In New Zealand, examples of historical explotation include the sea lion (Phocarctos hookeri), which has been protected since 1890s, but is still considered one of the most threatened species in the world (Forest and Bird, 2008), Southern bluefin tuna (Thunnus maccoyii) and Orange roughy (Hoplostethus atlanticus) (Ministry of Fisheries, 2010).

One of the main reasons that marine resources are heavily exploited is because marine resources are significant sources of food around the world and fisheries represent a major income source in many coastal regions (BenDor et al., 2009). Because of the high exploitation rates, many fisheries are declining and becoming unsustainable, despite numerous scientific efforts to avoid collapse (Myers and Worm, 2003). For example, the Atlantic cod stocks in the cold waters off the Canadian Atlantic coast have not recovered 
since their collapse in the early 1990s, even though the cod fishery has been closed to fishing since the collapse (Trippel, 1995; Spurgeon, 1997; Sumalia and Amstrong, 2006).

Marine Reserves have the potential to enhance fisheries (See Kelly et al., 2002; Stobart et al., 2009; Goñi et al., 2010; Goñi et al., 2011). Sanchirico (2002) has referred to MRs as an investment, because MRs are likely to improve the health of habitats, increase stock abundance, create healthier fish stocks, contain individual animals that are larger and older than in fishing areas, and therefore increase population reproductive potential (also see Bohnsack, 1998; Sanchirico, 2002; Halpern and Warner, 2002; Gell and Roberts, 2003; Halpern et al., 2010).

In many cases MRs are predicted to produce benefits outside of their boundaries. The benefits could be through two mechanisms: (1) net migration of adults and juveniles across borders, termed 'spillover', and (2) export of pelagic eggs and larvae (Allison et al., 1998; Gell and Roberts, 2003; Schnier, 2005), with subsequent increased recruitment potentially improving populations residing outside the MPA (Hastings and Botsford, 1999; Pezzey et al., 2000). Therefore, MPAs and MRs may enhance harvested populations beyond their boundaries (Gell and Roberts, 2003; Kellner et al., 2007; Halpern et al., 2010).

Previous studies have demonstrated how MRs are effective for sedentary species because they spend much of their life in the reserves, particularly invertebrates (e.g. Willis et al., 2003). However, several studies have also shown how mobile species can also be protected, with results showing higher densities inside of MPAs than the nearby fishing grounds. For example, Cowgly (2002) found through an experimental catch per unit effort (CPUE) study of four shorefish species inside Tsitsikamma National Park, that densities were between 5-21 times greater than in fished grounds. In New Zealand, studies have shown positive results for a number of species with high value for fishermen (commercial and recreational). For example, snapper (Pagurus auratus) body size was 1.4 times larger than the minimum legal, and more abundant inside of the Cape Rodney - Okakari Point MR, Hahei Marine Reserve and Tawharanui Marine Park MRs (Willis et al., 2003). Blue cod (Parapercis Colias) is another example; in the Long Island-Kokomohua reserve, fish were $22.4 \mathrm{~mm}$ longer compared to fished areas (Davidson, 2001a,b). A meta-analysis by Pande et al. (2008) found larger and more abundant blue cod and rock lobsters inside of many NZ MRs than control areas. There are many other examples of marine reserve benefits across the world (see for example Gell and Roberts, 2003; Abesamis et al., 2006; Shears et al., 2006; Kellner et al., 
2007; Bartholomew et al., 2008; Francini-Filho and Moura, 2008; Forcada et al., 2009; Halpern et al., 2010 and references therein).

\section{Goals of Proposed Research}

Research in New Zealand MRs has primarily focused on biological responses and as a result, there is a gap in other important areas such as social and economic research.

The overall aim of my thesis is to assess the economic costs and values, and social and biological effects of selected MRs within New Zealand. Values should be assumed in two terms: monetary value and something (this case MR's good and services) is held to deserve; the importance, worth, or usefulness to the people. My work specifically focuses on two MRs located to the south of New Zealand' North Island.

In the second chapter of my thesis I estimate the cost to establish and maintain a MR and I identify predictor variables across five MRs to explain differences in their management cost. In this chapter I also estimate the displacement cost as a result of a MRs to fishermen.

Specific objectives of chapter two includes:

(1) Development of a standard methodology to assess the costs of Marine Reserves

(2) Calculation of the costs as a result of MR designation at the local scale $\left(<100 \mathrm{~km}^{2}\right)$ using the Taputeranga MR in New Zealand as a model.

(3) Data collection on management costs of five MRs in New Zealand, and compare costs.

(4) Find potential predictor variables to explain variation in the management costs of New Zealand MRs.

(5) Calculate the displacement costs for commercial fishermen as a consequence of the Taputeranga MR establishment.

Chapter three will examine the social impacts of MRs, in a human dimensions context.

$\underline{\text { Specific objectives of chapter three includes: }}$ 
(1) Exploring social impacts of MRs referring to attitudes, knowledge, processes and perceptions related to how people understand, maintain, protect, enhance and use MRs.

(2) Consider the potential effects on attitudes, knowledge and perceptions of a hypothetical MR located in between the two actual MRs.

(3) Collect information on MR knowledge, issues related to MR establishment, people's perceptions of MRs, perceived impacts from marine reserve establishment, changes in perception (with respect to flora and fauna, and human interactions) since the MRs were established, changes in expectation, satisfaction levels, and attitudes to MRs.

(4) Assess the implications of future MR designation based on my results from the hypothetical MR.

The fourth chapter is about to understand and estimate good and services from MRs in New Zealand based, by using the Millennium Ecosystem Assessment framework. I aimed to identify and determine use and non-use values of two marine reserves in the Wellington region, New Zealand.

Specific objectives of chapter four includes:

(1) Identification of the use and non-use values at the Taputeranga and Kapiti MRs by using the TEV method.

(2) Identify the most appropiate methodology to calculate each of these values.

(3) Develop a specific TEV framework for each MR.

(4) Develop TEV guidelines that could be included in future MR monitoring.

(5) Assess the importance of ecosystems services provided by my study MRs by using the Millennium Ecosystem Assessment framework.

The fifth chapter will examine the effect of no-take areas as MRs on the most important commercial specie in the study areas, which is rock lobsters (Jasus edwardsii) with respect to biomass and abundance.

Specific objectives of chapter five includes: 
(1) Measure RL abundance and biomass inside and outside MRs, as well as along a distance gradient from the centre to the boundaries and outside of each MR.

(2) Determine and calculate RL catch per unit effort (CPUE) both in terms of number and biomass inside and outside MRs.

(3) Compare historical RL CPUE with current RL CPUE inside the MRs, and also among seasons.

(4) Compare different morphometric measures of RLs inside and outside the MRs, and for a distance gradient from the centre to the boundaries and outside of each MR.

By integrating all these different chapters (2, 3, 4 \& 5) and disciplines in chapter six, I am expecting to provide insights that will help in the future of conservation and $\mathrm{MR}$ establishment, by improving the level of information for better decision-making. 


\section{Chapter 2. Estimating the cost of marine reserve establishment and management in New Zealand}

Author contribution: URN designed the study, analysed the data and wrote the chapter. RC, JJB, Gardner, J.P.A co-designed the study and corrected the chapter.

\subsection{Abstract}

Much research has been published on marine protected areas (MPAs), and more specific in marine reserves (MRs). Nevertheless, very few of these publications have focused on the economic cost to establish and manage these protected areas. This study aimed to estimate all of the costs required to establish a MR. The Taputeranga MR was used as a case study along with an analysis of the management costs for four other MRs. I aimed to find predictor variables across these five MRs to explain variation in management costs. In addition, I also estimated the cost to fishermen of displacement from the MR once it was established. I found that the MR pre-establishment process cost around $\$ 508,000$, meanwhile the establishment process cost around $\$ 353,000$. Of the predictor variables, There was no statistically significant correlation between annual management costs and any of the predictor variables (reserve size, age, access, and adjacent human population size). However, the variable MR size did explain $12 \%$ of the variation in annual management costs across MRs. In addition, the annual fisher displacement cost was estimated around $\$ 22,000$. My study suggested that small MRs are more expensive to maintain than big MRs, but because my study considered a small sample (only five MRs) more detail about cost is needed to improve my model, and consequently more accurate and confident results. In addition, my study showed how volunteer jobs help to reduce the monetary cost of the MR pre-establishment process, and without them the TMR is unlikely to have been successful. Also this study gives a better understanding about how much each process cost, laying the groundwork for a more in-depth study to identify and calculate future expenses in MRs and to better design and plan future 
MRs. Therefore, these results can improve the use of conservation monetary resources, and achieve wideler results from MRs by a more equitability allocation of funding through conservation funding.

\subsection{Introduction}

Marine protected areas (MPAs) have long been used as a protection tool for marine environments (NRC, 2001). However, to designate, establish and manage MPAs requires the investment of money and time. As soon as a MPA becomes more than just an idea, it will generate different costs. Understanding and assessing these costs is fundamental at all conservation planning stages. These costs can be separated into two types, direct and indirect. Direct costs are related to the administrative costs, which are necessary to create, establish and operate the new MPA and include baseline data collection, surveys, staff salaries, information gathering, and document writing. Indirect costs are those incurred as a consequence of the MPA being established in a specific place, for example, the cost of displacement of fishermen to other fishing areas.

Understanding the cost of an MPA is extremely important for three main reasons: (1) to provide information to managers and non-government agencies to make the best use of current budgets (Turnet et al., 2003; Green et al., 2012); (2) to create systematic conservation planning and optimise the available resources to achieve specific goals (Polasky et al., 2001; Green et al., 2012); and (3) to identify, quantify, and if possible, map conservation costs to allow an understanding of where these costs are borne and by whom (Balmford and Whitten, 2003; Moore et al., 2004; Adams et al.,2010; Green et al., 2012). Unfortunately the costs of MPAs are poorly understood (Bruner et al., 2003; Balmford et al., 2004; Bruner et al., 2008), even in developed countries. While information is available for terrestrial protected areas (see Balmford et al., 2003; Green et al., 2012), marine areas require different types of management and therefore the cost or models applied to estimate costs cannot be easily applied to both ecosystem types.

Currently there is a global shortage of conservation funding, and for that reason, understanding conservation costs may help managers and stakeholders to design more efficient actions plans, allocate scarce budgets in the most effective way and/or look for more 
funding if this is necessary to meet proposed conservation goals (Green et al., 2012). Consequently, without a good and proper understanding of MPA costs, the effect of limited funds to cover conservation management may mean some social and biological benefits are lost (Bruner et al., 2008). In addition, a misunderstanding of cost may result in 'paper MPAs' being established. Paper MPAs means to those MPAs which are established by legislation, but it are not functioning as it should. This can occur where insufficient budget is provided to enable MPAs to meet their goals. Shortfalls in MPA budgets can lead to poor infrastructure, insufficient staffing and equipment and other management necessities (James et al., 1999; Wilkie et al., 2001; Bruner et al., 2003; Bruner et al., 2008), resulting in an in effective MPA. This is thought to be the case for many protected areas in developing countries such as Indonesia (Bruner et al., 2003; Bruner et al., 2008), South Africa (Vreugdenhil, 2003), Ghana (Oates, 1999), and Ecuador (van Schaik and Kramer, 1997), where the level of investment in protected areas is often insufficient to cover all costs, despite these sites containing high biodiversity (Balmford et al., 2003; Bruner et al., 2008). In addition, Bruner (2004) estimated that there is a financial shortfall for developing countries totalling US \$2.074 billion annually (inflation adjusted at year 2012) (US Inflation Calculator, 2012) to manage all existing protected areas.

Previous studies have attempted to develop different models to calculate the cost of protected areas at global and national scales as well as at sub-national scales (e.g. Balmford et al., 2003, 2004; Bruner et al., 2004; Moore et al., 2004; Green et al., 2012). However, none of these look for a way to calculate cost at smaller scales $\left(<100 \mathrm{~km}^{2}\right)$. Despite several agreements that encourage the expansion of MPAs (Balmford et al., 2003) (such as CBD, 2010, which is encouraging to to protect $10 \%$ of worldwide marine environments), without a good understanding of how much MPAs cost, it is very unlikely that MPAs will be expanded and better funded in the near future (Balmford et al., 2004).

Indirect costs, such as fishermen (commercial, recreational and customary) moving to areas other than their preferred fishing grounds because of the MPA closure, also need consideration. Such displacement of fishing activity often results in greater fishing costs for both commercial and recreational fishermen (Smith et al., 2012). Without a doubt MPAs can benefit open areas through density-dependent processes such that recreational and commercial fishermen can benefit too (e.g. Kelly et al., 2002; Stobart et al., 2009; Goñi et al., 2010; Goñi et al., 2011). However, it is important to recognise not only the benefits of MPAs, but also their costs, which have often been treated with scepticism by the advocates of MPAs 
(Smith et al., 2012). Because fishing costs increase when fishermen move to continue their fishing activities outside MPAs, the operational costs, such as extra fuel caused by travelling further and using new gear will increase, as does the number of man hours spent at sea.

Once the MPA is established in law, then fishermen have to decide where their new fishing grounds will be. This decision will be based on financial and opportunity costs. This means identifying where they go in order to catch the same amount of fish whilst trying to avoid extra costs. Fishermen will try to maximise their profits by using their local knowledge (Rojas-Nazar et al., 2012) and individual skills (Smith and Wilen, 2003) to decide which area is the best for them. This exercise is very important in decision-making by fishermen, and is an important topic for stakeholders, the public and government officials during the MPAs implementation process (Turner and Weninger, 2005). Therefore, to understand and take this into account is essential as part of an equitable and transparent MPA establishment and management process.

The aims of this chapter are to: (1) develop a standard methodology to assess the costs of one type of MPA, which is marine reserve (MR); (2) calculate the cost of MR designation at the local scale $\left(<100 \mathrm{~km}^{2}\right)$ by using the Taputeranga MR in New Zealand as a model;(3) gather data that details management costs of five MRs in New Zealand, and compare costs; and (4) find potential predictor variables for management costs of New Zealand MRs. 


\section{Background information about the Taputeranga Marine Reserve}

\section{The Taputeranga Marine Reserve pre-establishment process year by year}

The establishment of TMR was first considered in the late 1980's by the Department of Conservation, but it was not until 1991 that the Royal Forest and Bird Protection Society of New Zealand $(F \& B)$ decided to lead the project. The TMR pre-establishment process was one of the longest and more controversial conservation processes in New Zealand, and took nearly 20 years to complete. In January 1991 the first document for the MR proposal was written - the 'Island Bay marine reserve'-and included proposed boundaries from Pencarrow to Sinclair Head. Soon after, several meetings were held to explain the MR project and gather support for this application with Iwi groups (Te Ati Awa and Ngati Toa) (definition in the glossary - Appendix A), dive clubs, recreational fishers, and diving shops. In the same year the first public consultation was conducted, and 8000 questionnaires were sent out at the beginning of 1992. The survey's aim was to identify the level of support for a MR, and to identify preferred areas. Despite the completed survey being included in the MR proposal and with great support $(90 \%)$, the progress was slow. One of the major problems was the delination of the MR boundaries.

During 1993, a proposal draft was needed for the submission; however, controversy over the boundaries remained. A second public consultation with residents of Island Bay and adjoining suburbs (Owhiro Bay, Houghton Bay and Lyall Bay) was carried out and 6000 copies were printed and sent out in 1993, but it was not until nine months later (1994) that the results were presented, and included in the new submission (86\% support). In the same year the South Coast Marine Reserve Coalition (SCMRC) was formed. The SCMRC was a community group formed by members from $\mathrm{F} \& \mathrm{~B}$ and staff and students from Victoria University of Wellington (VUW), who were advocates for what later become TMR. Since the SCMRC was created, monthly meetings were held, where the discussion about the MR boundaries was the most recurrent topic.

In the following year (1995) several meetings and consultation occurred with the Wellington City Council (WCC), Victoria University of Wellington (VUW), and NIWA. In the same year, 93 people who were fishing or extracting sea life at Lyall Bay were consulted, and a three-stage survey was prepared, aimed at the recreational users. The initial stage included 85 schools in the Wellington area. The second stage was an observational survey that ran for three months at seven sites on the south coast, where 1507 individuals were observed 
engaging in 24 types of activities. The third stage included 60 face-to-face interviews with coastal users to determine attitudes towards the proposed MR.

Between 1996 and 1997 results from the surveys launched in 1996 were analysed (85\% support). In addition, more surveys were carried out, including a boat survey in 1996 and interviews with 26 fishers between 1996 and 1997. Work on the new proposal document included inclusion of results from previous surveys, and efforts were made to synthesize all comments resulting from meetings with Anglian Water International, Wellington Airport, local residents, Iwi, The Wellington Tenths Trust (definition in the glossary - Appendix A), and New Zealand Government Ministers. In 1998, F\&B and VUW were awarded a grant for $\$ 20,000.00$ ( $\$ 27,956.91$ value adjusted to year 2012) for research into the proposed MR funded by WCC. Between 1999 and the middle of 2000 the MR proposal progress was very slow. In those years only a few meetings with the Tenths Trust were held, where the Tenths Trust advised the SCMRC to carry out a consultation with the Customary Fisheries Committee. In September F\&B got a letter from Wellington airport, the Minister of Conservation and Anglian Water International in support of the MR. Then in July 2000, the Customary Fisheries Committee represented by the Te Ati Awa, stated their approval of the proposal, with some changes to the original proposal, including a major reduction in the size of the reserve. Then, the boundary issues were finally resolved (Fig. 2.2a,b). With this support F\&B and the SCMRC sent a joint application to the Minister of Conservation to establish a reserve of 969 hectares along the Wellington south coast. The formal application was lodge on 18 October 2000. Once the application was lodged the SCMRC's role changed. The SCMRC remained an advocate for the reserve, but also became a participant and respondent to a statutory process which was managed firstly by DOC, and then by the Ministry of Fisheries as each agency went through their approval process

In April 2002 the Minister of Conservation (the H Sandra Lee) decided to recommend the proposed MR be established by Order in Council and requested the concurrence of the Minister of Fisheries (the H Jim Anderton) and the Minister of Transport (the H Mark Gosche).

In June 2004 Ngati Toa (Te Runanga O Toa Rangatira Inc.) applied for a conditional (Judicial review) review of the MR process because they (believed they) were not consulted. These difficulties with Ngati Toa led to significant delays in the Ministerial approval process. During 2004 and 2005 another round of consultation was prepared (This was the 
Ministry of Fisheries own consultation - run by them to assess support / opposition from recreational and commercial fishers. The SCMRC were a respondent to this consultation process). As a result of this consultation, in December 2005, 200 letters were sent in support of the reserve.

At the start of 2006 the Dominion Post, the local newspaper published an article that contained confusing information in a negative way, referring to the reserve. This had a negative effect on some readers, who began writing letters to the SCMRC and F\&B opposing the reserve establishment. As a result of this, the SCMRC decided to work as soon as possible on new publicity about the reserve. In addition, the SCMRC contracted external consultants (Barry Webber) to write the submission document to present to the Minister of Fisheries. By the middle of September all dive shops declared their support for the reserve, however, at that time there had been no response from the Minister of Fisheries, who was still opposed to the reserve establishment. However, in parallel, the SCMRC held several meetings with different Ministers. With the approval of the Tenths Trust and the Minister of Transport and the Director of Maritime New Zealand agreeing the new reserve boundaries did not interfere with any existing right of navigation, the SCMRC was ready to submit once again, on 7th November, 2006. 


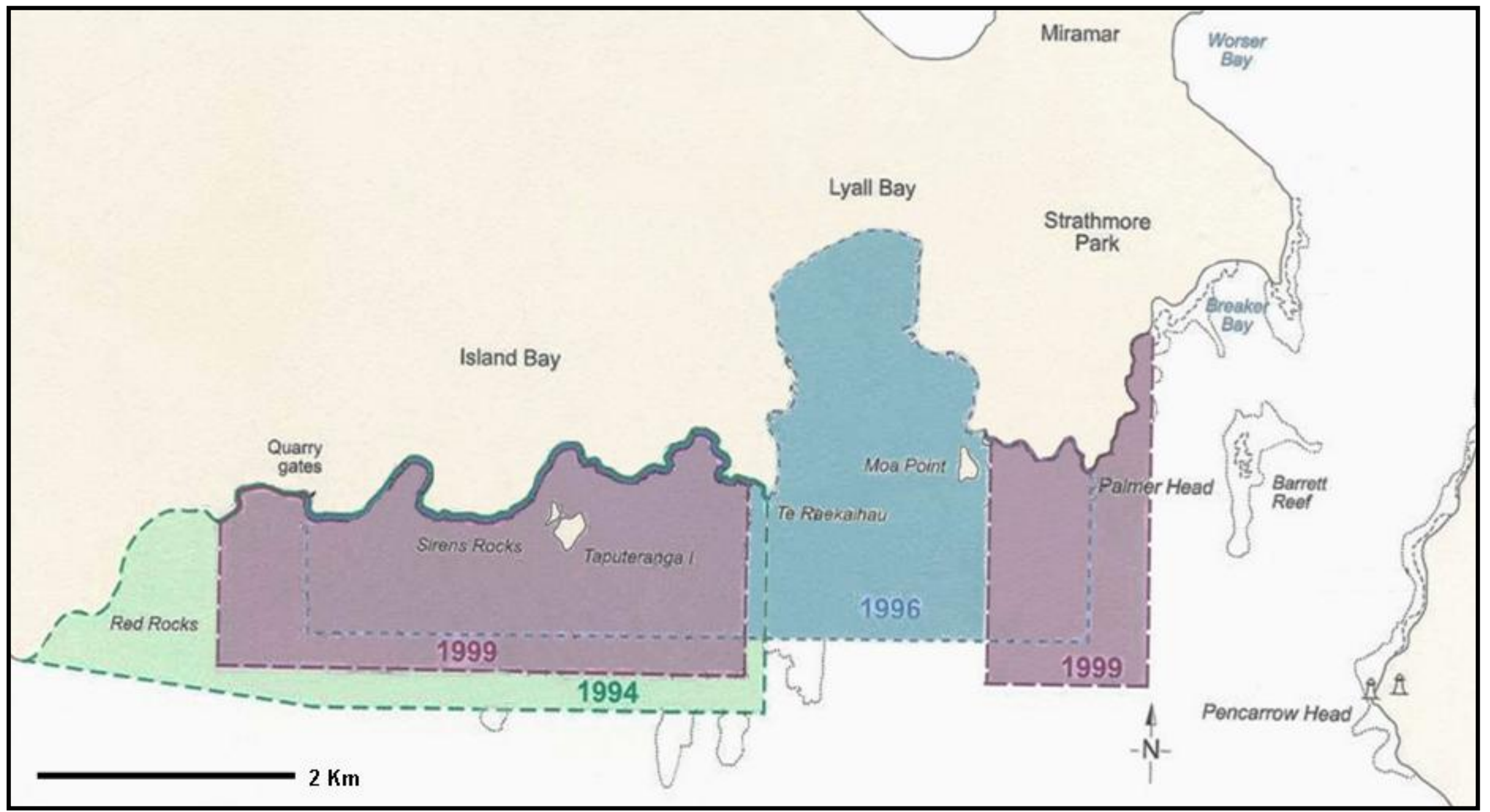

Figure 2.1a: Marine reserve boundaries proposed during the establishment process. Image from the Royal Forest and Bird Protection Society of New Zealand files. Different colours showing different years proposed. 


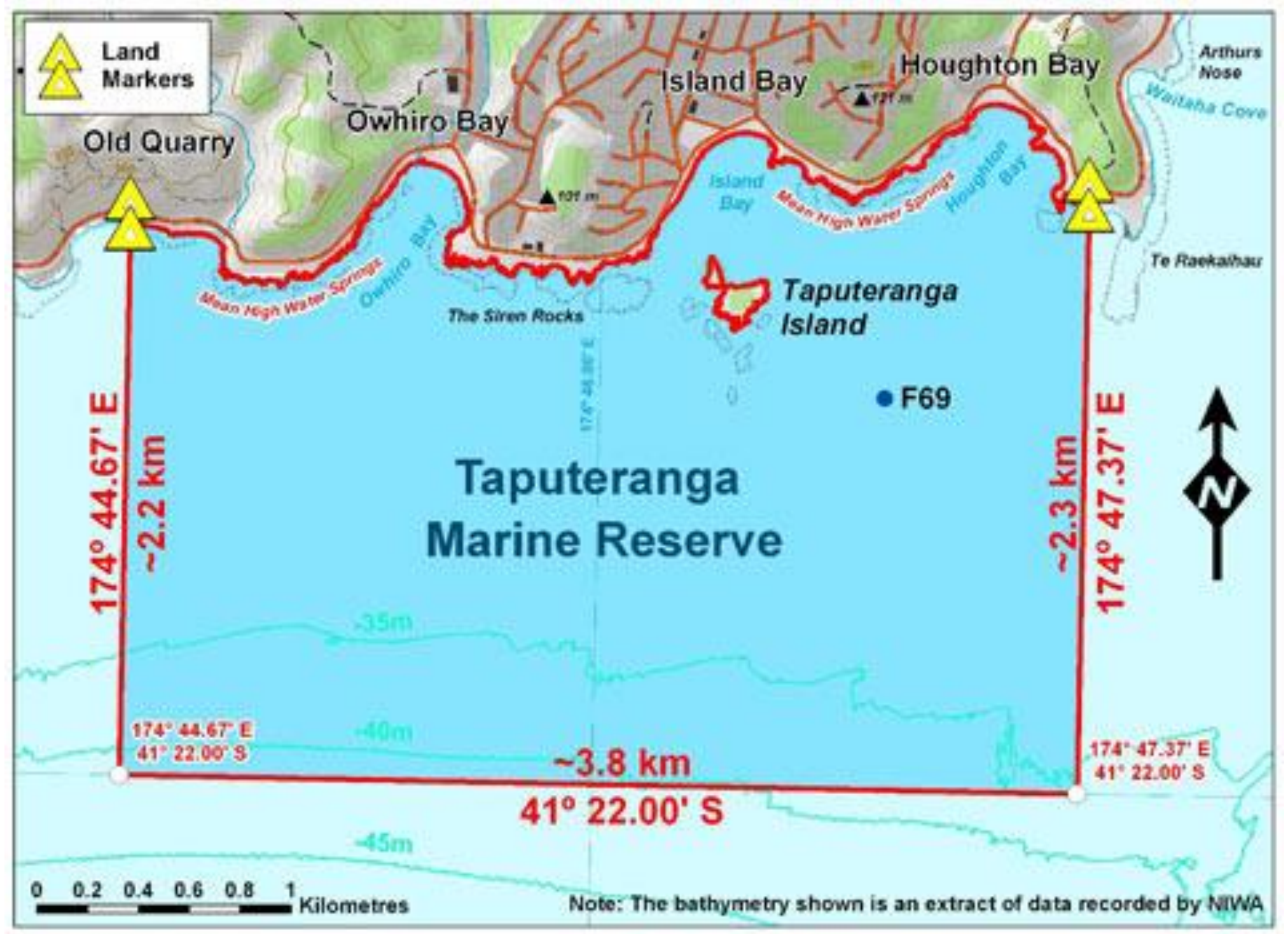

Figure 2.1b: Current marine reserve boundaries. Image from Department of Conservation webpage. 
Finally, in December of the same year the MR was approved by the Department of Conservation (the Minister of Conservation had granted her 'concurrence' in 2002 - it was not until 2006 that the Minister of Fisheries gave his concurrence) and the Ministry of Fisheries. Then a new announcement about the MR now called Kupe/Kevin Smith MR on the Wellington south coast (with new changes in the boundaries) was made. (The name Kupe/Kevin Smith was the idea of Hon Chris Carter, the then Minister of Conservation. However, it was not the SCMRC's preferred name - but they decided to go along with it).

\section{The Taputeranga Marine Reserve implementation stage}

After the Kupe/Kevin Smith MR was announced, there was a period waiting for it to be gazetted. This period was supposed to be no be longer than three to six months, however it took longer than expected.

While waiting for the gazettal, a marine Bioblitz (definition in the glossary - Appendix A) was proposed for the reserve area, in order to determine what species were present. The marine Bioblitz was funded by Wellington City Council, and sponsored by Wellington Regional Council, NIWA, VUW, F\&B, and Wellington dive shops and was carried out in October, 2007. One month afterwards, the SCMRC was called by Ngati Toa, because there was an issue with respect to the name of the marine reserve (Kupe/Kevin Smith).In addition, Ngati Toa were waiting for a formal apology that they felt they were due for the failure to consult them on the MR, though they were later consulted. Then the SCMRC and F\&B sent a letter to Ngati Toa in November, 2007 to recognise that the MR application process had caused the Ngati Toa people an offence. In that letter the SCMRC and F\&B recognised Ngati Toa have historical association with the MR area. The SCMRC and F\&B acknowledged and recognised that Ngati Toa have claimed mana whenua mana moana status, over the area(definition in the glossary - Appendix A). In addition, the name Kupe/Kevin Smith MR was deemed to be inappropriate, naming the MR as the Taputeranga Marine Reserve, based on the sacred Iwi Island called Taputeranga, which is located in the MR. This name was the SCMRC's original and preferred option.

Finally, after 17 years, on 31st July 2008, the Taputeranga MR was officially gazetted by Order In Council, and 28 days later, on the 28th August, 2008 the MR was officially in place, with an opening ceremony held on 7th September, 2008. 


\subsection{Methods}

\subsubsection{Study sites}

Marine reserves (MRs) are one type of MPA used to protect marine biodiversity. In New Zealand MRs are the most common marine protection tool in the provision of area-based biodiversity protection in the marine environment (DOC, 2008). Currently there are 34 marine reserves established in New Zealand territorial waters, from which I used five MRs as part of this study. Two of these MRs (Taputeranga and Kapiti) were selected by myself, however the other three MRs were selected by the Department of Conservation (New Zealand main conservation agency). The main reasons for selecting these other three MRs were: firstly because the Department of Conservation staff's availability to provide all the data necessary, and secondly, because these MRs were very similar in size to the MRs selected by me (Taputeranga MR and Kapiti MR).

The Taputeranga Marine Reserve (TMR) was used for this study because there is a considerable amount of information available since the establishment process started (data was not available for the other MRs). The TMR was gazetted in August 2008, and it is one of the newest MR in New Zealand. It is located in the Wellington region, on Wellington's south coast, from Princess Bay to Quarry Bay, and protects $8.54 \mathrm{~km}^{2}$ of coastal waters (Fig. 2.2a).

For the analysis of MR management costs only, I selected four further MRs. The first was Kapiti MR (KMR), which is one of the oldest MRs in New Zealand. It was established in 1992 in the Wellington region, and is located approximately $50 \mathrm{~km}$ north of Wellington. It is located on the Kapiti coast at Paraparaumu Beach and extends out to and around part of Kapiti Island. The KMR covers $20.90 \mathrm{~km}^{2}$ of coastal water, divided in two parts. The largest part is $17.50 \mathrm{~km}^{2}$ and is on the eastern side of the island extending to the mainland at Paraparaumu Beach. The smaller part is $3.4 \mathrm{~km}^{2}$ located on the western side of the island from between Tokahaki Point and Arapawaiti Point at the north, to Trig Point in the south, extending750 m out from the shore (Fig. 2.2b).The other three MRs are located outside the Wellington region. These are the Tonga Island MR, the Te Tapuwae o Rongokako MR and the Tapuae MR. 
Tonga Island MR is the third oldest MR in New Zealand, established in 1993and is located at the top of the South Island (opposite the Wellington south coast) alongside the Abel Tasman National Park (a terrestrial park). Tonga Island MR covers $18.35 \mathrm{~km}^{2}$ and extends one nautical mile offshore from the high tide water mark of Tonga Island and the coast between Awaroa Head and the headland separating Bark Bay and Mosquito Bay (DOC, 2008) (Fig. 2.2c). Te Tapuwae o Rongokako MR near Gisborne was the $16^{\text {th }}$ MR established in New Zealand in 1999, covering $24.52 \mathrm{~km}^{2}$, is the largest in this study, and is one of the largest MRs on the New Zealand mainland coast. This MR protects $5 \mathrm{~km}$ of coastline, extending up to 2.7 nautical miles offshore (to over $40 \mathrm{~m}$ depth) (Freeman, 2008) (Fig. 2.2d). The last MR included in this study is Tapuae MR located in the Taranaki region near New Plymouth. Established in 2008 (earlier than TMR), Tapuae MR protects $14.04 \mathrm{~km}^{2}$ of coastal waters, adjoining the Sugar Loaf Island marine protected area, extending to the Tapuae Stream (southwest) (Fig. 2.2e). 

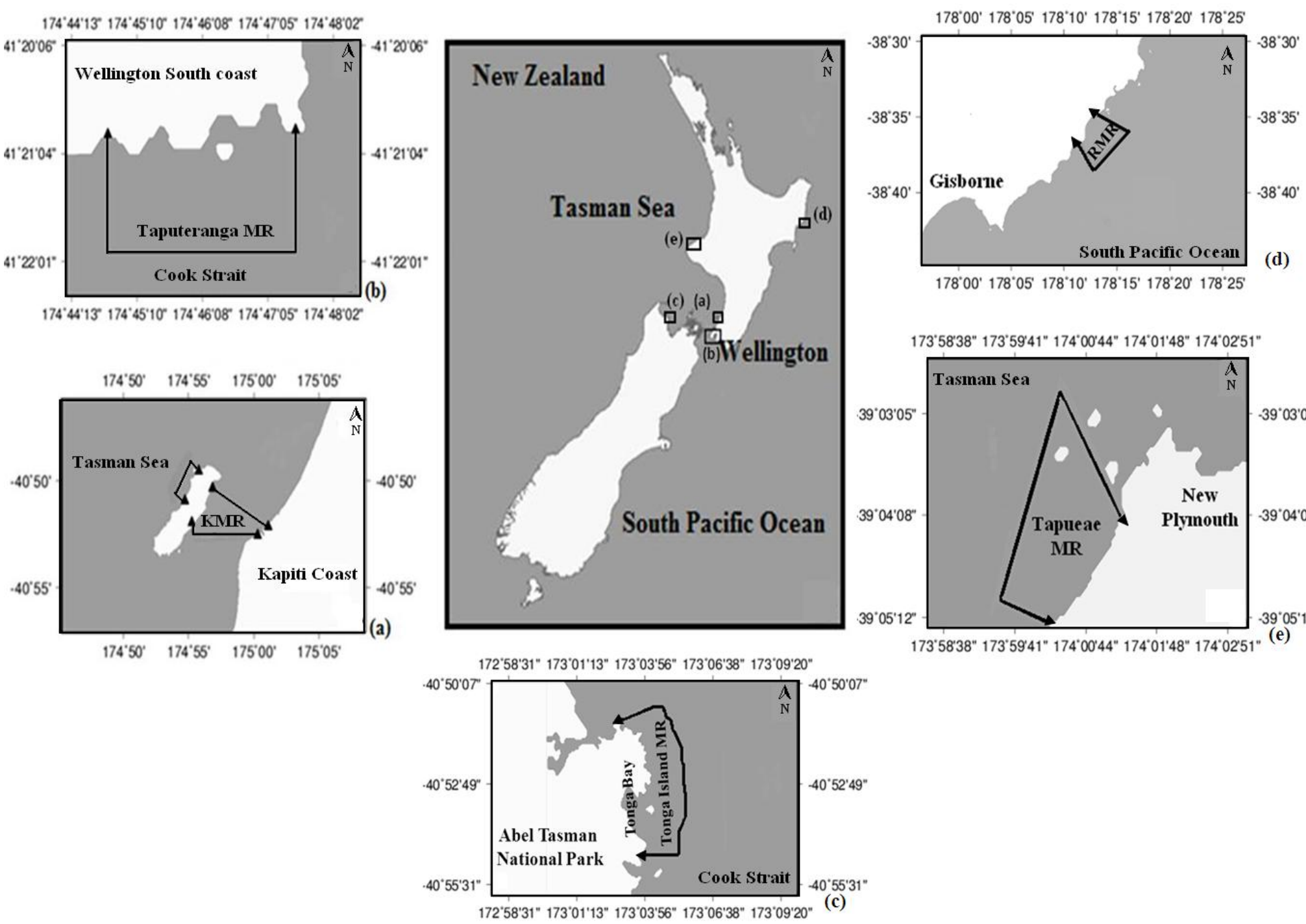

Figure 2.2: Location of study sites in five regions of New Zealand. (a) Taputeranga Marine Reserve, (b) Kapiti Marine Reserve, (c) Tonga Island Marine Reserve, (d) Te Tapuwae o Rongokako Marine Reserve (RMR) and (e) Tapuae Marine Reserve. 


\subsubsection{Marine reserve cost}

In order to establish and determine the cost incurred for the establishment and management of the MRs costs were divided into two categories, direct and indirect. For direct costs, I considered all costs directly incurred because of the MR establishment: these were the preestablishment cost, establishment cost and management cost. Indirect costs considered are the costs imposed on people or businesses that had to move their economic activities to other places due to the MR establishment (Fig. 2.3).

a) Pre-establishment cost: costs incurred in the consultation process prior to the MR being established.

b) Establishment cost: costs incurred in setting up the new reserve. All costs related to signs, baseline projects, purchase of equipment and boundary demarcation.

c) Management cost: costs directly incurred in maintaining the MR. These costs are divided as follows:

c.1) Management cost - Operational: fixed and variable costs (predictable and regular costs) related to employing staff such as salaries, equipment repairs, fuel, and casual labour and contractors.

c.2) Management cost - Capital: costs related to upgrading and/or purchasing equipment or facilities, such as boat purchases.

d) Indirect cost - displacement cost: the cost incurred by those fishermen who were fishing in the area that is currently a MR. In this case I used the cost of displacement of rock lobster (Jasus edwardsii) fishers because rock lobster fishing was considered the largest source of revenue for commercial fishers within TMR before it was a reserve. I only used TMR because I could not gather information from the other MRs, because this data were not available. 


\subsubsection{Cost calculation}

\section{a) Pre-establishment: The history}

In order to better understand the pre-establishment process I searched different resources including the minutes of the Royal Forest and Bird Protection Society of New Zealand (F\&B), local newspapers, the internet and personal files from people who participated in the preestablishment process. I also used the information published in a book on Taputeranga MR (Gardner and Bell, 2008). The F\&B files include the time period from the pre-establishment process, which started in 1991, and continued to the end of 2008. Through this data collection from historical document analysis/secondary data analysis I could calculate year by year the main cost components that were part of the process.

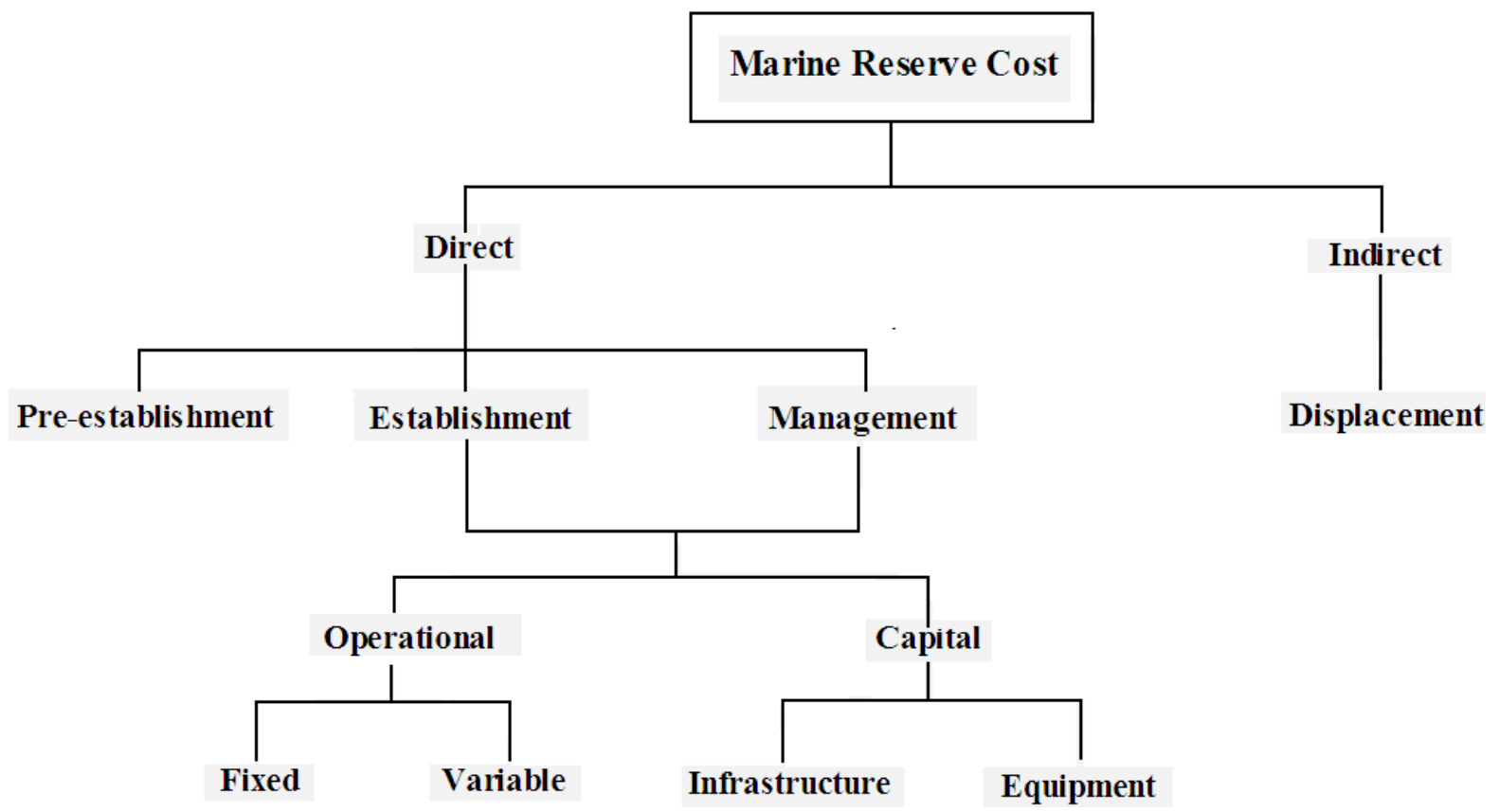

Figure 2.3: Marine reserve costs framework used in this study to determine and calculate pre-establishment, establishment, management and displacement costs.

\section{b) Pre-establishment cost analysis}

To estimate these costs I used information collected in the previous section. The information gathered was organized and classified amongst agencies and ministers that took part in the pre-establishment process. These were the Minister of Conservation, Ministry of Fisheries and Ministry of Transport, Department of Conservation (DOC) National office, DOC 
Conservancy office, the Royal Forest and Bird Protection Society of New Zealand (F\&B), the South Coast Marine Reserve Coalition (SCMRC), Victoria University of Wellington (VUW) and the marine Bioblitz event. Though marine Bioblitz was technically not a requirement for a MR, the information gathered during this event was important in terms of biodiversity in the MR, as well as the level of public participation in the MR.

With the information organized and classified, I separated it by types of activities and meetings carried out by different organizations, such as SCMRC, F\&B, Ministers \& Ministries, Iwi, , local residents, commercial and recreational fisher and divers, dive clubs, Wellington City Council, Wellington Airport, private individuals, the Wellington Tenths Trust, Anglian Water International (operators of the local Moa Point sewage treatment facility), Police and other emergency services, Interisland Ferry operators), administrative work, surveys (preparation, data collection, data analysis and public presentation), data analysis, events, publicity, working on the proposal documents, surveys carried out by VUW, and the marine Bioblitz.

Different approaches were used to estimate the monetary cost of all activities. I was not able to get specific files to permit me to quantify in detail the type of costs from the Ministries, DOC National office and DOC Conservancy office. Therefore, I used informal conversations with two key people, Colin Ryder and Murray Hosking. Colin Ryder (current treasurer of the Friends of the Taputeranga Marine Reserve) worked during almost the complete preestablishment process as a member of F\&B and the SCMRC. Moreover, he has more than twenty years' experience in project managing and resourcing conservation projects in the Wellington region. Murray Hosking (currently a member of the Trust of the Friends of the Taputeranga Marine Reserve) was the MR facilitator in DOC from 2001 to 2009 and was directly involved in the end stages of the Taputeranga MR establishment. By using their knowledge and experience, I estimated the total cost to the Ministries, DOC National office and DOC Conservancy office in the Taputeranga MR pre-establishment process. The data obtained were considered to be a conservative estimate, with a margin of error of $-10 \% /+30 \%$ (standard error used in accounting, specified by Colin Ryder, who is also a senior accountant).

With respect to the survey and the marine Bioblitz event I had access to the real cost expended on those activities. Through access to the F\&B and the SCMRC files and minutes I could establish the cost per activity and/or per number of hours invested, as: 
b.1) Proposal writing: In some cases external contractors were used, in which case I used the total actual cost. In other cases, I estimated cost by using the number of hours invested multiplied by the appropriate hourly salary rate (see below).

b.2) Meetings: I estimated cost by using the number of hours invested multiplied by relevant hourly salary rates. The salary value depended on the type of job or responsibility that people who participated in those meeting represented. Therefore, by using a salary guide for New Zealand jobs, available on the Internet I made a list with different types of salary by calculating an average salary amongst all salary guides found (see Appendix A). Then I used the following equation to calculate the fost meetings:

\section{Meeting cost $=($ Rate per hour $*$ Total meeting hours $) *$ Total attendance}

Salary list:

Local residents, recreational divers, recreational fishers and volunteers labour: $\$ 14.50$ per hour

$>$ Tenths Trust and Iwi: \$31.00 per hour (based on the Local and Regional Council salaries)

$>$ Scientist (VUW): $\$ 35.00$ per hour

$>$ Ministers: $\$ 81.00$ per hour

$>$ Local and regional council members: $\$ 31.00$ per hour

$>\mathrm{F} \& \mathrm{~B}, \mathrm{SCMRC}$ and DOC members: $\$ 30$ per hour

$>$ Proposal writers: $\$ 30$ per hour

$>$ Dive shop operators: $\$ 41.00$ per hour (based on sales managers salary)

b.3) Events: I used the actual cost for this.

Office: This means all types of small jobs carried out in an office such as getting quotes for printing. Then I used $\$ 23.00$ per hour as the salary cost.

b.4) Survey design: I estimated this by using the number of hours invested multiplied by $\$ 30.00$ per hour salary.

b.5) Data analysis: I estimated this by using the number of hours invested multiplied by $\$ 30.00$ per hour salary. 
b.6) Survey respondents: I multiplied the number of respondents by a minimum salary of $\$ 14.50$ per hour invested.

This information (number of hours and salaries) was completed in corroboration with Colin Ryder. All the costs analysed were inflation adjusted to the present year 2012, by using the Reserve Bank of New Zealand Inflator calculator (available at http://www.rbnz.govt.nz/).Preestablishmentcosts were presented in two forms, cost per year $\left(\mathrm{NZ} \cdot \mathrm{year}^{-1}\right)$ and cost per unit area $\left(\mathrm{NZ} \cdot \mathrm{km}^{-2}\right)$ by dividing the cost value by the MR size in $\mathrm{km}^{2}$.

\section{c) Establishment costs}

These costs are based in the information provided by the Department of Conservation. For the establishment cost I used the Taputeranga MR information for the year 2008. It was organised by following the structure presented in figure 2.2. All the costs analysed were inflation adjusted to the present year 2012, by using the Reserve Bank of New Zealand Inflator calculator (available at http://www.rbnz.govt.nz/). Establishment costs were presented in two forms, cost per year and cost per unit area $\left(\mathrm{km}^{-2}\right)$ by dividing the cost estimate by the MR size in $\mathrm{km}^{2}$.

\section{d) Management costs}

I obtained information for different years for the five MRs: Taputeranga Marine Reserve, Kapiti Marine Reserve, Tonga Island Marine Reserve, Te Tapuwae o Rongokako Marine Reserve and Tapuae Marine Reserve. For Kapiti, Tonga Island and Te Tapuwae o Rongokako MRs I compared the information from the last three financial years (2008/09, 2009/10 and 2010/11). This information includes salaries, operating costs, and wherever possible, information about surveys and boat costs.

To better understand if the management costs were influenced by the MR attributes and/or socio-demographic factors, I looked for any relationships between the MR cost and MR size, age, accessibility (access) and the human population surrounding it (Table 2.1). The MR size was measured in hectares and age in years. However, access and human population were ranked from one (low) to five (high). Low access means there is not direct access to the MR, and the MR has to be reached by using boat and/or 4WD vehicles (e.g. Tonga Island MR). In 
contrast, Taputeranga MR has the highest access score, because it does not need any specific transport or route to be accessed. In terms of human population I considered it 'low' when the population was almost nil or had only a few nearby houses, and high when it is located within a city or suburb.

Management costs were presented as an average cost per year (year $\left.{ }^{-1}\right)$ across the five MRs cost, and an average cost per unit area per year $\left(\mathrm{km}^{-2} \cdot\right.$ year $\left.{ }^{-1}\right)$, which was calculated as the average cost per year divided by the average MR size in $\mathrm{km}^{2}$.

Table 2.1: Marine reserve attributes and socioeconomic factors analysed as independent variables at five marine reserves. Size is expressed as hectares, age in years. Access is ranked from low (1) to high (5). Human population is ranked from low (1) to high (5).

\begin{tabular}{lrrrrr}
\hline & $\begin{array}{r}\text { Te Tapuwae o } \\
\text { Rongokako } \\
\text { MR }\end{array}$ & $\begin{array}{r}\text { Kapiti } \\
\text { MR }\end{array}$ & $\begin{array}{r}\text { Tonga Island } \\
\text { MR }\end{array}$ & $\begin{array}{r}\text { Tapuae } \\
\text { MR }\end{array}$ & $\begin{array}{r}\text { Taputeranga } \\
\text { MR }\end{array}$ \\
\hline Size & 2450 & 2090 & 1835 & 1404 & 854 \\
Age & 13 & 20 & 19 & 4 & 4 \\
Access & 2 & 2 & 1 & 4 & 5 \\
Human population & 1 & 4 & 1 & 5 & 5 \\
\hline
\end{tabular}

\section{e) Management cost and MR attributes data and analysis}

To determine the best model to explain the cost of management at each site using four independent variables (size, age, access and human population), I used an informationtheoretic approach (Green at el., 2012) and the Akaike Information Criterion (AICc) to measure goodness of fit (due to the small sample). This approach can be used to compare models with different model fit and the criterion penalizes larger models with equal fit. The model was calculated using distance based linear model (DISTLM), which performs linear models between the dependent (cost) and the independent variables. In the analysis 9999 permutations were completed.

Two analyses were run. In the first analysis each year was analysed separately (2008/09, 2009/10 and 2010/11). This is because each MR cost per year is not independent of the cost in the previous or following year. The second analysis was similar but used the average of the costs across years. 
The analysis was conducted using the statistical package PRIMER-E v6 (Plymouth Routines in Multivariate Ecological Research).

In order to understand and measure whether or not there was a relationship between the dependent and independent variables I ran a series of Pearson's correlations, with a level of statistical significance set at alpha $=0.05$, to measure the relationship between MR cost and size. I used Pearson correlation because cost and size has normal distributions. For the rest of the variables (age, access and human population) I used Spearman's rank correlation rho with a level of statistical significance set at alpha $=0.05$. Correlations were calculated by SPSS 10.0 .

\section{f) Indirect costs - displacement cost}

Because very little data was available, I decided to only calculate the displacement cost for TMR. The information on MR displacement of fishing was obtained from commercial rock lobster fisher. For this I used a questionnaire designed specifically for commercial rock lobster fisher. This questionnaire was the same questionnaire used in chapter 3, which included a specific section related to gathering information about displacement cost. Each questionnaire was conducted in a confidential manner (requiring no identification), and was carried out by the same four interviewers across the whole study. It took approximately 20 minutes to 1 hour to complete each questionnaire.

This research had Victoria University of Wellington Human Ethics Committee approval No 17028.

For the displacement cost calculation I assumed that the rock lobster catch outside the TMR was the same amount as before the MR was gazetted. Then the economic (displacement) cost was the additional costs to earn the same revenue. This cost was calculated annually and adjusted for the three years since the Taputeranga MR was established.

Each monetary cost calculated (direct and indirect) was inflation adjusted to 2012 by using the New Zealand Inflator Calculator tool available in the Reserve Bank of New Zealand's web page (http://www.rbnz.govt.nz/statistics/0135595.html). 


\subsection{Results}

\subsubsection{The pre-establishment cost}

The whole process described above, which included meetings, surveys, volunteer labour, paper work as others carried out during 17 years of effort, was estimated to have a total cost of NZ\$508,169 (valued at the present year - 2012). Therefore, the per unit area preestablishment cost was NZ\$59,505 $\mathrm{km}^{2}$ (Table 2.2).

\subsubsection{Establishment cost}

Since the reserve was gazetted (31st July, 2008), the Department of Conservation (DOC) took complete responsibility for the TMR. Then, DOC had to complete several duties, starting with the provision of signs and boundary marks to inform the public and users about the new MR boundaries. For this it was necessary to contract field operational contractors (item Signs in the Table 2.3), who were in charge of sign construction, sign printing, and sign placement in different locations. Some of the signs were placed along the coast, but others had to be placed on top of hills, and to achieve the latter, a helicopter was needed. 
Table 2.2: Pre-establishment costs used in the Taputeranga Marine Reserve from 1991 until the opening ceremony in 2008. Costs are inflation adjusted to 2012. DOC: Department of Conservation; F\&B: Royal Forest and Bird Protection Society of New Zealand; SCMRC: South Coast Marine Reserve Coalition. (*) Conservative cost with true cost in the range $-10 \%$; $+30 \%$ of the listed cost.

\begin{tabular}{lr}
\hline Item & Cost \\
\hline Ministries & $\mathbf{\$ 1 0 0 , 0 0 0 *}$ \\
DOC National office & $\mathbf{\$ 2 0 0 , 0 0 0 *}$ \\
$\quad$ Court \& Crown law costs & $\$ 100,000^{*}$ \\
$\quad$ Personnel costs & $\$ 100,000^{*}$ \\
DOC National office & $\mathbf{\$ 2 0 , 0 0 0 *}$ \\
F\&B \& SCMRC & $\mathbf{\$ 1 2 6 , 3 0 0}$ \\
$\quad$ Proposal (writing) & $\$ 9,000$ \\
$\quad$ Meeting & $\$ 11,000$ \\
Events & $\$ 2,000$ \\
Office & $\$ 300$ \\
Survey design & $\$ 29,000$ \\
Surveys & $\$ 45,000$ \\
Data analysis & $\$ 15,000$ \\
Survey respondents & $\$ 15,000$ \\
Survey & $\$ \mathbf{2 9 , 2 0 0}$ \\
Bioblitz & $\mathbf{\$ 3 2 , 6 6 9}$ \\
\hline TOTAL & $\mathbf{\$ 5 0 8 , 1 6 9}$ \\
\hline
\end{tabular}

In addition, a series of paperwork and legal costs was considered, as well as numerous administrative costs such as printing, office, phone calls, stationary, computer staff and emergent and/or miscellaneous costs. It was necessary to purchase a new boat (named Matahorua) to patrol the TMR area. The boat is considered as a Capital cost. All costs are summarized in Table 2.3. The total establishment cost of the TMR was approximately $\$ 353,166$ year $^{-1}$ (value adjusted at year 2012). The establishment cost per unit area was $\$ 41,355 \mathrm{~km}^{2}$. 
Table 2.3: Taputeranga Marine Reserve establishment cost. All values are adjusted to 2012 costs.

\begin{tabular}{lllr}
\hline Cost type & & & Value (NZ\$) \\
\hline Operational & Fixed & Boat running & $\$ 29,829$ \\
& Variable & Administrative & \\
& & Survey & $\$ 61,609$ \\
& & Signs & $\$ 39,616$ \\
& & Boat purchase & $\$ 108,507$ \\
Capital & Equipment & & $\$ 113,605$ \\
\hline TOTAL & & & $\mathbf{\$ 3 5 3 , 1 6 6}$ \\
\hline
\end{tabular}

\subsubsection{Management costs}

Current management costs (operational costs) for the five MRs assessed include personnel salaries (mainly a ranger's salary), boat running costs (plus depreciation), operating costs such as fixing and maintaining field equipment, tools, signs, printing brochures and posters (Table 2.4). The average management costs across the five MRs per year is $\$ 63,597$ year $^{-1}$, and the cost per unite area was $\$ 3,683 \mathrm{~km}^{-2} \cdot$ year $^{-1}$.

Table 2.4: Management costs from three consecutive years at five marine reserves in New Zealand.

\begin{tabular}{lccc}
\cline { 2 - 4 } & \multicolumn{3}{c}{ Year } \\
\cline { 2 - 4 } Marine reserve & $\mathbf{2 0 1 0 / 1 1}$ & $\mathbf{2 0 0 9 / 1 0}$ & $\mathbf{2 0 0 8} / \mathbf{0 9}$ \\
\hline Te Tapuwae o Rongokako MR & $\$ 68,700$ & $\$ 79,200$ & $\$ 55,600$ \\
Kapiti MR & $\$ 52,600$ & $\$ 56,700$ & $\$ 53,700$ \\
Tonga Island MR & $\$ 65,110$ & $\$ 62,543$ & $\$ 68,202$ \\
Tapuae MR & $\$ 50,900$ & $\$ 47,700$ & $\$ 43,200$ \\
Taputeranga MR & $\$ 60,400$ & $\$ 112,500$ & $\$ 76,900$ \\
\hline
\end{tabular}




\subsubsection{Management costs and relationships among variables}

From the scatter plots, it was not possible to determine any clear relationships between variables (Figs. 2.4-2.7). Hereafter, I tried to determine which of the variables or combination of variables best explained the cost across MRs and years. With the data obtained across the five MRs (small sample), the Distell analysis showed that the variable size explained $12 \%$ of the management cost across MRs (Table 2.5). Then across MRs, the AICc analysis showed that the variable size is the one that better explains cost, followed by access, and size (Table 2.6).

Table 2.5: Marginal test using Distell analysis performed using average cost per marine reserve across years. Size is the variable that explains the greatest variation in the cost data $(12 \%)$ of all variables analysed (bold).

\begin{tabular}{llcrrr}
\hline Year & Variable & SS (trace) & Pseudo-F & P & Prop \\
\hline \multirow{2}{*}{ Across years } & Size & $9.42 \mathrm{E}+07$ & 0.42 & 0.60 & $\mathbf{0 . 1 2}$ \\
& Age & $2.97 \mathrm{E}+07$ & 0.12 & 0.68 & 0.04 \\
& Access & $5.63 \mathrm{E}+07$ & 0.24 & 0.68 & 0.07 \\
& Human population & $1.24 \mathrm{E}+07$ & 0.05 & 0.87 & 0.02 \\
\hline
\end{tabular}

Table 2.6: Overall best results from AICc analysis by using average cost per marine reserve across years. The best results are shown in bold.

\begin{tabular}{lrrrrr}
\hline Year & AICc & $\mathbf{R}^{\mathbf{2}}$ & RSS & No. Vars & Variable selected \\
\hline Across years & $\mathbf{1 0 3 . 5 4}$ & $\mathbf{0 . 1 2 3 9}$ & $\mathbf{6 . 6 6 E}+\mathbf{0 8}$ & $\mathbf{1}$ & Size \\
& 103.81 & $7.41 \mathrm{E}-02$ & $7.04 \mathrm{E}+08$ & 1 & Access \\
& 104 & $3.91 \mathrm{E}-02$ & $7.31 \mathrm{E}+08$ & 1 & Age \\
\hline
\end{tabular}

No significant correlations were found between any of the variables (size, age, access and human population) and management costs at each year 2008/2009, 2009/2010 and 2010/2011, or across all years (Table 2.7). 
Table 2.7: Pearson correlation ( $\mathrm{r}$ ) and Spearman rank correlation (rho) between four variables size, age, access and human population, and the cost of management of five MRs in New Zealand in three years 2008/2009, 2009/2010 and 2010/2011.

\begin{tabular}{|c|c|c|c|c|c|c|c|c|}
\hline & \multicolumn{8}{|c|}{ Cost } \\
\hline & \multicolumn{2}{|c|}{$2008 / 2009$} & \multicolumn{2}{|c|}{$2009 / 2010$} & \multicolumn{2}{|c|}{ 2010/2011 } & \multicolumn{2}{|c|}{ Across years } \\
\hline & p-value & r/rho & p-value & r/ rho & p-value & r/rho & p-value & r/ rho \\
\hline Size & 0.474 & -0.427 & 0.439 & -0.457 & 0.560 & 0.353 & 0.561 & -0.352 \\
\hline Age & 0.994 & 0.004 & 0.514 & -0.392 & 0.712 & 0.228 & 0.750 & -0.198 \\
\hline Access & 0.935 & 0.051 & 1.000 & 0.000 & 0.434 & -0.462 & 0.741 & 0.205 \\
\hline Human population & 0.800 & -0.158 & 0.800 & -0.158 & 0.111 & -0.791 & 0.800 & -0.158 \\
\hline
\end{tabular}

p $<0.05$

Size: Pearson correlation $(\mathbf{r})$

Age, access and human population: Spearman's rank (rho)

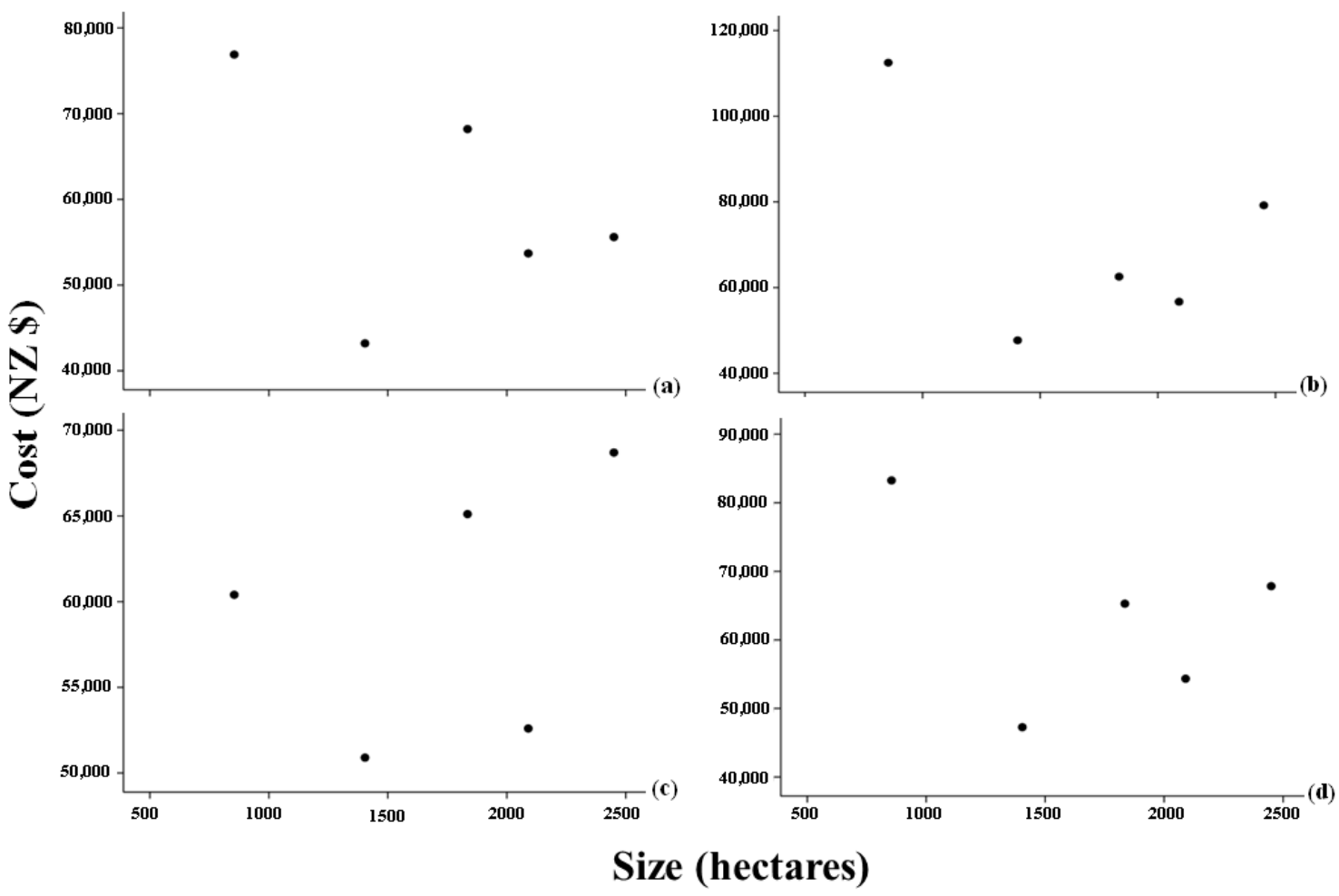

Figure 2.4: Scatter plots of management costs (NZ dollars $\$$ ) and the marine reserve size (hectares) (marine reserve N=5). In the top plots are years (a) 2008/2009, (b) 2009/2010, scatter plots below are years (c) 2010/2011 and (d) average cost across years. 


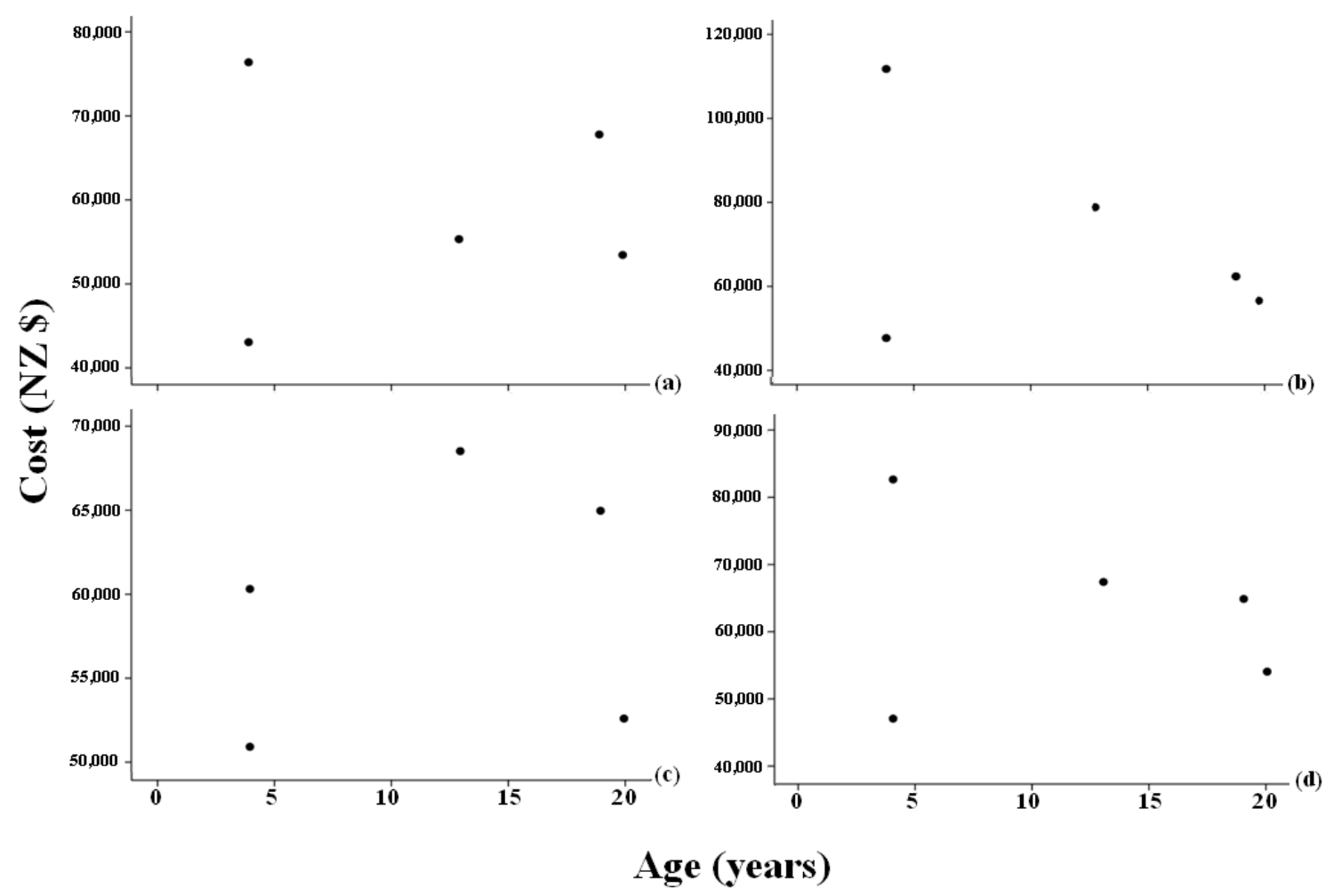

Figure 2.5: Scatter plots of management costs (NZ dollars $\$$ ) and the marine reserve age (marine reserve $\mathrm{N}=5$ ). In the top plots are years (a) 2008/2009, (b) 2009/2010, scatter plots below are years (c) 2010/2011 and (d) average cost across years.
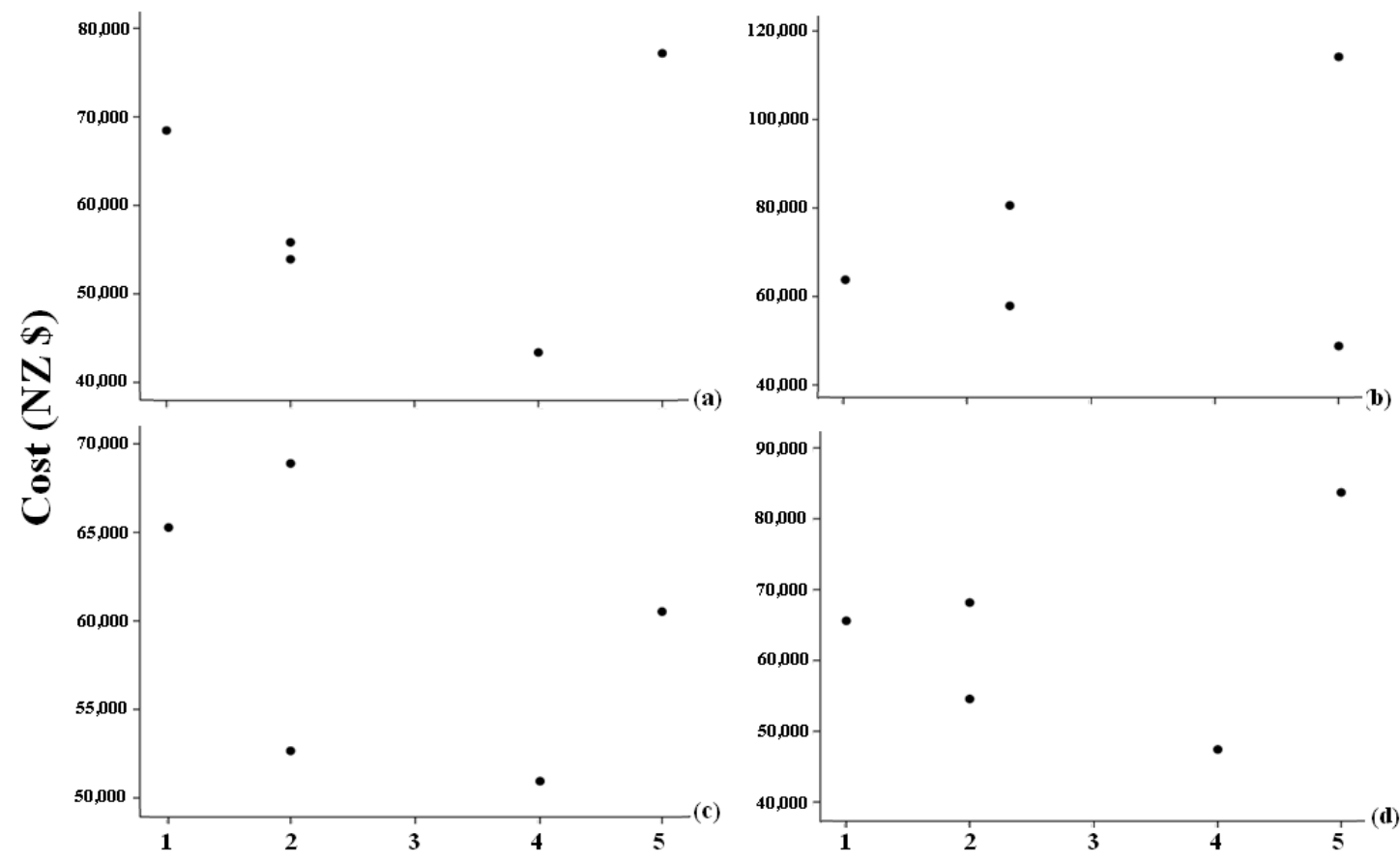

\section{Access}

Figure 2.6: Scatter plots of management costs (NZ dollars \$) and the marine reserve access (from 1-low access to 5-high access) (marine reserve $\mathrm{N}=5$ ). In the top plots are years (a) 2008/2009, (b) 2009/2010, scatter plots below are years (c) 2010/2011 and (d) average cost across years. 

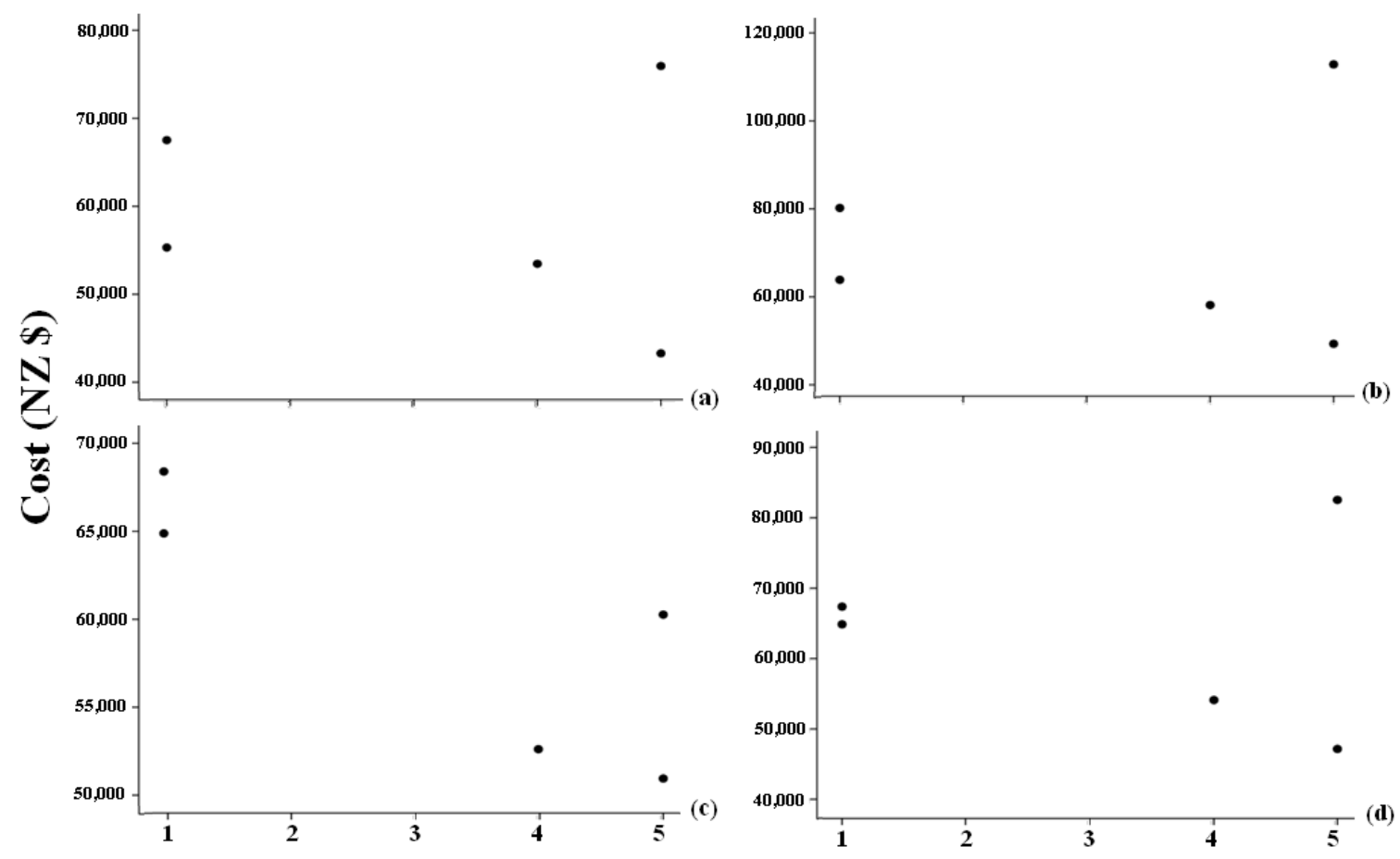

Human population

Figure 2.7: Scatter plots of management costs (NZ dollars \$) and the human population near to the marine reserve (from 1-low population to 5-high population) (marine reserve $\mathrm{N}=5$ ). In the top plots are years (a) 2008/2009, (b) 2009/2010, scatter plots below are years (c) 2010/2011 and (d) average cost across years.

\subsubsection{Indirect costs - displacement cost}

At the Taputeranga MR (TMR), commercial fishermen said that two vessels with an average of three men on board (one skipper and two crew) were displaced because the MR was established. After the TMR was established, these fishermen moved their fishing activities to Pencarrow, Turakirae Head and Cape Palliser at Palliser Bay (Fig. 2.8). Accessing these areas required fishermen to start work two hours earlier, and have an extended fishing area (the Cape Palliser area being bigger than the Island Bay area) meaning there was an increased fuel use. Because rock lobster fishing starts in the dark early in the morning, they also had to buy a more powerful generator to provide extra light. In order to catch the same amount of rock lobster as before the TMR, they had to buy 25 more craypots (colloquial name used by rock lobster fishermen to refer to the trap used to catch rock lobsters) with all the necessary equipment (rope, float, bait, basket, anodes and neck). The commercial fishermen declared they worked 106 days in a year. Therefore, based on the information obtained from commercial fishers, the annual displacement cost was estimated to be $\$ 22,160$ per vessel. The 
total displacement cost whilst the MR has been established i.e., the three year period 20082011 is therefore $\$ 66,480$ per vessel (Table 2.8).

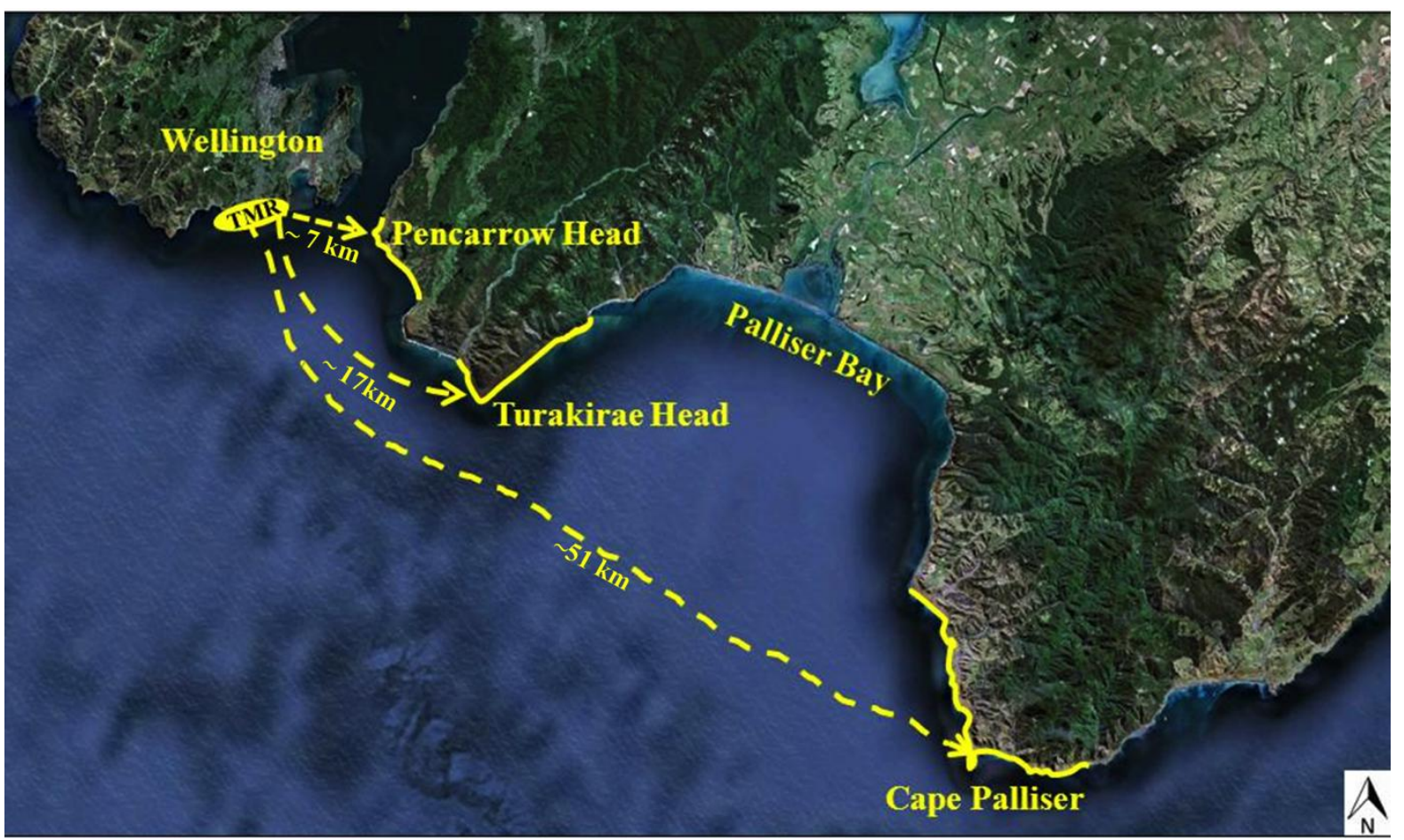

Figure 2.8: Displacement of rock lobster fishermen due to the Taputeranga MR (TMR) establishment (yellow dotted lines). The yellow solid lines along the coast show the current reef fishing areas by the rock lobster fishermen.

Table 2.8: Displacement costs for rock lobster fishers associated with the establishment of the Taputeranga Marine Reserve. Annual cost and total cost from 2008 to 2011. Values are in New Zealand dollars.

\begin{tabular}{lr}
\hline Extra fishing costs annually & \multicolumn{1}{c}{ Cost } \\
\hline Extra pots $^{*}$ & $\$ 2,080$ \\
Extra bait $^{* *}$ & $\$ 2,650$ \\
Extra fuel $^{*}$ & $\$ 9,540$ \\
Generator and lights $^{\dagger}$ & $\$ 1,000$ \\
Fuel for generator $^{+\dagger}$ & $\$ 530$ \\
Extra labour hour & $\$ 6,360$ \\
\hline Annual costs displaced fisherman & $\mathbf{\$ 2 2 , 1 6 0}$ \\
\hline Total cost from 2008 to 2011 & $\mathbf{\$ 6 6 , 4 8 0}$ \\
\hline${ }^{*}$ Craypot valued at $\$ 250.00$ each. Three years life, then it was divided \\
by three years. \\
${ }^{* *}$ Fuel price $\$ 1.20$ per litre \\
${ }^{\dagger}$ Generator and lights at $\$ 3000.00$. Three years life, then it was divided \\
by three years. \\
${ }^{\dagger}$ Two hours extra work/day x 106 days $\$ 30 /$ hour
\end{tabular}




\subsection{Discussion}

Despite much research being completed and a large amount of literature published on MRs, the costs of MRs have not received much attention (Sanchirico, 2000;Naidoo et al., 2006; McCrea-Strub et al., 2011). McCrea-Strub et al. (2011) stated that investigations into MR financial costs are rare in the published literature, particularly in the peer-reviewed literature. My research is the first to assess costs of MRs in NZ using a methodology that can be replicated by future studies.

Understanding costs are fundamental to MR planning, from the first inception of a MR, to running and maintaining a MR. It is important to note that there is a significant cost to establishing and implementing a MR (Naidoo et al., 2006). To not consider costs or to simply ignore them during the planning stage is likely to result in a missed opportunity to make best use of conservation resources and efficiently achieve conservation goals (Sanchirico, 2000; Bruner et al., 2003; Naidoo et al., 2006; Bruner et al., 2008; McCrea-Strub et al., 2011). The information and methodology provided in my research will contribute and help with future financial decision making both within NZ and overseas.

\section{Voluntary labour: The big help}

In this study I estimated four main costs encountered in MR establishment in NZ. These were pre-establishment costs, establishment costs, management costs and displacement costs. The pre-establishment and establishment costs compromised a series of stages that are not enterely covered by government budgets. In this study I found that after 17 years of effort and debate, this cost was approximately $\$ 500,000$. Despite the government role in this process that covered $\sim 60 \%$ of the total cost, there was another $\sim 40 \%$ which was covered by the donors and many hours of free labour from the Royal Forest and Bird Protection Society of New Zealand (F\&B), and the South Coast Marine Reserve Coalition Trust (SCMRC), which was fundamental to this process. Without the large amount of input by the other parties in the process, the establishment of the TMR is unlikely to have been successful. In addition, a high degree of voluntarism represents a high degree of commitment with the MR project analysed in my research, which is an alternative form of public participation. It is important for the government to consider the huge amount of time given by voluntary labour. Many of the 
people who participated as volunteers contributed their knowledge, which in paid projects would be expensive, making the pre-establishment process even more difficult due to scarcity of monetary resources.

The total monetary cost of the MR establishment is an estimate based on all available recorded data, meaning that the estimate itself is likely to be a minimum, in particular for the non-government portion. Because I only had access to the information that was recorded in files there is likely a lot of work carried out by people that was not documented, particularly by volunteers. Most of the jobs carried out by non-governmental agencies and volunteers were directly related to the meetings, negotiations, media releases, gathering information, and surveys.

\section{The pre-establishment and establishment costs}

A comparison of the pre-establishment total cost and cost per unit area for the TMR and the comparably sized tropical Saba Marine Park (SMP) (870 ha) (study carried out by McCreaStrub et al., 2011) located in Netherland Antilles, shows the TMR was cheaper on both cost measures, notwithstanding the pre-establishment process at Saba took only three years (from 1984 to 1987). The SMP pre-establishment total cost was approximately $\$ 800,000$ (value inflation adjusted for 2012 in New Zealand dollars). The cost per unit area estimated for TMR was $\$ 59,505 \mathrm{~km}-2$, while at SMP it was $\$ 92,700 \mathrm{~km}-2$. The differences in cost can be explained by other factors at SMP being considered in the cost calculation, which represented almost half of the cost; these included development of a management plan, community and stakeholder compensation, ecological and socio-economic research, management and training, and infrastructure (McCrea-Strub et al., 2011). In my study, compensation was not part of the process. In some MPAs (as the SMP case) there is a big investment in training people for new activities or to introduce local people to alternative activities such as tourism, with the idea to produce revenues to help with the MPA budgets, such taxes and /or entry fees. However, in New Zealand, it is not a goal to earn revenue from MRs, and there is little financial investment in training during the pre-establishment or establishment processes.

The total establishment cost for the TMR was estimated as $\$ 353,166$. This amount was for the first year of the establishment only. This value is variable amongst MRs and the cost varies depending on how much work is necessary to set up the new MPA or MR. In the TMR 
case, for example, it was necessary for external contractors to build and place all the MR boundary signs on the tops of hills by using a helicopter. In addition, it was necessary in this MR to purchase a new boat to patrol the area. These two things were very expensive, and constitute nearly two thirds of the cost.

McCrea-Strub et al. (2011) estimated that the cost of pre-establishment and establishment for areas of $5 \mathrm{~km}^{2}$ should be around $\$ 30,600 \mathrm{~km}^{2}$ based on their model. This model is based on the relationship between total establishment cost and the area of an MPA, however more detail about cost is needed on this model, as well as an increase in the number of MRs, because my study only included five. In this study I found that both processes cost approximately $\$ 100,859 \mathrm{~km}-2$. Therefore, the whole process from pre-establishment to gazetting the TMR cost 3.3 times more than the value estimated by McCrea-Strub et al. (2011). This could be explained by the length of time taken to establish the TMR.

\section{The management cost}

Data obtained on management costs across five MRs (noting there are 34 MRs in New Zealand in total) showed that these costs are mainly for staff salaries and operational expenses. McCrea-Strub et al. (2011) predicted that management costs should increase with MR size, and for an MPA of similar size to TMR the management costs should be around $\$ 345,500$ year $^{-1}\left(\$ 69,100 \mathrm{~km}^{-2} \cdot\right.$ year $\left.^{-1}\right)$, but I found that the average cost calculated for TMR was $\$ 83,2667$ year $^{-1}\left(\$ 9,750 \mathrm{~km}^{-2} \cdot \mathrm{year}^{-1}\right)$. In addition, the average management cost across the five MRs was $\$ 63,597$ year $^{-1}\left(\$ 3,683 \mathrm{~km}^{-2} \cdot\right.$ year $\left.^{-1}\right)$. The costs calculated in this study are under the median value reported by Balmford et al. (2003) for developed countries, with a median maintenance cost of $\$ 11,023 \mathrm{~km}^{-2} \cdot$ year $^{-1}$, while in developing countries the median maintenance cost is $\$ 2,445 \mathrm{~km}-2 \cdot$ year $^{-1}$ (Balmfordet al., 2003) (all values inflation adjusted at year 2012).

I was unable to find any strong relationship between management cost and MR size, MR age, MR access and neighbouring human population size. I found that $12 \%$ of the management cost could be explained by the MR size, where smaller MRs are more costly to maintain than the bigger ones. Despite the fact that McCrea-Strub et al. (2011) found from their model that a positive relationship exists between size and cost, they found through empirical analysis that there is a negative relationship between the actual cost and size. Balmford et al. (2003 
\&2004) found that bigger MPAs cost significantly less to maintain on a cost per unit area basis. In terrestrial habitats some authors have found that the management cost were always increased or reduced in direct proportion to size (Frazee et al., 2003; Bruner et al., 2004; Green et al., 2012). As a consequence, size is not a linear predictor variable to explain management cost. However, it is necessary to consider that the small number of MRs used in the analysis limits my power of interpretation. Therefore, it would be useful and interesting to run a complete analysis and see what relationships exist (if any) with respect to the cost of MRs and the variables used in this study including all 34 MRs in New Zealand.

\section{The displacement cost}

Fishermen displacement costs are an expected and inevitable cost resulting from MR designation, but these have not received enough attention (Sanchirico, 2000). I found that the TMR establishment resulted in an estimated cost of $\$ 22,160$ per vessel per year, with only two vessels displaced. These displacements were mainly at the boundaries of the MR (same region) and the largest movement is about $51 \mathrm{~km}$ (from TMR to Cape Palliser - next region). After a closure, fishermen tend to redistribute effort, based on behaviour and economic factors. For example, previous habits or vessel aggregation, catch value, cost of fuel, and distance to alternative fishing grounds, may all influence the redistribution of effort (Hutton et al., 2004; Mardle and Hutton, 2004; Pradhan \& Leung, 2004; Greenstreet et al., 2009).. Despite there being a cost to be covered by fishermen due to the establishment of the MR, fishermen are still able to make a living from the rock lobster fishery.. This is noticeable for two reasons: (1) according to Butardo-Toribio et al. (2009) 'only when fishing in farther locations becomes unprofitable can fishers be expected to shift to another livelihood activity', which is not the case here, and (2) CRA 4(refers to Appendix had an increase in Total Allowable Catch (TAC) from 610.625 tonnes (year 2011) to 661.9 tonnes (year 2012), and same year an increased the CRA 4Total Allowable Commercial Catch (TACC) from 415.625 tonnes (year 2011) to 466.9 tonnes (year 2012) in the study area (NZRLIC, 2012). Therefore, the TMR establishment did not negatively impact on the amounts of RLs captured (kg), only on where RLs are now captured (location). As a consequence, the TMR establishment impacted on fishermen in terms of displacement (time and distance travelled) which affects their monetary cost (budgets), but this impact was not so 
great as to caused them to replace their fishing activities for another source of income. Indeed, the increase in CRA 4 quota may have offset such displacement costs altogether.

\section{Conclusion}

In this study I showed that the current establishment process of MRs in NZ needs a considerable amount of money and effort from people willing to cooperate in this conservation action, particularly during the initial stages, where volunteers are essential, otherwise would be very difficult to cover all the work and knowledge necessary to establish a MR. Because some areas are more costly than others to conserve, due to accessibility, size, or just because the biodiversity is not equally distributed, it would be wrong to assume that all MRs are equally costly to conserve (from pre-establishment to manage it) (Naidoo et al., 2006). Therefore, cost differences between areas may be large and important for conservation management decisions. My results will help to improve decision making and conservation out comes at the national level. 


\title{
Chapter 3.The social impacts of two marine reserves: the perceptions of users and the local community
}

\author{
Author contribution: URN designed the study and performed data gathering, analysed the \\ data and wrote the chapter. RC, JJB, J.P.G.co-designed the study and surveys, corrected \\ the chapter. JJB and J.P.G. obtained the funding for this chapter.
}

\subsection{Abstract}

Marine Reserves (MRs) are amongst the most common tools used for marine conservation around the world. New Zealand (NZ) has 34 MRs protecting approximately $7.6 \%$ of NZ's territorial seas. In NZ the main purpose of MRs is to allow scientific research to be conducted in the absence of human disturbance. The establishment of MRs around the country produces different effects on the surrounding communities. However, evaluating the social effects is not the main priority of the MRs in NZ. Therefore, the majority of studies evaluate the biological effects and not the social effects. The aim of this chapter is to explore the social impacts of two MRs referring to attitudes, knowledge, processes and perceptions related to how people understand, maintain, protect, enhance and use two MRs established in NZ. In addition, I consider the potential effects on human dimensions of a hypothetical MR as a control MR. The methodology was divided in two sections, the first part was observational, from which a semi-structured questionnaire was designed. Three questionnaires were designed and used with five main groups affected by the establishment of the MRs. The results suggest that respondents' knowledge was generally inconsistent with respect to the MR Act (1991). In addition, the attitudes and perceptions of respondents revealed that many people consider MRs as something positive. From responses to the questions about a hypothetical MR at Plimmerton, I found that respondents believed that MRs are a good tool for protecting the environment. My study suggests that many issues identified could be easily solved if the current legislation (MR Act) would consider more aspects as part of the MR's goal. Also, the current legislation should be more flexible regarding public participation, giving more opportunity for local communities to be part of MR management. This study 
contributes to determining the impact of a MR, to evaluate public projects and the processes with respect to MR establishment in NZ.

\subsection{Introduction}

Many factors have contributed to declining global biodiversity. In coastal marine systems these activities include fishing, aquaculture, human settlement, construction, terrestrial runoff (e.g. from mining and farming), eutrophication, the introduction of exotic species, and climate change (NRC, 2001; Jenkins, 2003; Leslie et al., 2003; EMA, 2005; Day, 2006; Restrepo et al., 2006; Camargo et al., 2009). At present, human populations and coastal settlements continue to grow, and by 2025 it is estimated that 6.3 billion people will live in coastal areas (Barber et al., 2004; Lockwood and Kothari, 2006); this will increase resource use by humans. Different solutions have been proposed to manage marine resources including Marine Protected Areas (MPAs), which are one solution to protect marine biodiversity and enhance or protect overexploited marine resources; in addition they are important for scientific research. Spalding et al. (2008) estimated that there are 5,045 MPAs around the world, which represents less than $1 \%$ of the total area of the world's oceans. An international agreement - the Convention for Biological Diversity (CBD) - currently exists among 193 countries where signatories committed to create MPA networks by 2020 with the aim of protecting $10 \%$ of marine environments (CBD, 2010). Decisions to protect critical habitats by, for example, closing them to all forms of extractive use, will have many consequences for the users of these environments, which include socio-economic effects. These consequences may be positive or negative, direct or indirect. However, despite its importance, evaluating the social effects of MPA designation on the surrounding human community has not been a priority in the past. The majority of previous MPA and MR studies have evaluated their biological effects (such as Roberts and Polunin, 1991; Kelly et al., 2000; Roberts and Hawkins, 2000; Goñi et al., 2001, 2006; NRC, 2001; Fraschetti et al., 2002; Gell and Roberts, 2002; Russ, 2002; Gerber et al., 2003; Follesa et al., 2007; Follesa et al., 2008; Pande et al., 2008; Barrett et al., 2009), and have not considered the social consequences of designation. Mascia (2004) considers that the establishment of MPAs can help to shapenew directions in societies. This could be direct or indirect, because MPAs allocate uses and access to marine resources individually as well as collectively. Thus MPAs can generate positive and/or negative effects. For example in some communities MPAs can generate new 
sources of income through tourism. This is evident in the case of Hol Chan MR (Belize), where the old fisher communities decided to abandon their old activities to start tourism ventures. As a consequence of this economic growth, their socioeconomic levels benefited too. Thus the Hol Chan MR had high levels of satisfaction from its users, this satisfaction enhanced the Hol Chan MR, through expansion, and encouraged other places to establish MPAs too. However, negatives effects by MPAs can be possible (see Mascia \& Pailler, 2011). For example the creation of MPAs can produce fisher migration (change spatial allocation) from their local fishing ground, generating socioeconomic costs which are translated as negative consequences to the society (Mascia \& Claus 2009; Rassweiler et al., 2012).

Because fishers have to start to look for new fishing ground, this might generate multiples consequences such as changes in their traditional routines, competition between fishers for setting fishing gears in buffer areas (Lédée et al., 2012), need to buy new and/or change fishing gear (more examples see Murawski et al., 2005; Abbott \& Hayne, 2012; Campbell et al., 2012; Lédée et al., 2012; Horta e Costa et al., 2013; Stevenson et al., 2013).

Ultimately MPAs will depend on the type of value, local support and significance that the society can give to the MPA. Thus MPAs performance and success depends to a large extent on human behaviour (the principle of local support). For example, in the Fagatele Bay National Marine Sanctuary in American Samoa, the establishment was influences and supported from the beginning by the locals, where local authorities had a highly participative design process, which included important recognition of the Samoan culture. This has helped ensure the sanctuary has local support and success for long term. Local supports help to maximise the benefits from MPAs, and minimise the management costs (Holmes, 2013). Terrestrial cases have also shown how local support is important to conservation success. A well known and dramatic example, about how a protected area fails due to local disapproval, is the Amboseli in Kenya, where pastoralists unhappy with the protected area establishment killed the wildlife such as lions and elephants, by cooperating with poachers. Later on, conservationists decided to change their strategies, by ensuring the local support in their practices, then killing rates started to decrease, and finally the wildlife could recover (Western, 1994; Holmes, 2013). However, despite its importance, human perceptions, attitudes and behaviours have not received the attention they require for effective management outcomes (Gelcich et al., 2005a, b; McClanahan et al., 2005; Napier et al., 2005; Richardson et al., 2005; Gelcich et al., 2008; Dimitrakopoulos et al., 2010; Mascia et al., 2010). 
According to Decker et al. (2001) human dimensions can be defined as how people value wildlife, how they want wildlife to be managed, and how they affect or are affected by wildlife and wildlife management decisions. It is well known that successful conservation initiatives, such as MPAs, require the active participation of local users, and therefore changes in their perceptions should be monitored, in order to integrate local development with successful conservation (see Durrant and Shumway, 2004; Xu et al., 2006; Faasen and Watts, 2007; Dimitrakopoulos et al., 2010). Therefore, understanding the human dimensions of MPAs is a critical component of resource protection (Alexander, 2000; Salomon, 2008), and consequently the success of MPAs. The current paucity of information in this area also limits communication and understanding amongst users, non-users, stakeholders, managers and government agencies, and social data is vital to assist in the development of more effective conservation policies, and to assess the effectiveness of current conservation policies. In order to evaluate MPA effectiveness it is important to consider all consequences (positive and negative; biological and non-biological) and how such consequences change over time (e.g. Halpern and Warner 2002; Fraschetti et al., 2005; McClanahan et al., 2008; Camargo et al., 2009). Understanding the social effects of MPA designation is important in order to better understand the relationships between conservation actions and human well-being (Camargo et al., 2009). Human well-being has been defined by the Millennium Ecosystem Assessment (MEA) (2006) as 'the basic material needs for a good life, health, good social relations, security, and freedom of choice and action'. Better social information will make marine conservation more effective, because ultimately MPA success will depend on users and stakeholder actions and recognitions (Sanchirico, 2000; Carter, 2003; Pomeroy et al., 2004; Gelcich et al., 2005a, b; Gelcich et al., 2008; Alban, 2011; Christie and Pollnac, 2011). Therefore, is important to consider effectiveness of conservation in terms of social effects (see Pomeroy et al., 2004).

The aim of this chapter is to explore social impacts of MRs referring to attitudes, knowledge, processes and perceptions related to how people understand, maintain, protect, enhance and use two Marine Reserves established on the South Coast of the North Island of New Zealand. In addition, I consider the potential effects on human dimensions of a hypothetical MR located in between the two actual MRs. I collected information on MR knowledge, issues related to MR establishment, people's perceptions of MRs, perceived impacts from marine reserve establishment, changes in perception (with respect to flora and fauna, and human interactions) since the MRs were established, changes in expectation, satisfaction levels, and 
attitudes to MRs. Finally, I examined the implications of a future MR designation based on my results from the hypothetical MR.

\subsection{Background information}

\subsubsection{Overview of New Zealand Marine Protected Areas}

One of the most common protection tools used in New Zealand is Marine Reserves (MRs). The term 'marine reserve' was first suggested in New Zealand by Professor Chapman in May 1965, where marine reserves was under the purpose of 'special scientific reserve'. However no legislation existed to allow the sea to be 'reserved'. Soon after, 1971 a new Act was launched by the New Zealand government, entitled The Marine Reserves Act (1971). This was written based on the first ideas of MRs, which is 'An act to provide for the setting up and management of areas of the sea and foreshore as marine reserve for the purpose of preserving them in their natural state as the habitat of marine life for scientific study'. Later on, in 1975, the first MR was established in New Zealand. It was called the Cape Rodney-Okakari Point Marine Reserve, better known as Goat Island or the Leigh Marine Reserve, (Ballantine, 1991). MRs contain underwater scenery, natural features, or marine life, of such distinctive quality, or so typical, or beautiful, or unique, that their continued preservation is in the national interest. Therefore, unlike most other areas across the world, in New Zealand MRs are created for the principal to purpose of conducting scientific research in the absence of fishing pressure. This New Zealand purpose contrast with the main reasons MRs are established in other countries, which are typically to protect marine biodiversity and as fisheries management tools (Bohnsack and Ault, 1996; Dayton et al., 2000; Russ and Alcala 2004; Lester et al., 2009). Currently in New Zealand there are 34 full no-take marine reserves protecting $7.6 \%$ of New Zealand's territorial seas (the subantarctic reserves have not yet been established) (www.doc.govt.nz).

\section{3.2. Marine reserve establishment in New Zealand: from pre- to post-reservation status}

The MR pre-establishment process in New Zealand is a two stage process (Wolfenden et al., 1994). The first part of the process is called the 'non-statutory' stage, which involves consultation with different interest groups, which is then followed by the formulation of the 
first draft proposal; this draft is then released to the public for consultation. The second process is the 'statutory' phase, where the Minister of Conservation considers all the objections to, and submissions in support of the MR, resulting from the non-statutory process, and decides which issues should be upheld or rejected. After this second process is finished, the Minister of Conservation makes a recommendation to the Governor General to establish a MR in a specific location. This recommendation requires the agreement of the Minister of Transport and the Minister of Fisheries. The MR is officially gazetted when the Governor General releases the Order-in-Council to designate the MR, which comes into effect 28 days later. Therefore, members of the public (including local communities) are mostly involved during the non-statutory phase, and after this process has finished, public participation is generally limited. This limited public participation is largely because the Marine Reserves Act 1971 considers the main purpose of MR is for scientific research, and does not therefore include any public active participation in the legal framework.

In 2006, the NZ Department of Conservation launched a new MPA policy, entitled The Marine Protected Areas Policy and Implementation Plan. It proposes a combination of marine management tools for conservation, including MRs (see MPA Policy from paragraph 30 to 35). The MPA policy attempts to 'provide an integrated process, including regional consultation, for establishing a network of MPAs around New Zealand'. In the regional consultation councils, marine users, Tangata whenua (indigenous stakeholders), and all those with an interest in marine biodiversity are invited to take part.

\subsubsection{Social impact and monitoring effects in MRs}

Since the first MR was established in New Zealand in 1975 (the Cape Rodney-Okakari Point Marine Reserve, better known as Goat Island or the Leigh Marine Reserve; Enderby and Enderby, 2006), government agencies and research institutions have not yet evaluated the consequences or impacts of MR establishment on neighbouring human populations. Given that scientific research is the primary purpose of the MRs in New Zealand, then social research should be included as an important part of any research or monitoring programme. In addition, following the legislation of the MR Act (1971) in New Zealand, a MR might only be considered effective if someone is conducting research in it. Only a few studies have however been carried out in New Zealand MRs to quantify community reactions and social impacts (see Wolfenden et al., 1994; Craw and Cocklin, 1997; Taylor and Buckenham, 2003; DOC and Hunt, 2008). These authors agreed three main conlusions: (1) the consultation process 
was not as participative as it should be, (2) the establishing of a MR requires work with different communities and (3) it is necessary to increase public consultation.

\subsection{Methods}

\subsubsection{Study sites}

Kapiti Marine Reserve (KMR) was established in 1992 on the Kapiti Coast north of Wellington ( $50 \mathrm{~km}$ from Wellington city). KMR is located in the northwestern Cook Strait region of New Zealand (Eddy, 2011) and is and $5 \mathrm{~km}$ offshore (40 $51^{\prime} \mathrm{S}, 1^{\circ} 4^{\circ} 55^{\prime} \mathrm{E}$; Fig. 1a). The Kapiti Coast is a convergence zone for the cold clear Southland Current and the warm turbid and saltier d'Urville Current. KMR consists of two parts: the biggest part is located on the eastern side of the island occupying an area of 1825 ha extending to the Waikanae Estuary Scientific Reserve on the mainland. The smaller part (342 ha) is located on the eastern side of Kapiti Island (Eddy, 2011; Pande and Gardner, 2012). There are several small towns near KMR, however, for this study I selected the areas closest to the MR, which included Paraparaumu Beach (405 53' 24" S; $174^{\circ} 57^{\prime}$ 56.5" E), Raumati Beach (40 55' 7.3" S; $174^{\circ}$ 58' 1.2"E) and Waikanae Beach (40 51' 51.8" S; $175^{\circ} 0^{\prime} 30.9^{\prime \prime}$ E) (Fig.3.1a).

The Taputeranga Marine Reserve (TMR) is located on Wellington's south coast $\left(40^{\circ} 20 \mathrm{~S}\right.$, $174^{\circ} 45 \mathrm{E}$ ) and protects 854.79 ha of coastal waters. The reserve extends from Princess Bay on the eastern boundary to Quarry Bay on the western boundary (Pande and Gardner, 2009). TMR is located on Wellington city's coast (New Zealand's capital) (Fig. 1b) and was established in 2008. TMR is the first MR in NZ located within a city's boundaries. The marine environment is representative of the temperate Cook Strait region, which is a highly dynamic system, influenced by currents from the south as well as the zone of convergence for the East Cape, D’Urville and Southland currents (Carter, 2008; Eddy, 2011) (Fig. 3.1b). In this study I surveyed the following areas: Houghton Bay (412 20'31.9194” S; $\left.174^{\circ} 47^{\prime} 8.5^{\prime \prime} \mathrm{E}\right)$,

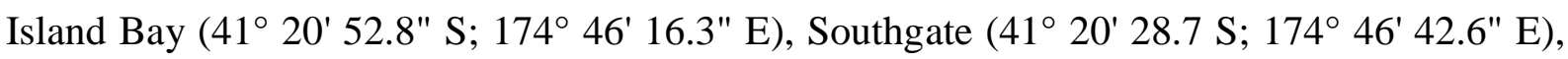
and Owhiro Bay $\left(41^{\circ} 20^{\prime} 44.5^{\prime} \mathrm{S} ; 174^{\circ} 45^{\prime} 5.03^{\prime \prime} \mathrm{E}\right)$.

The second part of this research was carried out at a non-reserve location, Plimmerton $\left(41^{\circ} 5^{\prime}\right.$ 0" S; $174^{\circ} 52^{\prime} 0^{\prime \prime} \mathrm{E}$ ), which is located in the northwest part of the Greater Wellington urban area of Porirua (Fig. 3.1c). This small beach-front village contains similar seascapes and biodiversity to the MRs where I sampled. Moreover, at Plimmerton, people are currently 
conducting those activities that were conducted at Kapiti and Island Bay before MRs were established. Because Plimmerton is similar in terms of biodiversity, seas and landscapes, and activities conducted at the two MR areas, it was selected as a study area to conduct a test of a hypothetical MR scenario. This site was called the 'hypothetical MR' (Fig.3.1d).

\subsubsection{Field methods}

Fieldwork was conducted at both MRs between December 2009 and January and February 2010, while fieldwork at Plimmerton was carried out in April and May 2010.

Fieldwork comprised two parts: (1) a qualitative assessment, and (2) a quantitative assessment. The first part was an in situ assessment of public perception, common knowledge and attitudes to the establishment and development of local marine reserves by using nonparticipative observations and short informal interviews (Taylor and Bogdan, 1986); several field visits were made to the study areas and informal conversations were held with the main users of the area to identify stakeholders and understanding the existing management framework. From the information previously gathered, I was able to identify the main users, and to understand how or if they used the area. This information was used later to inform the second part of the study, which involved the development of a structured multi-purpose quantitative questionnaire. This quantitative questionnaire was subsequently used to collect data on the different user groups and their ideas and knowledge as aligned to DOC goals for NZ's MRs. 

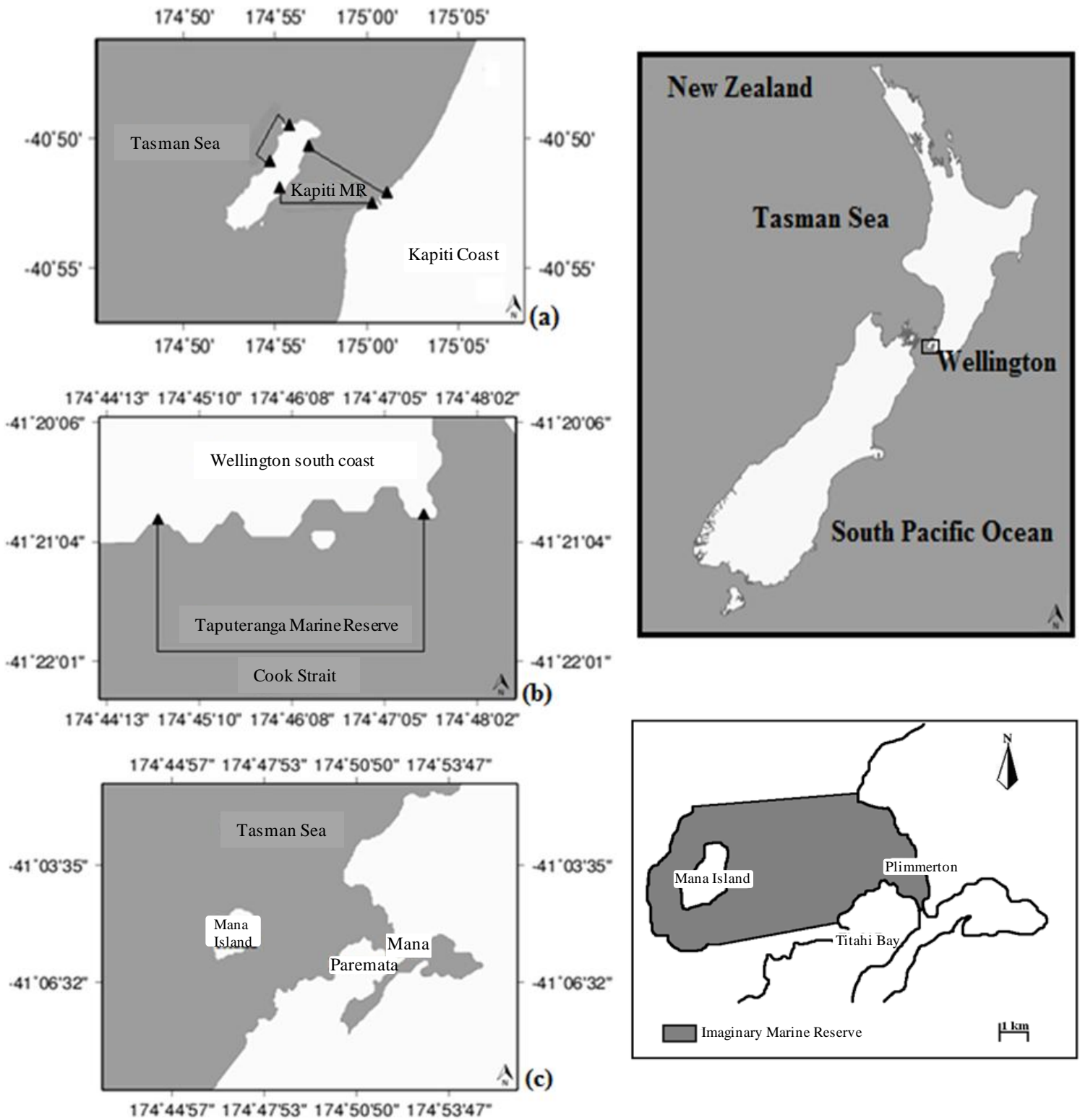

(d)

Figure 3.1: Map showing the study sites in Wellington region, New Zealand. Two marine reserves, Kapiti (a), and Taputeranga (c), and the hypothetical marine reserve located at Plimmerton (b). Location of the hypothetical marine reserve at Plimmerton (d).

\subsubsection{Questionnaire design}

Three questionnaires were designed and used. At each location, each questionnaire contained the same questions (so they were comparable), but questions were modified to reflect each locality (KMR, TMR and Plimmerton). At Plimmerton, care was taken to relate each question to the hypothetical MR in order to remind all respondents that questions were not related to any real or genuine MR establishment. The hypothetical MR was proposed around Mana Island and to extend to the Plimmerton coast (Fig.3.1d). 
Each questionnaire included a consent form and informative sheets are required by The Victoria University of Wellington Human Ethics Committee.

Each questionnaire was conducted face to face in a confidential manner (requiring no identification), and was carried out by the same four interviewers across the whole study. It took approximately 20 minutes to 1 hour to complete each questionnaire.

This research had The Victoria University of Wellington Human Ethics Committee approval No 17028.

\subsubsection{Sample groups}

From the initial observations it was possible to identify five main groups affected by the establishment of the MRs at Taputeranga and Kapiti:

(1) Local Businesses (LBs): all local businesses located in the study area were invited to participate in this study.

(2) Local Residents (LRs): people who live in the vicinity of the study sites. Vicinity means those suburbs which are located along the Taputeranga MR and where people could reasonably walk to the MR. In the Kapiti MR's case, due to the MR being located on an Island, vicinity means those suburbs located in front of the Kapiti MR.

(3) Visitors: all people who do not live in the study areas, but were at the sites for a holiday, relaxation or non-commercial reasons.

(4) Recreational Fishers and Divers (RDFs): people who use some of their leisure time for recreational diving or fishing, and who recognise themselves as a recreational fisher or diver. For this study, a fishers was defined as a person who conducted fishing activities above the water, from either the shore or from a boat, by using fishing gear such as fishing rods, hand lines, fishing nets, traps, etc. The term included those that were catch and keep, as well as catch and release, fishers. A diver was defined as a person who used SCUBA or free diving. Divers can conduct activities that involve hunting (sea food collection), spear fishing, crayfishing or non-consumptive activities such as observing wildlife, photography, etc.

Commercial Fishermen (CF). Fishermen for whom fishing is their main full time job and who hold a permit for such activity. In this study only The New Zealand Rock Lobster Industry Council Ltd was included, which is the body representing the interests of commercial rock 
lobster fishers in NZ. I invited this industry to participate, because from the qualitative assessment I recognised them as the most affected of the CF by the MR establishment. In addition, they are the only historical fisher community in this area. Also, rock lobster is the most important economic and cultural resource in my study areas. I interviewed a total of six $\mathrm{CF}(\mathrm{N}=6)$ which were the total number of $\mathrm{CF}$ affected by the MR establishment. This group participated only at TMR, because it was the main MR that affected them, while at KMR only recreational fishers rather than commercial fishers used the MR prior to MR establishment.

The trust with commercial fishers was developed by spending long times in conversation with them, especially the Director of The New Zealand Rock Lobster Industry Council, who is a key important and influential person within the rock lobster community. With his support, all fishers were following his support too.

Interviewees were chosen by convenience from interested volunteers. This means that the people who were answering the questionnaire were randomly chosen. Broad and Sanchirico (2008) suggest that in order to minimize potential biases inherent in this type of method, respondents could be intercepted by undertaking numerous strategies. In this study I used a snowball method following identification of key informants. My intercepting strategy was to visit public parks, fishing competitions, schools, shops, houses and to develop relationships with stakeholders to gain access to more potential interviewees (questionnaires can be found in Appendix B).

\subsubsection{Questionnaire contents}

Each questionnaire was divided into four main sections: (a) personal background, (b) marine reserve knowledge, (c) perception, satisfaction levels and attitudes, and (d) demographic information (see appendix B). From these sections I obtained the following information:

a) Respondent's profile: This section included respondent's personal background and the demographic information they provided.

b) Marine Reserve knowledge: This was measured by using open-ended and close-ended questions. Open-ended questions are a good instrument for gathering personal opinions (Cinti et al., 2010). In this section I assessed respondents' general knowledge with respect to MR goals (as stated in the NZ legislation and by DOC), and respondents' level of knowledge regarding activities conducted inside MRs. 
b.1) Activities permitted inside marine reserves: Based on the qualitative assessment conducted during the first part of this study, from information held in relevant reports (MR application form and survey reports carried out during the MR application), and from personal observations, I compiled a list of 29 different activities. From this list of activities respondents were asked to identify which activities they thought were permitted or prohibited inside the MR. They were also given the option to say they were unsure if a specific activity was prohibited or not. Activities, such as recreational fishing (including surfcasting), commercial fishing, beach-combing, and shellfish/seaweed/fire wood collection are all considered to be high impact (activities that stress or disturb the environment). Therefore, these activities are banned in all New Zealand MRs (MR Act, 1971). Other activities such as water-sports (e.g. surfing, boogie boarding, water skiing, swimming, diving, wind-surfing, and snorkelling), or non-water based activities (e.g. walking, playing, rock-pooling, picnicking, sunbathing, biking, and running, and academic/educational activities) are considered to be low impact activities (activities that do not stress or disturb the environment). As a consequence such activities are permitted inside MRs. A permit must be obtained from DOC for activities such as research that may involve direct contact with the biodiversity inside a reserve (e.g. conducting experiments, measuring species, and catch and release studies).

All data were divided into three groups; the first was permitted activities, the second prohibited activities, and the third for activities that respondents were unsure if it was permitted or not. For each of these groups, I calculated absolute frequency per activity conducted per MR. Then each absolute frequency was divided by the total number of data to obtain relative frequency, which was expressed as a percentage. Based on all answers to the questions, I calculated the mean number of responses per activity in each respondent group.

b.2) Current activities actually conducted in the MR: To investigate current activities conducted by users in the study area (both MRs and Plimmerton) I used the list from section b.1-Activities permitted inside marine reserves (see section $b .1$ ). I asked respondents to pick from the list of activities those activities that they are regularly conducting in MRs. By asking about current activities I was able to estimate the percentages of activities (legal and illegal) being conducted inside the MRs, and create a baseline with respect uses in these areas. All data were organised in order to calculate absolute frequency per activity conducted per MR. Then each absolute frequency was divided by the total number of data to obtain relative 
frequency, which was expressed as a percentage. Moreover, from the activity data I calculated the mean values for each response per activity. The frequency of each activity carried out by users was not measured during this study.

b.3) Marine conservation issues: To measure the degree of understanding and commitment to marine conservation I asked a close-ended question: 'Do you consider Marine Reserves to be a useful tool to protect the marine environment?' Then to complement this question I asked a close-ended question: 'Is marine conservation in general an important issue for you?'

b.4) Support for the establishment of Marine Reserves: To ascertain the overall attitude of the user groups to the establishment of the MRs at Kapiti and Taputeranga, respondents were asked the following question: 'From your perspective, do you think the establishment of the Kapiti/Taputeranga MR was a good decision?' In the case of the hypothetical MR this question was asked 'What would be your position regarding the proposal to create a hypothetical MR around Mana Island and extending to the Plimmerton coastline?' In the case of the real MRs, and the hypothetical MR, potential answers were: (a) I agreed with it, (b) I disagreed with it, (c) I didn't care and (d) I don't know.

c) Perceptions of marine reserves: To assess perceptions, respondents were presented with specific statements and were asked to indicate the level of agreement/disagreement on the five point Likert-scale of importance (Likert, 1932) (see Appendix B).

c.1) Important features of marine reserves: In order to understand what respondents believed were the most important features a MR should contain when established in New Zealand, respondents were asked to score 13 statements on a scale of importance (Likert scale), where 5 was the most important, and 1 the least important (see Appendix B).

c.2) Perceived negative impacts assessment: In order to determine if the MRs have been having negative impacts on respondents, and to determine what these impacts were, respondents were asked two questions, one close-ended followed with an open-ended question. The first question related to any personal problems: 'Has the establishment of the Taputeranga/Kapiti MR caused you or your family any problems (e.g. quality of life, economic loss, etc.)?' Then I asked about general impacts on other users: 'Are you aware of any other problem(s) that have arisen after the establishment of the Taputeranga/Kapiti $M R ?^{\prime}$ 
c.3) Perceived impacts of the hypothetical marine reserve establishment: To assess potential problems that people might expect with the establishment of a MR and to compare these with the current issues in the two actual MRs, I asked an close-ended question in a hypothetical context: 'In the case of the establishment of a marine reserve around Mana Island and extending to the Plimmerton coastline do you think that this will cause any problems for you or your family (e.g. quality of life, economic loss, etc.)?' Then to assess any other issues expected by respondents I asked: 'Are you aware of any other problem(s) that could arise if a MR is established around Mana Island and extending to the Plimmerton coastline?'

c.4) Overall perceived benefits and negative impacts of marine reserves: Respondents were asked to grade their individual personal benefits from the establishment of the MRs by expressing their perception as negative, positive, same before and after the establishment. The topics analysed by respondents were their perceived benefits with respect to their overall: economic status; wealth level; health, families' well-being; leisure time; work and well-being. I focused in these six items, because these have been indicated as the most measures of societal well-being by the IUCN.

c.5) Changes expected after marine reserve establishment: Respondents were asked to assess the most visible changes since the marine reserve was established with respect to: (1) changes in flora and fauna; and (2) changes in human usage. A mixture of close-ended and openedended questions was used. The first part of this question was 'Have you noticed any change in terms of the marine flora and fauna/ human usage (or activities) since the marine reserve was established?' If respondents considered that there had been changes they were asked to describe them. All responses were categorised in order to allow further quantitative analyses (see Appendix B).

d) Public satisfaction levels in response to the establishment of marine reserves: To evaluate respondents' satisfaction to various aspects of the MR after its establishment, respondents were asked their views on topics including biodiversity protection, litter, educational opportunities, management and MR policing (refer to Appendix B). Responses were ranked on the Likert scale (Likert, 1932).

e) General attitudes toward the Taputeranga/Kapiti Marine Reserve: To assess general attitudes towards the MRs I used an adaptation of the word association technique. This qualitative technique is widely used in psychology and marketing research to obtain information by indirect means, by employing the principle of projection (Green et al., 1988). 
Word association permits respondents to connect a given word or image (stimulus) and produce a new word. This word is an indirect way to explain the respondent's needs, motives, and values, where people connect ideas, feelings, experiences and information by way of associations. These ideas and experiences can be linked, or grouped, in the unconscious, which can influence an individual's behaviour. Therefore, attitudes and behaviour were measured indirectly with this technique.

I used the question When I say 'Taputeranga/Kapiti Marine Reserve', what is the first word that comes into your mind? So the stimulus words were 'Taputeranga/Kapiti Marine Reserve'. Moreover I asked each respondent to provide an explanation for the word provided (i.e., a justification), in order to better understand this association. All answers were grouped, based on their connotative meanings, based on explanations required on each word. From the groups, I considered answers to be positive, negative or neutral. Once all responses were categorised, I calculated the absolute frequency for each category (as positive, negative or neutral) per group per MR. Then each absolute frequency was divided by the total number of data to obtain relative frequency, which was expressed as a percentage.

e.1) Attitude toward potential marine reserve disestablishment: Attitude is defined as a predisposition towards something specific (Bennett, 1988). It is an individual's evaluation, which is action-oriented. This involves a person, concept, entity, or action, resulting in 'liking/disliking' or 'positive/negative' or a 'neutral' judgment (Bennett, 1988; Pascale et al., 2004, Solomon, 2007). Attitude is an important component of human dimension assessments, which affects different selective processes, involving learning with a mixture of beliefs, feelings and behavioural tendencies, and that eventually influences the individual or collective decision-making process (Pascale et al., 2004). It may help provide support for environmental policies and potential behaviour (Kollmuss and Agyeman, 2002; Rauwald and Moore, 2002; Gelcich et al., 2005a,b; Solomon, 2007).

These questions were used to assess the general attitude and potential future reactions of different groups if the Taputeranga/Kapiti MR were to be disestablished (note - this is a hypothetical scenario because there is no move to disestablish either MR). This situation could happen in New Zealand, because a review of any marine reserve may be undertaken at any time. Therefore, respondents were asked to answer two hypothetical open-ended questions: (1) If the Taputeranga/Kapiti Marine Reserve was disestablished, what do you think would be the implications for the environment? And (2) If the Taputeranga/Kapiti 
Marine Reserve was disestablished, what do you think would be the implications for you personally? At Plimmerton this question was phrased hypothetically: If, several years after its establishment, the hypothetical MR around Mana Island and extending to the Plimmerton coastline is opened up to fishing again, would you resume your activities in this area? In both cases (real and hypothetical MRs) potential answers were open-ended.

Responses obtained from the open-ended questions were categorised. Once all responses were categorised, I calculated the absolute frequency for each category (as positive, negative or neutral) per group per MR. Then each absolute frequency was divided by the total number of data to obtain the relative frequency, which was expressed as a percentage.

f) Marine reserve implications for future of the marine environment: In order to understand if the MRs created a real change in respondents' lives, I designed an opened-ended question of a hypothetical nature. With this question I aimed to predict potential attitudes to the environment if the MRs did not exist (refer to appendix B). All explanations given by respondents on each question were categorised to identify the main concepts, then the relative frequency as a percentage, per group was calculated.

\subsubsection{Data analysis}

Quantitative data were organised and entered in to SPSS 10.0 software for statistical analysis. Because the data were not normally distributed, I used non-parametric tests. A significance level of 0.05 was used ( $p$ values $\leq 0.05$ ).

Significant differences in attitudes (marine conservation issues and overall attitude toward MR establishment) were tested using the Pearson Chi-Square test $\left(\chi^{2}\right)$ for categorical variables. Differences in scores for the Likert-scale statements (continuous variables) among groups in each MR, and between the two MRs for questions about the 'important features of marine reserves' (see methodology c.1 and Appendix B), 'perceived benefits of marine reserves' (see methodology c.4), and 'satisfaction levels of marine reserves' (see methodology d) were tested using for each statement using a Kruskal-Wallis test.

Relative frequencies (\%) from the responses to questions about 'changes in the marine reserve (flora and fauna, and humans)' were analysed for each group of users, and compared between 
MRs with a Kruskal-Wallis test. Changes described later by respondents from the open-ended question were grouped and categorised and are presented graphically.

\subsection{Results}

\subsubsection{Respondents' profiles}

A total of 373 people completed the questionnaire, of which 214 respondents were from the TMR and 159 respondents were from the KMR. The respondents were divided into six age categories $(<20,21-30,31-40,41-50,51-60$, and $>60$ years old) at both sites. Fifty-eight percent of the respondents in KMR, and 49\% in TMR were female (Table 3.1). In Plimmerton $44 \%$ of respondents were male, and $56 \%$ females. All respondents were local residents, and $37 \%$ had been residing in the area for more than 20 years $(\mathrm{N}=10)$.

\subsubsection{Respondents' reasons for locating to the marine reserve area}

Five of the $13 \mathrm{LBs}$ in KMR were operating before MR establishment, while in the Taputeranga all $8 \mathrm{LBs}$ were operating before it was established. In the case of Kapiti LRs, $25 \%$ resided in the area before the MR was established $(\mathrm{N}=114)$, while in TMR $88 \%$ had been living in the area before the establishment $(\mathrm{N}=131)$. Most of the RDFs were active in the areas before the MRs were established, 60\% in KMR $(\mathrm{N}=10)$, and $84 \%$ in TMR $(\mathrm{N}=25)$. At TMR, all $\mathrm{CF}$ were conducting their activities in the area prior to the establishment of the MR (Table $3.1)$.

Of the people who arrived in the study area after the MRs were established, nobody selected either area specifically because there was a MR in the vicinity. When asked why they did select the area, LBs responded by saying that it is good place for selling their products; LRs chose these places to live because the house prices were cheaper compared to other areas, for family reasons, proximity to their workplace, friendly community and because they are safe places to live.

The majority of visitors were from surrounding areas in the Wellington region $(\sim 57 \%)$, followed by visitors from overseas ( $26 \%)$, and the rest of visitors were New Zealanders, but from areas outside of Wellington region $(\sim 17 \%)$. The reason why visitors selected these areas was because both places are good for outdoor activities, visiting friends and family, or simply because they were looking for surrounding areas to spend their leisure time around the capital, but the MRs were not the main reason for their decision to visit the area (Table 3.1). 


\subsubsection{Marine reserve knowledge}

Respondents were asked if they know what a MR is. At TMR, KMR and the hypothetical MR at Plimmerton, 97\%, 98\%, 93\% of the respondents believed they understood what a MR is (Table 3.2). However, the next question (open-ended) asked for a description of the main goal of MRs in New Zealand. At both MRs (with the exception of two people and all CF interviewed - $\mathrm{N}=6$ ) nobody correctly stated that the purpose of New Zealand's marine reserve is for scientific research in the absence of all forms of human disturbance. I grouped responses about the goals of MRs in to four main categories based on their connotative meanings, as follows: (1) protection (including conservation and preservation), (2) mitigation, (3) allow/not allow activities and (4) provision of goods (Fig. 3.2). Just three people selected the last category, which was related to scientific research.

\subsubsection{Activities permitted inside marine reserves}

Most interviewees at both MRs, as well as the hypothetical MR at Plimmerton, selected the same activities (that is over $70 \%$ selected per group). These activities were walking, playing, picnicking sunbathing, swimming, boating, boogie boarding, and snorkelling. Commercial fishing activities were highlighted as prohibited $(83 \%$ at TMR, 78\% at KMR, $73 \%$ the hypothetical MR). Moreover, at the hypothetical MR recreational fishing (73\%) and shellfish collecting (67\%) were also selected as prohibited activities. With respect to the other activities at the other MRs (i.e., recreational fishing, surfcasting, shellfish collection, motor biking, and wind surfing), just less than $60 \%$ of respondents selected them as banned at both MRs. Respondents at TMR and the hypothetical MR considered the collection of seaweed as a prohibited activity, while respondents at KMR considered motor biking as prohibited. The activities that respondents were most frequently unsure if they were permitted to conduct or not (average answer per group was over 30\%) at both MRs were beach-combing, water skiing and firewood collection. Respondents at KMR were more unsure about some activities, including seaweed collection (46\%), rock pooling (42\%), biking (36\%), running (33\%) and conducting research (33\%), sitting in the car and observing the environment, and general DOC activities (i.e. monitoring, patrolling) (31\%), shellfish collecting and surfing (30\%), than people at Taputeranga. Respondents at TMR were unsure about surf rescue activities (33\%). At the hypothetical MR the 'unsure' activities option was selected by less than $17 \%$ of respondents (Fig. 3.3a, b and c). 


\subsubsection{Current activities conducted in the MR}

The same list used to assess knowledge was used to establish which activities are currently being conducted inside the marine reserve. The most frequent responses for activities inside the MRs were: walking ( 14\%), sitting on or near to the beach $(\sim 11 \%)$, swimming $(\sim 8 \%)$, picnicking $(\sim 7 \%)$, playing on the beach, and sitting in the car on the beach and observing the environment ( $\sim 6 \%$ each) (these activities are considered low impact and are permitted by law in marine reserves). Moreover, there was a wide range of other activities that people were currently conducting inside the MRs (Fig. 3.4). These results show that there are still some illegal and high impact activities conducted inside the reserve, e.g. beach-combing $(\sim 5 \%)$, recreational fishing $(\sim 2 \%)$, surfcasting $(1 \%)$, and collection of shellfish, firewood and seaweed ( 1\% each, Fig. 5). At the hypothetical MR a greater number and more variety of activities were conducted on the Plimmerton coastline. The most common activities were education $(5.3 \%)$, collecting seaweed $(4.8 \%)$, wind-surfing $(4.2 \%)$, shellfish collecting $(4.4 \%)$, DOC activities (4.1\%), diving (4.1\%), and surfcasting (3.6\%) (Fig. 3.4). 
Table 3.1: Number of respondents per location.

\begin{tabular}{|c|c|c|c|c|c|c|c|c|c|c|}
\hline \multirow{3}{*}{ 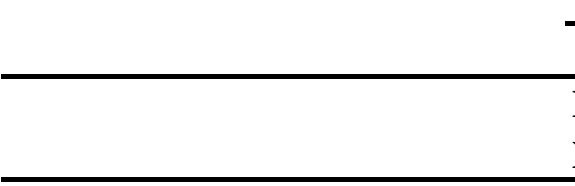 } & \multirow{2}{*}{\multicolumn{5}{|c|}{ Taputeranga Marine Reserve }} & \multirow{2}{*}{\multicolumn{4}{|c|}{ Kapiti Marine Reserve }} & \multirow{3}{*}{$\begin{array}{l}\text { Plimmerton } \\
\text { LR } \\
\mathrm{N}=\mathbf{3 0} \\
\end{array}$} \\
\hline & & & & & & & & & & \\
\hline & $\begin{array}{l}\mathrm{LB} \\
\mathrm{N}=8\end{array}$ & $\begin{array}{l}\mathrm{LR} \\
\mathrm{N}=128\end{array}$ & $\begin{array}{l}\text { RFandD } \\
N=25\end{array}$ & $\begin{array}{l}\mathrm{V} \\
\mathrm{N}=47\end{array}$ & $\begin{array}{l}\mathrm{CF} \\
\mathrm{N}=6\end{array}$ & $\begin{array}{l}\mathrm{LB} \\
\mathrm{N}=13\end{array}$ & $\begin{array}{l}\mathrm{LR} \\
\mathrm{N}=105\end{array}$ & $\begin{array}{l}\text { RFandD } \\
\mathrm{N}=10\end{array}$ & $\begin{array}{l}\mathrm{V} \\
\mathrm{N}=31\end{array}$ & \\
\hline Variables & $\%(n)$ & $\%(\mathrm{n})$ & $\%(\mathrm{n})$ & $\%(\mathrm{n})$ & $\%(\mathrm{n})$ & $\%(\mathrm{n})$ & $\%(\mathrm{n})$ & $\%(\mathrm{n})$ & $\%(\mathrm{n})$ & $\%(\mathrm{n})$ \\
\hline \multicolumn{11}{|l|}{ Gender } \\
\hline Male & $63(5)$ & $37(47)$ & $84(21)$ & $62(29)$ & $100(6)$ & $38(5)$ & $40(42)$ & $80(8)$ & $39(12)$ & $44(13)$ \\
\hline Female & $37(3)$ & $63(81)$ & $16(4)$ & $38(18)$ & - & $62(8)$ & $60(63)$ & $20(2)$ & $61(19)$ & $56(17)$ \\
\hline \multicolumn{11}{|l|}{ Age (years) } \\
\hline$\leq 20$ years & $12(1)$ & $3(4)$ & $4(1)$ & - & - & - & $4(4)$ & - & - & $4(1)$ \\
\hline $21-30$ years & $13(1)$ & $12(15)$ & $12(3)$ & $26(12)$ & - & $8(1)$ & $3(3)$ & - & $13(4)$ & $8(2)$ \\
\hline $31-40$ years & $38(3)$ & $21(27)$ & $28(7)$ & $13(6)$ & - & $15(2)$ & $14(15)$ & $20(2)$ & $29(9)$ & $12(3)$ \\
\hline $41-50$ years & $13(1)$ & $20(26)$ & $40(10)$ & $21(10)$ & $67(4)$ & $39(5)$ & $24(25)$ & $60(6)$ & $32(10)$ & $15(4)$ \\
\hline $51-60$ years & - & $13(16)$ & $4(1)$ & $17(8)$ & $33(2)$ & $15(2)$ & $13(14)$ & $20(2)$ & $10(3)$ & $23(6)$ \\
\hline$\geq 61$ years & $25(2)$ & $31(40)$ & $12(3)$ & $23(11)$ & - & $23(3)$ & $42(44)$ & - & $16(5)$ & $38(10)$ \\
\hline \multicolumn{11}{|l|}{ Education level completed } \\
\hline Primary school & - & $2(2)$ & - & - & - & - & $3(4)$ & - & - & - \\
\hline Secondary school & $37(3)$ & $20(26)$ & $8(2)$ & $19(9)$ & - & $8(1)$ & $27(28)$ & $20(2)$ & $16(5)$ & $11(3)$ \\
\hline Trade/technical qualification & - & $9(12)$ & $4(1)$ & $13(6)$ & $33(2)$ & $15(2)$ & $26(27)$ & $20(2)$ & $19(6)$ & $15(4)$ \\
\hline Degree/professional qualification & $63(5)$ & $66(84)$ & $76(19)$ & $57(27)$ & $50(3)$ & $54(7)$ & $37(39)$ & $40(4)$ & $61(19)$ & $70(19)$ \\
\hline Other & - & $3(4)$ & $12(3)$ & $11(5)$ & $17(1)$ & $23(3)$ & $7(7)$ & $20(2)$ & $3(1)$ & $4(1)$ \\
\hline \multicolumn{11}{|c|}{ Future participation availability in other similar surveys } \\
\hline Yes & $75(6)$ & $77(99)$ & $52(13)$ & $40(19)$ & $33(2)$ & $23(3)$ & $62(65)$ & $60(6)$ & $45(14)$ & $43(13)$ \\
\hline No & $25(2)$ & $23(29)$ & $48(12)$ & $60(28)$ & $67(4)$ & $77(10)$ & $38(40)$ & $40(4)$ & $55(17)$ & $57(17)$ \\
\hline
\end{tabular}


Continued from previous page

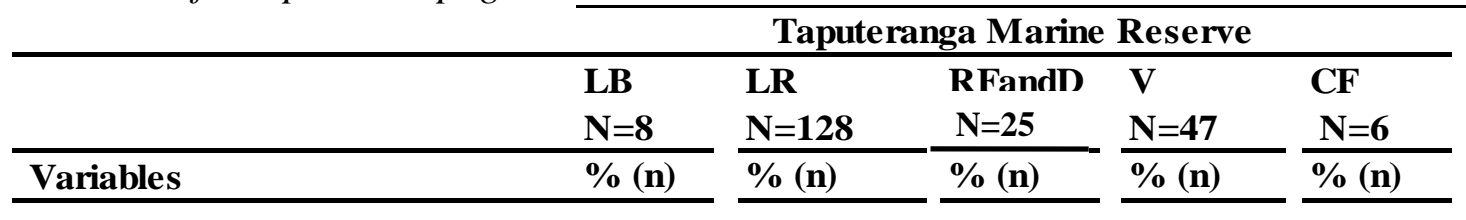

\begin{tabular}{|c|c|c|c|}
\hline \multicolumn{4}{|c|}{ Kapiti Marine Reserve } \\
\hline $\mathbf{L B}$ & $\mathbf{L R}$ & RFandD & $\mathbf{V}$ \\
\hline $\mathbf{N}=\mathbf{1 3}$ & $\mathrm{N}=105$ & $\mathbf{N}=\mathbf{1 0}$ & $\mathbf{N}=31$ \\
\hline$\%(n)$ & $\%(\mathrm{n})$ & $\%(\mathrm{n})$ & $\%(\mathbf{n})$ \\
\hline
\end{tabular}

Plimmerton

Business operate time (years)

$\begin{array}{lr}\leq 5 \text { years } & 50(4) \\ 6-10 \text { years } & 12.5(1) \\ 11-15 \text { years } & - \\ 16-20 \text { years } & 12.5(1) \\ \geq 21 & 25(2)\end{array}$

$50(4)$

25 (2)

\section{Residence time (years)}

$$
\begin{aligned}
& \leq 5 \text { years } \\
& 6-10 \text { years } \\
& 11-15 \text { years } \\
& 16-20 \text { years } \\
& \geq 21
\end{aligned}
$$

$\begin{array}{rr}- & 34(43) \\ - & 23(30) \\ - & 7(9) \\ - & 9(12) \\ - & 27(34)\end{array}$

$\begin{array}{ll}- & - \\ - & - \\ - & -\end{array}$

-

$$
\begin{aligned}
& - \\
& - \\
& -
\end{aligned}
$$

$46(6)$
$8(1)$
$8(1)$
$23(3)$
$15(2)$

$-$

$-$

$-$

$30(8)$

Fishing/diving time (years)

$$
\begin{aligned}
& \leq 5 \text { years } \\
& 6-10 \text { years } \\
& 11-15 \text { years } \\
& 16-20 \text { years } \\
& \geq 21
\end{aligned}
$$

$\begin{array}{rrr}- & - & 36(9) \\ - & - & 8(2) \\ - & - & 12(3) \\ - & - & 4(1) \\ - & - & 40(10)\end{array}$

$$
-
$$$$
-
$$

$$
\begin{array}{rr}
- & 41(43) \\
- & 17(18) \\
- & 15(16) \\
- & 3(3) \\
- & 24(25)
\end{array}
$$

Visit time (years)

First visit

1-12 months

1 - 5 years

6-10 years

$>10$ years

$\begin{array}{rrrrr}- & - & - & 83(39) & - \\ - & - & - & 17(8) & - \\ - & - & - & - & - \\ - & - & - & - & - \\ - & - & - & - & -\end{array}$

$\begin{array}{lrr}- & - & 20(2) \\ - & - & 20(2) \\ - & - & 40(4) \\ - & - & - \\ - & - & 20(2)\end{array}$

LR

$\mathbf{N}=\mathbf{3 0}$

$\%(n)$

Table will continue on next page

\begin{tabular}{rrrrr}
- & - & - & $55(17)$ & - \\
- & - & - & $13(4)$ & - \\
- & - & - & $16(5)$ & - \\
- & - & - & $6(2)$ & - \\
\hline & - & - & $10(3)$ & -
\end{tabular}




\begin{tabular}{|c|c|c|c|c|c|c|c|c|c|c|}
\hline & \multicolumn{5}{|c|}{ Taputeranga Marine Reserve } & \multicolumn{4}{|c|}{ Kapiti Marine Reserve } & \multirow{2}{*}{$\begin{array}{l}\text { Plimmerton } \\
\text { LR } \\
\mathrm{N}=30 \\
\end{array}$} \\
\hline & $\begin{array}{l}\mathrm{LB} \\
\mathrm{N}=8\end{array}$ & $\begin{array}{l}\mathrm{LR} \\
\mathrm{N}=128\end{array}$ & $\begin{array}{l}\text { RFandD } \\
\mathrm{N}=25\end{array}$ & $\begin{array}{l}\mathrm{V} \\
\mathrm{N}=47\end{array}$ & $\begin{array}{l}C F \\
N=6\end{array}$ & $\begin{array}{l}\mathrm{LB} \\
\mathrm{N}=13\end{array}$ & $\begin{array}{l}\mathrm{LR} \\
\mathrm{N}=105\end{array}$ & $\begin{array}{l}\text { RFandD } \\
\mathrm{N}=10\end{array}$ & $\begin{array}{l}V \\
N=31\end{array}$ & \\
\hline Variables & $\%(\mathrm{n})$ & $\%(\mathrm{n})$ & $\%(\mathrm{n})$ & $\%(\mathrm{n})$ & $\%(\mathrm{n})$ & $\%(\mathrm{n})$ & $\%(\mathrm{n})$ & $\%(\mathrm{n})$ & $\%(\mathrm{n})$ & $\%(n)$ \\
\hline
\end{tabular}

Main reason to select this area for living/working/visit

Close to shops

Good business location, close to many customers

Porperty price or rentals

Family business

Easy transport to work/school

Beautiful seas and landscape

Popular place

Safe place

Away from the inner city

Close to my house

Equipment rentals

Accommodation

Shopping

Easy access from our house/place

rented

Boating

Fishing

Diving

Collecting seaweed

Taputeranga/Kapiti MR

Other
$6(17)$

$20(8)$

$10 \overline{(2)}$

5 (1)

$10(2)$

- $4(11)$

- $7(19)$

- $10(27)$

- $2(5)$

- $\quad-$

- $\quad-$

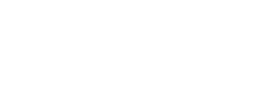

- $\quad-$

- $\quad-$

-

$15(3)$

$23(64)$

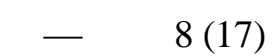

$8(17)$

$-$

-

$5(3)$

$$
19 \text { (6) }
$$

9 (3)

$16(5)$

16 (5)

9 (3)

12 (4)

-

$16(5)$

-

-

-

-

10 (24)

28 (66)

2 (5)

12 (28)

15 (34)

-

$-$

-

-

-

-

-

-

3 (1)

$\begin{array}{rrr}- & - & - \\ - & - & - \\ - & - & - \\ - & - & 14(9) \\ - & 27(16) & 38(24) \\ - & 2(1) & 8(5) \\ - & 7(4) & 13(8) \\ - & 3(2) & 10(6) \\ - & 5(3) & - \\ - & - & - \\ - & - & - \\ - & 3(2) & - \\ - & 2(1) & - \\ - & - & - \\ - & 13(8) & - \\ - & - & - \\ - & - & - \\ - & - & - \\ - & 38(23) & 13(8)\end{array}$




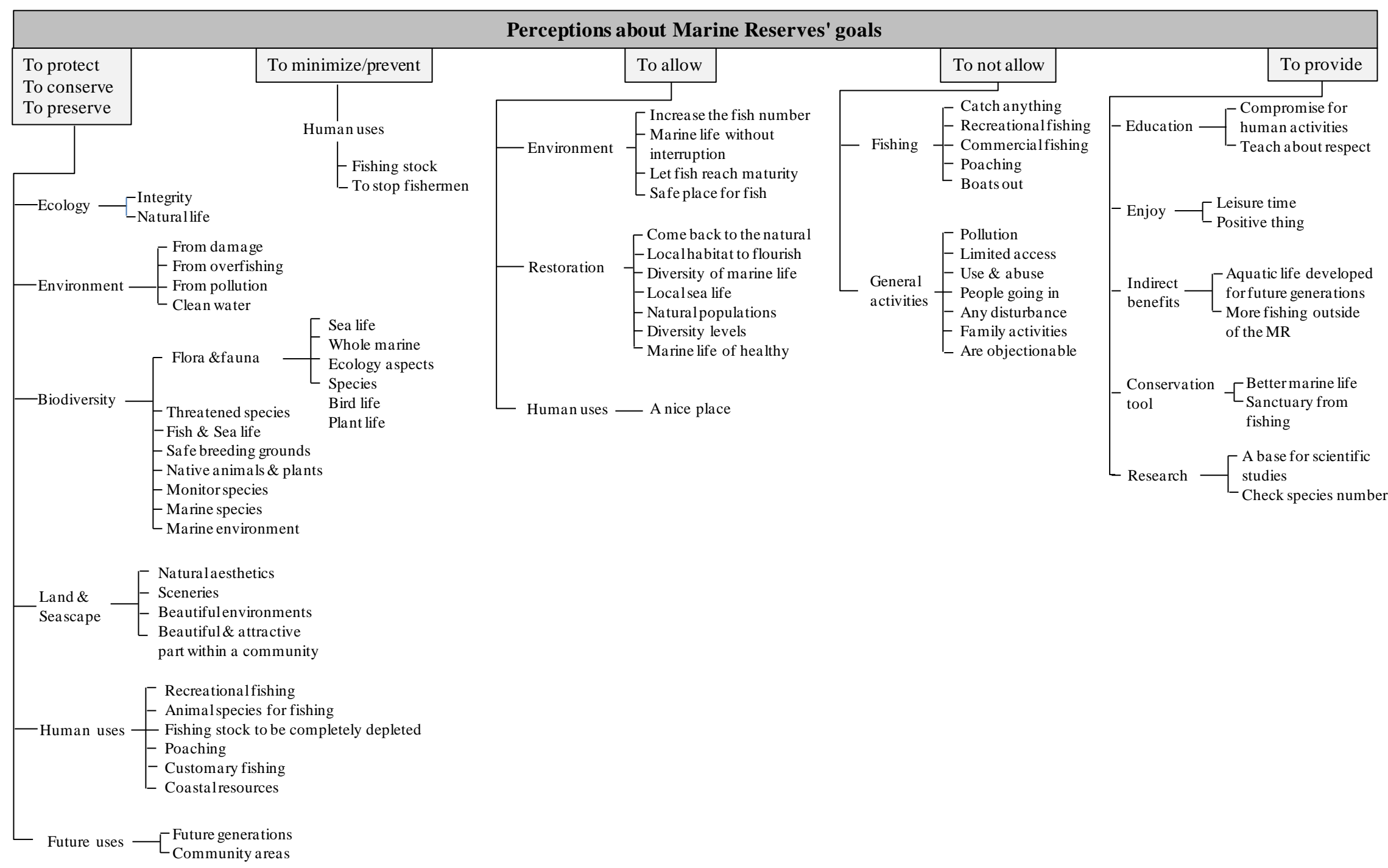

Figure 3.2 The main marine reserve goals perceived by respondents in this study. Responses were grouped into five main categories. Each category was split into sub-categories 

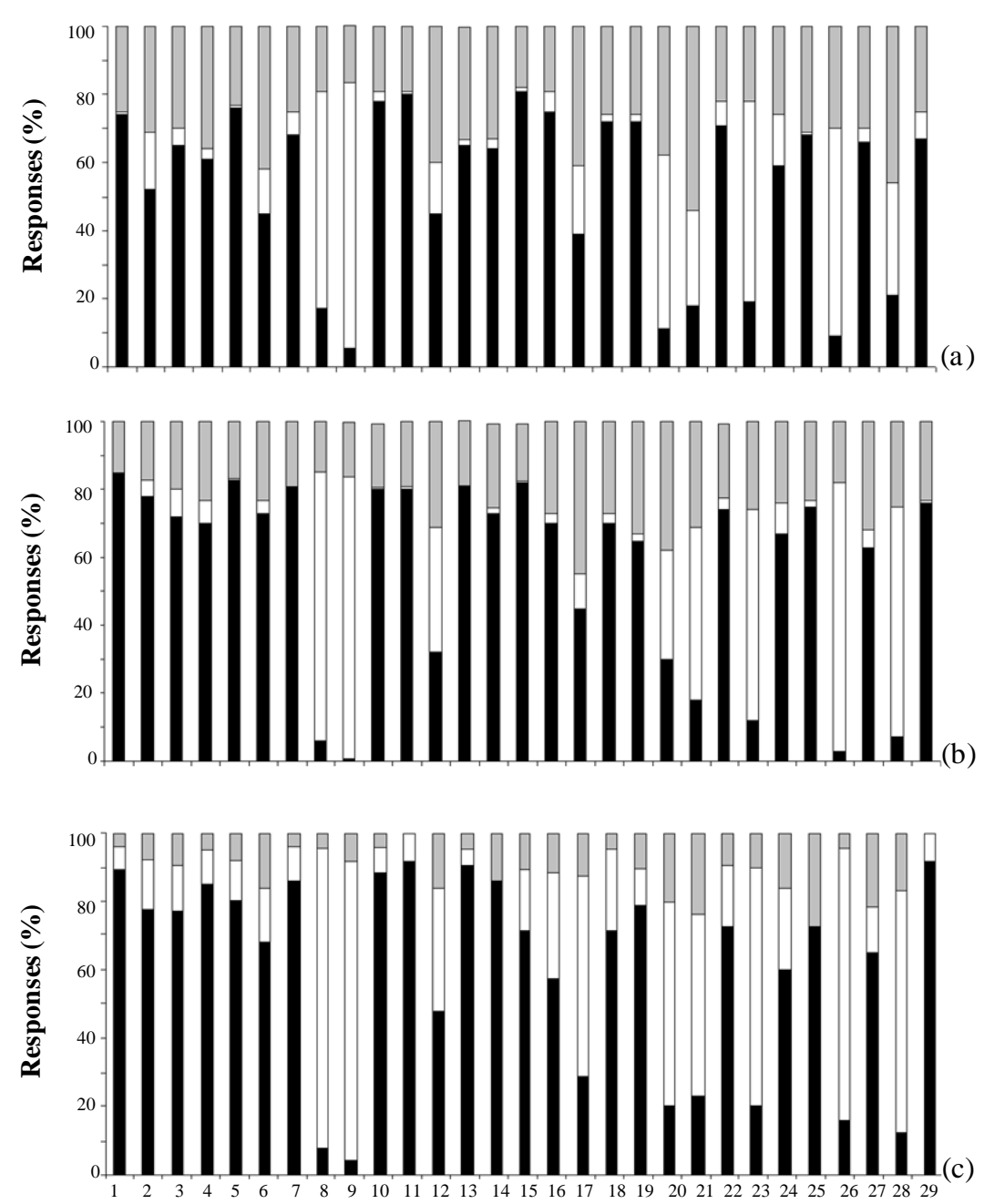

Activities
Id Activities

1 Walking

2 Sitting in the car on the beach

3 Surfing

4 Biking

5 Playing

6 Rock pooling

7 Sitting on or near to the

beach

8 Recreationalfishing

9 Commercialfishing

10 Picnicking

11 Sunbathing

12 Beach-combing

13 Running

14 Conducting research

15 Swimming

16 Boating

17 Water skiing

18 Boogie boarding

19 Surf rescue

20 Motor-biking

21 Collecting firewood

22Snorkelling

23 Surfcasting

24 Diving

25 DOC activities

26 Shellfish collecting

27 Wind-surfing

28 Collecting seaweed

29 Education

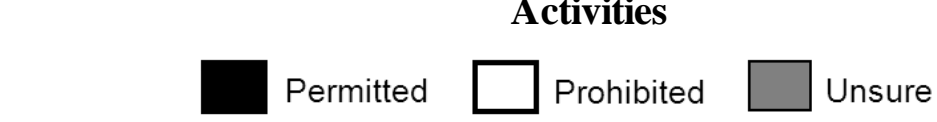

Figure 3.3: Each graph shows all the activities considered in this study. Each bar represents relative frequency as a percentage per activity per marine reserve, at Kapiti Marine Reserve (a), Taputeranga Marine Reserve (b) and Plimmerton as the hypothetical marine reserve (c). The black colour represents those activities considered by respondents as permitted, while the proportion of people considering an activity prohibited in the marine reserve is shown in white, and grey bars show which respondents were unsure if the activity is prohibited or permitted in the marine reserve.

\subsubsection{Marine conservation issues}

At both MRs, and at the hypothetical MR, the majority of groups considered MRs to be a useful tool to protect the marine environment ( 96\%) (Table 3.2). However, when the question was asked if marine conservation is an important issue in their life, there was little difference in the respondent's answers among groups and sites. At KMR (93\%) and at the 
hypothetical MR (90\%), respondents thought that marine conservation issues were important to them. At TMR responses were slightly lower than at the other MRs (81\%). At KMR 100\% of RDFs considered marine conservation to be an important issue in their life, followed by visitors (94\%), LBs (92.3\%), and LRs (84.8\%). At TMR, the group responses to this question were RDFs (92\%), visitors (89.4\%), LRs (86\%), LBs (57\%), and CF (33\%,) (Table 3.2).

\subsubsection{Support for marine reserve establishment}

At both MRs (Taputeranga and Kapiti) I asked each respondent if they had participated in the MR establishment process. As many as $26 \%$ of the TMR respondents had participated actively during the establishment process, mostly by attending public meetings or answering surveys. At KMR, just $5.8 \%$ had participated in this process. From the people who had participated in the process, I asked them if they supported the MR when it was proposed. Significant differences were found between responses for each $\operatorname{MR}\left(\chi^{2}=29.682, D F=4\right.$, $\mathrm{p}<0.001)$, and between MRs $\left(\chi^{2}=212.407, \mathrm{DF}=12, \mathrm{p}<0.001\right.$ at TMR; $\chi^{2}=71.468, \mathrm{DF}=9$, $\mathrm{p}<0.001$ at KMR). At TMR, 58\% supported it, 38\% opposed and 4\% did not care. At KMR $88 \%$ supported it and $12 \%$ opposed the MR. Answers from LBs at both MRs were similar, with the majority of LBs being supportive of MR establishment at the time. However, responses of LRs and RDFs (including CFs) were significantly different between MRs $\left(\chi^{2}=29.930, \mathrm{DF}=3, \mathrm{p}<0.001\right.$ for LRs; $\chi^{2}=6.825, \mathrm{DF}=2, \mathrm{p}=0.033$ for RDFs - including $\left.\mathrm{CFs}\right)$. Answers at TMR indicated that respondents were more supportive of MR establishment than at KMR. Moreover, when asked if their opinion about the MR had changed since that time, the majority of respondents at both MRs stated No (78\% at TMR, 89\% at KMR) (Table 3.2).

I asked every respondent if they supported the establishment of the Taputeranga/Kapiti MR. At TMR, $78 \%$ of respondents supported it, $6 \%$ did not care about it (i.e., were neutral), and $16 \%$ still think it was a bad decision. This $16 \%$ who considered it a bad decision mostly believed it was the wrong place to establish a MR. At KMR, $87 \%$ of people agreed, $12 \%$ did not care, and only $1 \%$ disagreed with it.

Results from the hypothetical MR at Plimmerton revealed that the majority of respondents would disagree with it (37\%) or would not care about it (37\%), whilst only a few respondents agreed with its establishment (13\%) (Table 3.2). 
Table 3.2: Breakdown of respondents' answers with respect to 'marine conservation issues' and 'support for marine reserve establishment'. Responses are per marine reserve and per group in each marine reserve. Responses are expressed as a percentage.

\begin{tabular}{|c|c|c|c|c|c|c|c|c|c|c|}
\hline \multirow[b]{3}{*}{ Marine Reserve knowledge } & \multicolumn{10}{|c|}{ Marine Reserve } \\
\hline & \multicolumn{5}{|c|}{ Taputeranga $(\%)$} & \multicolumn{4}{|c|}{ Kapiti (\%) } & \multirow{2}{*}{$\begin{array}{c}\text { Imaginary (\%) } \\
\text { LB } \\
\end{array}$} \\
\hline & LB & LR & ndD & $\mathbf{V}$ & $\mathbf{C F}$ & LB & LR & RFandD & $\mathbf{V}$ & \\
\hline \multicolumn{11}{|c|}{ Do you know what a marine reserve is? } \\
\hline Yes & 100 & 98 & 96 & 89 & 100 & 100 & 94 & 100 & 97 & 93 \\
\hline No & - & 2 & 4 & 11 & - & - & 6 & - & 3 & 7 \\
\hline \multicolumn{11}{|c|}{ Do you consider marine reserves to be a useful tool to protect the marine environment? } \\
\hline Yes & 100 & 91 & 92 & 96 & 100 & 100 & 96 & 80 & 100 & 97 \\
\hline No & - & 6 & 8 & - & - & - & 4 & - & - & 3 \\
\hline I don't know & - & 3 & - & 4 & - & - & - & 20 & - & - \\
\hline \multicolumn{11}{|c|}{ Is marine conservation in general an important issue for you? } \\
\hline Yes & 57 & 86 & 92 & 89 & 33 & 92 & 85 & 100 & 94 & 90 \\
\hline No & 29 & 10 & 8 & 11 & 67 & 8 & 10 & - & 3 & 7 \\
\hline I don't know & 14 & 4 & - & - & - & - & 5 & - & 3 & 3 \\
\hline \multicolumn{11}{|c|}{ Do you know about the existence of the marine reserve? } \\
\hline Yes & 71 & 96 & 96 & 70 & 100 & 92 & 85 & 100 & 67 & - \\
\hline No & 29 & 4 & 4 & 30 & - & 8 & 15 & - & 33 & - \\
\hline
\end{tabular}

What was your position regarding the proposal to create a marine reserve on the Island Bay/Kapiti coast?

Imaginary MR: What would be your position regarding the proposal to create a marine reserve around Mana Island and extending to the Plimmerton coastline?

\begin{tabular}{|c|c|c|c|c|c|c|c|c|}
\hline I agreed with it & 67 & 65 & 76 & - & 71 & 48 & 80 & 13 \\
\hline I disagreed with it & 17 & 14 & 20 & 100 & - & 2 & - & 33 \\
\hline I didn't care & & 15 & 4 & - & 11 & 25 & 20 & 41 \\
\hline I wasn't here & 16 & 6 & -100 & - & 18 & 25 & -100 & - \\
\hline I don't know & - & - & - & - & - & - & - $\quad-$ & 13 \\
\hline
\end{tabular}

\subsubsection{Perceptions of marine reserves}

\subsubsection{Perceived important features of marine reserves}

At both MRs, respondents had similar views of the features of MRs (no significant differences were found; Table 3). The most important feature was 'MRs should be for protection of threatened species'; secondly, 'MRs have to be far away from contamination and pollution', and the third most important feature is 'MR biodiversity'. There were significant differences between both MRs and the hypothetical MR in almost all the analysed statements, with the exception of 'Being close to my house' responses (Kruskal-Wallis=9.190, 2 d.f., p=0.02) where there were no differences between both MRs ( $\mathrm{p}>0.05)$. The statement 'Important for research' was not considered an important feature of MRs in New Zealand, but at the hypothetical MR it was the fourth most important (Table 3.3). 


\subsubsection{Perceived impacts of marine reserves}

Most groups surveyed at KMR indicated that its establishment had not personally affected them. The only problem highlighted was related to the feeling of the loss of property rights as they are now unable to carry out some leisure activities (98\% of people who had a problem, $\mathrm{N}=47$ ), particularly recreational fishing, surfcasting, taking of seaweed from the beach, and shellfish collection. Respondents did indicate other indirect problems related to $\mathrm{MR}$ establishment, which I considered to be 'external problems' (Fig. 3.5). External problems are defined as any type of problem which are not concerning them (interviewed) personally. The main external problems identified were 'lack of awareness regarding the MR', because general users not do have enough knowledge of the MR; 'lost freedom' because there are too many rules, for example fishermen (commercial and recreational) are not allowed to fish in the MR; 'people not adhering to rules' (referring to poaching).

At TMR, all groups believed they had experienced direct (personal) problems since the establishment of the MR ( $42 \%$ of the total, $\mathrm{N}=52)$. The TMR residents feel they have 'lost freedom' $(89 \%$, of these who had a problem, $\mathrm{N}=48)$, because they are not able to conduct some activities they consider important, such as taking seaweed from the beach (for producing compost), shellfish collection and recreational fishing at the beach and in rock pools. All CF at the TMR reported an increase in their fishing costs (such as fuel and boat maintenance costs - see chapter 2), an increase in the number of fishing hours and time travelling to new fishing grounds, and increased pressure on the new fishing grounds. Moreover, commercial fishermen reported that since the TMR was established, they can no longer conduct recreational fishing with their families in sheltered waters. As a consequence of these impacts, commercial fishermen felt the MR caused increased stress in their lives.

With respect to indirect problems (not personal problems) at the TMR, the most common cited was 'dirty and smelly beaches', which refers to the large amount of seaweed on the beach below the high tide mark that is no longer collected by Wellington City Council as part of its beach 'grooming' programme. Respondents believe that since the MR has been established, quantities of seaweed have increased dramatically, making the area an: unhealthy place to relax. Moreover, the increased amount of seaweed has in turn led to increased numbers of mosquitoes in the area; therefore families are not able to enjoy the area due to the 'rubbish' (seaweed) and associated mosquitoes $(11 \%, \mathrm{~N}=6)$. Respondents that identified other problems since the establishment of the MR, were recreational and commercial fishermen, 
because they are no longer allowed to fish in the MR area (Fig. 3.6a, b). Another issue reported by respondents was poaching within the TMR. In addition, some respondents stated that they have conflicting feelings about the marine reserve, because while they are happy to have the reserve to protect the environment, they are also concerned about the effects the reserve establishment has on fishermen, which I perceived as negative.

Despite the respondents having different perceptions regarding direct or external problems due to the establishment of the MRs, and having different views as to who is responsible for finding a solution to those problems, the majority of responses show that respondents believe that at both MRs the Government and Department of Conservation (DOC) directly are responsible for solving all these problems, and they believe that the community has no responsibility for the situation because it was the government's idea to establish these MRs.

\subsubsection{Perceptions of the impacts of the hypothetical marine reserve}

The majority of respondents perceived that the establishment of the hypothetical MR would not cause any personal or family problems (73\%). However, the remaining $27 \%$ of respondents believed that the MR establishment would cause problems (Fig. 3.6c). These problems were mainly related to 'being unable to fish' $(\mathrm{N}=5)$, 'not allowed to conduct activities at the beach' $(\mathrm{N}=2)$, 'economic loss' $(\mathrm{N}=1)$, and 'concern about getting a police record if they do something wrong in the $M R^{\prime}(\mathrm{N}=1)$.

With respect to the question if respondents are aware of any other problems that could arise with the potential MR establishment, respondents were equally divided between those that believe the MR would cause problems (50\%) and those who believed the MR would not cause any problem (50\%) (Fig. 3.6c). Principally, the main problems anticipated were related to 'community issues such as conflicts between the interests of recreational fishers, divers and spear fishers' $(\mathrm{N}=11)$, 'poaching might start' $(\mathrm{N}=3)$, and 'beach activities could be prohibited, such as wind-surfing' $(\mathrm{N}=1)$.

When asked who is responsible for solving these problems if they arise in this hypothetical MR, Plimmerton respondents considered that The Royal Forest and Bird Protection Society of $N Z$ should have the major responsibility (25\%), followed by local residents and local council (15\% each). 


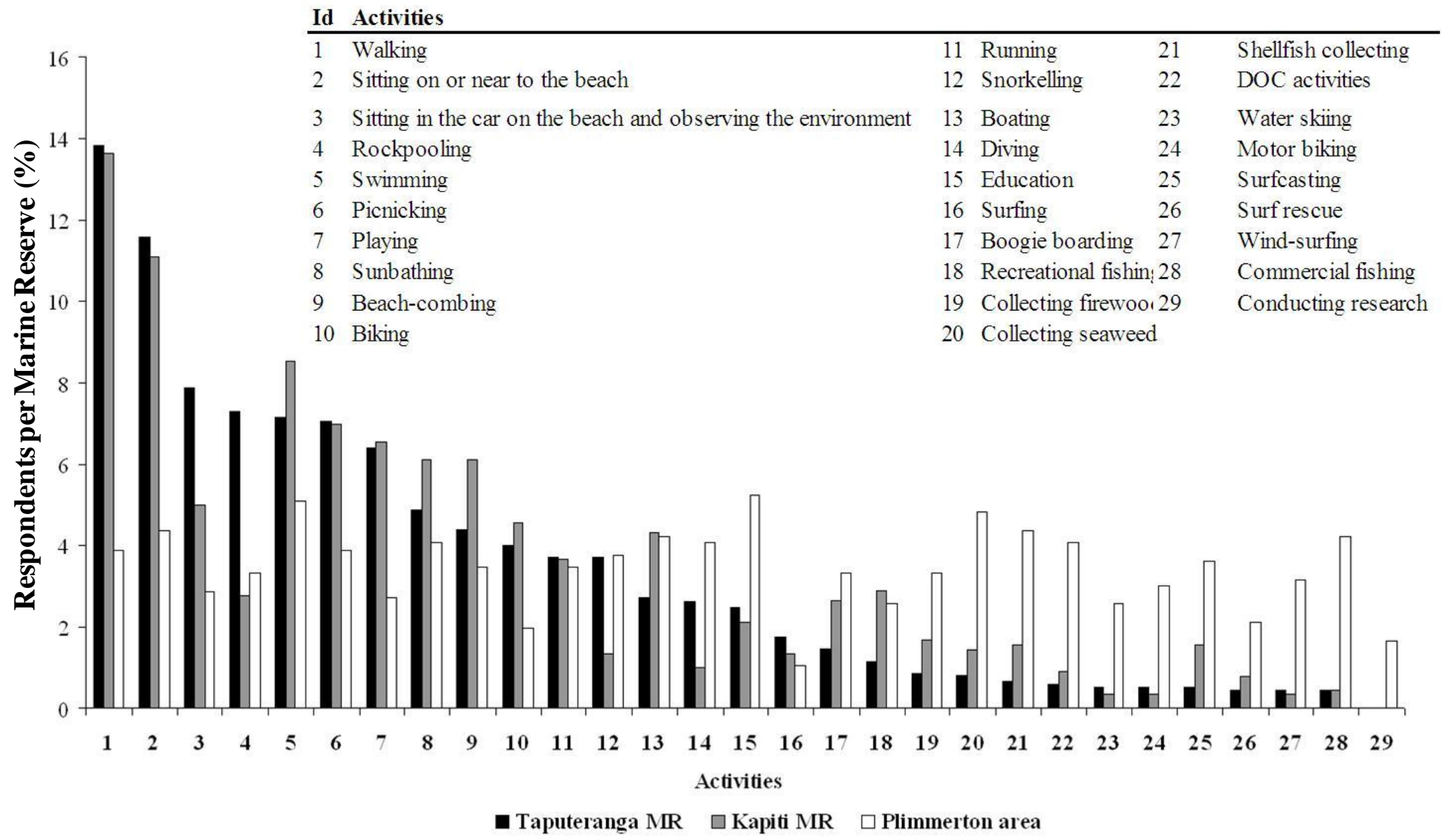

Figure 3.4: Current activities conducted by users in the marine reserves, plus the hypothetical marine reserve (Plimmerton area). Responses are calculated as relative frequency as a percentage per activity per marine reserve. 
Table 3.3: Mean respondents' perceptions of marine reserves regarding important features of marine reserves perceived by them. Each statement contains standard errors (SE). Responses are per group in each marine reserve including the hypothetical marine reserve (Plimmerton). Statistical comparisons (p-value) within Kapiti MR's groups and within Taputeranga MR's groups are shown in the column after Kapiti visitors. Statistical comparisons (p-value) between both marine reserves groups and the hypothetical reserve is in the last column in the table. LB: Local business; LR: Local residents; RDFs: Recreational fishers and divers; V: Visitors; CF: Commercial fishermen.

\begin{tabular}{|c|c|c|c|c|c|c|c|c|c|c|c|c|c|c|c|c|c|c|c|c|c|c|}
\hline & \multicolumn{22}{|c|}{ Marine Reserve } \\
\hline & \multicolumn{10}{|c|}{ Taputeranga } & \multicolumn{8}{|c|}{ Kapiti } & \multicolumn{4}{|c|}{ Plimmerton } \\
\hline & LB & & LR & & RFandD & & $\mathbf{V}$ & & $\mathbf{C F}$ & & LB & & LR & & RFandD & & $\mathbf{V}$ & & & & $\mathbf{L R}$ & \\
\hline Marine reserves should be placed for: & $\begin{array}{l}\text { Mean } \\
\text { rank }\end{array}$ & SE & $\begin{array}{l}\text { Mean } \\
\text { rank }\end{array}$ & SE & $\begin{array}{l}\text { Mean } \\
\text { rank }\end{array}$ & SE & $\begin{array}{l}\text { Mean } \\
\text { rank }\end{array}$ & SE & $\begin{array}{l}\text { Mean } \\
\text { rank }\end{array}$ & SE & $\begin{array}{l}\text { Mean } \\
\text { rank } \\
\end{array}$ & SE & $\begin{array}{l}\text { Mean } \\
\text { rank }\end{array}$ & SE & $\begin{array}{l}\text { Mean } \\
\text { rank }\end{array}$ & SE & $\begin{array}{l}\text { Mean } \\
\text { rank }\end{array}$ & SE & $\underline{p-v a l u e}$ & $\begin{array}{l}\text { Mean } \\
\text { rank } \\
\end{array}$ & SE & p-value \\
\hline Close to my house & 3.14 & 0.32 & 3.05 & 0.13 & 2.80 & 0.31 & 2.89 & 0.22 & 1.67 & 0.42 & 2.92 & 0.40 & 2.44 & 0.13 & 1.80 & 4.95 & 2.63 & 0.28 & 0.06 & 2.45 & 1.29 & 0.01 \\
\hline Close to shops & 2.71 & 0.34 & 1.91 & 0.10 & 1.84 & 0.24 & 2.04 & 0.18 & 1.67 & 0.42 & 1.92 & 0.33 & 2.00 & 0.12 & 1.00 & 3.16 & 2.60 & 0.25 & 0.20 & 1.76 & 1.17 & 0.15 \\
\hline Provision of services & 3.14 & 0.48 & 3.55 & 0.12 & 3.24 & 0.23 & 3.62 & 0.20 & 1.83 & 0.40 & 3.08 & 0.42 & 3.48 & 0.13 & 3.00 & 4.58 & 3.77 & 0.23 & 0.93 & 3.59 & 1.17 & 0.83 \\
\hline Close to a research centre & 2.71 & 0.34 & 3.32 & 0.12 & 2.76 & 0.28 & 2.98 & 0.19 & 2.00 & 0.52 & 3.08 & 0.42 & 3.19 & 0.13 & 2.20 & 4.95 & 2.80 & 0.27 & 0.75 & 2.72 & 1.22 & 0.31 \\
\hline Far away from contamination and pollution & 3.71 & 0.53 & 4.38 & 0.09 & 4.20 & 0.21 & 4.00 & 0.18 & 3.17 & 0.75 & 4.15 & 0.34 & 4.37 & 0.11 & 4.60 & 4.06 & 4.27 & 0.23 & 0.41 & 4.17 & 1.23 & 0.29 \\
\hline Beautiful beaches & 3.43 & 0.57 & 3.48 & 0.13 & 2.84 & 0.26 & 3.49 & 0.21 & 3.00 & 0.68 & 3.31 & 0.40 & 3.59 & 0.14 & 4.20 & 4.26 & 3.67 & 0.26 & 0.33 & 3.48 & 1.25 & 0.31 \\
\hline Biodiversity & 3.57 & 0.49 & 4.05 & 0.12 & 4.28 & 0.24 & 3.79 & 0.17 & 3.50 & 0.62 & 3.62 & 0.40 & 4.05 & 0.11 & 4.00 & 4.16 & 3.87 & 0.24 & 0.77 & 4.10 & 1.10 & 0.89 \\
\hline Important for research & 3.29 & 0.39 & 3.95 & 0.11 & 3.56 & 0.30 & 3.49 & 0.20 & 2.00 & 0.52 & 3.62 & 0.46 & 4.19 & 0.11 & 3.60 & 5.11 & 3.60 & 0.23 & 0.27 & 4.00 & 1.12 & 0.10 \\
\hline Availability of rental gear & 3.57 & 0.35 & 2.74 & 0.12 & 2.96 & 0.25 & 2.57 & 0.17 & 1.83 & 0.54 & 2.31 & 0.33 & 2.60 & 0.13 & 2.00 & 4.89 & 2.73 & 0.23 & 0.71 & 2.28 & 1.12 & 0.11 \\
\hline Beautiful Seas and landscape & 3.57 & 0.53 & 3.69 & 0.13 & 3.24 & 0.28 & 3.98 & 0.20 & 3.00 & 0.68 & 3.54 & 0.37 & 3.71 & 0.14 & 4.40 & 4.06 & 4.00 & 0.24 & 0.88 & 3.76 & 1.17 & 0.85 \\
\hline Popular place with lots of visitors & 3.29 & 0.53 & 2.89 & 0.12 & 2.60 & 0.29 & 3.06 & 0.18 & 1.83 & 0.54 & 2.69 & 0.40 & 3.01 & 0.13 & 3.20 & 4.81 & 2.77 & 0.20 & 0.54 & 2.52 & 1.20 & 0.21 \\
\hline Protection for threatened species & 3.71 & 0.53 & 4.52 & 0.10 & 4.40 & 0.24 & 4.34 & 0.16 & 2.50 & 0.72 & 4.15 & 0.34 & 4.52 & 0.09 & 4.80 & 3.61 & 4.27 & 0.21 & 0.80 & 4.59 & 1.04 & 0.48 \\
\hline Away from inner city & 2.86 & 0.48 & 3.51 & 0.12 & 2.76 & 0.27 & 3.74 & 0.19 & 3.00 & 0.68 & 3.17 & 0.37 & 3.90 & 0.13 & 2.60 & 4.06 & 3.57 & 0.28 & 0.09 & 3.34 & 1.23 & 0.06 \\
\hline
\end{tabular}




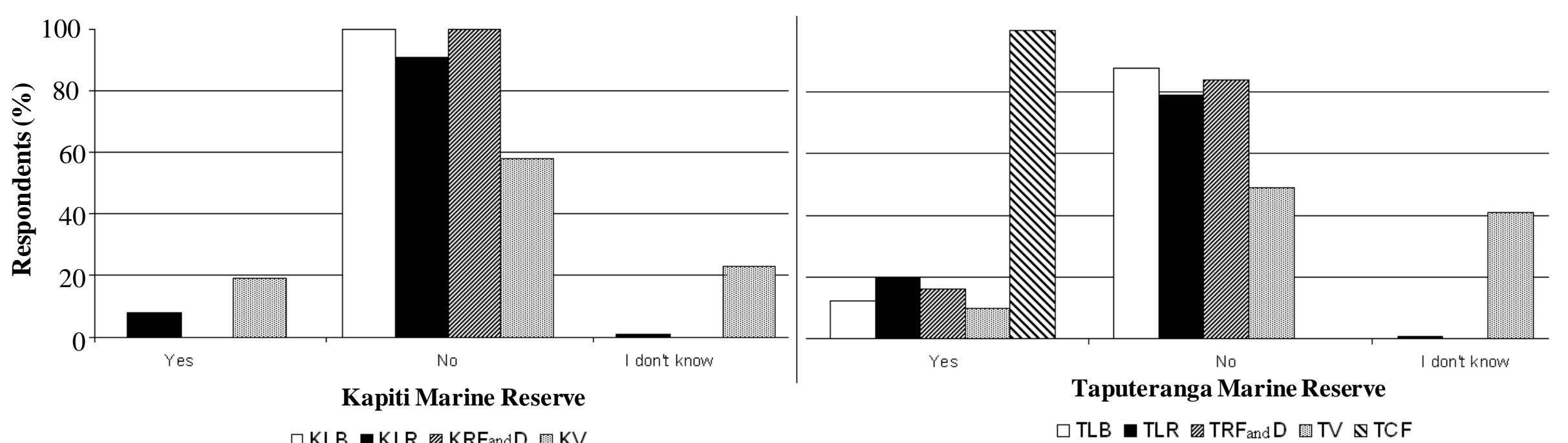

Figure 3.5: Percentage of respondents answering the question 'Has the establishment of the Kapiti/Taputeranga MR had a negative impact on you or your family?' K: Kapiti; T: Taputeranga; LB: Local business; LR: Local residents; RDFs: Recreational fishers and divers; V: Visitors; CF: Commercial fishermen. 


\subsubsection{Perceived benefits of marine reserves}

Generally, there were no significant differences between MRs with respect to the benefit perception statements analysed. The only significant difference was Work, where respondents at KMR felt a greater benefit than TMR's respondents (Kruskal-Wallis=0.043, p<0.05). However, almost all statements analysed between groups at the two MRs showed significant differences in responses. The only similar statement was Overall well-being, with all groups feeling positive benefits from these MRs (Fig. 3.7a). Breaking down the data into groups, at both MRs recreational fishers and divers stated that they benefited more compared to other groups. Similar feelings were showed by local residents at TMR.

At the hypothetical MR each statement was compared with both MRs, and significant differences were found in every case ( $\mathrm{p}<0.05)$ (Fig.3.7b). The most expected benefit was regarding overall well-being.

\subsubsection{Biological changes in the marine reserves}

Respondents at TMR reported that there were more changes $(20.4 \%)$ than respondents at KMR (7.4\%) (Fig. 3.8a, b). At TMR, the LR and RF\&D groups reported the most positive changes. The most significant change perceived by both groups at both MRs was the increased abundance and size of organisms inside the MR, in particular of paua, kina and crayfish $\left(\chi^{2}=7.751, \mathrm{DF}=2, \mathrm{p}=0.021\right)$. Other groups (LRs and visitors) perceived an increase in the abundance of life in the rock pools and in bird populations. Some respondents had witnessed visits by marine mammals such as dolphins and orcas, and reported seeing more marine mammals inside the MR since establishment. However, all commercial fishermen $(\mathrm{N}=6)$ shared the same opinion that there was no change in flora and fauna post TMR establishment. In KMR, the general perception (Fig. 3.9a, b) was that there has been an increase in the abundance of fish and birds, but a decrease in crab numbers (all usual types).

With respect to human usage, significant differences were found $\left(\chi^{2}=8.214, \mathrm{DF}=2, \mathrm{p}=0.016\right)$ between MRs; more perceived changes were reported in the TMR (36\% vs. $21.4 \%$ at KMR). LRs thought that most changes occurred, and felt there was considerably less poaching since the MR was established $\left(\chi^{2}=8.335, \mathrm{DF}=2, \mathrm{p}=0.015\right)$ (term less poaching refers to taking marine species under minimum legal size and/or during specific closures). Moreover, the LRs 
at TMR considered the area to be quieter because there is no recreational or commercial fishermen around $(52 \%, \mathrm{~N}=58)$. However, there is also the perception that the number of visitors has been increasing $(10 \%, \mathrm{~N}=11)$. Another perception that has changed is that currently nobody is taking seaweed from the shore. RDFs agreed with LR with respect to the change in fishing, however, they felt more divers are fishing outside the MR boundaries putting increased pressure on other areas $(6.2 \%, \mathrm{~N}=7)$. Moreover, RDFs reported that the TMR establishment has created new activities in the area, such as underwater photography/video making, and they are now able to appreciate the environment in a different way than they did previously $(11 \%, \mathrm{~N}=12)$. The general perception of the RDFs was that since the areas have become protected the increased biodiversity has made the area more interesting (Fig. 3.9a, b). CF perceived fewer divers in the MR compared to outside. At KMR the most changes perceived were related to more tourism $(36 \%, \mathrm{~N}=10)$, no more fishing activities $(25 \%, \mathrm{~N}=7)$, and respondents believed there are more people educated in the area in terms of environmental issues $(11 \%, \mathrm{~N}=3)$.

\subsubsection{The expectation of change after the establishment of the hypothetical marine reserve at Plimmerton}

The majority of respondents expected changes in flora and fauna, and human use; 53\% of respondents expected positive changes if the hypothetical MR is established. The expected changes include a greater variety of species, improved fish stock as well as greater size of commercial species, and increase ability to watch more birds in the area.

In terms of human use, $57 \%$ of the respondents expected changes with the hypothetical establishment, while 10\% did not expect anything, and the rest of the respondents did not know. From the respondents who thought changes would occur, they expect fewer human activities in the area, such as boating, hunting, and fishing (42\%). In addition, some respondents believed that the hypothetical MR establishment would result in an increase in the number of diving visitors to the area (42\%). Other expected changes included changes to human behaviour, such as more respect shown for the environment, and more fishing for species of legal size (16\%) (Fig.3.10). 

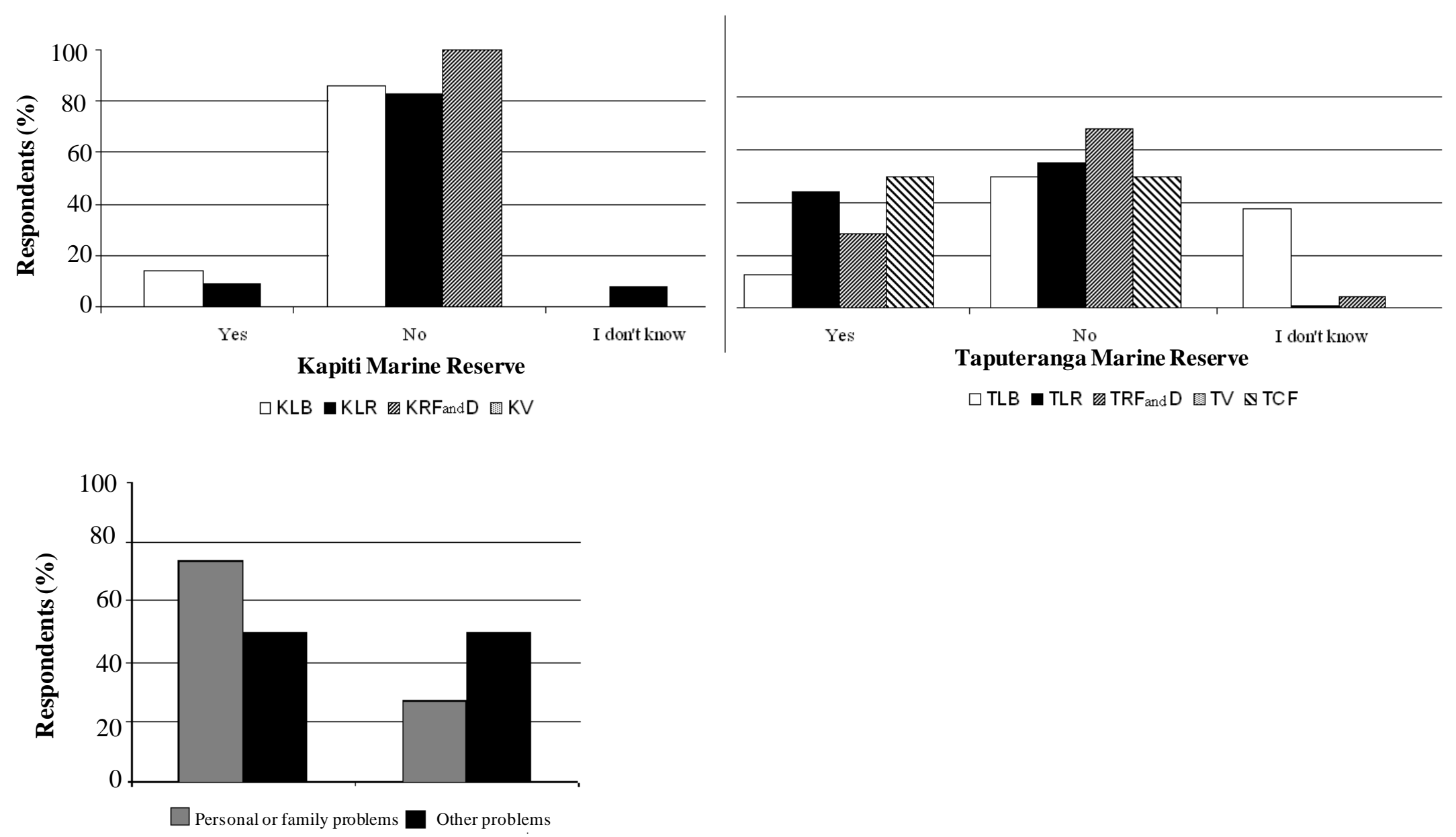

Figure 3.6: Responses to the question at both MRs: 'Are you aware of any other problems that have arisen after the establishment the Kapiti/Taputeranga MR?' The third graph shows the percentage of people from the hypothetical marine reserve in relation to personal/familiar problems and other problems that could arise if the marine reserve is established 


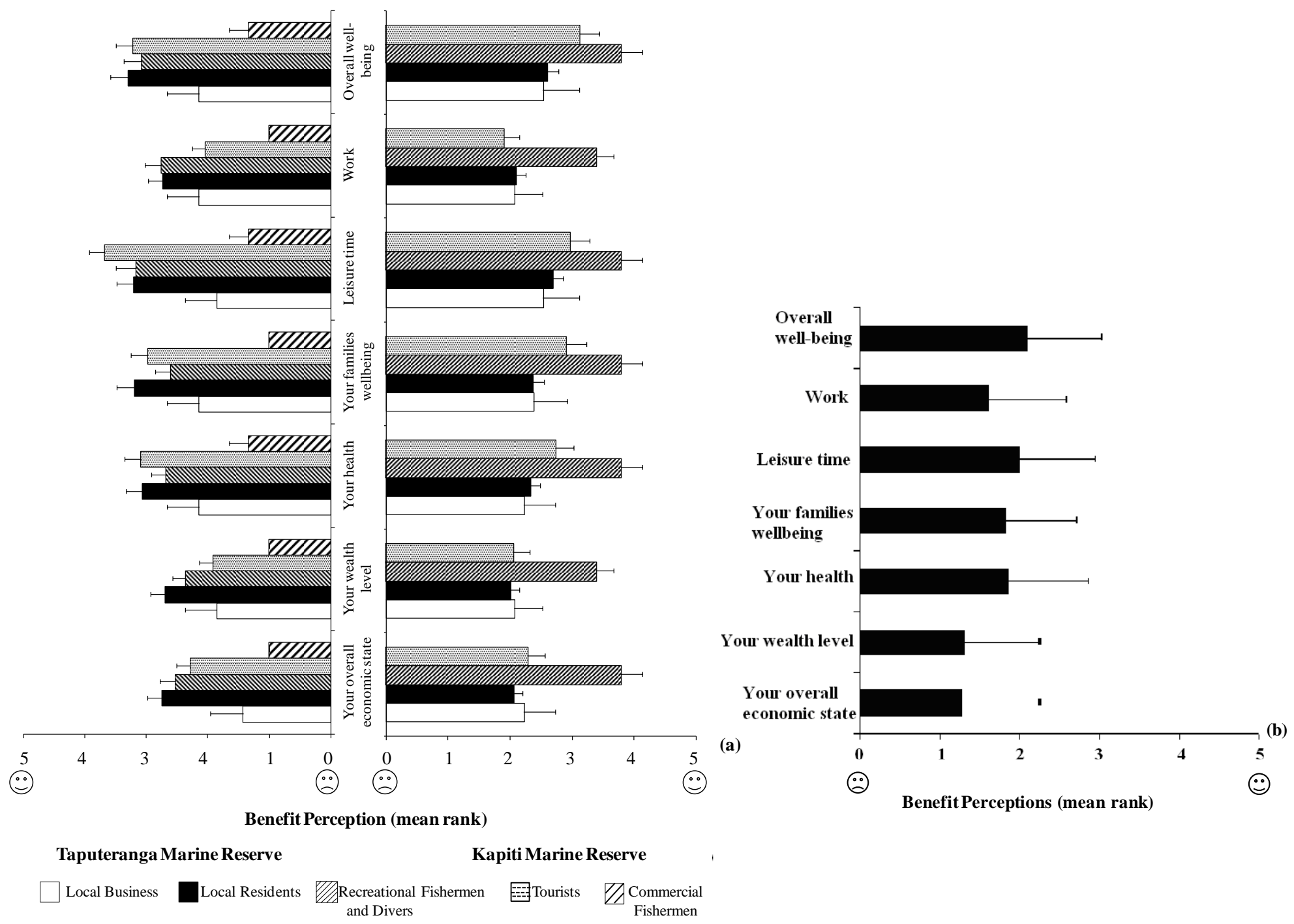

Figure 3.7: Perceived benefits of marine reserves in Taputeranga and Kapiti Marine Reserves (a), and at the hypothetical marine reserve (b). The scale is from zero (negative impacts) to five (very beneficial). Errors bars represent standard deviations. 


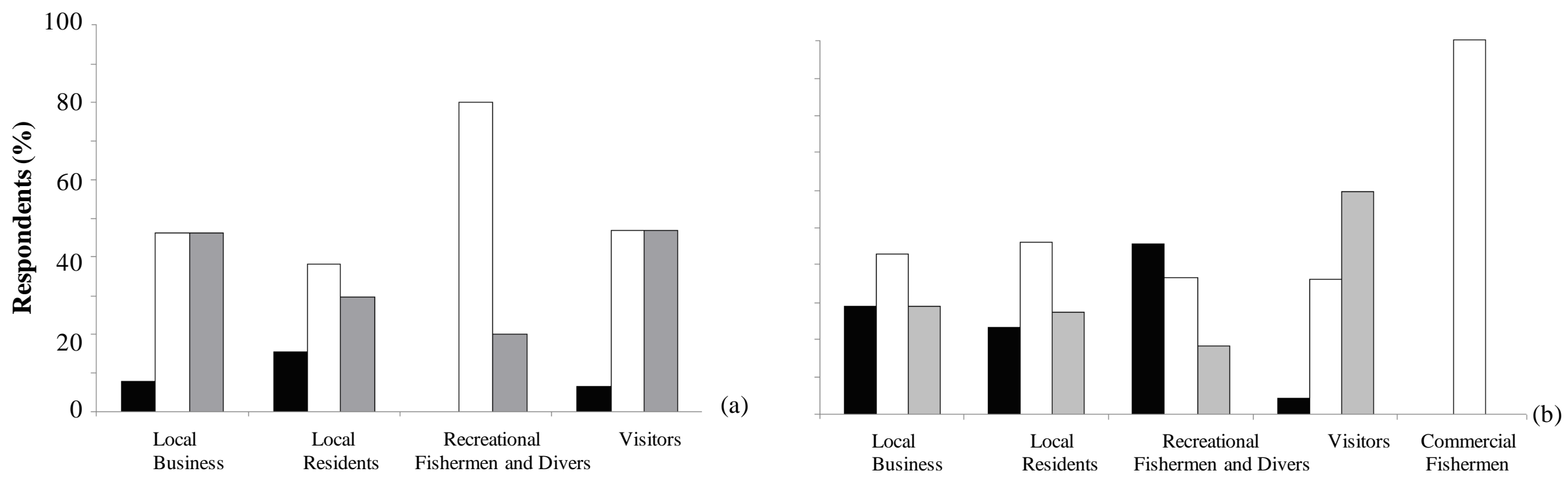

- Yes $\square$ No $\square$ I don't know

Figure 3.8: Changes perceived per group in terms of flora and fauna since the Kapiti (a) and Taputeranga (b) MRs were established. 

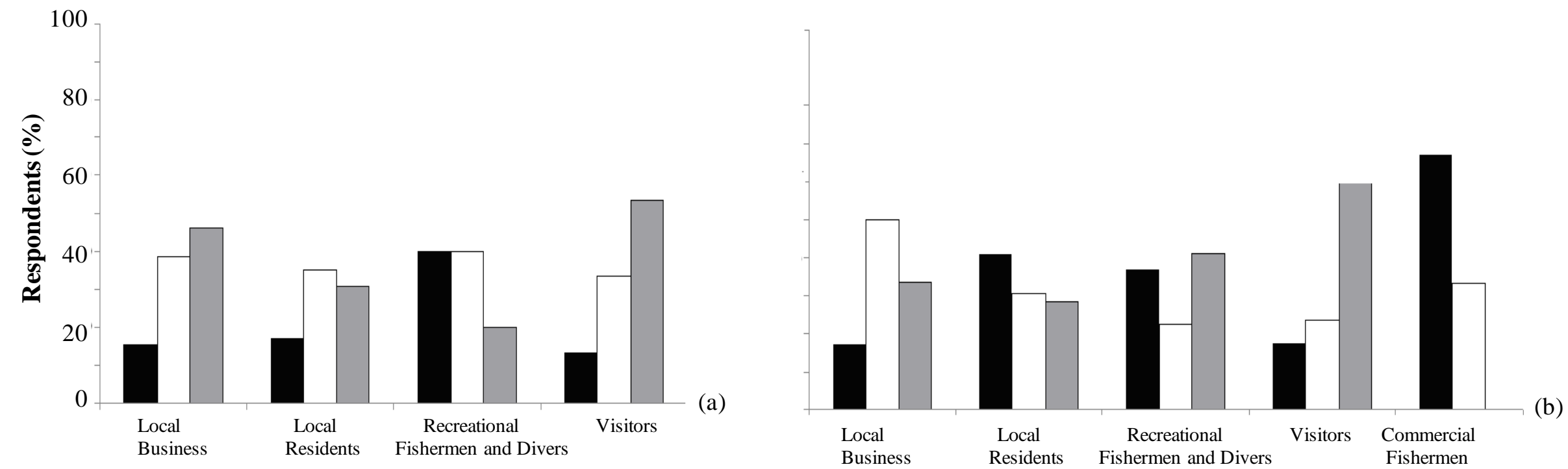

Yes $\square$ No $\square$ I don't know

Figure 3.9: Perceived changes in human uses since the designation of the Kapiti (a) and Taputeranga (b) MRs. 


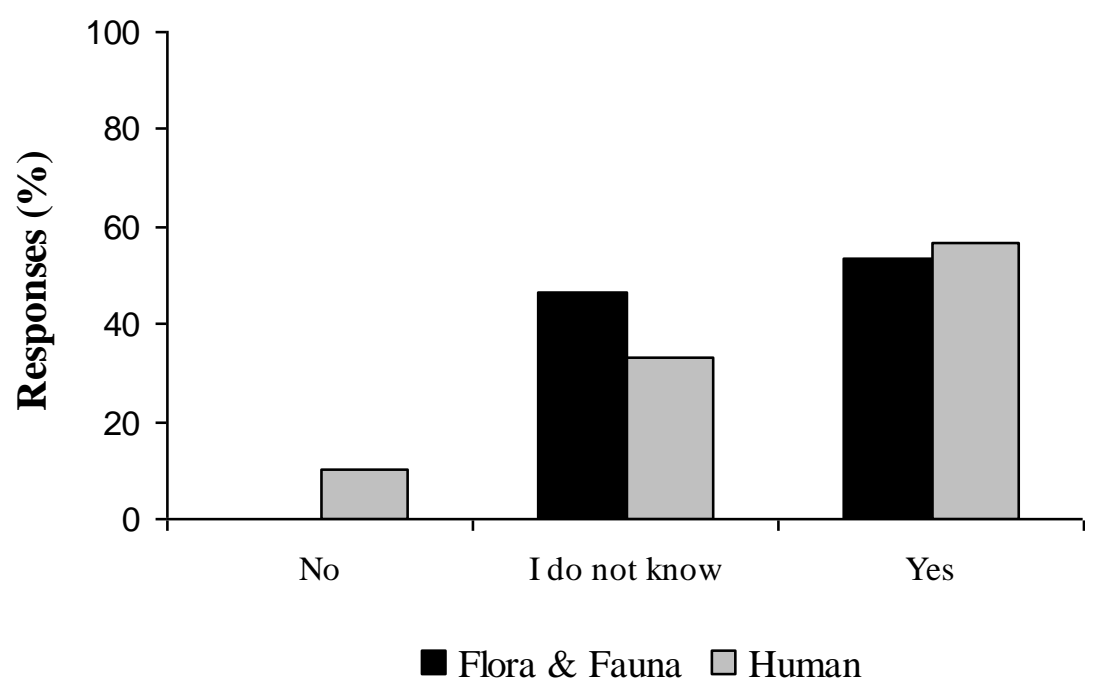

Figure 3.10: Expected changes in flora and fauna, and human uses in the hypothetical marine reserve if it were established

\subsubsection{Satisfaction levels of marine reserves}

There were significant differences in the number of respondents at both MRs with respect to their satisfaction levels when considering Biodiversity protection (Kruskal-Wallis $<0.001$, $\mathrm{p}<0.01$ ), Litter on the beach and in the water (Kruskal- Wallis<0.001, $\mathrm{p}<0.01$ ), and Biodiversity recovery (Kruskal-Wallis $=0.02, \mathrm{p}<0.05$ ); respondents from KMR showed increased levels of satisfaction than respondents from TMR in these aspects. Between groups, LBs reported higher satisfaction in the KMR than in the TMR (Table 3.4). However, LRs at both MRs showed similar satisfaction levels in all statements analysed (Table 3.4). RDFs and CF showed similar satisfaction levels with local participation, surveillance (Taputeranga RDFs were more satisfied) and biodiversity protection (Kapiti RDFs were more satisfied). Between MRs, Kapiti Visitors were more satisfied than TMR Visitors in terms of Biodiversity protection, Litter on the beach and Education opportunities. The rest of the statements had similar answers across all groups at both MRs (Table 3.4).

At the hypothetical MR I compared the satisfaction expectation with the current satisfaction level at both real MRs. I found significant differences in almost everything ( $>>0.05)$. Respondent satisfaction levels were higher compared with TMR and LMR, with special emphasis on Educational opportunities, Biodiversity protection, and Biodiversity recovery (Table 3.4). 


\subsubsection{General attitudes toward Taputeranga/Kapiti Marine Reserve}

General responses at KMRs showed a positive association pattern (83\%). Respondents at the KMR responded to these questions with words including: protection, something good, heaven, sanctuary, beauty, fishing (because they might expect more fish outside the MR in the future), pristine, great, dune grass, and future (83\%). Some negative associations were: no fishing and trapped in between boundaries [referring to the limitations of their current activities by physical boundaries and regulations] (8\%). Some people could not associate KMR with any word (9\%). The responses of these people were categorised as neutral (Fig.3.11a).

At the TMR the percentage of overall responses was similar for both positive and negative attitudes (33\% for both). Positive attitudes were described by the words proud, restoration, sea life, harmony, brilliant, education, improvement, sustainability and exciting. Negative words and concepts included: no fishing, disappointment, waste, angry, lie, restrictions, the build-up of seaweed and wood at the beach, mistake, wrong place and scary/unneeded stress (feel like you are being watched all the time, potential to get fined for something silly). An analysis of the positive and negative attitudes at the group level however, showed more divergence. In each group around $60 \%$ of respondents answered positively. The negative attitudes were mostly from two particular groups - CF and some RDFs. Through the same association question, other people (especially visitors) related this MR to other successful MRs in New Zealand, such as the Poor Knights and - Cape Rodney - Okakari Point MR, because they believe that those MRs have beautiful seascapes, therefore they were using those MRs as exemplars to answer this questions (Fig.11b).

In the hypothetical MR, respondents were asked to associate ideas and words with 'Plimmerton coast and Mana Island'. All respondents associated these words with something positive (100\%). Their answers were mainly related to beach and biodiversity (62\%), home place, $(25 \%)$ and beautiful (13\%).

\subsubsection{Attitude toward potential marine reserve disestablishment}

Attitudes to the environmental consequences of MR disestablishment were classified according to the most common answers from respondents. The majority of responses at Taputeranga and Kapiti MRs were: negative environmental consequences (42\% at TMR and $35 \%$ at KMR) and resource overexploitation (30\% at TMR and 26\% at KMR) (Fig.12a, b). 
However, respondents did not provide an in depth explanation of the types of negative environmental consequences that may occur if the MRs were to become open areas again. With respect to resource overexploitation, respondents based their beliefs on the perception that the marine reserves contain bigger commercial species (e.g. snapper, rock lobster, paua) in higher abundance than areas outside the MR boundaries, and disestablishing the MR may result in more people fishing in the once reserved area. Consequently, the area could see a rapid decline of fish stocks. Some respondents were of the opinion that disestablishing the MR will have a negative effect on the lives of those residing in the surrounding areas $(11 \%$ at TMR and $12 \%$ at KMR), because these respondents believe that the MRs have brought benefits (refers to section 'Perceived benefits of MRs'). It was generally thought by respondents at the hypothetical MR that the quality of life would be enhanced in areas close to the MR compared to open fishing areas. Therefore, if these current MRs were disestablished, biodiversity would decrease, as would the quality of life. A few respondents were unsure about the potential consequences to the environment $(6.3 \%$ at TMR and $9 \%$ at KMR). There were also respondents at both MRs that do not envisage any potential negative consequences on the environment if the MRs were disestablished. Attitudes towards the potential personal consequences if the MRs were disestablished were different for the two MRs. At KMR respondents were principally divided between neutral and negative personal consequences. At TMR attitudes were more diverse encompassing negative, neutral, and positive effects. Commercial fishermen (100\%) considered it would be a positive thing, because they would be able to fish on their historical fishing grounds again. Recreational fishermen and divers were divided, $37 \%$ positive vs. 53\% negative. The main reasons given for the latter were 'reduced diving quality' and 'less number and variety of fish'. Overall, the feelings of respondents could be summarized by the following responses: 'they would not enjoy living in the area as much', because 'it will affect my recreational fishing/diving at the boundaries of the MR', and 'would affect negatively tourism'.

With respect to the hypothetical MR, if it was established and then disestablished again, respondents stated that the most noticeable environmental consequences if this was re-opened would be 'overexploitation' (32\%) and 'negative consequences to the environment' (e.g. pollution, poaching) (20\%). A portion of respondents (20\%) believed if the hypothetical MR was re-opened it would not have any consequences for the environment (Fig.13c). In terms of personal effects of this disestablishment, the majority of respondents (59\%) believed it would not make any difference to their personal lives, some respondents felt that this decision would 
affect them negatively (29\%), by expressing feelings such as disappointment, regret and sadness. A few respondents (12\%) believed that this decision would be positive to them based on their chance to fish again without being considered poachers.

\subsubsection{Hypothetical implications of future marine reserve environments}

In general all groups, at both sites, said their lives would not be affected if the MRs did not exist. Therefore, they do not think the existence of the MR has any importance or makes any difference to their lives. In addition, more than $60 \%$ of CF and RDFs at both MRs stated they would (or likely possible) return to their activities in the MR (Fig. 3.13a,b).

With respect to the hypothetical MR, respondents were faced with the hypothetical situation in the future, to project their attitudes with the potential disestablishment of the MR after it had been set up for many years. The majority of respondents agreed that this hypothetical situation would not change their lives, and they would continue living in the area without the MR ( 41\%). However, $22 \%$ of respondents stated they would not continue living in the area if the MR was disestablished (Fig. 3.13c). 
Table 3.4: Breakdown of mean respondents' satisfaction levels in each statement and standard errors (SE). Responses are per group in each marine reserve including the hypothetical marine reserve (Plimmerton). Statistical comparison (p-value) between Kapiti and Taputeranga marine reserves are shown in the column after Kapiti visitors. Statistic comparison (p-value) between both marine reserves and the hypothetical reserve is shown in the last column in the table. LB: Local business; LR: Local residents RDFs: Recreational fishers and divers; V: Visitors; CF: Commercial fishermen.

\begin{tabular}{|c|c|c|c|c|c|c|c|c|c|c|c|c|c|c|c|c|c|c|c|c|c|}
\hline \multirow[b]{4}{*}{$\begin{array}{l}\text { Setisfaction level with respect to } \\
\text { the marine reserves: }\end{array}$} & \multicolumn{21}{|c|}{ Marine Reserve } \\
\hline & \multicolumn{10}{|c|}{ Taputeranga } & \multicolumn{8}{|c|}{ Kapiti } & \multicolumn{3}{|c|}{ Imaginary } \\
\hline & $\mathbf{L B}$ & & $\mathbf{L R}$ & & RFD & & $\mathbf{V}$ & & $\mathbf{C F}$ & & $\mathbf{L B}$ & & $\mathbf{L R}$ & & RFD & & $\mathbf{V}$ & & & $\mathbf{L R}$ & \\
\hline & $\begin{array}{l}\text { Mean } \\
\text { rank }\end{array}$ & SE & $\begin{array}{l}\text { Mean } \\
\text { rank }\end{array}$ & SE & $\begin{array}{l}\text { Mean } \\
\text { rank }\end{array}$ & SE & $\begin{array}{l}\text { Mean } \\
\text { rank }\end{array}$ & SE & $\begin{array}{l}\text { Mean } \\
\text { rank }\end{array}$ & SE & $\begin{array}{l}\text { Mean } \\
\text { rank }\end{array}$ & SE & $\begin{array}{l}\text { Mean } \\
\text { rank }\end{array}$ & SE & $\begin{array}{l}\text { Mean } \\
\text { rank }\end{array}$ & SE & $\begin{array}{l}\text { Mean } \\
\text { rank SE }\end{array}$ & $\underline{\text { p-value }}$ & $\begin{array}{l}\text { Mean } \\
\text { rank }\end{array}$ & SE & p-value \\
\hline Biodiversity protection & 3.86 & 0.24 & 3.54 & 0.07 & 4. & 00.25 & 3.66 & 0.11 & 2.83 & 0.31 & 3.62 & 0.23 & 3.88 & 0.08 & 4.00 & 0.22 & 3.550 .11 & $<0.00$ & 4.10 & 1.01 & 0.02 \\
\hline Litter on beach and in the water & 3.43 & 0.35 & 3.46 & 0.10 & 3. & 80.24 & 3.87 & 0.12 & 2.33 & 0.42 & 2.92 & 0.28 & 3.10 & 0.10 & 3.20 & 0.26 & 3.550 .12 & $<0.00$ & 3.72 & 21.09 & 0.07 \\
\hline Edcucation oportunities & 3.86 & 0.32 & 3.56 & 0.07 & 3. & 60.20 & 3.74 & 0.12 & 3.00 & 0.45 & 3.15 & 0.29 & 3.57 & 0.07 & 3.80 & 0.14 & 3.260 .14 & 0.72 & 4.17 & 70.96 & $<0.00$ \\
\hline Local participation in management & 3.71 & 0.34 & 3.46 & 0.07 & 3. & 60.18 & 3.19 & 0.09 & 2.67 & 0.33 & 3.08 & 0.23 & 3.35 & 0.07 & 3.40 & 0.17 & 3.260 .10 & 0.30 & 3.55 & 51.01 & 0.04 \\
\hline Biodiversity recovery & 3.71 & 0.34 & 3.49 & 0.07 & 3. & 60.21 & 3.38 & 0.10 & 3.33 & 0.21 & 3.69 & 0.13 & 3.62 & 0.08 & 3.80 & 0.26 & 3.350 .11 & $<0.00$ & 4.10 & 0.99 & 0.01 \\
\hline MR surveillance/policing & 3.43 & 0.28 & 3.31 & 0.07 & 2. & 60.22 & 3.19 & 0.08 & 3.50 & 0.22 & 3.31 & 0.17 & 3.39 & 0.08 & 3.60 & 0.17 & 3.350 .13 & 0.58 & 3.79 & 9.97 & 0.01 \\
\hline
\end{tabular}




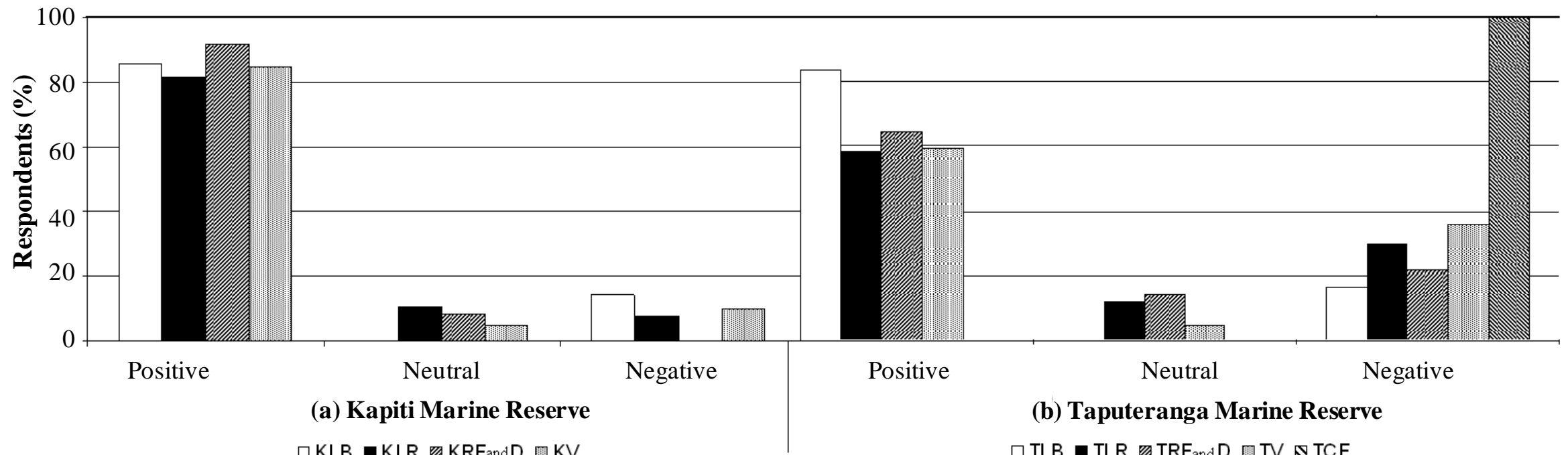

$\square \mathrm{KLB} \square \mathrm{KLR}$, KRFand D $\mathrm{KV}$

$\square T L B \square T L R$ 解

Figure 3.11: General attitudes toward Kapiti (a) and Taputeranga (b) marine reserve from the word association question. K: Kapiti; T: Taputeranga; LB: Local business; LR: Local residents; RDFs: Recreational fishers and divers; Vs: Visitors; CF: Commercial fishermen. 
If the Marine Reserve could be disestablished,
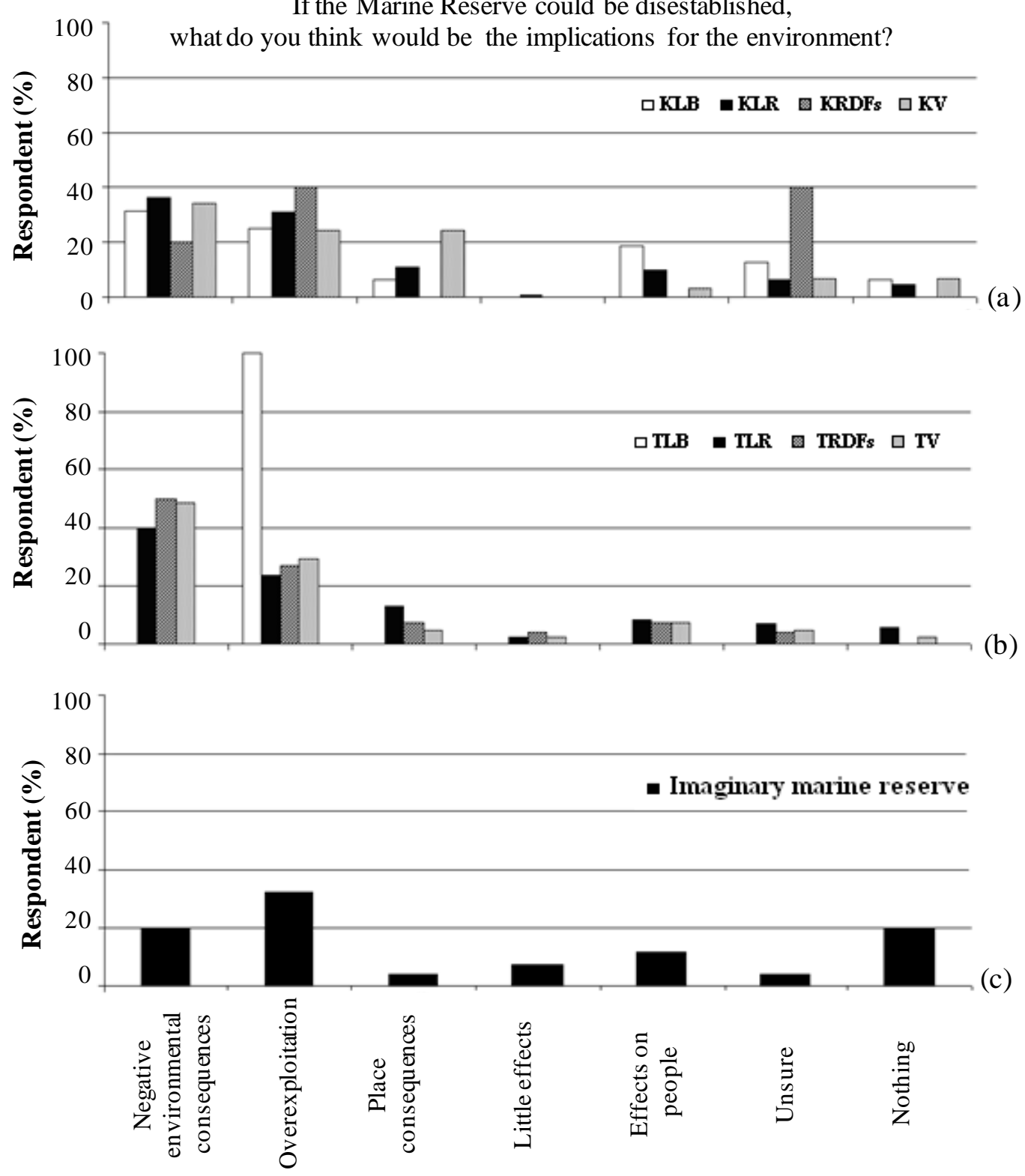

Figure 3.12: Responses concerning general attitudes regarding the environmental consequences toward potential marine reserve disestablishment at both marine reserves Kapiti (a), Taputeranga (b) and Hypothetical marine reserve (c). K: Kapiti; T: Taputeranga; LB: Local business; LR: Local residents; RDFs: Recreational fishers and divers; V: Visitors; CF: Commercial fishermen. 

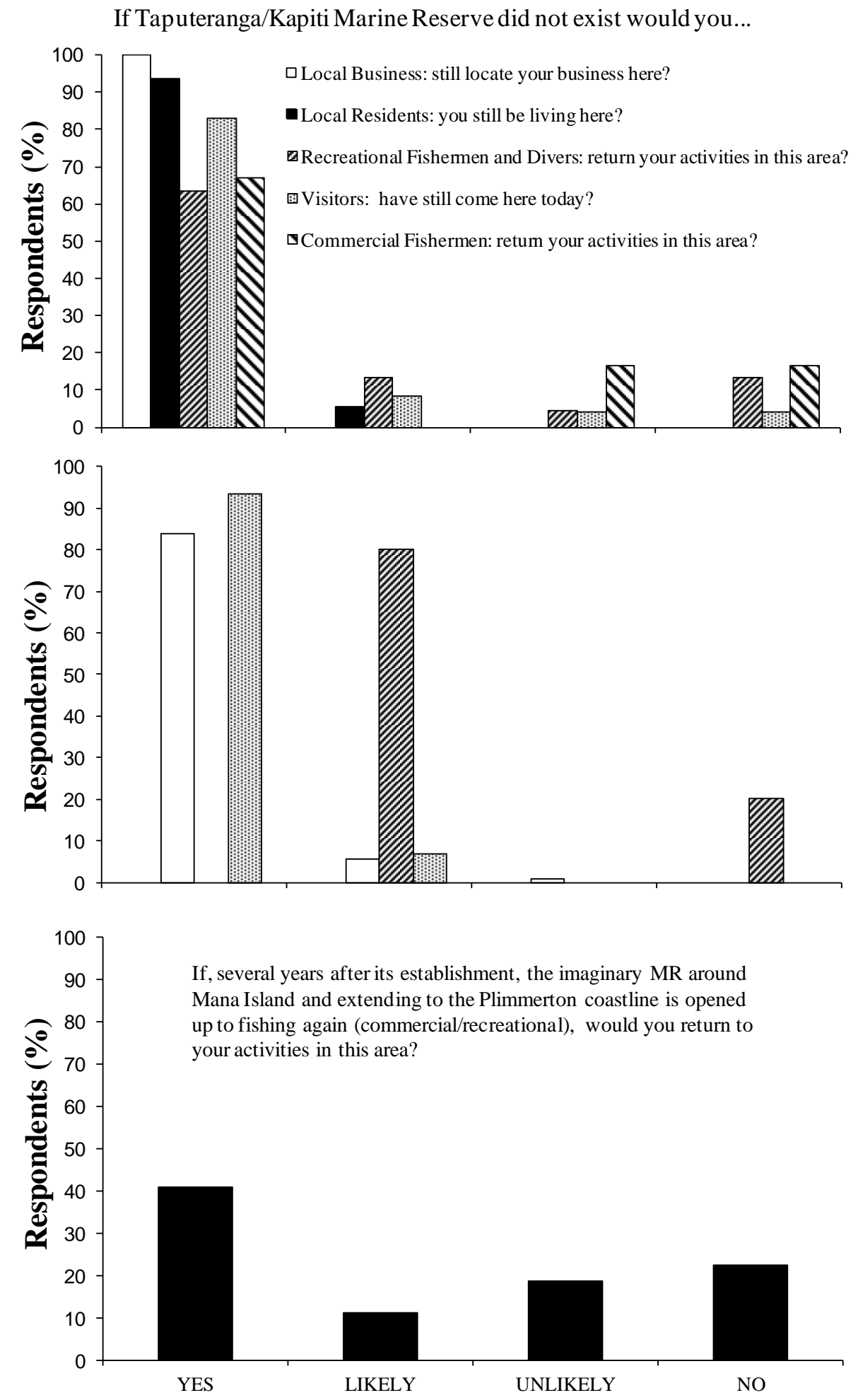

Figure 3.13: Responses to the hypothetical implications of future marine reserve environments if the Kapiti (a), Taputeranga (b) marine reserves and the Hypothetical marine reserve (c) were disestablished. 


\subsection{Discussion}

This is the most recent and more complete study in New Zealand to use a human dimensions approach to understand the impacts of the establishment of MRs. Respondents believed that they had a high level of knowledge about MRs in New Zealand, however their knowledge was generally inconsistent with respect to the MR Act (1991). Respondents most expected to see visual changes in the MRs, but most did not think there were any changes after the MRs were established.

The attitudes and perceptions of respondents revealed that many people consider MRs as something positive. However, commercial fishers and some recreational fishers believe that MRs are having a negative impacts on their lives. Moreover, respondents believed that MRs are a good tool for protecting the environment, however, they do not want MRs close to where they live. This was particularly evident from responses to my questions at the hypothetical MR at Plimmerton. At TMR and KMR respondents did not perceive any direct benefits from the MRs on their lives, and similarly the respondents at Plimmerton did not believe that a MR would benefit their lives.

In New Zealand, environmental attitudes towards MRs have not received significant attention, particularly public knowledge, perceptions and attitudes, despite NZ having a large number of MRs. Exploring human dimensions is important to explain the relationship between humans and the environment. Therefore, as Lockwood and Kothari (2006) argued, by understanding human dimensions, managers of MRs should be able to develop more effective strategies for MPA management.

\section{Marine reserve public knowledge and beliefs}

This study revealed that the majority of respondents believed that they knew the purpose of a marine reserve. The responses provided about the goals of MRs were closer to those used overseas, rather than the scientific basis of the MR Act in NZ. In other countries MRs are designated for the protection of marine biodiversity, but in New Zealand the MR Act primarily supports the creation of MR for research purposes, and biodiversity protection is an indirect benefit. This misunderstanding was most noticeable when examining the answers to questions relating to activities permitted inside MRs. Many respondents were unaware or unsure of what activities are allowed or prohibited in MRs. 
Communication is a critical component of creating protected areas, which needs careful incorporation through the process from the planning stages to final implementation (Wolfeden et al., 1994; Taylor and Buckenham, 2003). Ideally, this should include a wide range of stakeholders (e.g. local people, government agencies, businesses, scientists, and Iwi). The type and accessibility of information to stakeholders should be clear and accurate to enable people to make their own decisions (De Lacy and Whitmore., 2006). In New Zealand, the Department of Conservation is responsible for Marine Reserves when designated, but a number of agencies are involved in the planning stages. It is important that these agencies work together to communicate to all stakeholders. Fiallo and Jacobson (1995) found that the poor relationship between the Machalilla National park staff (Ecuador) and the local community contributed to negative attitudes and actions towards the protected area. Therefore, improving public participation will create a bond of trust between users and government through MRs, while helping to create a common understanding of MRs concepts. For this reason the relationship has to be maintained, otherwise conservation plans are likely to fail (Rojas-Nazar et al., 2012). This in turn will facilitate the resolution of conflicts and will contribute to more effective enforcement of rules and regulations by increasing the probability of compliance, and empowerment levels by MRs users (Jentoft and McCay, 1995; Kapoor, 2001; Pita et al., 2010).

The interviews in respect to illegal activities, have some limitations, however what I could identify in my study was that a small proportion of people are continuing to carry out activities in the MRs such as recreational fishing, seaweed collection and other activities that are banned under the MR Act. This could be because: (a) people are not receiving enough information, or the information provided is not sufficiently clear to explain what activities are permitted/banned to conduct inside MRs, and/or (b) people are not following the rules in the MR. The lack of information and misunderstanding can be addressed through education programmes focused on different age groups, or by using media resources, to publish correct, clear and accurate information, to the public (for example see Port-Cross National Park, France. Francour et al. 2005). With respect to the people who are not following rules within the marine reserve, and conducting illegal activities such as poaching, it could be explained because there is a general perception that MRs could enhance fisheries outside their boundaries by increasing abundance and size of targeted species, which can attract noncompliant users to go into the reserve to poach (Sethi, 2007). In addition, boundaries are more difficult to mark in MRs in comparison to terrestrial reserves, therefore some harvest within MRs might occur as a result of users not knowing the location of a reserve or whether 
a reserve exists (McClanahan, 1999; Sethi, 2007). To better understand about illegal activities inside of MRs, other types of methodologies such as ethnographic study using qualitative interviews and participant observation can help to elicit this sensitive information, because the methods used in my research were probably not accurate enough.

When a MR or a MPA is established, the goals and how these will be measured over time to assess their effectiveness should be clearly identified (Alder et al., 2002; Well and Mangubhai, 2005; Pomeroy et al., 2004; Heck et al., 2011). It is therefore important that these goals are clear to all stakeholders, especially with respect to permitted/banned activities.

\section{Human perceptions and expectations of changes in flora and fauna}

Respondents from both MRs did not think that many changes had occurred in the MRs in terms of flora and fauna. Recreational fishers and divers at TMR reported most of the changes. With respect to changes in activities conducted by respondents in the MRs, the majority of changes were reported by commercial fishermen at TMR where they said that people carried out fewer activities than before the MRs were established. The reason why fishers seem to recognise more changes than the rest of the groups could be explained by the close relationship and the time that they spend in activities related with the sea. Many of these people have been carrying out activities prior to the MR being established, and are most likely to see any changes in the MR area.

Generally respondents were mostly expecting visual changes in flora and fauna, therefore many were uncertain about the success of the MRs because they have not seen any obvious changes. It is because many changes are underwater. It is important for MR managers to understand users' expectations in order to improve management practices, and include this into MRs monitoring plans (Lédée et al., 2012).

\section{The effects of marine reserves on attitudes and perceptions}

Despite positive attitudes towards the MRs by the majority of respondents, commercial fishermen and some respondents belonging to other groups surveyed perceived themselves as 'losers' with regards to MR designation or a potential designation (in the hypothetical MR) because they were displaced from their fishing grounds. Similar negative attitudes towards marine protected areas (Lédée et al., 2012), as well as other types of regulations for biodiversity or stock recovery has been found in other studies (see Ojeda and Loureiro, 2010). Comparable perceptions were found in New Zealand by Taylor and Buckenham (2003) in 
three MRs - Cape Rodney - Okakari Point MR, Pohatu MR and Tonga Island MR, where the local community, commercial fishers, recreational fishers and local customary fishers perceived MRs as negative in their lives (Taylor and Buckenham, 2003). Therefore negative perceptions and unsupportive attitudes to MRs were not unexpected (Jones, 2008; Mangi and Austen, 2008; Lédée et al., 2012). The negative perception of these users is because they have had to redistribute their fishing effort, had decreased property rights and reduced freedom in their fishing grounds. As a result of current MRs, commercial fishermen have increased fishing costs, have longer fishing hours, spend more time looking for new and safe fishing grounds, or concentrating their effort on the boundaries of the MRs. The strategy of fishing close to the boundaries of marine reserves is commonly known as 'fishing the line' (Kellner et al., 2007), and it may affect negatively the spill-over process (Wilcox et al., 2003; Stelzenmüller et al., 2008; Lédée et al., 2012).

Historically, at Island Bay the local community used the current TMR area as a family fishing ground, but due to MR regulations, they are no longer able to conduct this activity. Family time spent fishing is an important social activity in their lives for two main reasons: (1) quality family time; and (2) good way to provide food for their families. For this reason, some respondents would like to remove the MR and continue fishing in TMR area. Another problem at the TMR is that people are not allowed to remove anything from the MR area, but the beaches inside the MR have seen an accumulation of large kelp (which is natural) and rubbish (which is a man-made problem) on the beach; the local council removed this material prior to MR establishment. This issue is a source of tension among users with two distinct groups of respondents; those who feel the seaweed on the shore should be left because it is part of the environment and those who strongly oppose seaweed on the beach, because they consider the seaweed as rubbish, and from the user's point of view seaweed is disturbing the beauty of their seascapes. However, in the TMR Order 2008, there is an explicit paragraph that refers to the excessive amount of seaweeds in the MR that can be removed under specific circumstances (paragraph 7 entitled Conditions relating to beach cast seaweed and debris, MR (Taputeranga) Order 2008). Therefore, this conflict could be resolved by management intervention.

Respondents generally had conflicting feelings about MRs, because they are concerned about problems experienced by commercial fishermen as a result of MR designation and the other potential problems they create (e.g. interfering with family fishing time and seaweed/rubbish problems), but at the same time respondents are concerned about marine conservation issues. 
Therefore, these conflicting feelings should be considered as a critical factor in MR management. These conflicting feelings could change into negative attitudes or increase levels of uncertainty (Fort et al., 1993) among those people who currently have positive attitudes and perceptions about MRs. The degree of compliance to MR rules might then be reduced, creating reduced support for the current MRs and future similar conservation projects (Halvey and Seeking, 2004; Lédée et al., 2012). Therefore, my results point out the importance of sampling to understand the heterogeneity of perceptions, in especial in conservation, where decision-made affect different groups in deferent ways.

\section{Marine reserve support}

The responses based on the hypothetical MR in Plimmerton revealed contrasting feelings among respondents as to whether marine conservation is an important issue. Respondents consider MRs to be useful tools to protect the marine environment, but not all the respondents would support a MR being established in their local area. These results are similar to other environmental studies. Wolfenden et al. (1994) suggested that MRs in New Zealand would get more support when the implementation process includes social and environmental impact assessment, in order to make this process more comprehensive.

Results released by the World Wildlife Fund (WWF-NZ) in 2011, showed that most New Zealanders (96\%) think more of New Zealand's oceans should be protected as 'no take' marine reserves. However, this study did not consider whether respondents knew what the function of a MR is in New Zealand. Moreover, this study did not consider whether or not respondents would support the creation of MRs in their surrounding area. In this study the percentage of respondents supportive of establishing the MR in Plimmerton was only $13 \%$. Musall and Kuik (2011) describe this effect as the 'Not In My Back Yard' (NIMBY) syndrome, which is widely used to describe local people who give their strong support to some projects but they oppose implementing it close to their local geographic area. This syndrome has been well described in a range of environmental decisions, such as renewable energy (Wolsink, 2000; Devine-Wright, 2005; Musall and Kuik, 2011), and waste management (Kikuchi and Geraldo, 2009), and public risk evaluation (Fort et al., 1993). In New Zealand, Ryan (1995) found similar NIMBY attitudes at Wainui MR, Banks Peninsula, where respondents declared they were not against the MR, but there were opposed to establishing it in their area. 
In order to anticipate, reduce and/or mitigate the NIMBY syndrome in future MR designation, it is important to change the way that people perceive MRs, by enhancing the benefits. If users feel that they will experience a big loss because a MR is to be established in their surrounding areas, then government should find a solution or a mitigation measure to create 'win-win' scenarios as much as possible, in order to create better outcomes (for example see Adams and Hulme, 2001; Rees et al., 2010; Simon et al., 2012). Compensation methods or incentives could be included or considered by managers. There is a strong relationship between local conflicts and the role of compensation offers, because compensation could facilitate affected people to accept government decisions, such as conservation measures (Kikuchi and Geraldo, 2009). Compensation might include economic subsidies and education programmes to the community, or by providing incentives for example by encouraging ecotourism. This could encourage particular behaviours, perceptions and attitudes to influence more pro-environmental towards MRs (Jacobson et al., 2006; Salomon, 2008). However, these types of mitigation strategies have not been considered in the MR act (1971), nor in the Marine Protected Areas Policy and Implementation Plan (MPA Policy) (www.biodiversity.govt.nz), because there is not government funds set to cover these types of strategies.

\section{Benefits from marine reserves}

Another significant finding from this study is that recreational fishermen and divers feel they have benefited from the MRs, specifically because of how they spend their leisure time. However, the general range of responses across all groups regarding the benefits gained since the establishment of the MRs were neutral or negative. Nevertheless, I found positive trends in satisfaction levels in some of the statements analysed. Those results show that despite respondents not perceiving direct personal benefits they are still satisfied with respect to some aspects including biodiversity protection, less litter on the beach, and education opportunities. On the other hand, the majority of respondents felt the disestablishment of the MRs would not make any difference to their lives with respect to changing their current location (living or business) or decision to visit. However, recreational fishermen and divers, as well as commercial fishermen, stated that if the MR areas were re-opened again, they would return to the activities in those areas before the MRs were designated. This is important because MRs in New Zealand can potentially be repealed using the same process for establishment (Marine Reserves Act, 1971), therefore, potentially the MR status could be revoked. 


\section{MPA policy and current MRs}

The new system of MPA designation was launched in New Zealand in 2005. It includes a series of statements referring to different protection tools (e.g. marine reserves, wildlife refuges, marine mammal sanctuaries just to name a few) and the Fisheries Act. In this new policy, the government has proposed to include people in different ways in order to create more viable long term MPAs (Paragraph 69 - MPA Policy, 2005). One of the proposals is to create monitoring programmes which: (1) will assess the performance of the MPA network, (2) monitoring based on, site biodiversity and performance on the MPA management tools (Paragraph 78,79,80 - MPA Policy, 2005). Moreover, there is a list of principles that should guide the process of MPA establishment, reinforcing the bottom up process: principle 4 'MPA establishment will be undertaken in a transparent participatory, and timely manner', principle 5 'Adverse impacts on existing users of the marine environment should be minimised in establishing MPAs', and principle 9 'The management regime must be enforceable'. However, this process should include a social assessment, which is not currently included. Managing MRs and MPAs is essentially dealing with human-mediated problems, something that needs to be acknowledgement from the outset (Lockwood and Kothari, 2006). For this reason, public participation is a key component of good governance (Pita et al., 2010). Therefore, understanding human dimensions of MRs is essential for effective governance of MPAs and MRs. Currently, the New Zealand government is looking to assess MRs based only on biodiversity performance. The social context is not a priority in the evaluation system. Prior studies in MRs in New Zealand found a similar lack of local participation in MRs (Wolfeden et al., 1994; Taylor and Buckenham, 2003). These studies also recognised the necessity to work with local communities and involve local participation from the planning stages, taking into account that in New Zealand this is a bottom up process.

Finally, the importance of social information for conservation purposes should not be underestimated (Gelcich et al., 2005a,b). It is important to understand the level of knowledge and understanding of MRs by the general public and users of MRs, because from their knowledge people will be able to build perceptions, attitudes, and consequently make informed decisions about MRs. Lastly, is important to include local users as much as possible, and try to take decisions with the local users, rather than only government by themselves, because this type of interaction known as co-management will ensure more effective conservation actions. REFERENCIAS DE CO-MANEJO!!!!!!!!!!!! BETHANY 


\title{
Chapter 4.Understanding the use and non- use values of no-take marine protected areas: case studies from the Taputeranga and Kapiti Marine Reserves
}

\author{
Author contribution: URN and RC co-designed the study. URN performed the fieldwork
} and analysed the data and wrote the chapter. RC, JJB, JPAG provide editorial input.

\subsection{Abstract}

New Zealand has 34 MRs, protecting approximately $7 \%$ of New Zealand's Territorial Seas. Despite the level of public interest in MRs little is known about their value to the public. The aim of this study was to identify and determine use and non-use values of the Taputeranga Marine Reserve (MR) and the Kapiti MR, both located in the Wellington region. Two approaches were used in order to determine the value of these MRs, the ecosystem services approach developed by the Millennium Ecosystem Assessment and a total economic value (TEV). For the direct uses values I used two methods: market and non-market methods. Indirect uses values were compiled from the literature. Non-use values were estimated by using Willingness to Pay (WTP). Results showed eight different values of the MRs (direct, indirect and non-use values): (1) Potential commercial fishing benefits; (2) Nature based tourism; (3) Education; (4) Research; (5) Public recreation; (6) Recreational fishing benefits; (7) Ecosystem health; and (8) Existence-Bequest values. The existence-bequest values (nonuse values) were estimated based on the public's WTP and had a mean value of NZ \$61.54 at the Taputeranga MR and NZ \$31.45 at the Kapiti MR per household. This research is the first public valuation of MRs in New Zealand. My research describes a standard methodology to assess and value environments that can be used for comparison in the future. Despite the legislation supporting MR establishment in New Zealand being for scientific research, my study suggests that people are obtaining direct and indirect benefits from MRs, which are improving the quality of their lives (human well-being). Also, people are willing to pay in order to protect and maintain MRs and their benefits. 


\subsection{Introduction}

Marine reserves (MRs) have been used as a tool to protect marine biodiversity, to enhance or protect marine resources from overexploitation, to improve the management of marine resources and also for scientific research (NRC, 2001). MRs can contribute spillover effects, support increased size of commercially important species, and conserve essential habitats and populations (Roberts et al., 2001; Pauly et al., 2002; Halpern, 2003; Gell \& Roberts, 2003; Balmford et al., 2004; Hilborn et al., 2004, Conrad, 1999; Sumaila, 1998; Hannesson, 2002; Armstrong, 2007). MRs can also contribute to sustainable resource use, education, recreation and culture, (Castilla, 1976; NRC, 2001; Shipp, 2003), ecotourism and fishing in adjacent areas (Allison et al., 1998, Schnier, 2005), and provide an environment in which research can be conducted without major anthropogenic influences.

Marine Reserves (MRs) are one of the most common form of protection with the consequence of conservation in New Zealand. Currently there are 34 MRs in New Zealand protecting approximately $7.6 \%$ of New Zealand's Territorial Sea (www.doc.govt.nz). Ecotourism, which includes visits to MRs, is one of the largest industries for the New Zealand economy, with the tourism industry being worth NZ \$23.4 billion a year to New Zealand's economy in 2012 (www.tourismnewzealand.com). Despite numerous international studies showing that there are both direct and indirect benefits provided by MRs (e.g. Roberts and Polunin, 1991; Bohnsack, 1993; Carr and Reed 1993;Dugan and Davis, 1993; Roberts, 1998a; Pauly et al., 1998; Murray et al., 1999; Palumbi, 2000; Davidson, 2001a,b; Gell and Roberts, 2003; Willis et al., 2003; Schnier, 2005; Kellner et al., 2007; Bartholomew et al., 2008; Francini-Filho and Moura, 2008; Forcada et al., 2009; Halpern et al., 2010 and references therein), in recent years the New Zealand government has reduced the funding provided to the Department of Conservation (DOC), which is likely to have affected DOC's ability to establish and manage MRs (The New Zealand Treasury, 2012).

Insufficient investment in existing MRs can result in 'paper' marine protected areas (MPAs) where there is insufficient and ineffective management, which results in further degradation (Wilkie et al., 2001). MR evaluations need to include all the associated values to assist the policy making process, because this will provide a more accurate basis for any type of decision-making. The value of MRs can be studied from different perspectives including 
cultural, social, biological, spiritual and economic. However, despite the importance of MRs to people, not all of these values are widely estimated. Generally, a standard economic approach considers only tangibles values; however, because MRs are no-take areas, the majority of values are related to non-tangible values, which are equally important in environmental assessments (Pouliquen-Young, 1997; Farber et al., 2006; Hearnshaw et al., 2010). A useful way to include and consider both tangible and non-tangible benefits of MRs is by using an ecosystem services approach (Costanza et al., 1997), such as the Millennium Ecosystem Assessment (MEA) (MEA, 2005; Hearnshaw et al., 2010).

To assess and compare diverse values associated with different environments under the MEA framework, a number of tools can be used. One way is to express environmental values in a common denominator, which could be a monetary unit. Total Economic Value (TEV) approaches have been used by economists for many years to estimate the value of ecosystems according to how people use them (NRC, 1999; Bateman et al., 2002; Banzhaf et al., 2006; Dziegielewska, 2009; TEEB, 2010; Bateman et al., 2011). This approach includes:(i) direct use value (used directly by humans, for example, food products, medicine, and building materials) plus the value of non-consumptive uses such as the enjoyment of recreational and cultural activities that do not require harvesting of products; (ii) indirect use value (benefits outside the ecosystem itself, such as natural water filtration, storm protection functions of mangrove forests, and carbon sequestration); (iii) option value (preserving the option to use in the future, either by oneself (option value) or by others/heirs (bequest value)); and (iv) non-use value (enjoyment people may experience simply by knowing that a resource exists even if they never expect to use that resource directly themselves). This kind of value is usually known as existence value (or, sometimes passive use value) (IUCN at el., 2004; DEFRA, 2007). Generally, direct use values are easier to assess or determine than the other values because they involve observable quantities of a product or resource, where prices are already determined in a real market. However, to assess the benefit or contribution of the other values in a monetary unit is a more complex.

The contingent valuation method (CVM) has been widely used for estimating monetary values of a wide range of environmental changes and entities, with special emphasis on those situations when there is no real market available. CVM can be used to estimate both use values and non-use values (Hoevenagel, 1994; Pearce and Moran, 1994; Emerton and Bos, 2004;Mmopelwa et al., 2007). By using the CVM it is possible to establish people's 
Willingness to Pay (WTP) for a given policy change, and to estimate WTP for conservation activities. In addition, CVM can be used to measure the willingness to pay for items such as entrance to protected areas and for diving/snorkelling (Arin and Kramer, 2002; CruzTrinidad et al., 2011).

The principal assumption of CVM is that environmental goods have value, and that the values can be estimated through means such as individual's responses to hypothetical markets (Hoevenagel, 1994; Mmopelwa et al., 2007). The theoretical basis for CVM is based on individuals expressing their preference in order to maximise their utility subject to an income constraint, or to minimise their expenditure, subject to a utility constraint (Spash, 2006). Through this utilitarian theory of value, people are able to value parts of the world (O'Neill, 1993) and the public act as environmental consumers. Therefore, total economic value is an expression of utilitarianism preferences, where non-economic motives (such as a belief in rights, attitudes towards to the environment, responsibility and obligations) cannot be separated from the economic ones (such as economic use, natural value) (Cooper et al., 2004). The WTP technique may reflect all of those underlying motives, which are associated with public concern for moral choice (Vadnjal and O'Connor, 1994), assuming that consumers are purchasing moral satisfaction through expressing what is ethically right rather than a direct exchange value to the environment. In the case of WTP, consumer surplus is defined as 'proposed welfare gain due to provision of public good' (Venkatachalam, 2004), and the environmental consumers are prepared to sacrifice an amount of money to prevent the loss of the goods from occurring in the future, and not only for their own use (Bateman and Turner, 1993; Venkatachalam, 2004; Amirnejad et al., 2006). Consequently, if WTP is expressing what is ethically right for consumers, their environmental value is directly related to their WTP. But if consumers (based on their attitudes towards a specific environment) consider they are losing a 'right' because of MRs, then consumers will give a poor representation of the economic value of MRs through their WTP.

Thousands of non-market valuations have been completed, many of them asking WTP questions about various non-market items, including questions about conservation and environmental management (Amirnejad et al., 2006; Asafu-Adjaye and Tapsuwan, 2008; Saengsupavanich, 2012). WTP is thought to provide information for stakeholders and decision-makers about coastal protection (Saengsupavanich et al., 2008, Winckel et al., 2008, Saengsupavanich, 2012). In addition to WTP, studies have been conducted to help 
communities and governments estimate the value of their environments (Cruz-Trinidad et al., 2011). These studies have found that the indirect values of ecosystem are what most contributes to total economic valuations, suggesting that the government interventions should consider or focus on these values for decision-making.

The aim of this study was to identify and determine use and non-use values of two marine reserves in the Wellington region, New Zealand. The specific goals of this research were to: 1) identify use and non-use values at the Taputeranga and Kapiti MRs by using the TEV framework: 2) identify the best methodology to calculate each of these values; 3 ) develop a specific TEV framework for each MR; 4) develop TEV guidelines that could be included in future MR monitoring; and 5) assess the importance of ecosystems services of MRs by using the Millennium Ecosystem Assessment approach.

\subsection{Study sites}

The study was carried out at two MRs. The first, Kapiti Marine Reserve (KMR), was established in 1992 on the Kapiti Coast in Wellington. KMR is located in the northwestern Cook Strait region of New Zealand (Eddy, 2011), approximately $50 \mathrm{~km}$ from Wellington ( $40^{\circ} 51^{\prime} \mathrm{S}, 174^{\circ} 55^{\prime} \mathrm{E}$; see chapter 2, Fig. 2.1a). The KMR protects an area of 2167 ha, where the eastern side is 1825 ha, and the western side covers 342 ha. The Kapiti Coast is a convergence zone for the cold clear Southland Current and the warm turbid and saltier d'Urville Current. East of KMR there are several small towns, that are located in Kapiti Coast District, which is part of the Greater Wellington Region (Fig. 4.1).

The second marine reserve, Taputeranga Marine Reserve (TMR) (40 $\left.20 \mathrm{~S}, 174^{\circ} 45 \mathrm{E}\right)$ protects 854.79 ha of coastal waters. The reserve extends from Princess Bay on the eastern boundary to Quarry Bay on the western boundary (Eddy, 2011). TMR is located in Wellington (New Zealand's capital) (see chapter 2, Fig. 2.1b) and was established in 2008. TMR is the first rocky reef MR in New Zealand located close to a city. The marine environment is representative of the temperate Cook Strait region, with highly dynamic systems, receiving currents from the south as well as the zone of convergence for the East Cape, D'Urville and Southland currents (Eddy, 2011). The TMR forms part of Greater Wellington Region, but only Wellington City residents were directly invited to participate in this study (Fig. 4.1). 
Some residents outside the Kapiti Coast District and Wellington City participated in this study, however, they were not directly invited to participate. For this study I used three location types. Small towns and suburbs surrounding the MR (within a radius of $6 \mathrm{~km}$ at both MRs) were considered as being very close to the MRs (coded as location 1). Then middle distance towns (between 6 and $8 \mathrm{~km}$ from the TMR, and 6 to $14 \mathrm{~km}$ from the KMR) from the MR were coded as location 2, and all the areas further away from the MR were coded as location 3 (Fig. 4.1).

\subsection{Methods}

Marine reserve values were estimated in this study using the Total Economic Value (TEV) framework (Bateman et al., 2002). To use the TEV approach I had to identify all the current benefits from each MR, I then had to decide which of these benefits could be measured, and what type of method would be more appropriate to estimate their values. I decided not to measure indirect benefits such as spill-over processes, and bio-chemical and biological cycles (e.g. nutrients and carbon).

\section{Direct use values - market based values}

These were measured by conducting a market analysis. For that, I used information from those shops that were conducting paid-for activities in the MR, such as boat charters, diving shops and eco-tourism companies. Moreover, I estimated the potential fishing benefits (FB) from MRs by using rock lobster prevalence (Jasus edwardsii) as a measure. Rock lobster fishing has been considered the largest source of revenue for commercial fishers within the study area. In addition, there is an important recreational fishery within the study area (Eddy, 2011). 


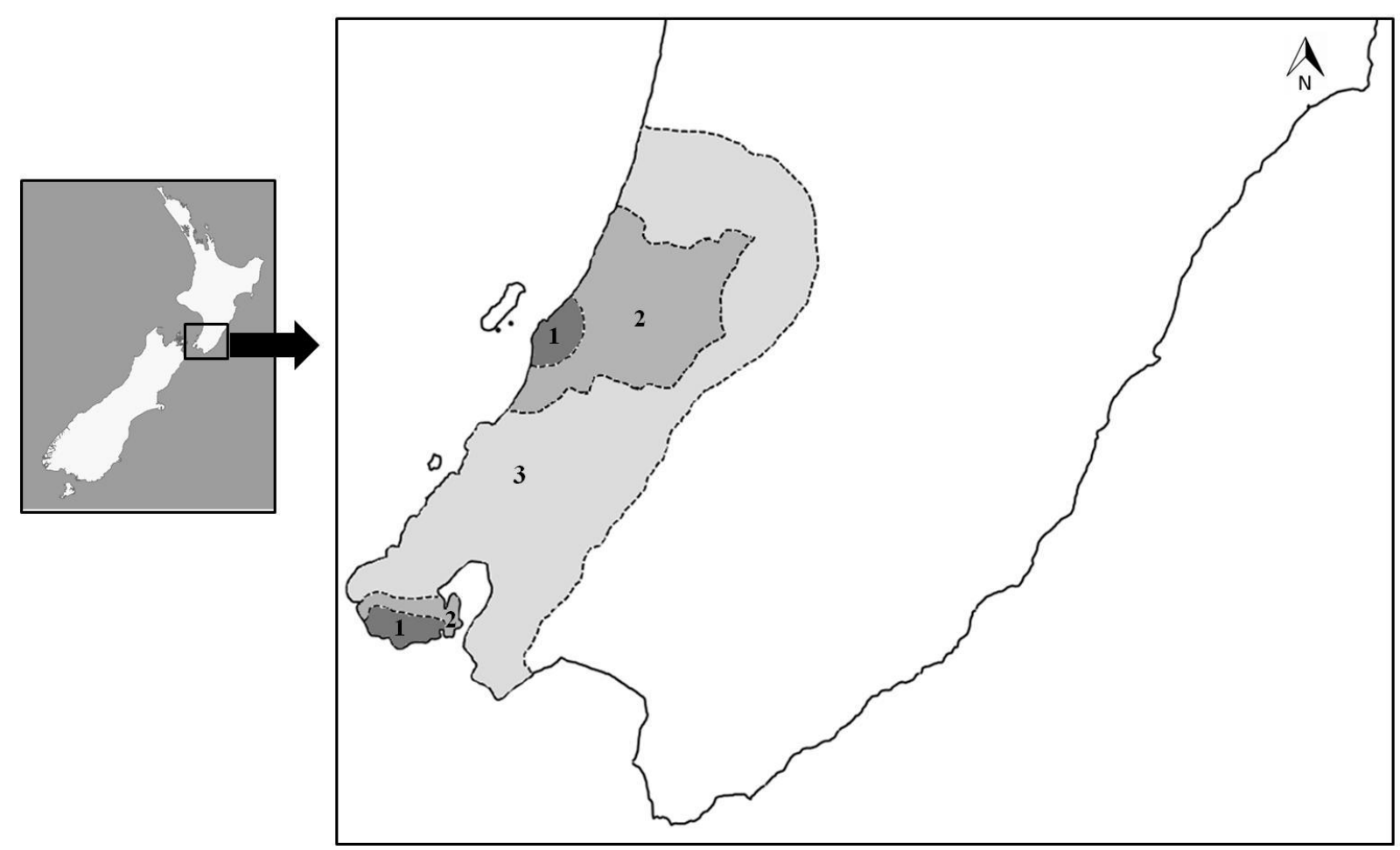

Figure 4.1: Sample locations according to distance from the marine reserve. (1) Closest to the MR; (2) middle distance areas from the MR; (3) those areas farthest away from the MR.

MRs are predicted to produce benefits outside their protected areas, with net emigration of adults and juveniles across borders, termed 'spillover', with subsequent increased recruitment potentially improving populations residing outside the MPA (Allison et al., 1998; Hastings and Botsford, 1999; Pezzey et al., 2000; Gell and Roberts, 2003; Schnier, 2005; Kellner et al., 2007). Therefore MRs may enhance harvested populations beyond their boundaries through indirect effects (Kellner et al., 2007; Gell and Roberts, 2003; Halpern et al., 2010). Therefore, I defined the fishing benefits as the potential number of RLs that come from inside the MR to the outside (open - area) and are then available in the sea to be captured. To measure FB from within MRs I have employed a Schaefer biomass dynamic fishery model (Schaefer, 1954; equation 1), described by the terms: $B=$ biomass of lobsters, $t=$ time, $r=$ intrinsic rate of population growth, $k=$ carrying capacity, and $C=$ catch to predict lobster biomass growth. The Schaefer biomass dynamic model (equation 1) was chosen because of the absence of age-structured data for the time scale of the fishery catch record I examined (Hilborn and Walters 1992).

$$
\frac{d B}{d t}=r B\left(1-\frac{B}{k}\right)-C
$$


Intrinsic rate of increase $(r)$ was estimated using data for the recovery of 14 Jasus edwardsii populations following the reduction of fishing pressure in New Zealand after MR implementation (Pande et al., 2008). These values were calculated for a highly exploited stock biomass indicating that they should be accurate values of growth for the model and had a low variance of $0.06 \%$ (Hilborn and Walters, 1992). Biomass dynamic models are sensitive to the intrinsic rate of population growth $(r)$ at low biomass (Hilborn and Walters, 1992). Carrying capacity $(k)$ was estimated using virgin biomass $\left(\mathrm{B}_{0}\right)$ estimates (Breen and Kim, 2006).

Landings data from the 915 and 934 statistical areas of the CRA4 management area were scaled for the size of the TMR and KMR, respectively (Ministry of Fisheries 2010). The most recent estimate of recreational take of lobster is approximately $10 \%$ of commercial landings (Ministry of Fisheries, 2010), which I incorporated into the landings estimate. Initial vulnerable lobster biomass was determined assuming that landings were half of the vulnerable biomass (Breen and Kim, 2006).

The biomass dynamic model was run for 40 years until 2050 in order to predict the vulnerable biomass of lobster in the KMR and TMRs throughout that time. The intrinsic growth rate $(r)$ was calculated from the response of lobster to MR protection at multiple reserves throughout New Zealand, and therefore takes into account any 'spillover' or movement of lobster out of the MR. It should be noted that as the biomass inside the MRs increases over time, the spillover rate could increase, which would result in a smaller biomass of lobster inside the reserve, however, a greater biomass of lobster would be available to the surrounding fishery.

The monetary value of the biomass was estimated by using the port price (market). Port price is defined as 'being established by an independent survey, conducted by the Ministry of Fisheries, of the prices that would be paid during each 12 month period for the fish (excluding goods and services tax) by an independent processor buying from an independent fisher or fish farmer. Where survey data is inadequate an estimate is made' (Seafood Industry Council, 2012). The values depend on the area where the fish are landed as port prices indicate the net value of fish to the buyers (Ministry of Fisheries pers.com). I estimated these prices based on the information published by Ministry of Fisheries (MoF) for 2010/2011 (NZ\$63.00 per kg) and 2011/2012 (NZ\$68.00 per kg) (http://www.fish.govt.nz). 


\section{Direct use values - non- market based values}

Education: To determine if there are benefits from MRs, I searched for all projects that involved the MRs as a key part of their education programme. Then, co-ordinators of these projects were invited to take part in an interview in order to learn about their programme and its relationship with the MR. I could only conduct one interview, which lasted approximately 2 hours and I used an unstructured interview to obtain information from interviewees. This is because from the two education programmes identified, only one agreed to take part in this research.

Research: The value of research in MR was estimated by quantifying how many projects (university, research organization, public/private organizations and NGOs) are currently using or had used the MR for research projects. In addition, I searched the DOC database (Kettles and Hughes, 2009) for numbers of publications and reports published from research conducted in each MR. This information was complemented by searching other databases (including JSTOR, Elsevier, Scirus, Springer-Verlag, Thomson Reuters, Web of Knowledge, Wiley- Blackwell Science).

Public recreation: Information on these uses was gathered during the survey carried out in 2010, which is described in Chapter 3.

\section{Indirect use values - Use values}

Ecosystem health of marine reserves: Based on available reports and studies I decided to use only those examining 'before/after MR establishment' and/or 'studies using comparisons between inside/outside of MRs' in order to compare and define the MR ecosystems health compared to non-protected areas.

For KMR I decided to use reef fishes including butterfish (Odax pullus), blue cod (Parapercis colias), red moki (Cheilodactylus spectabilis), and the rock lobster (Jasus edwardsii) as the Kapiti Marine Reserve health indicators, as these species are heavily targeted by fishers.

For TMR, I mainly used the study carried out by Eddy (2011) who used an ecosystem-based modelling approach to analyse food web linkages for the TMR. The author used data from Pande and Gardner (2009), Byfield (Thesis in progress), Tam (Thesis in progress), and Jones 
(Thesis in progress) invertebrates and macroalgae. In addition, I used my own data from chapter 5 to describe rock lobster rebuild status as indicator of health.

I used these species because it have been described as key species in temperate reef communities. For example RL plays an important role in trophic cascades (Babcock et al., 1999), as well as in structuring soft sediments communities (Langlois et al., 2005b). From an economic perspective, it has been the most important invertebrate targeted for commercial and recreational fishing, supporting large fisheries in Australia and New Zealand (Kellner et al., 2007).

\section{Non-uses values - Option, Bequest and Existence values (Non-market goods)}

\subsubsection{Contingent valuation method}

The contingent valuation method (CVM) used was a willingness to pay (WTP) survey. Respondents were asked to answer a questionnaire, which contained two questions directly related to the contingent valuation method. The questionnaire used is described in section 3.2. Questionnaire design and contents. The first questions asked if respondents were willing to pay a new levy: Are you willing to pay a new environmental levy annually to fund management of Taputeranga/Kapiti Marine Reserve? The second question aimed to assess how much they were willing to pay: What is the maximum amount that you (your household) are willing to pay each year to manage Kapiti/Taputeranga Marine Reserve?

\subsubsection{Questionnaire design and contents}

Two questionnaires were designed. They contained the same questions (so they were comparable), but focused separately on each MR. Each questionnaire had a Consent form and an Information sheet. The latter item advised respondents about the complete research project, and how the data they provided will be used in the future. The Consent form sheets are required by The Victoria University of Wellington Human Ethics Committee. Then some information was provided to the respondents about MRs, in order to give them all the information necessary before they answered the survey questions. These sheets contained information about the role and scope of marine reserves, when the TMR or KMR was established, where they were located, reasons why each place was designated as a marine reserve, each MR's biodiversity, uses and issues (Appendix C). Part of this information was 
based on the results described in Chapter 3; the rest of the information was taken from relevant literature (e.g. Hall et al., 2002; Turpie, 2003; Kniivilä, 2006; McCartney, 2006; Sattout et al., 2007; Cruz-Trinidad et al., 2011).

Each questionnaire was divided into three main sections: 1. Marine reserve background (general questions) which asked questions regarding: the respondent's knowledge about marine reserves. 2. Contingent valuation questions. 3. Socio-demographic questions (See Appendix C).

Most MR knowledge questions were closed questions, but in some cases respondents were asked to provide a brief explanation for their answer (partially closed questions). For the contingent valuation section, a hypothetical scenario was described. The respondents were asked to decide if they would be willing to pay toward the management of the Kapiti/Taputeranga Marine Reserve. The payment vehicle used in this study was an environmental levy. This hypothetical environmental levy was to be paid each year. To those respondents who answered ' $n o$ ', the survey asked the main reason for not contributing and provided a list with eight different potential reasons to choose from. For those who agreed to contribute to the environmental levy the survey asked a follow up question - how much they would be willing to pay. Finally, the survey asked them to rank from 5 (least important) to 1 (most important) various options for use of the levy: How should the funds that are collected by the environmental levy be used at Taputeranga/Kapiti Marine Reserve? All the responses which were as $\$ 0.00$ contribution were considered as 'unwilling to contribute'. It was important to keep separate those people who are willing to contribute from those who were not.

As part of the MR knowledge section the questionnaire contained the following questions in order to understand the respondents WTP (yes/no and \$). The questions were: Have you heard of the Taputeranga/Kapiti MR? How many times have you visited the Taputeranga/Kapiti MR? and Do you intend to visit the Taputeranga/Kapiti MR in the future? The question regarding the maximum amount to contribute was an open-ended question. I needed to determine the maximum amount of money that would be considered as useful response. For that, I contacted different conservation/environmental organizations 'to determine the maximum amount that people in New Zealand are willing to contribute per year?' Information from conservation/environmental organizations indicated the amount that people in New Zealand are willing to donate to those organizations is no higher than $\$ 200.00$ per person per year. As 
higher amounts than $\$ 200.00$ are unlikely to be paid, and also because I got a low number of responses above $\$ 200.00$, all responses over $\$ 200.00$ per year were discarded from the analysis.

Because the question regarding the maximum amount to contribute was an open-ended question, I had to determine the maximum amount of money to be considered in this survey as useful responses. For that, I ontacted different conservation/environmental organizations 'to determine the maximum amount that people in New Zealand are willing to contribute per year?' Information from conservation/environmental organizations indicated the amount that people in New Zealand are willing to donate to those organizations is no higher than $\$ 200.00$ per person per year. As higher amounts than $\$ 200.00$ are unlikely to be paid, all responses over $\$ 200.00$ per year were discarded from the analysis.

Responses to the questionnaire were anonymous. The survey was freely available via the internet and I used the Qualtrics software (http://www.qualtrics.com/). It took between 20 minutes to 1 hour to complete the questionnaire.

The survey was promoted on several web pages including the Department of Conservation (DOC), Ministry of Fisheries (MoF), National Institute of Water and Atmospheric Research (NIWA), non-governmental agencies such Royal Forest and Bird Protection Society of New Zealand, as well as on web pages for some fishing shops, diving shops, and tourism shops. It was also promoted using social media such as Twitter and Facebook linked to environmental topics. Moreover, flyers promoting this survey were dropped in mail boxes in the areas surrounding the MRs and posters were pasted around the city advertising the survey and inviting people to take part. The respondents were self-selected, means it included contributions from interested members of the public.

Characteristics of the set of respondents were compared with those of suburbs surveyed, (Wellington City, Kapiti Coast District and Wellington Region) by using a $\chi^{2}$ goodness of fit test. I used a level of significance level of 0.05 ( $p$ values $\leq 0.05$ ). Socio-demographic data were obtained from Census 2006, Statistics New Zealand (available at http://www.stats.govt.nz/). 
Qualtrics software gives data regarding the numbers of surveys started and surveys completed, and response rates were calculated by using equation 2 :

$$
\mathbf{R R}(\%)=\underline{\mathbf{T S S} * \mathbf{1 0 0}}
$$

TSC

(Equation 2)

Where:

$\mathbf{R} \mathbf{R}=$ Response rate $(\%)$

TSS $=$ Total surveys started

TSC $=$ Total surveys completed

An online survey was used because it has some significant advantages over other types of survey. Evans and Mathur (2005) describe in depth all of the major strengths and potential weakness of online surveys. Accordingly to Evans and Mathur (2005) this type of survey was useful for this project because it could be administrated in a time-efficient manner, minimising the time in the field and/or data collection. Moreover, respondents had the opportunity to self-manage their response times (Evans and Mathur, 2005; Tait et al., 2009). Hogg (2003) indicates that this advantage is more convenient than a telephone survey, which can be perceived as annoying. In addition, the survey software was prepared to give respondents a friendly and simple format to complete (Evans and Mathur, 2005). Also, this software can store all data collected instantly in a database ready to be analysed (Wilson and Laskey, 2003; Tait et al., 2009). Therefore, these characteristics greatly reduce the cost of surveys (Evans and Mathur, 2005; Tait et al., 2009). In terms of response rates (RR), online surveys can gain higher response rats than other survey formats. For example, Jackson (2003) found that internet surveys can get response rates of $25 \%$, compared to $13 \%$ or $14 \%$ for comparable mail surveys. In terms of bias, online surveys may have less bias than mail surveys if they are constructed to ensure that respondents must answer a question before continuing to the next question (Evans and Mathur, 2005). This eliminates non-responses, giving higher item completion rates than mail surveys (Ilieva et al., 2002). Because of all the advantages described above, online surveys are being adopted as a useful instrument for nonmarket valuation (e.g. Tsuge and Washida, 2003; Ready et al., 2006; Stamieszkin et al., 2009; Wallmo and Edwards, 2008; Bliem and Getzner, 2010; Gillespie and Bennett, 2011; Rogers, 
2011). Moreover, some researchers have compared different survey approaches, and found no statistical difference between traditional methods (such as mail, telephone, intercept-mail, face to face) and online surveys (see Marta-Pedroso et al., 2007; Fleming and Bowden, 2009; Tait et al., 2009). One of the major potential weaknesses of online surveys (and the most often cited problem) is sample frame bias. Tait et al. (2009) explain that the non-random exclusion of individuals from the sample frame is one of the common problems, because not all households have access to the internet. This could restrict potential respondents to specific sectors of society, and the anticipated bias is toward higher income households who can afford a computer and internet at home (Evans and Mathur, 2005; Tait et al., 2009).

The survey was pre-tested by seeking volunteer responses from the Faculty of Sciences of VUW ( $\mathrm{N}=45)$. The pre-testing checked if there were clear instructions, determine if questions were logical, and had unbiased wording,(Gaddis, 1998; Evans and Mathur, 2005).

\subsubsection{The models}

\section{3. 3.1 Determinants of willingness to pay to the environmental levy (Yes/No)}

Two simple models were tested for respondents' answers to questions for both MRs. The first model analysed respondents' willingness to contribute to an environmental levy (yes/no). The second model was used to assess responses to the willingness to pay question (WTP AMOUNT).

The null models tested were:

$$
\begin{aligned}
& \mathrm{WTP}_{i}(\mathrm{YES} / \mathrm{NO})=f\left(\mathrm{H}_{i}+\mathrm{V}_{i}+\mathrm{IV}_{i}+\mathrm{A}_{i}+\mathrm{G}_{i}+\mathrm{Ch}_{i}+\mathrm{Ed}_{i}+\mathrm{Em}_{i}+\mathrm{I}_{i}+\mathrm{L}_{i}+\mathrm{BG}_{i}\right) \\
& \text { WTP AMOUNT }_{i}(\$)=f\left(\mathrm{~V}_{i+} \mathrm{IV}_{i}+\mathrm{A}_{i}+\mathrm{G}_{i}+\mathrm{Ch}_{i}+\mathrm{Ed}_{i}+\mathrm{Em}_{i}+\mathrm{I}_{i}+\mathrm{L}_{i}+\mathrm{BG}_{i}\right)
\end{aligned}
$$

Where:

$\mathbf{H}_{i}=$ Has the respondent visited the marine reserves (yes $=1 ;$ no $\left.=0\right)$ ?

$\mathbf{V}_{i}=$ Has the respondent previously visited the MR (less than five times; more than five times; no)?

$\mathbf{I V}_{\boldsymbol{i}}=$ Does the respondent intend to visit the MR (yes; likely; not sure; no)? 
$\mathbf{A}_{i}=$ Respondent's age $(<20 ; 21-30 ; 31-40 ; 41-50 ; 51-60 ;>60)$

$\mathbf{G}_{i}=$ Gender (Female; Male)

$\mathbf{C h}_{i}=$ Respondent has children or not

$\mathbf{E d}_{i}=$ Respondent's highest education level (Primary school; Secondary school;

Trade/technical qualification; Degree/professional qualification; Other)

$\mathbf{E m}_{i}=$ Respondent's employment status (Unemployed; Student; Employee; Self-employed; Retired)

$\mathbf{I}_{i}=$ Respondent's income (Less than $\$ 20,000 ; \$ 20,001$ to $\$ 40,000 ; \$ 40,001$ to $\$ 60,000$; $\$ 60,001$ to $\$ 80,000 ; \$ 80,001$ to $\$ 100,000$; More than $\$ 100,000$ )

$\mathbf{L}_{i}=$ Location (postcode)

$\mathbf{B G}_{i}=$ Does the respondent belong to a specific group (Local resident; Recreational fishermen;

Diver; Commercial fishermen; Environmental/conservation group; University; Other)?

All the explanatory variables used in the model were chosen based on the information gathered during the first part of this study (Chapter 1) and those variables that had been suggested as the most typical explanatory variables (Bateman et al., 2002; McCartney, 2006). In this null model I assumed that the respondent's willingness to contribute and their willingness to pay amount are positively related to:

(1) Respondents having visited the MR before.

(2) Respondents wanting to or intending to visit the MR.

(3) Age of respondent

(4) Respondent's sex

(5) Respondent's having children.

(6) Respondent's education level.

(7) Respondent's employment status

(8) Respondent's income 
(9) Respondent's residential proximity to the MR

(10) Respondent's belonging to a specific group, for example Environmental/conservation or University.

\subsubsection{Data analysis}

To determine the best model to use for the first equation, willingness to contribute, I used an information-theoretic approach (Green at el., 2012) using the Akaike Information Criterion (AIC), which is a criterion to decide which is the smallest model (fewest variables) with the best fit to the data. It can be used to compare models with different model fits. The model was calculated using Probit analysis on the chosen model. The analysis was conducted using R (Core Team 2012).

The second equation, willingness to pay amount (WTP AMOUNT), was tested using Spearman's rank correlation rho. For binary questions, it was analysed with a Mann-Whitney $\mathrm{U}$ test with a level of statistical significance level of 0.05 .

\subsubsection{Total value of indirect use values and non-uses values}

To estimate the total value of both MRs I tested if the population sample who answered these questionnaires matched the three areas analysed (suburb, city and region) based on the CENSUS information in 2006. I hoped to be able to extrapolate the mean value per household obtained in this study at both MRs to the suburb/city/region.

To extrapolate the mean value per MR, I assumed the same percentage of people that were willing to pay per MR occurred at the three areas analysed (suburb, city and region). The total value was determined by calculating the number of people willing to pay (in the relevant suburb/city region) and multiplying by the mean and median WTP estimated for each MR

\subsubsection{Assessment of MR ecosystem services}

To summarise important characteristics and trends in the important ecosystems services (ES) of both MRs I used the Millennium Ecosystem Assessment (MEA) (2005) approach. Ecosystem services are defined by the MEA as 'all benefits that people can obtain from ecosystems', and the MEA approach examines how ES changes are affecting and/or 
influencing human well-being. From this definition ES are categorised in four classes: (1) provisioning services such as food and water; (2) regulating services that affect climate, floods, and water quality; (3) cultural services that provide recreational, aesthetic, and spiritual benefits; and (4) supporting services such as soil formation, photosynthesis, and nutrient cycling. However, in this study I didn't include supporting services because it reflects how ES can affect other ES production. The spiritual values - particularly Maori values were beyond the scope of this study. Because my study areas (MRs) are small, I do not know how much contribution MRs are providing to support ES, therefore supporting services were not assessed.

From the information gathered for Chapter 3, and then through the course of this study I determined which ES corresponded to the three ESs classes at both MRs. Then, I determined the current impacts of MRs on those ES. Moreover, I estimated the potential future impact of MRs on those ES. To estimate the potential impact on food and water purification I based this on other MR cases with similar conditions in terms of habitats, management and activities.

Estimates of cultural ecosystem values were based on information gathered during my surveys in 2010 and 2011, plus many conversations with local communities, recreational divers and fishers, as well as with business owners. These conversations were conducted on different occasions through 2010 and 2012. The remaining ES are denoted by the '?' sign, which means 'uncertain', because for some ES it is very difficult to estimate potential trends. The reason lies in MRs being a part of non-controlled systems and there could be many natural or non-natural events such as La Niña, or El Niño that could affect the ES performance.

\subsubsection{Total economic value}

I also attempted to estimate the total economic value of each MRs in monetary terms. For commercial and recreational values I used rock lobster fisheries data again.

In order to estimate the potential recreational fishing value inside the reserve in monetary terms, I calculated the value of $500 \mathrm{~kg}$ of rock lobster biomass, which is based on the most recent estimate of recreational take of lobster being approximately $10 \%$ of commercial landings (Ministry of Fisheries, 2010). 
The value from diving activity was calculated based on information obtained from interviews with diving shop managers.

Therefore net benefits for commercial and recreational fishing, and diving were calculated by multiplying quantity $(Q)$ of activities carried out with the fishing cost and diving shop prices $(P)$ at each case, using equation 3.

$$
\boldsymbol{B}=\boldsymbol{Q P}
$$

\section{(Equation 3)}

Then the net benefits $(N B s)$ per year were calculated by subtracting all operational costs $(C)$ from the benefits:

$$
N B=B-C
$$

(Equation 4)

Non-use values were based on the information gathered through the contingent valuation method (see section methods 3.1).

The Education value was estimated based on the monetary value that any project spent on the educational programmes carried out in the marine reserve including the school education programme at the Island Bay Marine Education Centre. It was not possible to calculate some non-extractive activities, and some of the indirect use values so I used the categorical terms: 'High' - 'Medium'-'Low', to indicate possible values from a societal point of view.

\subsection{Results}

\section{Marine reserve values}

By following the TEV framework, I aimed to determine the direct and indirect values for each MR (Fig. 4.2). At KMR and TMR I could identify eight main value-categories that are described in Figure 4.2. These value categories are:

1. Commercial fishing benefits from MR (Direct use value - market based)

2. Nature-based tourism (Direct use value - market based)

3. Education (Direct use value - non-market based value)

4. Research (Direct use value - non-market based value)

5. Public recreation (Direct use value - non-market based value)

6. Recreational fishing benefit from MR (Direct use values - non-market based values)

7. Ecosystem health (Indirect use value - Use value)

8. Existence - Bequest value. 


\subsubsection{Value 1: Commercial and recreational fishing benefits that spill over from MR}

Rock lobsters biomass at both MRs is expected to increase from the 2010 values. At TMR biomass is predicted to increase from $5,000 \mathrm{~kg}$ to $12,795 \mathrm{~kg}$ by 2035 , and to $16,637 \mathrm{~kg}$ by the 2050. At KMR the biomass is predicted increase from $7,000 \mathrm{~kg}$ (2010) to $14,879 \mathrm{~kg}$ in the year 2035 , and to $17,813 \mathrm{~kg}$ by 2050 (Fig.4.3).

The potential dollar value of the biomass at TMR was estimated by using the export price for the rock lobster. Calculated values for TMR were NZ\$315,000 (2010/2011), NZ\$357,136 (2011/2012) and NZ\$374,830 (2012/2013). The corresponding values at KMR were NZ\$460,263 (2010/2011), NZ\$517,981(2011/2012), and NZ\$539,532 (2012/2013).

Therefore, the potential net benefit for commercial fishers calculated using equations 3 and 4 at the TMR was NZ\$124,494 and at KMR was NZ\$365,013.

\subsection{2 - Value 2: Nature based tourism}

There are six dive shops in the Wellington region, and five agreed to participate in this study. Two dive shops were located close to the TMR, one is located near to KMR location 2 in Figure 4.1).

Interviews were completed with the five dive shop owners and they all provided similar responses to many of the questions. All dive shop owners stated that there were no direct benefits to their businesses from the MR. In addition, they declared that the MRs do not contribute any additional benefits in terms of increased attractions for divers. However, all dive shop owners stated they regularly used the TMR when the weather permits. A different situation was found at KMR, where only the dive shop close to the MR regularly takes divers to Kapiti Island and to KMR.

Business owners consider that MR establishment does not make any difference to the number of activities and customers in their shops. One of the dive shops which was operating prior to the TMR establishment stated with respect to business changes after the TMR:

'The number of divers is pretty much the same, just where they are diving now is different. It is because they [divers] can't go and catch [fish] since the [TM] reserve was established...From an economic point of view, the real benefit for shops is going to be when 
people turn around and start to go into the reserve because of the life and the scenario...and that will change minds, but it hasn't come about yet, maybe in 20 years'. (Dive shop operating since 1985).

'Going to the TMR is not about making money, it is actually to get people to support and care for the marine environment. To go the TMR costs more money to me'. (Dive shop operating since 1998).

The activities carried out in the TMR and KMR include diving courses (from PADI Open Water to Rescue Diver), recreational diving, night dives and others (Table 4.1). However, these activities were all carried out in the areas before the MRs were established. But there are no complaints about the MRs, in fact the dive shop managers feel proud, happy and very supportive of both MRs. One of the shops stated:

'...for the shops it is not a matter of the economic benefits [from MRs], no matter what happens the shop will survive, and being profitable....we [shop's owners] all believe the [marine] reserve is a good thing, and no one or anyone [dive shops] will go into the [marine] reserve saying the reason I am going into the [marine] reserve or put effort into it, is because I will make a lot of money....that wasn't the point...the fact was over 25 years... I have been diving in these sites since 1975 and it being a different decline in life... and as the technology is getting better and better, and is becoming easy to learn to dive, then more divers come through, then will put a huge pressure on the resources, so something had to be done to protect the fish life' (Dive shop operating since 1985).

In order to promote the MRs, dive shops have advertisements on their web page about the MRs, where they describe all the attractions and benefits that the MRs offer to divers. Dive shops said that they offer all their customers the opportunity to go into the MRs, but the majority of customers do not want to go into the reserve, so they said they are not generating revenue for the dive shops. The reason not many people are interested in diving in the reserves was the same across all of the dive shops. It is because of the New Zealand culture regarding diving as a way to take food from the sea, in particular rock lobster, which is one of the most targeted species.

'We [New Zealanders] are obsessed with getting crayfish [rock lobster] particularly. People go out there if they don't get all the crayfish [rock lobster] then it is a bad dive! You can see 
whales, dolphins, but if you don't get a crayfish [rock lobster] it is a bad dive!' (Dive shop operating since 1998)

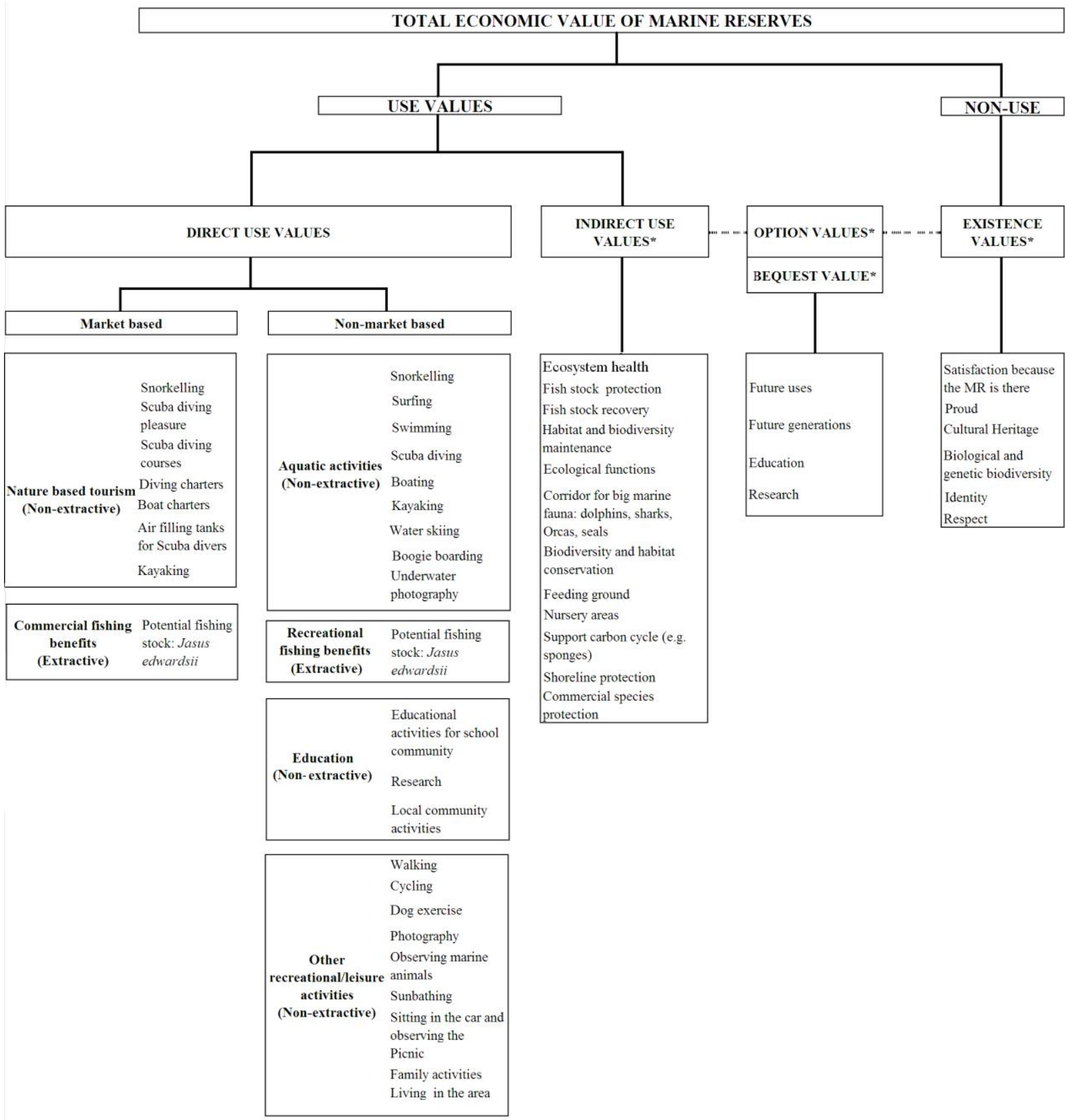

Figure 4.2: Total economic value of Taputeranga and Kapiti Marine Reserves. Option value and Bequest values were combined as they represent similar values in this case. 


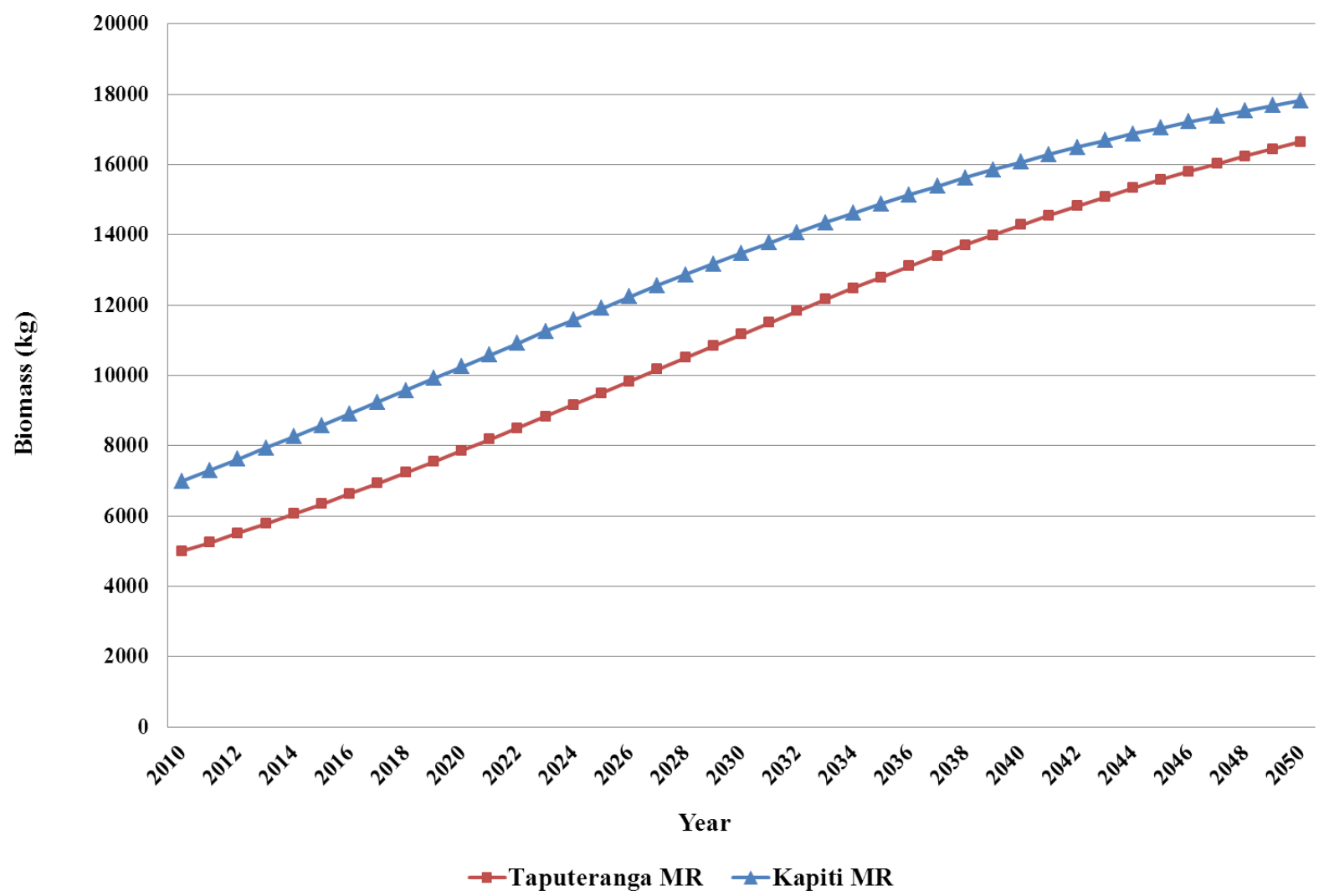

Figure 4.3: Projected Rock lobster biomass for Taputeranga and Kapiti Marine Reserves. The estimation was projected until 2050 by using information on harvest rates provided by commercial fishers.

Table 4.1: Activities conducted in the Taputeranga and Kapiti Marine Reserves by five dive shops. Dive shop numbers 1 and 2 corresponding to the dive shops close to the TMR; numbers 3 and 4 are the shops located in between TMR and KMR; and number 5 is the dive shop located closest to KMR. T: Activity conducted at Taputeranga Marine Reserve, K: Activity conducted at Kapiti Marine Reserve. (Wreck dive on the frigate HMNZS Wellington - F69 was sunk in 2005 to increase tourism in the area prior to the TMR establishment).

\begin{tabular}{lrrrrrr} 
& $\begin{array}{c}\text { Dive } \\
\text { course }\end{array}$ & $\begin{array}{c}\text { Recreational } \\
\text { dive }\end{array}$ & $\begin{array}{c}\text { Wreck } \\
\text { dive }\end{array}$ & $\begin{array}{c}\text { Night } \\
\text { dive }\end{array}$ & $\begin{array}{c}\text { Photography } \\
\text { course }\end{array}$ \\
\hline Dive shop 1 & $\mathrm{T}-\mathrm{K}$ & $\mathrm{T}-\mathrm{K}$ & $\mathrm{T}$ & $\mathrm{T}$ & $\mathrm{T}$ \\
Dive shop 2 & $\mathrm{T}$ & $\mathrm{T}-\mathrm{K}$ & $\mathrm{T}$ & $\mathrm{T}$ & - \\
Dive shop 3 & $\mathrm{T}-\mathrm{K}$ & $\mathrm{T}-\mathrm{K}$ & $\mathrm{T}$ & $\mathrm{T}$ & - \\
Dive shop 4 & $\mathrm{T}-\mathrm{K}$ & - & $\mathrm{T}$ & - & - \\
Dive shop 5 & $\mathrm{T}-\mathrm{K}$ & - & $\mathrm{T}$ & - & - \\
\hline
\end{tabular}


'In Wellington the culture of diving is strongly hunting... when we do a charter trip we ask the people what would you like to do, what is the dive objective, and they want some crayfishing [rock lobster fishing] or spearfishing... 95\% of our business is about hunting and gathering. This is not to say there is anything else to do as a diver, but it is just the culture in New Zealand'. (Dive shop operating since 2009)

'Is better to take people for Open Water [courses] here [TMR]. Because there is more life, so that is what will keep them [novel divers] diving. But I am not getting revenue for training. No one charges a realistic price. But the point is if you get these people [novel divers] staying diving you will get this money back and more. This is because it is important to get people in the reserve if you have good conditions' (Dive shop operating since 1985).

Pleasure dives are run by Dive Clubs, where each diver has to pay a membership fee (6 months - 1 year membership) plus a small cost per person per trip (between $\$ 10.00-\$ 15.00$ ) to pay the dive guide. Recreational dives (not dive clubs) and snorkelling trails are free of charge. Wreck dives occur once a week at TMR, and the price per person is around $\$ 70.00$ (boat charter and air fills included). Night dives are once a week, and cost around $\$ 40.00$ (dive guide costs $\$ 50.00$ ). The diving shops declared that the only revenue comes if the divers need to hire gear, because every dive shop has to pay one or two dive guides (depending on the number of divers). Pleasure trips at KMR are expensive due to the distance, and the price is between $\$ 100.00$ and $\$ 450.00$, which covers the diving (inside and outside the reserve), equipment, boat fuel (cost approximately $\$ 70.00)$ and skipper (\$50 - \$100).

The total number of dives conducted by the dive shops each year under good weather conditions conducted is approximately 748 in the TMR, and 205 at KMR (Table 4.2).

Despite the current equivocal stance of dive shops towards MRs, dive shop operators believe that the situation will change in their favour in the future, and they expect increased revenues from diving activities at the MRs. Specifically they believe this will occur at TMR, because it has easy access and is located close to Wellington city centre.

'I am located next to a resource [TMR] with a huge potential for tourism, local, national and international, for snorkelling, not for scuba diving, where anyone can do it, and you don't need to be qualified, but not now, this is the long term...'(Dive shop operating since 1985). 
Table 4.2: The amount of diving in a year per dive activity for each dive shop. The number of dives was calculated based on good weather conditions.

\begin{tabular}{ll}
\hline MARINE RESERVE & \\
\hline TMR & KMR \\
\hline
\end{tabular}

\begin{tabular}{|c|c|c|c|c|c|c|}
\hline & Courses* & Pleasure** & $\begin{array}{c}\text { Night } \\
\text { dive }^{* * * *}\end{array}$ & $\begin{array}{c}\text { Wreck } \\
\text { dive }\end{array}$ & Courses* & Pleasure** \\
\hline Dive shop 1 & 60 & 96 & 24 & & & 40 \\
\hline Dive shop 2 & 48 & 96 & 24 & 48 & & \\
\hline Dive shop 3 & 38 & 18 & 24 & & 8 & 6 \\
\hline Dive shop 4 & 96 & 96 & 24 & 48 & & 3 \\
\hline Dive shop 5 & 8 & & & & 88 & 60 \\
\hline
\end{tabular}

'I think the TMR over time will become like Goat Island [Leigh MR]. Because of the size, the number of fish, crayfish [rock lobster], easy dive shore, close to the city, it is easy for the dive leader, shallow water, less dangerous. The amount of fish life is about 10 times what it was before the MR [TMR]' (Dive shop operating since 2009).

\subsubsection{Value 3: Education}

Two educational programmes are operating at TMR. The first one is the Experiencing marine reserve programme (EMR). The second is part of the Marine Education Centre. The latter derives revenues from the TMR area, however, I could not get access to this information. Therefore the results below correspond only to the EMR programme.

At the KMR there is no school-based programme as in the TMR. The only available educational resource is on the DOC web page, published in 2006. This teacher guide includes a worksheet to be used by students. Through the worksheet, students learn about the KMR. For example, the history of use of the waters around Kapiti Island for fishing and whaling and the benefits of the marine reserve. There is a special resource kit that can be given to teachers/schools if requested. This kit includes general information about marine resources and marine reserves, consisting of fact sheets, photographs, a DVD, videos, books, species photo cards, posters and newspaper articles. 


\section{Experiencing Marine Reserves programme}

In 2002 a new educational programme was launched in Northland, New Zealand, entitled 'Experiencing Marine Reserves' (EMR) - http://www.emr.org.nz/. The main goal of EMR is a national school-based programme of experiential-learning, where students can learn about marine conservation by using marine reserves. To achieve this goal, EMR provides quality first-hand marine education experiences and initiatives to schools and communities throughout New Zealand. For this EMR takes the school community into MRs, then they are taken into a place outside the MR in order to permit them to experience the difference and generate their own judgments. The EMR programme is under the auspices of the Mountains to Sea Conservation Trust, of which the Department of Conservation (DOC) is a foundation partner. Since its introduction in Northland in 2002, this programme has spread throughout the country. The Tindall Foundation now also supports the programme's national expansion (www.emr.org.nz). This programme started in Wellington in 2007 under the umbrella of the Marine Education Centre. Nowadays (2013) EMR is funded by the Wellington City Council, WWF-NZ, and the Mountains to Sea Conservation Trust (via the Tindall Foundation support for national expansion). The EMR is currently running in five schools in Wellington city, including seven classes, making the Wellington programme one of the biggest in New Zealand. Of these five schools, two signed in 2011 to take part for first time in the 2012.

The EMR programme is described in figure 4.4. The total programme includes between 70 80 hours. Of these 70 hours, 20 hours are context time such as school meetings, schools visits, pool training, snorkelling inside and outside the MR, etc. Another 40 hours are of extra work (e.g. clean up, paperwork, etc.), plus 10 hours of co-coordination. The total cost of this programme for all schools and communities involved in 2012 was $\mathrm{NZ} \$ 14,159.77$. The programme cost per school is between NZ\$1,600.00 and NZ\$1,800.00, which depends on the number of students per class (average 30 students/class). The programme cost includes coordinator and co-coordinator salaries, library equipment, snorkelling gear, insurance, petrol, and other costs. This is financed by the EMR. The agreements with the schools are: (1) this programme runs during school times; (2) the school is responsible for obtaining snorkelling gear for their students by giving a donation, which costs NZ $\$ 2.00$ per/student for gear replacement if it is broken; and (3) encouraged to involve the wider school community (parents, students and teachers). 
Through conversations with the EMR coordinator, I could identify how the MR and the EMR are mutually beneficial. The benefits for the EMR would be difficult to achieve without the MR. These benefits are described in four different ways:

From the students' perspective: '[students] can get themselves out of the classroom, and get into the environment and get the experiences for kids - it is probably the best kind of learning they get. Also for many other experiences they would otherwise not have, plus the level of information and engagement that they get. From a learning perspective the kids get this quite amazing programme for almost nothing and they get this experience and this new learning'. Also the coordinator adds: 'I think the first step about caring about something, is knowing about it. The experience is the first step'.

From the teacher's perspective: 'it [EMR] is a new way to reach students, who otherwise can struggle to engage with traditional literacy or numeracy. As a teacher this kind of stuff is really invaluable'. As a teacher you are always looking for a way to engage your learners. From a teacher's experience, I know there are a bunch of kids who have really poor literacy, so they are really struggling to write. So from the MR experience they [students] would go back to the classroom to write the history about what did you do today? or what did you experience?. So we [teachers] will use it [the MR experience] as basis to run out other programmes such as maths, literacy or art. He [the teacher] got an amazing level of engagement from those kids, because what they [students] want to do is write about what the [students] see'.

From a parent's perspective: 'a lot of them get to engage in something that otherwise the will not be able to do. In a way that they can engage with kid's learning, and can have effects in terms of them [kids] learning and understanding what an MR is about, and the importance of them [MRs]'. 


\section{EMR process - Wellington}

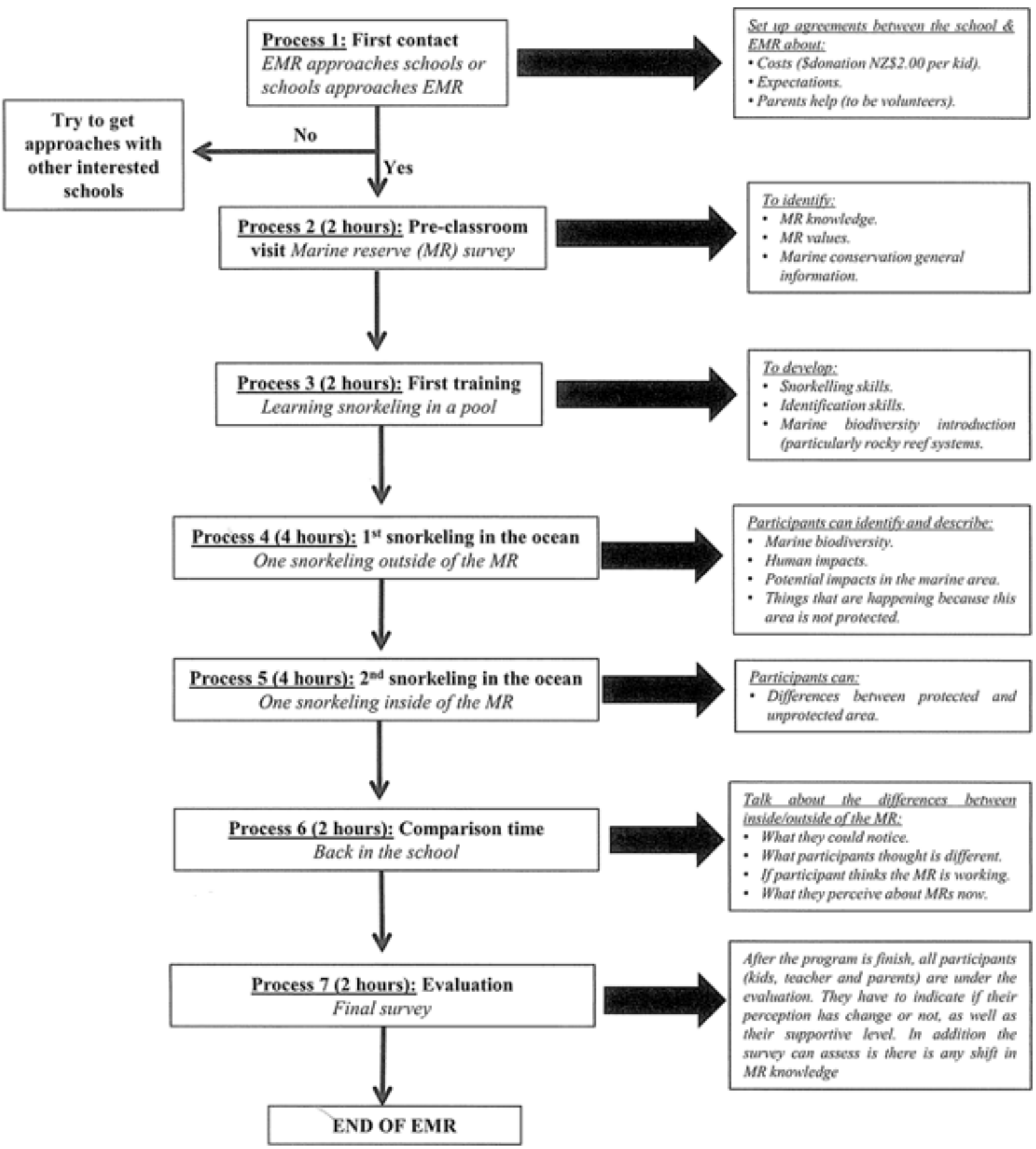

Figure 4.4: The diagram shows the Experiencing Marine Reserves (EMR) programme used in the Wellington region, which currently includes TMR. The time invested in Process 1 is variable and depends on each school. This diagram only shows the content time, and does not include non-content time that is approximately $40-60$ hours. Non-content time is everything related to the organization and preparation of material for the EMR programme. 
After the programme has finished, students are able to create conservation programmes to help the environment in a different ways. Some of the outcomes from the students are: signs to support the MR; short films, fundraising (to help Hector dolphins); web pages; books and media releases (see examples in the Appendix D).

\subsubsection{Value 4: Knowledge development \& Research}

Since the MRs were established, a total of 45 publications have been published that relate to the MRs (Appendix E). Fourteen different publications have result from work at KMR, which are mainly government reports $(\mathrm{N}=6)$. For the TMR, there have been twenty-five publications, led by journal publications $(\mathrm{N}=6)$ and research theses $(\mathrm{N}=6)$. In addition, a number of community newsletters have been produced since the TMR was established.

\subsubsection{Value 5: Public recreation}

All activities conducted at both reserves are described in Chapter 3.

\subsection{6 - Value 6: Rock lobster recreational fishing benefits from MR}

In 2011 Traville (2011) conducted a survey using non-conventional indicators of recreational rock lobster fishermen on the Wellington south coast to understand fishers' perceptions of how the Wellington south coast rock lobsters size and abundance have changed over the past 25 years. The author found that the general perception was that rock lobster abundance has decreased in open areas, especially during the past five years.

Survey of perceptions of the Taputeranga and Kapiti MRs completed in 2010 (see Chapter 1) showed that since the MRs were established fishermen perceive that rock lobster abundance and size have increased. This change has led to an increase in the occurrence of some activities inside of the MRs, for example underwater photography.

Moreover, interviews conducted in 2011 and 2012 in dive shops that were operating before the TMR and KMR were established show that the general perception is positive with respect to biodiversity recovery. At TMR the dive shop operators perceived that the number of rock 
lobsters has increased dramatically over the last two years (2010 to 2012). Shop managers consider this to be a big positive change compared with the years prior to the TMR being established, because the number of rock lobsters was so much less, and the opportunity to find a rock lobster during a dive was low, due to the high harvesting pressure in the area. At Kapiti the general perception by dive shop operators was that the KMR has increased rock lobster size and abundance compared to non-protected areas. This set of responses is thought to have occurred for two main reasons: (1) the KMR is far away from the city (Wellington), and it is difficult to get to giving the areas some degree of protection from extractive pressures (e.g. poaching); (2) because KMR is relatively old (20 years old), it is possible to see the changes not only inside, but also outside the MR where divers can find big rock lobsters as well.

From the point of view of recreational fishers, the reason why some people do not see the changes inside the reserve is because not enough people actually dive in the reserve, but only watch it from above the water line. They are expecting tangibles changes, but to experience that they should go into the reserve, and not only look at it from outside. One of the recreational divers stated:

'...compared with the past most of the people are supporters [of the MRs]...there are some people who are still antagonistic about the marine reserve. But these are old divers, they never dive, so they complain about anything!' (Diver since 1975)

In addition to the qualitative information, the net benefit calculated using equations 3 and 4 for recreational fishers at the TMR was NZ\$27,396 and at KMR was NZ\$39,420.

\subsection{7 - Value 7: Ecosystems health of marine reserves}

At KMR a snap-shot baseline survey was conducted immediately before the MR opened (Battershill et al. 1993). Subsequently, Pande \& Gardner (2012) established a key species list to determine differences in size and abundance. There are thirty-four of these species in total, including macroalgae, fishes and macro invertebrates.

At TMR during the period January 1998 to December 2000, Pande and Gardner (2009) conducted the baseline survey prior to the reserve's establishment. Using this baseline, the Department of Conservation and Victoria University of Wellington have been carrying out a 
monitoring programme since 2008, which includes macroalgae, rock lobster, paua, kina, and fish.

\subsubsection{Ecosystem health of Kapiti Marine Reserve:}

Monitoring conducted by Stewart and MacDiarmid (2003) between 1999-2000 found an increase in abundance and size of butterfish between inside/control (outside) areas. In addition, $25 \%$ of blue cod were larger in the reserve. Later, between 2003-2004 Struthers (2003), using baited underwater video, found significant differences (larger and more abundant) in blue cod between inside/outside of the KMR (Gardner and Struthers, 2013). Eddy (2011) conducted the most recent study of reef fish at KMR. For his PhD thesis, Eddy monitored individual sites at Kapiti Island between 1998 - 2010 using data from his own study and that of Pande (2001) that used underwater visual census techniques. Eddy found significant changes in size and biomass of reef fishes at KMR, principally in blue cod, butterfish and red moki, which showed an increase over the last 10 years of the 18 years the KMR had been established, indicating recovery of this targeted species. With respect to rock lobsters (RLs) (Jasus edwardsii), I found that RL has responded positively but slowly to protection at KMR in terms of population structure and abundance (CPUE; Chapter 5).

\subsubsection{Ecosystem health of Taputeranga Marine Reserve:}

Information based on subtidal (Byfield Thesis in progress) and intertidal (Tam Thesis in progress, Jones Thesis in progress) macroinvertebrates and macroalgae data, and Eddy (2011) indicates that the TMR habitats and communities, as well as RLs, paua and some fishes are responding positively to MR protection, permitting the TMR re-build populations and come back to a more natural state. I found that rock lobsters have responded quickly and positively to protection in terms of abundance (number) and biomass (kg) (CPUE; Chapter $5)$. 


\subsection{8 - Value 8: Existence - Bequest values.}

\subsubsection{1 - Respondents profiles}

The valuation questionnaire was completed by 131 respondents for TMR and 48 for KMR. The response rate was $74.4 \%$ at TMR, and $62.0 \%$ at KMR (equation 2). Table 4.1 contains the sample socio-demographics compared with the New Zealand Census 2006 data for: (a) those suburbs surveyed; (b) city (Wellington City and Kapiti Coast); and (c) the Wellington region. The largest group of respondents at TMR was between 21-30 years old (35.88 \%) and at KMR 41-50 years old (29.17\% of all respondents). Whilst $45 \%$ of those respondents at TMR were male, and 55\% were female, at KMR $62.5 \%$ were male, and $37.5 \%$ were female. At both MRs the majority of respondents stated they have a degree or professional qualification ( $\sim 85 \%$ at TMR, and $\sim 79 \%$ at KMR). However, annual household income (before tax) differed between respondents at the two MRs. The TMR respondents typically had much higher incomes levels (40.6\% had income greater than $\$ 100,000)$, whereas at KMR, $55 \%$ of respondents declared incomes between $\$ 40,001$ and $\$ 80,000$. The numbers of respondents with, and without children, at KMR were similar, but at Taputeranga MR more respondents had children ( $69 \%)$ than did not have children $(\sim 31 \%)$. At both MRs over half of all respondents were located close to the MR (Fig. 4.2) ( $\sim 54 \%$ at TMR, and $\sim 57 \%$ at KMR).

With respect to the similarities between my sample size in terms of suburbs, city and region with data from CENSUS (2006) at each MR, the respondents at TMR were statistically similar to the population in the suburbs, city and region in terms of 'gender' (Suburbs: $\chi^{2}=$ 2.902, $\mathrm{DF}=1, \mathrm{p}=0.089$; Wellington city: $\chi 2=2.712, \mathrm{DF}=1, \mathrm{p}=0.100$; Region: $\chi 2=1.474$, $\mathrm{DF}=1, \mathrm{p}=0.225)$.

At KMR gender ratio was statistically similar amongst the suburbs, the Wellington city and region (Suburbs: $\chi 2=0.808, \mathrm{DF}=1, \mathrm{p}=0.369$; Wellington city: $\chi 2=1.363, \mathrm{DF}=1, \mathrm{p}=$ 0.243; Region: $\chi^{2}=3.00, \mathrm{DF}=1, \mathrm{p}=0.083$ ). The variable 'age' was statistically similar amongst suburbs and the city (Suburbs: $\chi^{2}=9.067, \mathrm{DF}=7, \mathrm{p}=0.248$; Wellington city: $\chi^{2}=$ $10.3, \mathrm{DF}=7, \mathrm{p}=0.172)$, while the variable 'location' was similar among the suburbs $\left(\chi^{2}=\right.$ $0.673, \mathrm{DF}=2, \mathrm{p}=0.714)$. The rest of the variables compared at both MRs were statistically different between my sample and the suburbs surveyed, city and region $(\mathrm{p}<0.05)$ (Table 4.3). 


\section{4. 8. 2 - Willingness to pay an environmental levy}

Respondents were asked if they were willing to pay a new annual environmental levy to fund management of Taputeranga or Kapiti Marine Reserve. At both MRs the majority of respondents agreed to contribute ( $\sim 62 \%$ at TMR, and $\sim 69 \%$ at KMR) (Fig. 4.5). The main reasons given by respondents who stated they would not contribute were 'I pay income tax and GST and am opposed to any additional payments to central government' (54\% at TMR and $57 \%$ at KMR), followed by 'I believe the government should seek funding from alternative sources' (8\% at Taputeranga, and 4\% at Kapiti MRs) (Fig. 4.6).

Table 4.3: Sample and population socio-demographics characteristics.

\begin{tabular}{|c|c|c|c|c|c|c|c|c|c|}
\hline \multirow[b]{3}{*}{ Variable } & \multicolumn{2}{|c|}{ Sample } & \multirow[b]{2}{*}{$\begin{array}{l}\text { Suburb } \\
\text { surveyed } \\
(\%)\end{array}$} & \multirow[b]{2}{*}{$\begin{array}{l}\text { Wellington } \\
\text { city }(\%)\end{array}$} & \multicolumn{2}{|c|}{$\overline{\text { Sample }}$} & \multirow[b]{2}{*}{$\begin{array}{l}\text { Suburb } \\
\text { surveyed } \\
(\%)\end{array}$} & \multirow[b]{2}{*}{$\begin{array}{l}\text { Kapiti } \\
\text { coast } \\
(\%)\end{array}$} & \multirow[b]{2}{*}{$\begin{array}{l}\text { Wellington } \\
\text { region }\end{array}$} \\
\hline & $\begin{array}{l}\text { Tapu } \\
\text { MR }\end{array}$ & Iteranga & & & \multicolumn{2}{|c|}{ Kapiti MR } & & & \\
\hline & $N$ & $\%$ & & & $N$ & $\%$ & & & \\
\hline \multicolumn{10}{|l|}{ Gender } \\
\hline Female & 131 & $54.96 \%$ & $47.53 \%$ & $47.77 \%$ & 48 & $37.50 \%$ & $43.93 \%$ & $45.87 \%$ & $49.66 \%$ \\
\hline Male & 131 & $45.04 \%$ & $52.47 \%$ & $52.22 \%$ & 48 & $62.50 \%$ & $56.07 \%$ & $54.09 \%$ & $50.34 \%$ \\
\hline \multicolumn{10}{|l|}{ Age } \\
\hline$<20$ & 131 & $3.05 \%$ & $3.05 \%$ & $8.38 \%$ & 48 & $4.17 \%$ & $8.80 \%$ & $6.81 \%$ & $2.00 \%$ \\
\hline $21-30$ & 131 & $35.88 \%$ & $35.88 \%$ & $23.41 \%$ & 48 & $10.42 \%$ & $10.36 \%$ & $9.44 \%$ & $19.36 \%$ \\
\hline $31-40$ & 131 & $14.50 \%$ & $14.50 \%$ & $23.12 \%$ & 48 & $14.58 \%$ & $16.36 \%$ & $16.24 \%$ & $20.97 \%$ \\
\hline $41-50$ & 131 & $20.61 \%$ & $20.61 \%$ & $17.66 \%$ & 48 & $29.17 \%$ & $18.53 \%$ & $16.69 \%$ & $20.42 \%$ \\
\hline $51-60$ & 131 & $11.45 \%$ & $11.45 \%$ & $12.78 \%$ & 48 & $16.67 \%$ & $15.71 \%$ & $15.39 \%$ & $15.92 \%$ \\
\hline $61-70$ & 131 & $11.45 \%$ & $11.45 \%$ & $7.23 \%$ & 48 & $8.33 \%$ & $10.79 \%$ & $14.66 \%$ & $10.54 \%$ \\
\hline $71-80$ & 131 & $2.29 \%$ & $2.29 \%$ & $4.83 \%$ & 48 & $16.67 \%$ & $11.85 \%$ & $13.52 \%$ & $6.80 \%$ \\
\hline$>80$ & 131 & $0.76 \%$ & $0.76 \%$ & $2.60 \%$ & 48 & $0.00 \%$ & $7.60 \%$ & $7.25 \%$ & $3.99 \%$ \\
\hline \multicolumn{10}{|l|}{ Education } \\
\hline No Qualification & 131 & $0.76 \%$ & $13.36 \%$ & $11.57 \%$ & 42 & $0.00 \%$ & $5.04 \%$ & $23.10 \%$ & $19.34 \%$ \\
\hline Secondary school & 131 & $5.34 \%$ & $33.55 \%$ & $34.80 \%$ & 42 & $9.52 \%$ & $83.60 \%$ & $34.45 \%$ & $34.61 \%$ \\
\hline Trade/Technical qualification & 131 & $3.82 \%$ & $17.43 \%$ & $17.38 \%$ & 42 & $7.14 \%$ & $6.49 \%$ & $19.66 \%$ & $18.17 \%$ \\
\hline Degree/propfessional qualification & 131 & $84.73 \%$ & $24.31 \%$ & $26.65 \%$ & 42 & $78.57 \%$ & $2.25 \%$ & $9.43 \%$ & $16.34 \%$ \\
\hline Other & 131 & $5.34 \%$ & $11.34 \%$ & $9.59 \%$ & 42 & $4.76 \%$ & $2.62 \%$ & $13.36 \%$ & $11.54 \%$ \\
\hline \multicolumn{10}{|l|}{ Children } \\
\hline With & 131 & $69.05 \%$ & $78.16 \%$ & $79.83 \%$ & 48 & $46.56 \%$ & $83.08 \%$ & $83.46 \%$ & $81.08 \%$ \\
\hline Without & 131 & $30.95 \%$ & $21.84 \%$ & $20.17 \%$ & 48 & $53.44 \%$ & $16.92 \%$ & $16.54 \%$ & $18.92 \%$ \\
\hline \multicolumn{10}{|l|}{ Annual household income } \\
\hline Less $\$ 20,000.00$ & 131 & $16.03 \%$ & $38.45 \%$ & $38.03 \%$ & 42 & $7.14 \%$ & $52.72 \%$ & $36.28 \%$ & $43.72 \%$ \\
\hline$\$ 20,000-\$ 40,000$ & 131 & $13.74 \%$ & $28.16 \%$ & $28.49 \%$ & 42 & $9.52 \%$ & $28.51 \%$ & $51.03 \%$ & $30.44 \%$ \\
\hline$\$ 40,001-\$ 60,000$ & 131 & $11.45 \%$ & $15.05 \%$ & $15.52 \%$ & 42 & $28.57 \%$ & $9.90 \%$ & $6.83 \%$ & $13.04 \%$ \\
\hline$\$ 60,001-\$ 80,000$ & 131 & $10.69 \%$ & $7.34 \%$ & $7.64 \%$ & 42 & $26.19 \%$ & $4.23 \%$ & $2.90 \%$ & $5.85 \%$ \\
\hline$\$ 80,001-\$ 100,00$ & 131 & $7.63 \%$ & $4.20 \%$ & $4.24 \%$ & 42 & $16.67 \%$ & $1.90 \%$ & $1.32 \%$ & $2.97 \%$ \\
\hline More than 100,000 & 131 & $40.46 \%$ & $6.79 \%$ & $6.08 \%$ & 42 & $11.90 \%$ & $2.74 \%$ & $1.64 \%$ & $3.99 \%$ \\
\hline \multicolumn{10}{|l|}{ Location } \\
\hline 1 (Closest to the marine reserve) & 131 & $54.20 \%$ & $41.23 \%$ & - & 48 & $57.14 \%$ & $58.18 \%$ & - & - \\
\hline $\begin{array}{l}2 \text { (Middle distancefrom the marine } \\
\text { reserve) }\end{array}$ & 131 & $16.03 \%$ & $34.87 \%$ & - & 48 & $26.19 \%$ & $29.06 \%$ & - & - \\
\hline 3 (Farthest from marine reserve) & 131 & $29.77 \%$ & $23.90 \%$ & - & 48 & $16.67 \%$ & $12.76 \%$ & - & - \\
\hline
\end{tabular}

$* p>0.05$ 


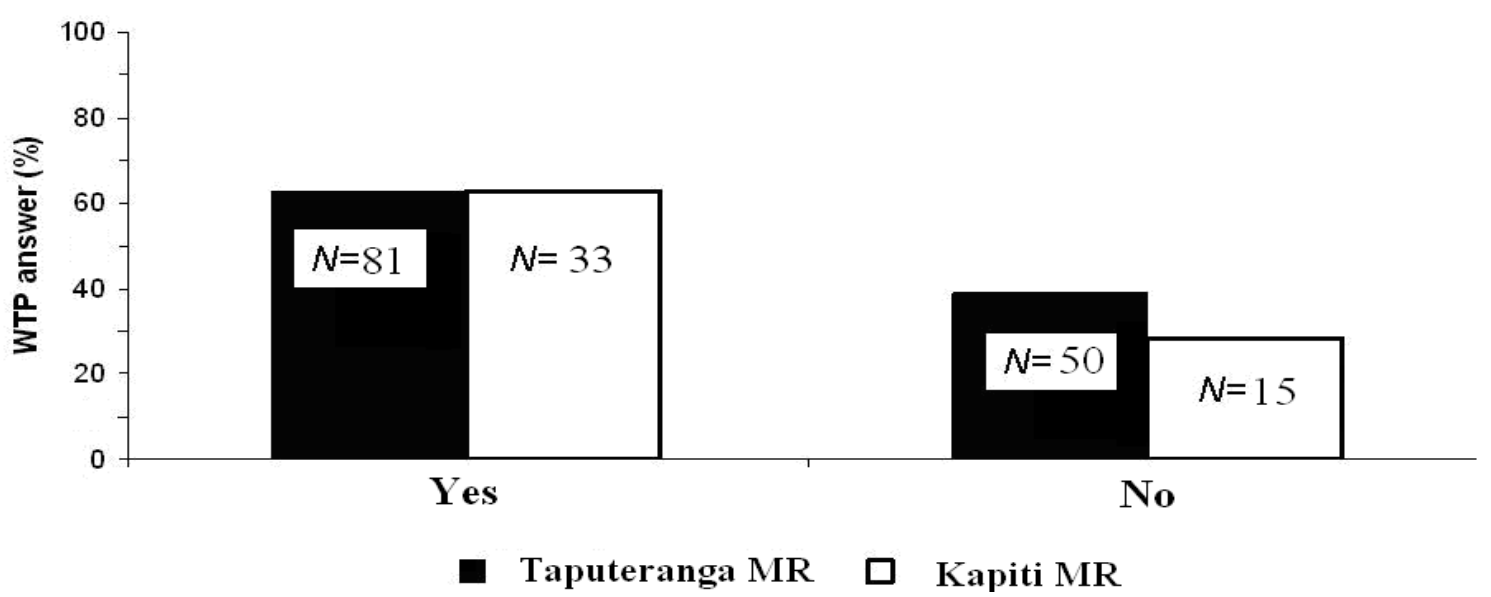

Figure 4.5: Proportion of respondents willing to pay a new environmental levy proposed for this study.

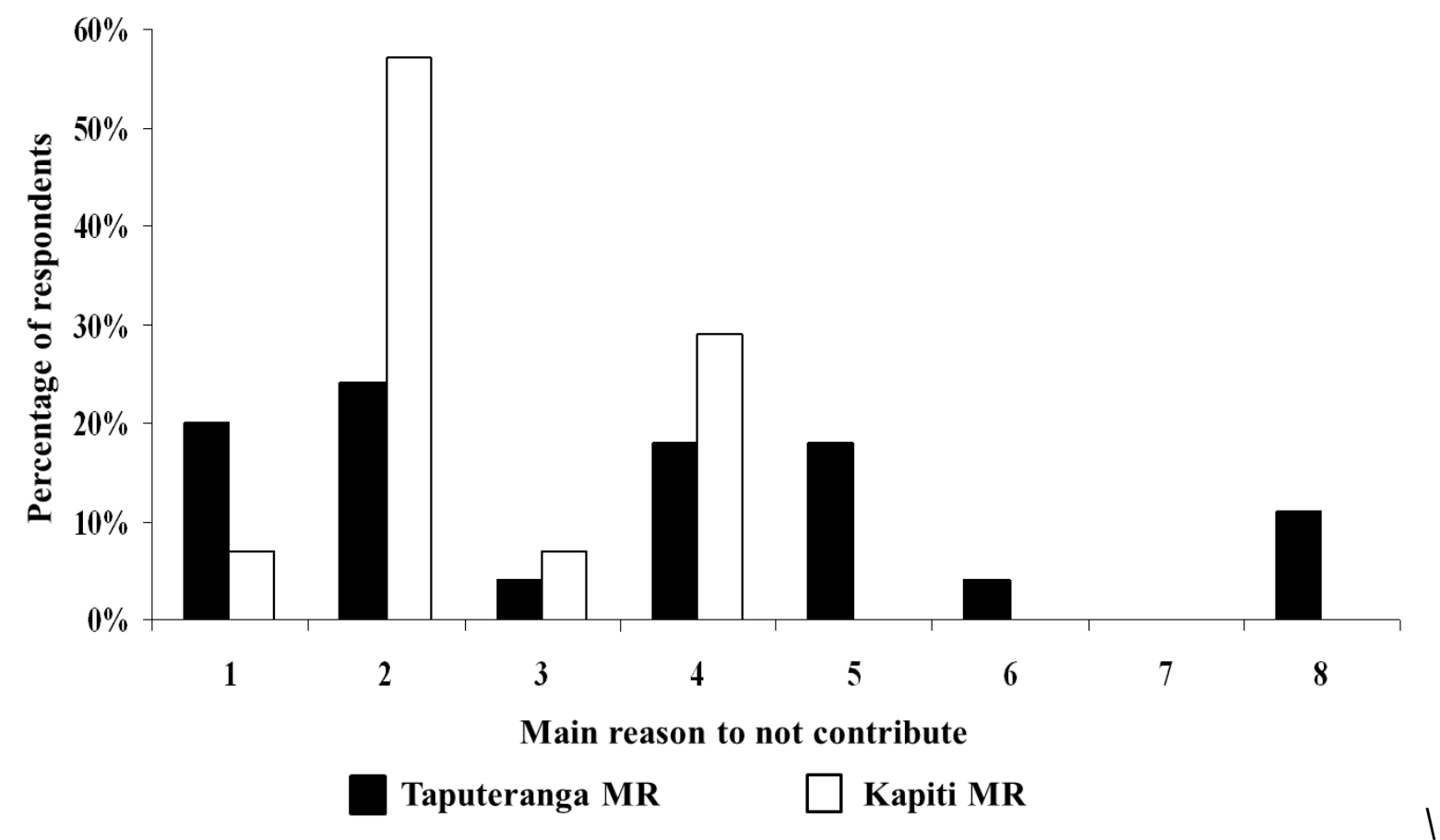

Figure 4.6: Main reasons provided by respondents from TMR and KMR for declining to contribute to a new annual environmental levy proposed in this study. Numbers on the $x$ axis are coded as follows: (1) I support the idea, but I cannot afford to pay based on my financial circumstances. (2) I pay income tax and GST and am opposed to any additional payments to central government. (3) I believe the marine reserve is already well managed. (4) I believe the government should seek funding from alternative sources. (5) I do not believe that paying such an amount will result in improved conservation of the marine reserve. (6) Only people who will receive direct benefits from the existence of the marine reserve should pay for the fund. (7) Conservation is not an important issue for me. (8) I do not believe if I give my money to a government fund, it will be used for that purpose. 
With respect to the second question, which was how much they were willing to pay annually per household, at KMR responses ranged between $\$ 0.00$ and $\$ 120.00$, while at TMR the responses were from $\$ 0.00$ and to more than $\$ 500.00$, however responses in excess of $\$ 200$ were discarded from the analysis. The mean WTP amount at TMR was $\$ 61.54$, and at KMR $\$ 31.45 \mathrm{NZ}$ (Table 4.4). The possible reason why WTP was higher with TMR than KMR is because TMR is located close to a big city (New Zealand's capital), where the population who live there have higher salaries, whereas at KMR many of the population are retired, and therefore, have lower incomes.

Table 4.4: Descriptive statistics of willingness to pay (NZ\$) amount at both marine reserves.

\begin{tabular}{lccc}
\cline { 2 - 4 } & \multicolumn{3}{c}{ WTP amount (\$) } \\
\cline { 2 - 4 } & Mean & Median & SD \\
\hline Taputeranga MR & $\$ 61.54$ & $\$ 30.00$ & \pm 102.10 \\
Kapiti MR & $\$ 31.45$ & $\$ 20.00$ & \pm 34.82 \\
\hline
\end{tabular}

At the KMR the same percentages of male and female respondents were willing to contribute, and their willingness to pay amount was similar $(\sim 41.00)$. But at TMR, while similar percentage of males and females were willing to pay, males were willing to pay more (mean of \$103.65) than females (mean of \$70.12). For respondents at TMR willingness to pay generally increased with age and the largest WTP value was for respondents aged between 51-60 years (mean of \$113.18). Respondents with children were more willing to contribute, and to pay a higher amount than people without children at both MRs. Respondents at Kapiti with a secondary education had the highest mean willingness to pay, but for Taputeranga, the highest amount was for respondents with a degree or professional qualification $(\$ 150.00)$. People who belong to an environmental/conservation group, or are involved with, universities or with aquatic activities (fishing and diving) were willing to pay larger amounts than are other respondents (Table 4.5). 
Table 4.5: Breakdown of respondents' socio-demographics and their WTP (Yes/No) and WTP amount (NZ\$) and standard errors (SE). Asterisks show cases where it was not possible to calculate SE due to low numbers of respondents.

\begin{tabular}{|c|c|c|c|c|c|c|c|c|}
\hline & \multicolumn{8}{|c|}{ Marine reserve } \\
\hline & \multicolumn{4}{|c|}{ Taputeranga } & \multicolumn{4}{|c|}{ Kapiti } \\
\hline & Yes $(\%)$ & WTP (\$) & SE & No $(\%)$ & Yes $(\%)$ & WTP (\$) & SE & No $(\%)$ \\
\hline \multicolumn{9}{|c|}{ Gender } \\
\hline Male & 63 & 103.65 & 11.59 & 37 & 67 & 40.94 & 5.33 & 33 \\
\hline Female & 61 & 70.12 & 9.10 & 39 & 67 & 41.33 & 6.44 & 33 \\
\hline \multicolumn{9}{|l|}{ Age } \\
\hline$<20$ & 50 & 75.00 & 5.95 & 50 & 50 & 30.00 & * & 50 \\
\hline $21-30$ & 55 & 61.93 & 9.91 & 45 & 60 & 50.00 & 7.80 & 40 \\
\hline $31-40$ & 47 & 112.24 & 12.33 & 53 & 71 & 40.00 & 6.06 & 29 \\
\hline $41-50$ & 63 & 99.59 & 10.86 & 37 & 57 & 39.38 & 5.63 & 43 \\
\hline $51-60$ & 69 & 113.18 & 12.30 & 31 & 75 & 29.33 & 4.21 & 25 \\
\hline $61-70$ & 80 & 91.00 & 7.76 & 20 & 75 & 43.33 & 7.02 & 25 \\
\hline $71-80$ & 100 & 33.37 & 5.37 & 0 & 75 & 100.00 & * & 25 \\
\hline$>80$ & 100 & 20.00 & * & 0 & 0 & 0 & 0 & 0 \\
\hline
\end{tabular}

Education

No Qualificatio

Secondary school

Trade/Technical qualification

Degree/propfessional qualific:

Other

Children

With

Without
* $*$

$47.50 \quad 5.76$

$\begin{array}{lll}60 & 133.33 & 10.20\end{array}$

$\begin{array}{lll}57 & 150.00 & 15.29\end{array}$

$\begin{array}{lll}60 & 82.62 \quad 10.30\end{array}$

72

53

$91.03 \quad 10.51$

$78.79 \quad 10.50$

28

47

Current employment status

Unemployed

Student

Employee

Self-employed

Retired

Homemaker

Annual household income Less $\$ 20,000.00$ $\$ 20,000$ - $\$ 40,000$

$\$ 40,001-\$ 60,000$

$\$ 60,001-\$ 80,000$

$\$ 80,001$ - $\$ 100,00$

More than 100,000

Belong to a group

0

1

2

3

4

5
6

Location

1 (Closest to the marine reserve)

2 (Middle distancefrom the marine reserve)

3 ( Farthest from marine

reserve)

\section{0}

62

56

67

91

50

57

56

56
73

57

50

66

58

50

70

100

20

0
100
23.37

$96.03 \quad 11.38$

$139.00 \quad 12.07$

$70.21 \quad 8.42$

200.00 *

$38.76 \quad 5.35$

$36.01 \quad 5.36$

$65.00 \quad 6.06$

$128.13 \quad 12.73$

$60.00 \quad 6.27$

$115.86 \quad 11.72$

$78.01 \quad 10.27$

$50.00 *$

$74.93 \quad 9.23$

$138.78 \quad 15.55$

100.00

$0 \quad 0$

$132.22 \quad 12.43$

$\begin{array}{rrrr}0 & 0 & 0 & 0 \\ 100 & 70.00 & 5.97 & 0 \\ 67 & 37.50 & 6.12 & 33 \\ 64 & 37.90 & 5.74 & 36 \\ 50 & 0.00 & * & 50\end{array}$

$\begin{array}{llll}69 & 43.50 & 5.81 & 31\end{array}$

$\begin{array}{llll}62 & 35.13 & 5.98 & 38\end{array}$

$\begin{array}{rrrr}0 & 0 & 0 & 100 \\ 80 & 45.00 & 7.12 & 20 \\ 58 & 34.64 & 5.29 & 42 \\ 77 & 39.00 & 5.96 & 23 \\ 100 & 66.67 & 5.37 & 0 \\ 0 & 0 & 0 & 100\end{array}$

$\begin{array}{rrrr}75 & 50.00 & 7.80 & 25 \\ 60 & 51.67 & 6.89 & 40 \\ 100 & 53.75 & 5.91 & 0 \\ 50 & 30.00 & * & 50 \\ 58 & 32.29 & 5.62 & 42 \\ 67 & 37.50 & 5.37 & 33\end{array}$

$\begin{array}{llll}87 & 41.54 & 6.12 & 13\end{array}$

$\begin{array}{llll}50 & 30.00 & 5.32 & 50\end{array}$

$\begin{array}{llll}100 & 70.00 & 8.41 & 0\end{array}$

$\begin{array}{llll}70 & 38.00 & 5.52 & 30\end{array}$

$\begin{array}{lrrr}0 & 0 & 0 & 100\end{array}$

$\begin{array}{llll}60 & 40.00 & 4.16 & 40\end{array}$

$\begin{array}{llll}50 & 25.00 \quad * & 50\end{array}$

\begin{tabular}{rrrrrrrr}
65 & 99.53 & 11.20 & 35 & 69 & 31.91 & 5.35 & 31 \\
55 & 77.30 & 10.29 & 45 & 72 & 41.54 & 5.84 & 28 \\
67 & 76.15 & 9.75 & 33 & 50 & 65.00 & 6.60 & 50 \\
\hline
\end{tabular}


A large percentage of respondents for both MRs had already heard about the Taputeranga or Kapiti MR. The majority of respondents stated they had visited the MRs more than five times (both MRs). Those respondents were willing to pay an average amount of $\$ 72.52$ at the TMR, and $\$ 45.92$ at the KMR. People who stated they are likely to visit the MR in the future, are willing on average to pay $\$ 40.00$ towards the new conservation levy. A majority of respondents believed that the establishment of these MRs was a good decision (95\% at TMR, and $100 \%$ at KMR), and were willing to pay mean amounts of $\$ 85.44$ (TMR), and $\$ 41.11$ (KMR) (Table 4.6).

Table 4.6: Breakdown of respondents' awareness and their WTP (Yes/No) and WTP amount (NZ\$) and standard errors (SE). Asterisks show cases where was not impossible to calculate SE due to low number of respondents.

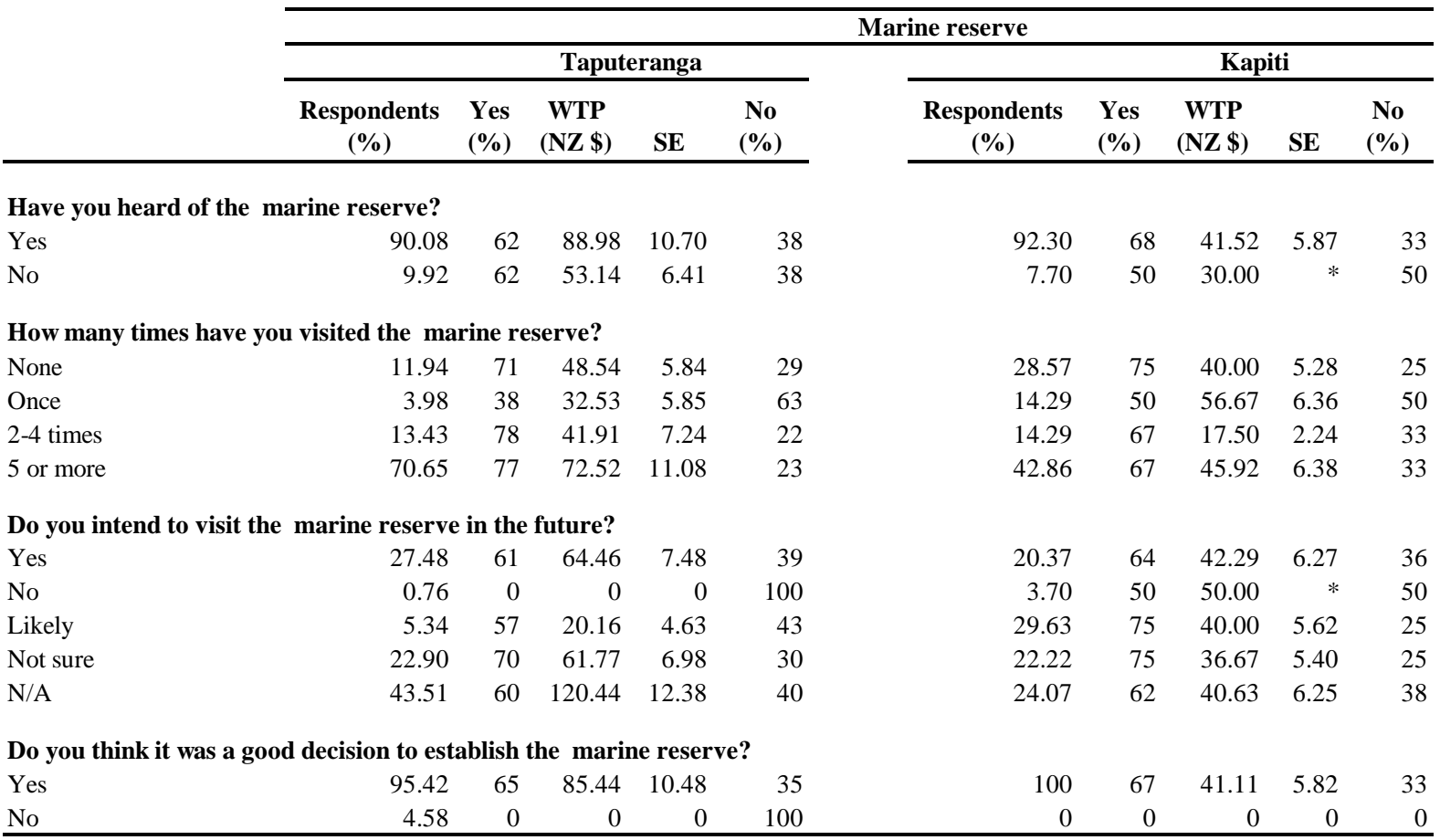

Socio-demographic data for my sample compared to corresponding data for suburb, city (Wellington City and Kapiti Coast) and Wellington Region did not closely match for most of the variables analysed (Table 4.7). Despite my socio-demographic sample not matching very closely to the three areas analysed (suburb, city and region) I have, with caution, used the data to estimate the total value of indirect use values and non-uses values by extrapolating the values per household obtained in this study at both MRs together with the CENSUS information for 2006. For the analysis I discarded the percentage of people who were not willing to contribute, which was $38 \%$ at the TMR and $31 \%$ at the KMR. Consequently, the 
total value was calculated using the $62 \%$ and $69 \%$ of people of willing to contribute at Wellington city and Kapiti coast, respectively, for the three areas analysed (suburb, city and region). Therefore, based on mean (and median) WTP values obtained at each MR, the total value at the suburb level in 2011 was $\$ 917,089$ (median $\$ 447,070$ ) for TMR and $\$ 512,154$ (median $\$ 325,694$ ) for KMR. At the city level for TMR the value calculated was $\$ 5,091,491$ (median $\$ 2,482,040$ ) and for KMR \$727,900 (median \$462,893). At the regional level at TMR the value was $\$ 13,372,189$ (median $\$ 6,518,779$ ) and for KMR the value was $\$ 7,605,418$ (median $\$ 4,836,514$ ).

Table 4.7: Comparison between socio-demographic data for my sample and the three areas analysed: suburb, city (Wellington City and Kapiti Coast) and Wellington Region.

\begin{tabular}{|c|c|c|c|c|c|c|c|c|c|c|c|c|}
\hline \multirow{3}{*}{$\begin{array}{l}\text { Demographic } \\
\text { variables }\end{array}$} & \multicolumn{6}{|c|}{ Kapiti marine reserve } & \multicolumn{6}{|c|}{ Taputeranga marine reserve } \\
\hline & \multicolumn{2}{|c|}{ Suburb } & \multicolumn{2}{|l|}{ City } & \multicolumn{2}{|c|}{$\begin{array}{c}\text { Wellington } \\
\text { region }\end{array}$} & \multicolumn{2}{|c|}{ Suburb } & \multicolumn{2}{|l|}{ City } & \multicolumn{2}{|c|}{$\begin{array}{r}\text { Wellington } \\
\text { region }\end{array}$} \\
\hline & p-value & DF & p-value & DF & p-value & DF & p-value & DF & p-value & DF & p-value & DF \\
\hline Gender & $0.369 *$ & 1 & $0.243 *$ & 1 & $<0.0001$ & 1 & $0.0885^{*}$ & 1 & $0.0996 *$ & 1 & $0.2247 *$ & 1 \\
\hline Age & $0.248 *$ & 7 & $0.172 *$ & 7 & $<0.0001$ & 7 & 0.0027 & 7 & 0.00081 & 7 & 0.0001 & 7 \\
\hline Education & $<0.0001$ & 4 & $<0.0001$ & 4 & $<0.0001$ & 4 & $<0.0001$ & 4 & $<0.001$ & 4 & $<0.0001$ & 4 \\
\hline Children & $<0.0001$ & 1 & $<0.0001$ & 1 & $<0.0001$ & 1 & 0.0088 & 1 & 0.0015 & 1 & 0.0003 & 1 \\
\hline $\begin{array}{l}\text { Annual } \\
\text { household }\end{array}$ & & & & & & & & & & & & \\
\hline income & $<0.0001$ & 5 & $<0.0001$ & 5 & $<0.0001$ & 5 & $<0.0001$ & 5 & $<0.0001$ & 5 & $<0.0001$ & 5 \\
\hline Location & $0.714^{*}$ & 2 & - & - & - & - & $<0.0001$ & 2 & - & - & - & - \\
\hline
\end{tabular}

\subsection{3 - Determinants of Willingness to pay to the environmental levy (Yes/No)}

In order to explain whether or not respondents were willing to contribute to a new environmental levy, the roles of eleven explanatory variables were analysed. In the first analyses the Akaike Information Criterion (AIC) reduced the explanatory variables to only the most explicative variables for this model (WTP Yes/No), which were Belong to a group $\left(\mathrm{BG}_{i}\right)$, and have children $\left(\mathrm{Ch}_{i}\right)$ for the TMR case, and have Children $\left(\mathrm{Ch}_{i}\right)$, Age $\left(\mathrm{A}_{i}\right)$ and Belong to a group $\left(\mathrm{BG}_{i}\right)$ for the KMR case.

Those variables were used in a Probit model, which showed that $\mathrm{Ch}_{i}$ is the most significant variable $(p<0.01)$ explaining TMR responses and for $\mathrm{KMR}, \mathrm{BG}_{i}$ was the most significant variable $(p<0.001)$ explaining Willingness to contribute to a levy response (Table 4.8). 
Table 4.8: Variables influencing willingness to pay an environmental levy (Yes/No) at Taputeranga and Kapiti MRs.

\begin{tabular}{|c|c|c|c|c|c|c|}
\hline & \multicolumn{6}{|c|}{ Marine reserve } \\
\hline & \multicolumn{3}{|c|}{ Taputeranga } & \multicolumn{3}{|c|}{ Kapiti } \\
\hline & Df & F value & P> IzI & Df & F value & P> IzI \\
\hline Age & 3 & 0.4202 & 0.73882 & 3 & 1.4559 & 0.24388 \\
\hline Children & 1 & 5.3374 & $0.02254 *$ & 1 & 0.0083 & 0.92807 \\
\hline Group & 3 & 2.225 & 0.08863 & 3 & 5.2156 & $0.004521 * *$ \\
\hline
\end{tabular}

\section{4.8. 4 - Determinants of willingness to pay amount (\$)}

The regression results from TMR show that the variables Employment and Income are positively correlated with the amount that respondents are Willing To Pay. However, at KMR I did not find a positive correlation with any of the variables analysed, but there was a negative correlation between the variable Education and WTP (\$). The rest of the variables analysed were non-significant at explaining the second dependent variable (WTP amount) (Table 4.9).

Table 4.9: Variables influencing WTP amount responses at Taputeranga and Kapiti MRs.

\begin{tabular}{lrrrrrr} 
& \multicolumn{2}{c}{ Taputeranga MR } & & \multicolumn{3}{c}{ Kapiti MR } \\
\cline { 2 - 3 } \cline { 5 - 6 } Variables & p-value & rho & & p-value & rho \\
\hline Visit** & 0.151 & - & & 0.328 & - \\
Intent to visit* & 0.302 & 0.116 & & 0.888 & -0.022 \\
Age* & 0.169 & 0.154 & & 0.888 & 0.224 \\
Gender** & 0.451 & - & & 0.605 & - \\
Children** & 0.498 & - & & 0.571 & - \\
Education* & 0.606 & -0.058 & & $\mathbf{0 . 0 1 5}$ & $\mathbf{- 0 . 3 7 4}$ \\
Employment* & $\mathbf{0 . 0 1 4}$ & $\mathbf{0 . 2 7 2}$ & & 0.143 & 0.23 \\
Income* & $\mathbf{0 . 0 1 3}$ & $\mathbf{0 . 2 7 4}$ & & 0.548 & -0.095 \\
Location* & 0.819 & -0.026 & & 0.333 & 0.153 \\
Belong to a group* & 0.313 & 0.113 & & 0.337 & -0.152 \\
\cline { 5 - 6 } & & & & &
\end{tabular}




\subsection{5 - Funds distribution}

Respondents who agreed to pay a levy were asked to rank seven options on how the funds should be used. At both MRs the respondents' highest ranked uses of the funds were 'More surveillance to reduce fishing at the boundaries of the marine reserve' $(22.05 \% \pm 1.39 \mathrm{SD}$ at TMR; $18.38 \% \pm 1.97 \mathrm{SD}$ at KMR), and 'Clearing the beach of litter in the marine reserve' $(18.83 \% \pm 2.11 \mathrm{SD}$ at TMR; $21.48 \% \pm 1.64 \mathrm{SD}$ at KMR) (Fig. 4.7). 


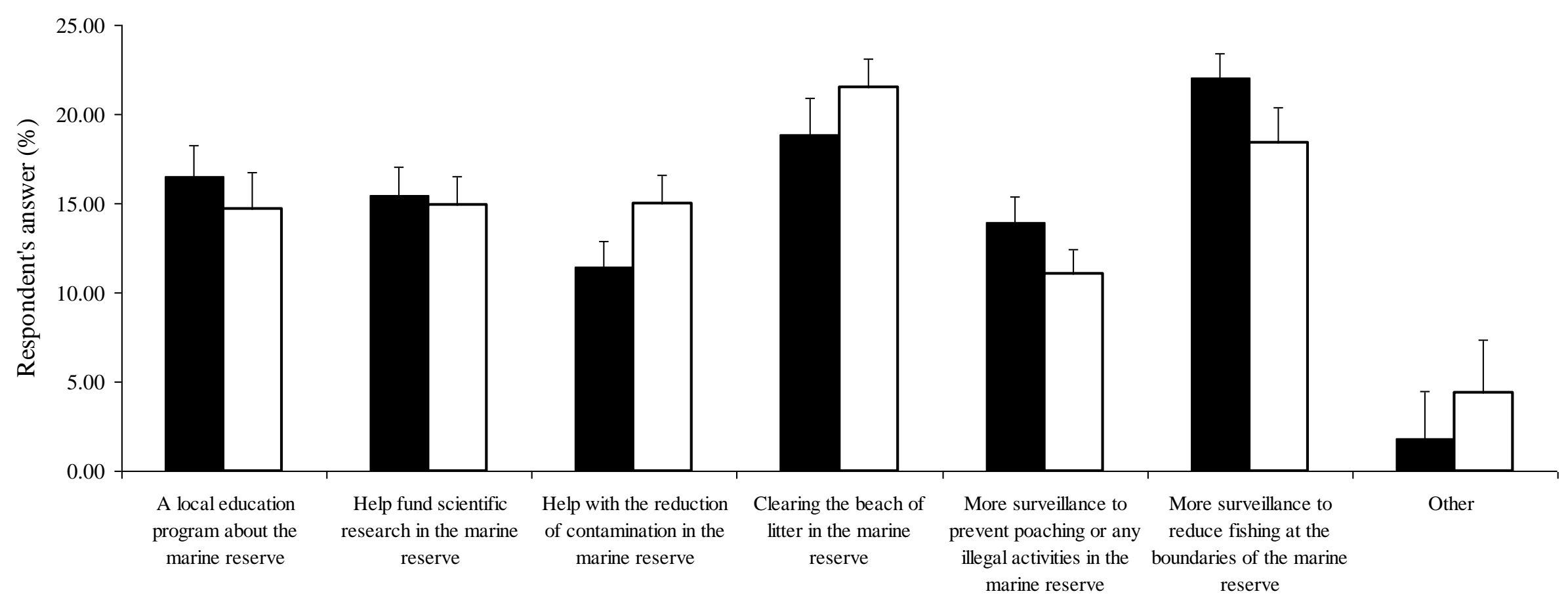

口 Taputeranga MR $\square$ Kapiti MR

Figure 4.7: Responses (and \pm SD) on how respondents would like the funds that are collected by an environmental levy to be used. Black bars represent Taputeranga MR and white bars represent Kapiti MR. 


\subsection{Discussion}

In this study, I investigated the value of two marine reserves in New Zealand, and focused on the ecosystems services they provide. My study provides a useful framework and new insights about ecosystem services of temperate coastal environments such as MR's and their values to New Zealand. Moreover, it provides a good example of how to assess and value environments using different techniques and methods including literature review, contingent valuation, interviews, and others methods in order to build a more comprehensive and complete evaluation.

The main reason I used the Millennium Ecosystem Assessment (MEA) framework in this study is because prior to the MEA approach being developed (2005) there was only a general idea that ecosystem values were of economic value to society. However, since the concept of ecosystem goods and services was popularised by Costanza et al. (1997) ecosystems have not only been valued for their potential economic influence, but also for their contribution and importance to human well-being and their ecological functions (Costanza et al., 1997; Amirnejad et al., 2006; Hearnshaw et al., 2010; Austen et al., 2011). Therefore, because of the flexibility provided by MEA approach, I was able to include a larger range of MR values in my study. Because there is no goal to produce economic revenue from MRs in New Zealand (it is not required by legislation), then the MEA approach is an appropriate framework to study MR value.

\section{Use and non-use values of the Taputeranga and Kapiti Marine Reserves and the Total Economic Value (TEV) approach}

There have been few economic valuations of marine ecosystems beyond those focused on fisheries management (Sanchirico, 2000; Alban et al., 2006). In addition, economic assessment of terrestrial areas usually cover larger areas than for MRs. Generally, economic valuation of MPAs is very difficult, and it is even more difficult to include use and non-use values. This has resulted in under-recording of the total value of MPAs (Hoagland et al., 1995, Alban et al., 2006).

In this study I used the TEV approach to estimate both use and non-use values of Taputeranga and Kapiti MRs. Generally, benefits associated with biodiversity protection are related to non-use values from an economic perspective (Weisbrod, 1964). I noted that 
despite MRs in New Zealand being created technically for scientific purposes and principally to minimise anthropogenic disturbance, Taputeranga and Kapiti MRs are providing many services that contribute to human well-being. These services are not only non-use values, they are also related to direct use (market and non-market based) and indirect values.

In terms of direct use values, both MRs provide direct benefits to the fisheries by potential fish stock rebuilding. This is the case for the rock lobster (Jasus edwardsii). In fact, both commercial and recreational fishers have potentially benefitted. Similar results of direct impacts of MPAs on fisheries (due to fishing stock recovery) have been found by other studies (Bohnsack 1996, McClanahan and Mangi 2000 and Roberts et al. 2001). Moreover, other studies have found that species such as rock lobster can quickly recover in no-take areas (see Chapter 5; Pande et al. 2008; Diaz Guisado et al. 2012). Due to the increasing biomass and abundance inside MRs, this has helped to create and/or increase the number of activities within the reserve. For example, nature-based tourism (market based) where the MRs have been used as an example on diving courses to show to their diving students how a protected area looks, and providing the opportunity to compare with open areas and make their own judgment. As well as the diving shops, MRs have benefited via non-market based education. Therefore, diving shops and education programmes are helping to promote conservation and awareness by using those MRs as real examples.

Considering the main goal of MRs in New Zealand is for scientific purposes (MR Act, 1971), there is a general expectation that MRs should contribute to increasing knowledge about marine ecosystems (Alban et al., 2006). In this study I found that both MRs have high values in terms of scientific studies compared to other MRs in the country, such as Parininihi MR, Ulva Island MR or Westhaven MR, where there are very few published studies. Numerous scientific projects are currently conducted at both MRs, with around 45 publications from work in the MRs. Consequently, these MRs are contributing increased scientific knowledge about marine ecosystems, which is not a very common value on MPAs, but one that should be increased. MRs are a unique opportunity to conduct research without some forms of anthropogenic stress, providing an opportunity to have natural control areas (Ballantine and Langlois, 2008).

Indirect values and non-use values come from the utility given by the respondent's perceptions of the ecosystem, in this case for both MRs (Walsh et al., 1984; Brun, 2002; Amirnejad et al., 2006). As part of this study, I assessed the indirect values and non-use 
values by asking whether people would willingly pay a new annual environmental levy to fund management of the MR. Results were that the majority of respondents are willing to contribute to a new environmental levy for these MRs. However, the mean and median annual amount that a respondent was willing to pay for the environmental levy differed between MRs. The TMR mean was twice that of KMR per household per year (TMR is $\$ 61.54 \pm 102.10 ; \mathrm{KMR}$ is $\$ 31.45 \pm 34.82$ ). These amounts are broadly similar to those found in studies that use NMV techniques to establish WTP for marine conservation (e.g. McCartney, 2006; Gillespie, 2011).

Hall et al (2002) surveyed people who lived close to the sandy and rocky beaches in Orange County, California, USA to determine how much people value the prevention of further deterioration in the area. After 220 interviews the authors found that the mean value was $\$ 10.50$ (value adjusted to NZ \$) per family visit. Hall et al. (2002) compared their results with studies that valued beach recreation and those values ranged from NZ \$18.45 to \$130.38 (values adjusted to NZ dollar for 2012).

Similarly, McCartney (2006) found that the mean amounts people were willing to pay for protection of the seascapes in the Jurien Bay Marine Park (Australia) was NZ \$ 47.441 per year. Moreover, McCartney (2006) in a recent choice modelling study estimated that respondents WTP on average was NZ \$188 per household per year to maintain seascapes in their current condition in Ningaloo Marine Park in Australia. In addition, Gillespie (2011) used an open-ended question (as this study has) to assess how much people were WTP for the creation of additional MPAs in the South-West Marine Region in Australia, finding that respondent were willing to pay NZ\$124 per respondent household.

Therefore, the WTP values estimated in my study are in the range of mean WTP values found in other contingent valuation studies for conservation. In addition, some authors (Langford and Bateman, 1993; McFadden, 1994; Cameron et al., 2002; Gillespie, 2011) found that dichotomous questions produce higher estimation of WTP than open-ended questions.

Many study focused on the relationship between the WTP and independent variables that could explain respondents' answers (e.g. Turpie, 2003; Kniivilä, 2006; Sattout et al., 2007). Hall et al., (2002) suggested that the beach value depends on the quality of the beach. In this study I looked for any relationship between the WTP amount and a series of independent variables, as well as between the WTP to contribute to the environmental levy (yes/no) and 
several independent variables. At both MRs there were only three independent variables from the eleven tested that were statistically significant. These variables were: the respondent's age, whether they have children or not, and if they belong to some specific group. At the TMR respondents with children were more willing to contribute to the environmental fund. Meanwhile, at the KMR local residents were more willing to contribute to the environmental fund, followed by people who belong to environmental groups. With respect to the factors that explain the WTP amount (\$), I found that at TMR, respondents with higher incomes and who are located closer to the TMR, would pay more. At KMR respondents with higher education levels (postgraduate studies) had a lower WTP (\$) than people with fewer qualifications. Amirnejad et al. (2006) found that income was one of the most important factors explaining the WTP amount, with education and age as the next factors when people were asked to pay for forest conservation. However, some authors consider that other factors positively influence WTP responses, such as the familiarity with the resource/area, previous knowledge (e.g. Kniivilä, 2006), and previous experiences in the study area (e.g. Cameron and Englin, 1997).

The willingness to pay results that I found showed that both MRs are important to the local community. At both MRs respondents would like to invest the hypothetical levy in 'more surveillance to reduce fishing at the boundaries of the marine reserve'. This could mean that people are concerned about the protection of marine biodiversity.

\section{Ecosystems services provided by MRs}

Estimating the ES provided by MPAs (including MRs) is complicated and rarely reported in the literature (Walmo and Edwards, 2008), and ES is more difficult to measure and analyse than terrestrial ecosystems. This is mainly because in marine ecosystems resources are open and common to everyone. So its is not just about creating boundaries to keep people apart as in terrestrial environments, where changes happen and are obvius over time. This is because the major changes are happening mainly underwater, where it is more difficult for people to appreciate and value the benefits provided from the MPAs establishment. In no-take areas ES are mainly non-use values, and to recognize and value the rest of the use-values is not an easy task. In 2000, the New Zealand Biodiversity Strategy valued marine ecosystem services at $\$ 184$ billion per year (including $\$ 315$ million from fishing). However, this is a general valuation, and there is little information about the value of ES at local scales, despite the fact that such knowledge is important for decision-making. 
In this study I found that both MRs are producing many ecosystems services (ESs) and values that improve or help human well-being. To determine those ESs and values is very important at local scales in terms of conservation policies, and for local decision-making and actions. However, to determine these ESs and their values at each MR was not an easy task, due to the small size of both study areas compared to the natural systems they are part of. The newer MR (TMR) seems to be providing more benefits than the older MR. This is because the main changes (such as bigger and greater abundance of rock lobsters and fish) became apparent during the early years after establishment when fishing and gathering activities in the areas were prohibited (Polacheck, 1990; Carr and Reed, 1993; Rowley, 1994, Halpern and Warner, 2002; Pande and Gardner, 2009; Pande et al., 2008; Diaz Guisado et al., 2012). Hence people can perceive and experience more changes and feel more benefits. At KMR the range of ESs now seems to be more constant compared to the TMR, as the former MR was established in 1992

In contrast to other studies that have calculated a total value for ES (e.g. Costanza et al., 1997; Pimentel et al., 1997; Patterson and Cole, 1999; Williams et al., 2003), I could not complete such a calculation. To calculate a total value requires a comprehensive understanding about all the processes that are occurring in the place being valued. However, as these MRs are small compared with the surrounding area, it is very difficult to identify all the ES that they are providing. However, I used categories high, medium and low to indicate values for those ESs depending on their level of use. This is a coarse way to describe the benefits that are obtained from those ES.

\section{Limitations of the study}

One of the first limitations of this study was the population representation in my sample compared with the population in the Wellington region (regional/city/suburb). There were differences between my sample and regional, city and suburb populations, in terms of educational levels and income, which were higher in my sample. This could bias the WTP amounts that I obtained. Therefore, the total value of indirect values and non-use values at each MR can be considered as an insight about how much people value those MRs, and how willing they are to contribute to MRs. Therefore, through those values, it is possible to appreciate that there is an important potential contribution of residents to support MRs, that 
should be considered by policy makers. However, further analysis is necessary, with a larger sample size in order to obtain a sufficient number of responses to calculate the total indirect values and non-use values for TMR and KMR.

Another limitation that I faced was regarding the data collection. This is because the data necessary to conduct this type of analysis was not always available or easy to gather. For example, with the dive shops, not all of them wanted to tell me their current charges on diving activities. In the education section, only the non-profit education programme agreed to speak about costs, whilst the other education programme did not agree, due to business confidentiality reasons. This makes the task of data gathering difficult for ecosystems valuation. There is a general reluctance about providing financial information for research. Some studies have found business people believe if they provide financial information, then they will need to pay extra taxes for conducting their activities in the reserves as occurred in other protected areas, where tourist organizations pay a percentage of their revenues to the government (Mmopelwa et al., 2007)

\section{Conclusions}

This study has shown how important MRs are to society, through the estimation of the current social value of some of the ES of two MRs in New Zealand. It provides new and valuable information about how the public is aware, concerned, appreciative and willing to take care of the marine environment, through their monetary value and their willingness to participate in this study. These values at both MRs indicate how strongly people perceive that MRs provide them with benefits (the impact on human well-being). Monetary values can also contribute to the development of indicators of human well-being and sustainability (Howarth and Farber, 2002; Amirnejad et al., 2006; Rees et al., 2012), as well as the formulation and/or improvement of environmental policies. Therefore, this study provides a useful and valuable link between economic policies and environmental outcomes (Bishop, 1999; Amirnejad et al., 2006), giving the opportunity for decision makers to adjust their policies and budgets within the national context and priorities. Using the ecosystem approach means considering and integrating their economic, social and ecological value (Rees et al., 2012). In this process public opinion should be integrated (Sattout et al., 2007), making the conservation process more sustainable for the public and the environment. 


\section{Chapter 5. No-take areas: protection effects on rock lobster (Jasus edwardsii) populations}

Author contribution: URN designed the study and performed the field work, analysed the data and wrote de Chapter. JJB and JPAG co-designed the study and corrected the chapter.

\subsection{Abstract}

Rock lobsters (RLs) support large fisheries in Australia and New Zealand (NZ). Therefore, stock assessment and protection of this fishery is extremely important. Because RLs are one of the most valuable commercial species in NZ their stock assessment and protection are important. Although NZ's marine reserves (MRs) are created for conducting scientific research, where human-induced disturbance is minimised and if possible eliminated, they are indirectly protecting many populations of commercial species including RL. In this study I investigated how rock lobsters (RLs) (Jasus edwardsii) have responded to the protection afforded by two marine reserves (MRs) in the Wellington region, by comparing rock lobster Catch Per Unit Effort (CPUE) in terms of biomass and abundance inside and outside two MRs, of different ages. By using commercial craypots, each MR was sampled inside its boundaries, at the boundaries, and outside the MR to calculate the Catch Per Unit Effort (CPUE) on five separate days, in summer, winter, and spring from 2010 to 2011. The average CPUE was higher inside both MRs than outside. Also bigger RLs were caught inside at both MRs'. In addition, the TMR catches were twice as high compared with historical catches, and the KMR compared with historical catches were 1.93 times higher. The results suggest that RLs are responding positively to protection, allowing them to rebuild. This information can be used as a powerful tool as evidence for the effectiveness of MRs. 


\subsection{Introduction}

Fishing along with other anthropogenic stressors have a major impact on marine environments (Pauly et al., 2002; Shears et al., 2006). As a result, many nations are working to create or increase the number of Marine Protected Areas (MPAs), including full no-take areas like Marine Reserves (MRs) (Shears et al., 2006). MRs may be created for a number of reasons including conservation, fisheries management, aesthetic reasons and as in New Zealand for the purposes of conducting research in the absence of human pressures (Pande et al., 2008). Because no-take MRs are established to prevent or minimize human disturbance (all forms of extractive use are prohibited), habitats and species may benefit from such closures. Outcomes from MR designation have been explored for many species (e.g. Allison et al., 1998; Pande et al., 2008), with special emphasis on species targeted by commercial and recreational fishing. Many studies have reported increases in the abundance, biomass and/or size of such species inside MRs compared to outside (Halpern, 2002; Pande et al., 2008; Diaz Guisado et al., 2012).

A commonly employed harvesting strategy when MRs are established is called 'fishing the line', which is where fishing effort is concentrated at the boundaries of MRs. Fishers use this strategy because there is an inherent assumption that catch rates at the boundaries should be enhanced by the net export of individuals from the reserve called the 'spillover effect' (Kellner et al., 2007). While this harvesting tactic could benefit some fishers when the total number of fishers is small, if the effort is larger, then there may be declines in both the fished stock and the protected population (Hilborn, 2002; Halpern et al., 2004; Kellner et al., 2007). Species with high site fidelity, which spend long periods on inshore reefs, but move seasonally offshore (e.g., larval hatching and feeding) are more vulnerable to being caught at MR boundaries (McDiarmid, 1991; Kelly at el., 1999; Kelly, 2001; Gardner et al., 2003; Kelly and McDiarmid, 2003; Kellner et al., 2007). The Southern rock lobster (RL) (Jasus edwardsii) is one of the species with high site fidelity, and is therefore vulnerable, where their distribution and abundance could be the most affected.

RLs are both ecologically and economically important in New Zealand and Southern Australia. RL are considered to be a keystone species in temperate reef communities, playing an important role in trophic cascades (Babcock et al., 1999), as well as in structuring soft sediments communities (Langlois et al., 2005b). From an economic perspective, it has been 
the most important invertebrate targeted for commercial and recreational fishing, supporting large fisheries in Australia and New Zealand (Kellner et al., 2007). Within New Zealand, RLs have been managed under the Quota Management System since 1990, and regulations include minimum legal sizes (for male and females), gear regulations (escape gap restrictions), local closures (some) and the return of berried females and soft-shelled RLs to the water (Ministry of Fisheries, 2009). Within NZ, RL is the second highest valued seafood export, worth approximately \$220.4 M gross in 2011. Most of the RLs are live exports, and go to China (55.4\%), Hong Kong (39.9\%) and Thailand (4.4\%) (Ministry for Primary Industry, 2012). Due to the economic and ecological importance of RL it is important to understand and quantify how RL respond to MR protection in order to better understand how to improve or reinforce fisheries management rules for this resource, as well as to enhance fishery stock in open areas. Research from Tasmanian MRs showed increased biomass of legal-sized RL of more than 20 times inside MRs compared with outside the MRs (Edgar and Barrett, 1999). Similar results have been found in New Zealand between fished and MRs areas, with larger and more abundant RL in MRs (Davidson et al., 2002; MacDiarmid and Breen, 1992; Shears et al., 2006; Freeman, 2008). In addition, recent meta-analyses by Pande et al. (2008) and Diaz Guisado et al. (2012) have demonstrated that there is a strong positive, but site-specific effect of MRs on RL abundance and size. In addition, some authors (Kramer \& Chapman, 1999; Sale and Kritzer, 2003; Murawski et al., 2004; Abesamis and Russ, 2005; Babcock et al., 2007; Freeman, 2008) have suggested fishing pressure at the boundaries of marine reserves (MRs) creates a gradient of population density and mean size across the MRs, with highest densities and mean sizes at the centre, and minimum density and mean size near the boundary.

In this chapter I hypothesise that lobsters inside the two MRs (Taputeranga MR and Kapiti MR) will, on average, be larger, be more abundant, and have higher biomass (kg) (based on Catch per Unit Effort, CPUE), than lobster populations outside MRs. Moreover, I predict that lobster abundance and size will decrease with increasing distance from the centre of the MRs to the furthest areas sampled outside of MRs.

Therefore, in order to test these hypotheses the aims of this research are: 1) Measure RL abundance and biomass inside and outside MRs, as well as along a distance gradient from the centre to the boundaries and outside of each MR; 2) Determine and calculate RL catch per unit effort (CPUE) both in terms of number and biomass inside and outside MRs; 3) Compare historical RL CPUE with current RL CPUE inside the MRs, and also among seasons; and 4) 
Compare different morphometric measures of RLs inside and outside the MRs, and for a distance gradient from the centre to the boundaries and outside of each MR.

\subsection{Methodology}

\subsubsection{Study locations}

Two MRs were selected for this study in the Wellington region. The first is Taputeranga MR (TMR), which was designated in 2008. It is located on the Wellington south coast, and is the first rocky reef MR in NZ located close to a major city. The reserve extends from Princess Bay on the eastern boundary to Quarry Bay on the western boundary, protecting 854.79 hectares of coastal waters. The marine environment is representative of the temperate Cook Strait region, with highly dynamic systems, receiving currents from the south as well as being a zone of convergence for the East Cape, D'Urville and Southland currents (Carter, 2008; Eddy, 2011) (Fig. 5.1a). The second reserve is Kapiti MR (KMR), which was designated in 1992. KMR is located at Kapiti Island, which is located in front of Paraparaumu beach (5 km offshore), on the Kapiti coast, approximately $50 \mathrm{~km}$ north of Wellington city. The KMR is divided into two parts, one is on the eastern side of the island extending to the mainland in Paraparaumu beach, being the larger part of the reserve (1750 hectares); the other part is smaller (340 hectares), located on the western side of the island and does not connect with any part of the mainland. This study was carried out on the western side of the reserve, where there are more complex reef structures. The western side of the Kapiti Island is where historical RL fishing sites were located on this side of the reserve (Fig. 5.1b). In addition, Stewart and MacDiarmid (2003) reported that the majority of RLs were generally found on this side of the island.

\subsubsection{Historical Catch Per Unit Effort}

Commercial RL fishing in this central part of New Zealand occurs in the CRA4 quota management area (QMA). According to Breen et al. (2009) 'The CRA 4 quota management area (QMA) defines a rock lobster fishery which covers the southern half of the North Island of New Zealand, extending from Hawke's Bay on the central east coast into Cook Strait, past Wellington and ending in the South Taranaki Bight on the lower west coast of North Island' (Fig. 5.2a). This area is divided in to statistical sub-areas, where the Wellington south coast is area 915, and Kapiti Island is area 934 (Fig 5.2b). The size of area 915 is $1,902.82 \mathrm{~km}^{2}$, 
including $130 \mathrm{~km}$ of coastline, whereas area 934 is $3,124.89 \mathrm{~km}^{2}$, including $190 \mathrm{~km}$ of coastline (NABIS, 2012). Commercial rock lobster data were provided by the Ministry of Fisheries (now Ministry for Primary Industries). Commercial data obtained covered the period 1989 to 2010 (Fig. 5.3). However, I only could get monthly historical catch data between 1998 and2005 at both areas 915 and 934, which permitted me to make seasonal comparisons between my data and the commercial data. After 2005 I could get only catch per year (not monthly). For that reason I decided to use commercial data until 2005.

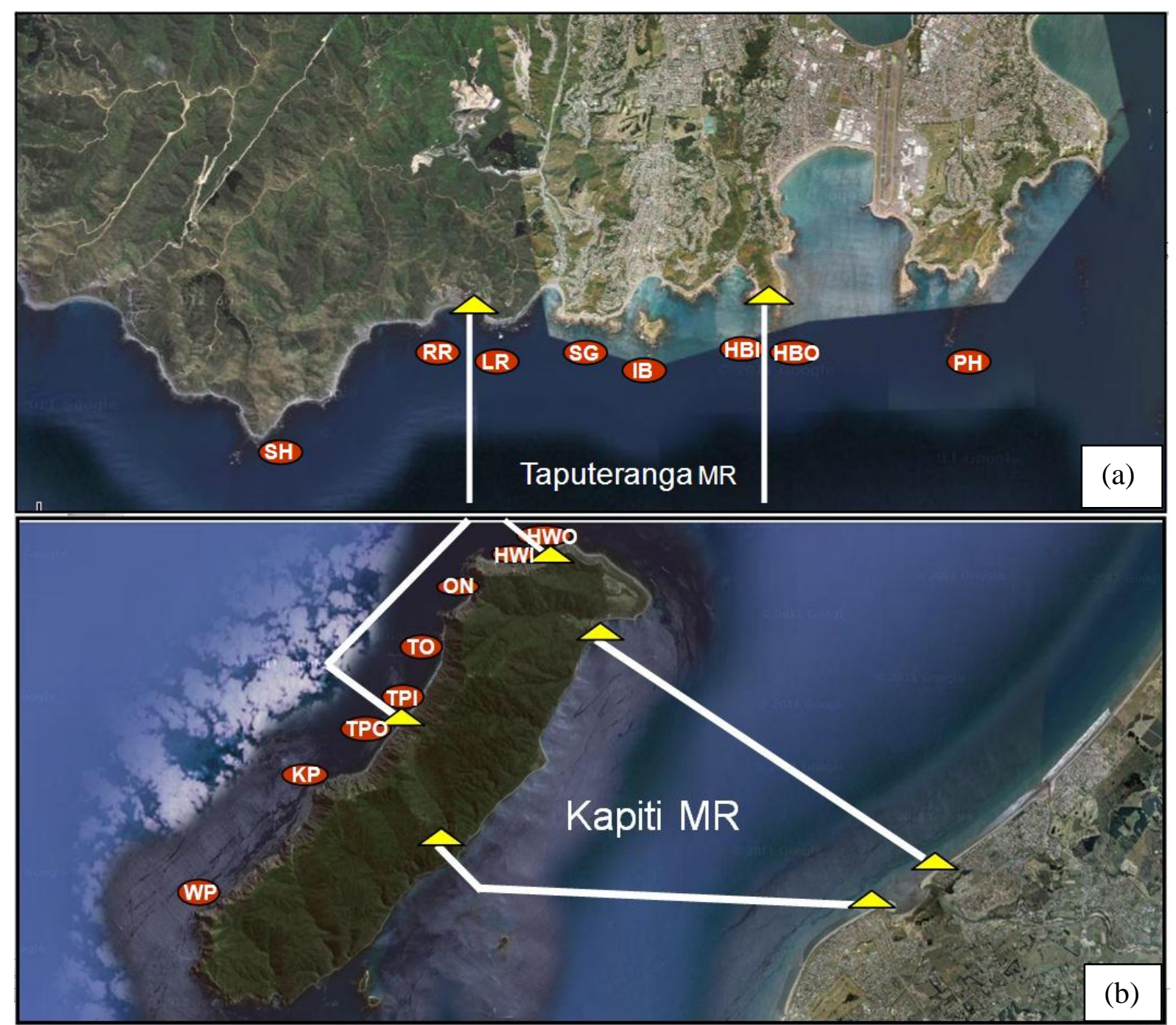

Figure 5.1: Maps showing the two marine reserves and study sites at each marine reserve used as in Wellington region, New Zealand. (a) Taputeranga MR: PH: Palmer Head, HBO: Houghton Bay Outside, HBI: Houghton Bay Inside, TI: Taputeranga Island, TSR: The Sirens Rock, WOB: Western side Owhiro Bay, RR: Red Rocks and SH: Sinclair Head. (b) Kapiti MR: HWO: Hole in the wall outside; HWI: Hole in the wall inside; ON: Onepoto; TO: Te Oneroa; TPI: Trig Point inside; TPO: Trig Point outside; KP: Kaiwharawhara Point; WP: West Point. 


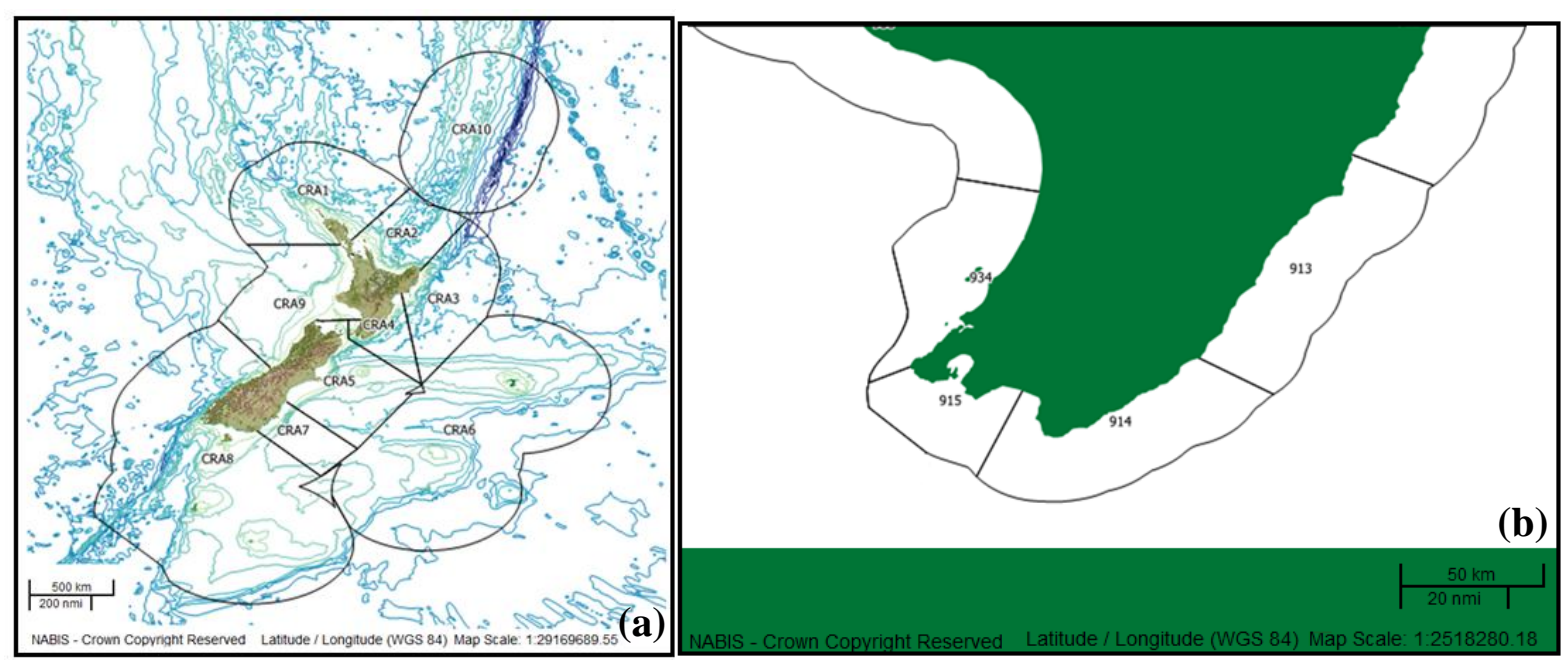

Figure 5.2: Statistical areas for rock lobster fishing in New Zealand CRA 4 (Fig. 5.2a). Statistical zones for rock lobster fishing in the Wellington region. The 915 area corresponds to the Wellington south coast, and the 934 area corresponds to the Kapiti Coast (Fig. 5.2b).

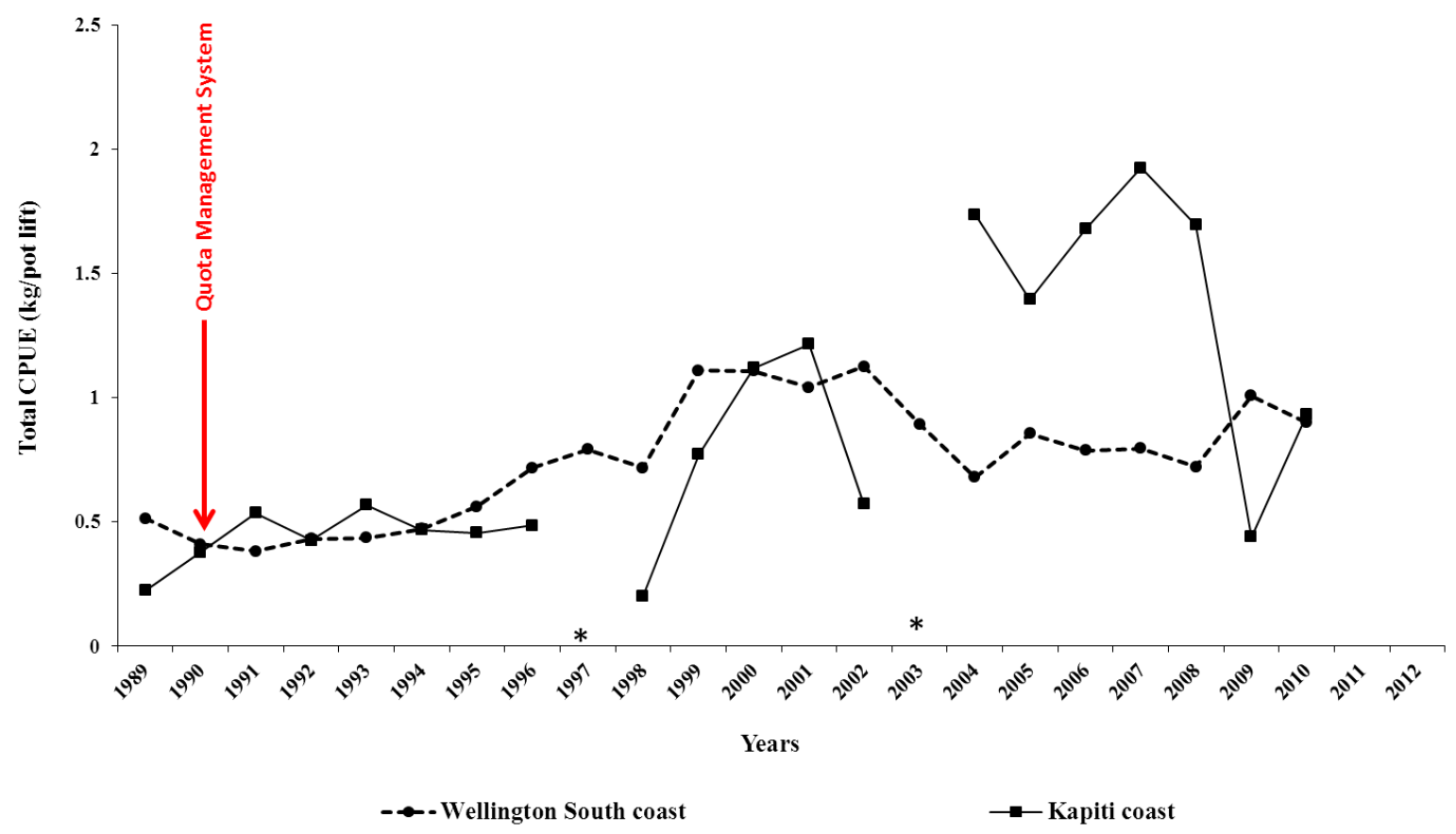

Figure 5.3: Total CPUE (kg rock lobster per pot lift; sex and seasons pooled) in Wellington south coast (statistical area 915) and Kapiti coast (statistical area 934) from 1989 to 2010. The asterisk (*) is showing no data were reported in those years (1997 and 2003) for Kapiti coast. Red arrow indicates the year that quota was introduced for RLs. 


\subsubsection{Rock lobster pot survey}

Eight commercial rock lobster pots (RLP) were deployed along the Wellington south coast during Summer 2010 - 2011 and 2012, Winter 2010 - 2011 and Spring 2010 - 2011. Therefore, each RLP was deployed 27 times over two years along the Wellington south coast making 216 RLP drops in total. At Kapiti Island these RLPs were deployed in Winter 2010 2011, Spring 2010 - 2011, and Summer 2011 - 2012. Each RLP was deployed 17 times for a total of 136 drops along Kapiti Island. These deployments were within and surrounding TMR (Wellington south coast) and Kapiti MR (Kapiti Island). These deployments were carried out under Ministry of Fisheries (current Ministry of Primary Industries) permit.

The RLP type used was the standard legal commercial RLP, with a steel frame and mesh. Inside the RLP was a bait box. Each RLP had a $20 \mathrm{~m}$ rope, plus a yellow buoy. Each RLP had two gaps (one at each site) to permit small RLs to escape and followed the Ministry for Primary Industries - Manatū Ahu Matua requirements (Fig. 5.4). 


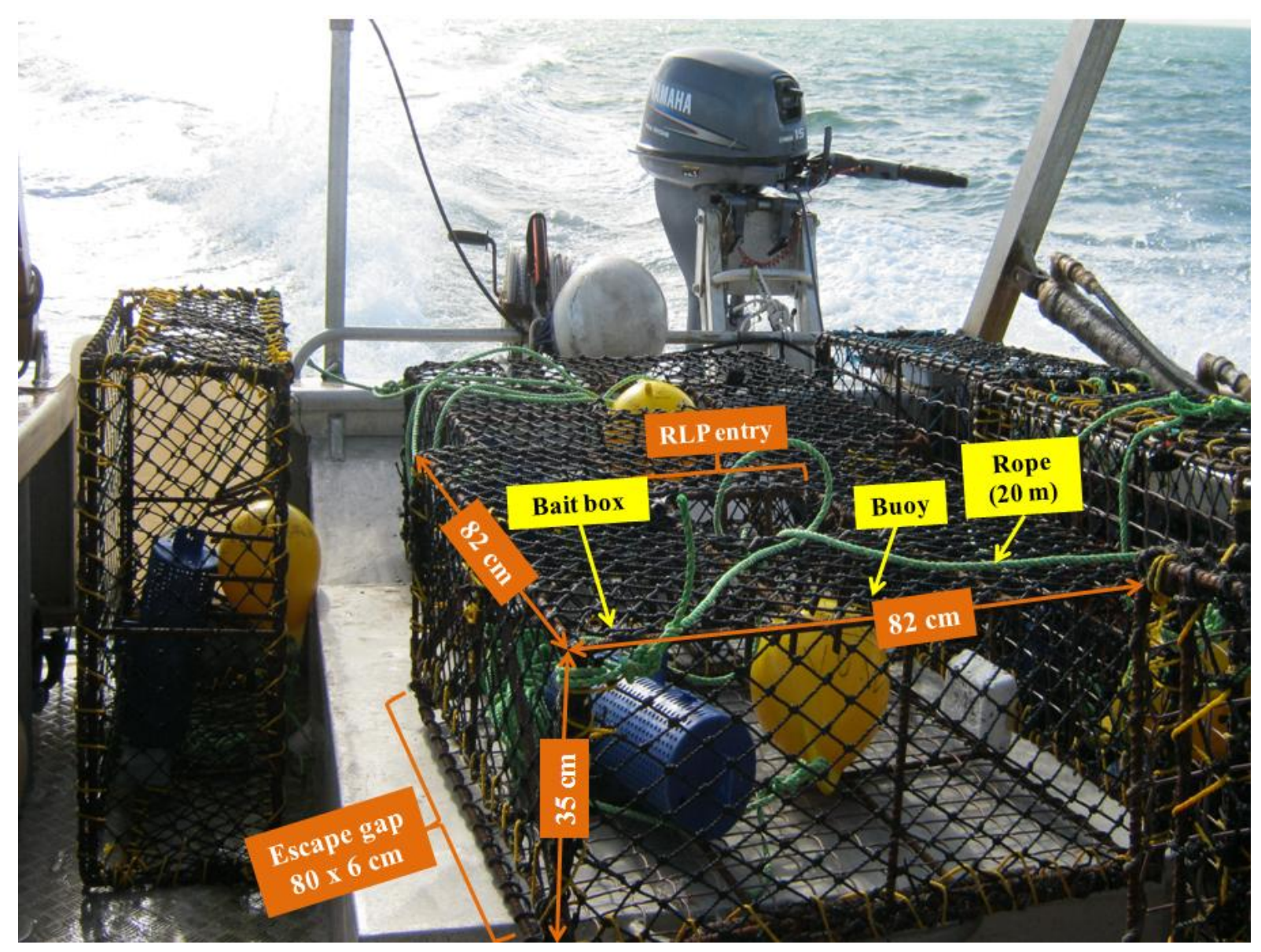

Figure 5.4: Rock lobster pots used in this study. The escape gaps are based on Ministry of Primary Industries regulations: 'Square or rectangular pots must have at least 2 escape gaps/or apertures (other than the mouth) in opposite faces of the pot. Each aperture shall not be less than $80 \%$ of the height or length of the face of the pot in which the apertures are contained. Each aperture shall have an inside dimension of not less than $54 \mathrm{~mm}$ x $200 \mathrm{~mm}$.' (Ministry of Fisheries, 2011)

The sampling locations at both sites were selected based on historical fishing sites (within and surrounding MRs) in rocky reefs. Eight sites were selected at each location (one site per RLP), four inside the MR, and four outside. Based on historical fishing sites at Taputeranga MR, two RLP were deployed on the east side of the MR, and another two RLP on the west side of the MR (Fig. 5.1a). Due to the geographic complexity of Kapiti Island I decided to deploy three RLP at the south head of the island, and just one in the north head, as well as at the four sites inside KMR (Fig. 5.1b).

The number of sampling days in each season was dependent on weather and sea conditions. I attempted to sample over a period of 5 consecutive days, however, the sampling was undertaken between two days and six days per season at each MR. 
Every bait box was baited with fish frames provided by Moana Pacific Ltd and Wellington Trawling Co. Ltd. Consistent with commercial fishing practice, sometimes I used only one type of fish, and other times I used mixed species. Baits included: red gurnard, snapper, blue moki, blue warehau, tarakihi, trevally, red cod, hoki and flounder. The bait box was held next to the RLP entrance, in order to make RL climb and go into the RLP to get the bait. Then RLP were deployed at depths between $10 \mathrm{~m}$ and $15 \mathrm{~m}$ (because the rope was $20 \mathrm{~m}$ long), only on rocky reefs.

Though I attempted to sample RL over a period of 5 consecutive days, and over a narrow depth range (between $10 \mathrm{~m}$ and $15 \mathrm{~m}$ ) my samples were truly independent because I always used the same fishing ground during my research, as well as the same depths over those consecutive days. Also I tagged all RL caught, so I could know if I had recaptured or know, from where, these RLs came.

Pots were normally set one day and retrieved the next (less than 24 hours soak time). However, because sampling was weather dependent, in some cases RLPs remained in the water longer. In storm situations, the RLP were not lifted until the storm was over (between 2-3 days). However, when they were lifted we did not find any injured, damaged or dead animals (RL and by-catch included).

All RLPs were retrieved using the winch on board the RV Raukawa Challenger (Victoria University of Wellington) and Matahorua (Department of Conservation). Once on board, every RL, and any other animal caught (by-catch), was removed from the inside of RLP by hand, trying to avoid any stress or body damage. RLs were placed into a black container with sea water, and covered to prevent sun damage.

\subsubsection{Rock lobster data records}

Each RL was measured and sexed on board. Weight was determined to the nearest gram. Carapace and tail width/length were measured with vernier callipers. Tail widths were measured in a straight line between the tips of the primary spines on the second segment of the tail (Freeman, 2008) (Fig. 5.5a, b). Tail lengths were measured along the underside in a straight line just before the rear of the calcified bar on the first segment to the tip of the middle fan of the tail (Fig. 5.5c). Carapace widths were measured across the carapace at its widest part (Fig. 5.5d). Carapace lengths were measured from the antennal platform to the dorsal posterior margin of the carapace along the midline (Freeman, 2008) (Fig. 5.5e). 
RL sex was determined using Ministry of Fisheries guidelines. These are: (1) females have small pincers on the rear pair of legs, and (2) pleopods are in paired form on each side of the underside of female tails, and are in single form in male tails (Fig. 5.6). After being measured, each RL was released in the same place as they were caught.

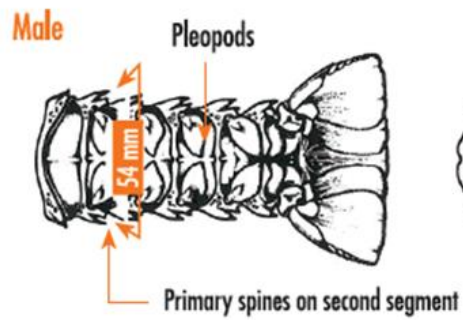

(a)

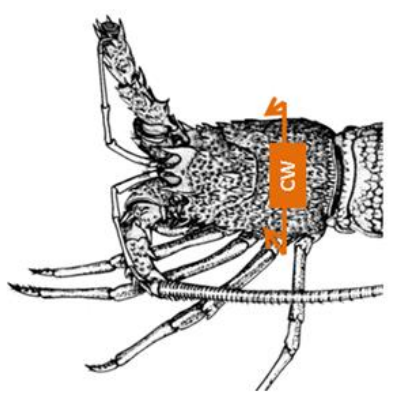

(d)

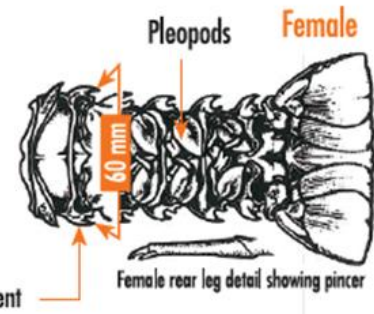

(b)

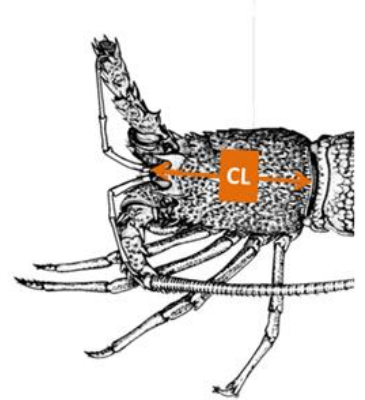

(e)

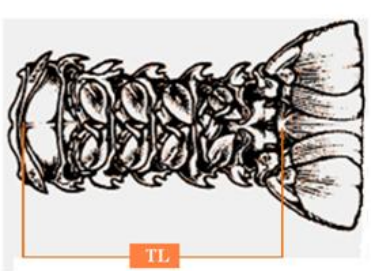

(c)

Figure 5.5: Types of measures to determine population structure. ( $a, b)$ Tail width, between the tips of the primary spines of the 2nd segment of the tail. (c) Tail length, along the underside in a straight line just before of the rear of the calcified bar on the first segment to the tip of the middle fan of the tail. (d) Carapace width, across the carapace in the widest part of it. (e) Carapace length, from the antennal platform to the dorsal posterior margin of the carapace along the midline. Figures a $\&$ b taken from Ministry of Fisheries, the rest were made by own. 

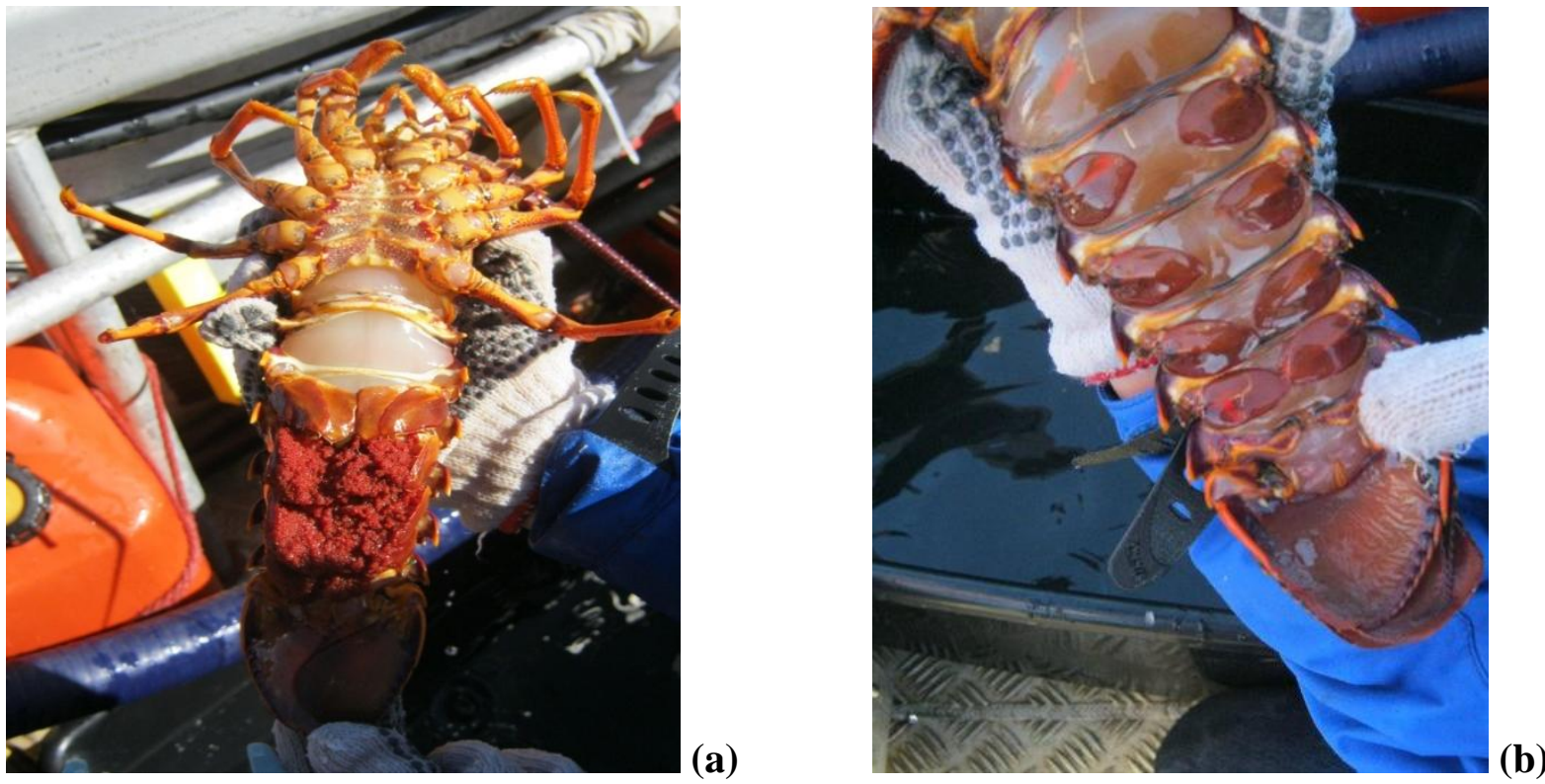

Figure 5.6: Rock lobster pictures. (a) Female rock lobster carrying eggs. Females have small pincers on the rear pair of legs, plus pleopods are in paired form on each side of the underside of female tails. (b) Male rock lobster. Male's pleopods are in single form in the tails.

\subsubsection{Data analysis}

RL abundance in terms of Catch Per Unit Effort (CPUE) abundance and numbers inside/outside were compared by using a two-tailed $t$-test $(\mathrm{p}=0.05)$ between inside and outside of each MR. For CPUE comparison between seasons and inside/outside at each MR I used a two way ANOVA ( $\mathrm{p}=0.05$ ), where seasons and inside/outside were considered as fixed factors. To compared total biomass caught inside/outside between MRs I used Chisquare test for independence $(\mathrm{p}=0.05)$.

Because the historical commercial CPUE data did not conform to a normal distribution (it was highly right skewed - strong evidence of overdispersion), the historical RL catch data from statistical areas 915 (Wellington south coast) and 934 (Kapiti coast) were compared with my sampled data by using a two factor permutational multivariate analysis of variance (PERMANOVA) $(\mathrm{p}=0.05)$. The factors incorporated in the PERMANOVA design were 'Origin' (two levels: commercial and data collected in this study), and 'Season' (with three levels were Summer, Winter and Spring).. The analysis was based on similarity matrices calculated using Bray-Curtis coefficients. In cases were PERMANOVA results showed significant effects, I ran pair-wise comparisons in PERMANOVA $(\mathrm{p}=0.05)$. The tests were run by the statistical package PRIMER-E v6 (Plymouth Routines in Multivariate Ecological Research). 
Morphometric (carapace length, carapace wide, tail length, tail wide and weight) differences inside and outside each MR, and between MRs were investigated using a two-tailed $t$-test $(p=0.05)$. Because weight was not normally distributed, it was $\log _{10}$ transformed to normalise it. Seasonal differences in morphometric measures inside and outside the reserve were compared by using a two way ANOVA $(\mathrm{p}=0.05)$.

\subsection{Results}

\subsubsection{Rock lobster abundance between MR and fished areas}

A total of 234 RLs were caught on the Wellington south coast from Summer 2010 to Summer 2012 during the pot surveys. Catches inside the TMR were almost always higher than outside of the MR. From the total RL caught, $78 \%(\mathrm{n}=183)$ came from inside of Taputeranga MR. At Kapiti Island, catches were always higher inside of KMR. At Kapiti Island a total of 118 RL were caught from winter 2010 to Summer 2012, and 64\% were from inside of the reserve.

At Taputeranga MR most RLs were caught in Spring 2010, with an average of 2.5 and 11.9 $\mathrm{RLs}_{\operatorname{pot}^{-1}}$ ( \pm 1.3 and 1.9 s.e.) outside and inside the MR, respectively. At Kapiti MR the most RLs were caught in Winter 2010, when the average catch was 5.3 and $9.8 \operatorname{RLs}_{\operatorname{pot}^{-1}}( \pm 1.2$ and 1.7 s.e.).

\subsubsection{Catch Per Unit Effort (CPUE)}

The average CPUE was higher inside both MRs than outside. However, this difference was only significant at TMR (Two-way ANOVA $\mathrm{F}_{(1,50)}=12.094, \mathrm{p}=0.001$ ). The average CPUE at TMR was around 3.1 times higher than outside TMR with a mean of $1.33 \mathrm{~kg}$ pot $\operatorname{lift}^{-1}( \pm$ 1.13 s.e.) inside and $0.43 \mathrm{~kg}$ pot $\operatorname{lift}^{-1}$ ( \pm 0.91 s.e.) outside. The total catch in kilograms caught inside TMR was $160.71 \mathrm{~kg}$, while outside it was $57.63 \mathrm{~kg}$. Significant differences were found between seasons (Two-way ANOVA, $F_{(2,50)}=6.205, \mathrm{p}=0.004$ ), where CPUE was approximately twice as high in spring (Fig. 5.7). There was no interaction between season and inside/outside of the reserve (Table 5.1). 
Table 5.1: Catch Per Unit Effort (CPUE) comparison between seasons and inside/outside in each MR (Taputeranga and Kapiti). Comparisons were made using a Two-way ANOVA $(\mathrm{p}=0.05)$, where seasons and inside/outside were considered as fixed factors.

\begin{tabular}{|c|c|c|c|c|c|c|c|c|c|c|}
\hline & \multicolumn{10}{|c|}{ Marine Reserve } \\
\hline & \multicolumn{5}{|c|}{ Taputeranga } & \multicolumn{5}{|c|}{ Kapiti } \\
\hline & $\begin{array}{l}\text { Type III } \\
\text { Sum of } \\
\text { Squares }\end{array}$ & $\mathrm{df}$ & $\begin{array}{c}\text { Mean } \\
\text { Square }\end{array}$ & $\mathrm{F}$ & Sig. & $\begin{array}{l}\text { Type III } \\
\text { Sum of } \\
\text { Squares }\end{array}$ & $\mathrm{df}$ & $\begin{array}{c}\text { Mean } \\
\text { Square }\end{array}$ & $\mathrm{F}$ & Sig. \\
\hline Intercept & 47.939 & 1 & 47.939 & 48.262 & 0 & 41.155 & 1 & 41.155 & 18.268 & 0 \\
\hline In/Out & 12.013 & 1 & 12.013 & 12.094 & 0.001 & 1.342 & 1 & 1.342 & 0.596 & 0.446 \\
\hline Season & 12.411 & 2 & 6.205 & 6.247 & 0.004 & 19.886 & 2 & 9.943 & 4.413 & 0.02 \\
\hline In/Out * & 1.38 & 2 & 0.69 & 0.695 & 0.504 & 0.134 & 2 & 0.067 & 0.03 & 0.971 \\
\hline Error & 49.666 & 50 & 0.993 & & & 76.599 & 34 & 2.253 & & \\
\hline
\end{tabular}

In the TMR, I found that the CPUE tended to be highest in the reserve, principally in the centre, and declined towards to the boundaries, with very low catches at the sampling sites furthest away from the reserve boundaries (Fig. 5.8a, b).

At KMR, the average CPUE was always higher within the reserve than outside $(\sim 1.36$ times higher) with the exception of Winter 2011 (total catch $101.21 \mathrm{~kg} \pm 5.16$ s.e.; mean CPUE $5.35 \mathrm{~kg}$ pot lift ${ }^{-1} \pm 2.54$ s.e. ; total catch $69.92 \mathrm{~kg} \pm 3.9$ s.e.; mean CPUE $3.93 \mathrm{~kg}$ pot lift $^{-1} \pm$ 1.93 s.e.), and the difference was statistically significant (Table 5.1)(Fig. 5.9).

Significant differences were found between seasons (Two-way ANOVA, $\mathrm{F}_{(2,34)}=4.413, \mathrm{p}=$ 0.02), but there was no significant interaction between season and inside/outside the KMR (Table 5.1). 


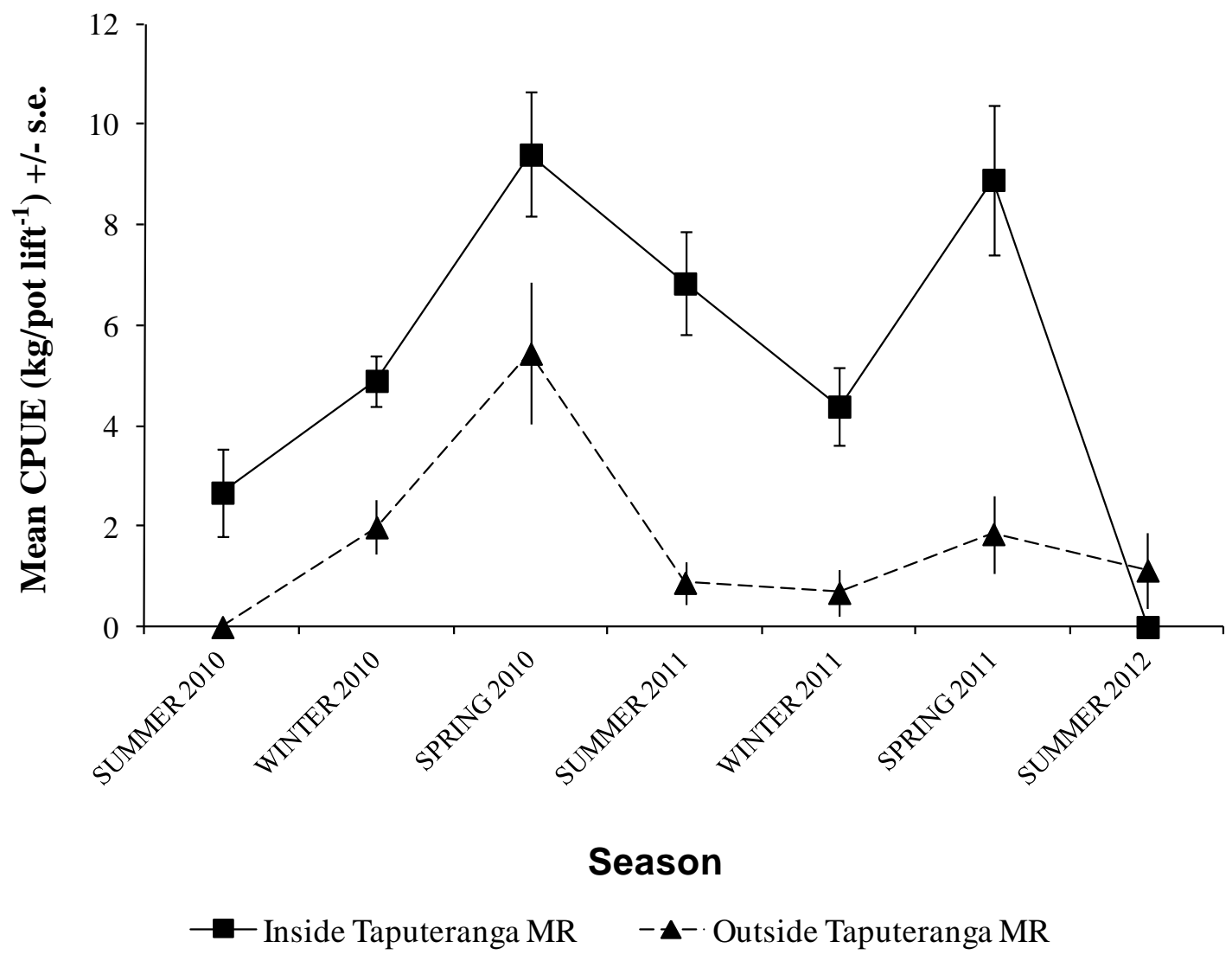

Figure 5.7: Mean CPUE (kg rock lobster per pot lift; males and females pooled) in three different seasons from 2010 to 2012.

In contrast to the TMR, at KMR I caught most of RL in the reserve and outside of the KMR during Winter 2010 (total catch $65.71 \mathrm{~kg} \pm 3.02$ s.e.; mean CPUE $16.43 \mathrm{~kg}_{\text {pot lift }}{ }^{-1} \pm 1.7$ s.e;

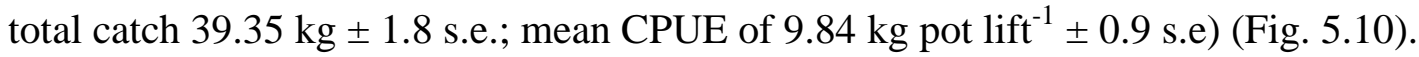

Comparion of total catches (biomass) of Kapiti Island with total catches along Wellington south coast inside /outside of MRs, Chi squeare showed significant differences $\left(\chi^{2}=8.90\right.$, $\mathrm{DF}=1, \mathrm{p}=0.003)$. 


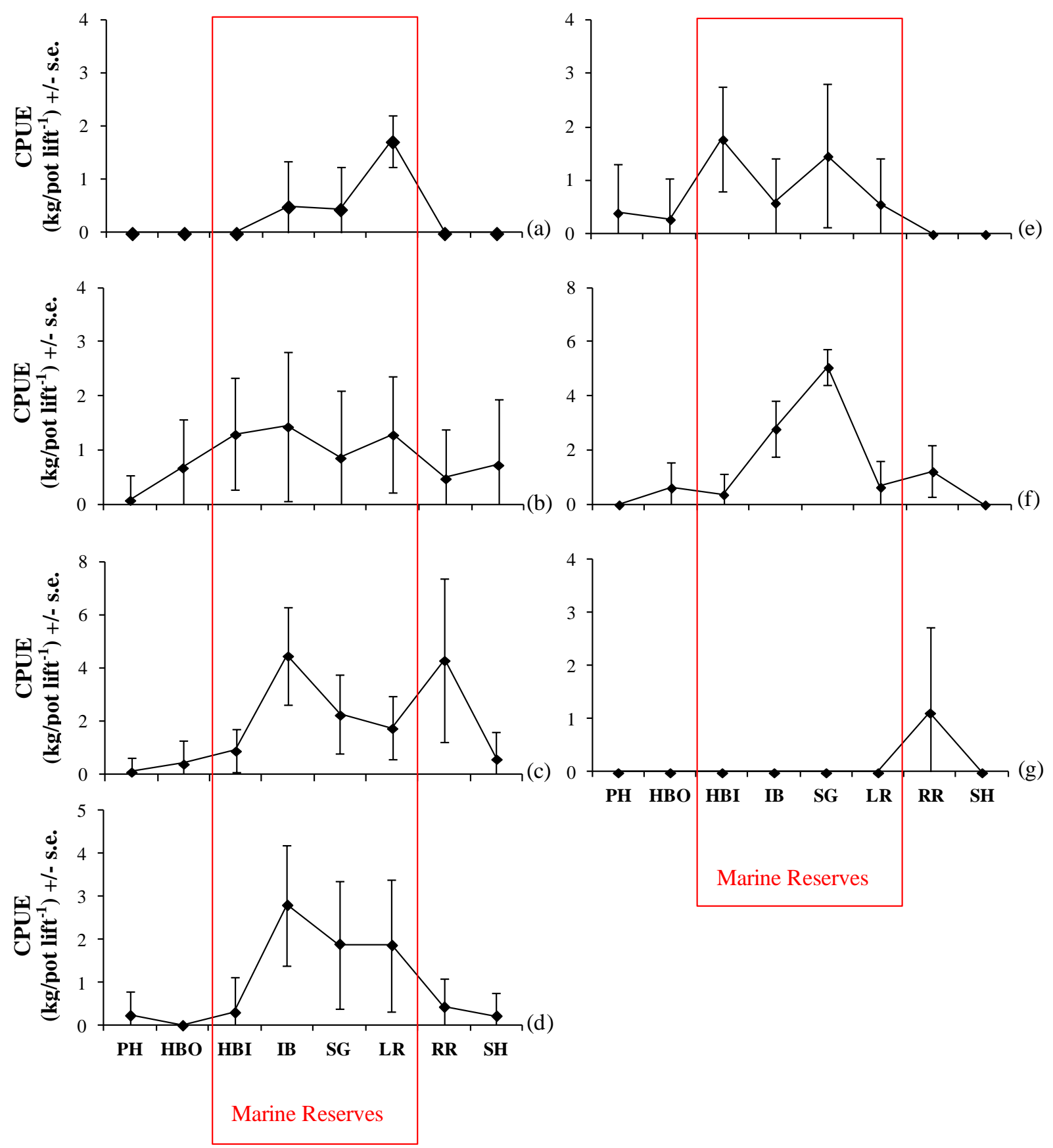

Figure 5.8: Mean Catch Per Unit Effort (CPUE) expressed as $\mathrm{kg}$ per pot lifted between different sites among season from Summer 2010 to Summer 2010. (a) Summer 2010, (b) Winter 2010, (c) Spring 2010, (d) Summer 2011, (e) Winter 2011, (f) Spring 2011 and (g) Summer 2012. The sites outside the reserve were (from East to West on the Wellington south coast) PH: Palmer Head, HBO: Houghton Bay Outside, HBI: Houghton Bay Inside, TI: Taputeranga Island, TSR: The Sirens Rock, WOB: Western side Owhiro Bay RR: Red Rocks and SH: Sinclair Head. 


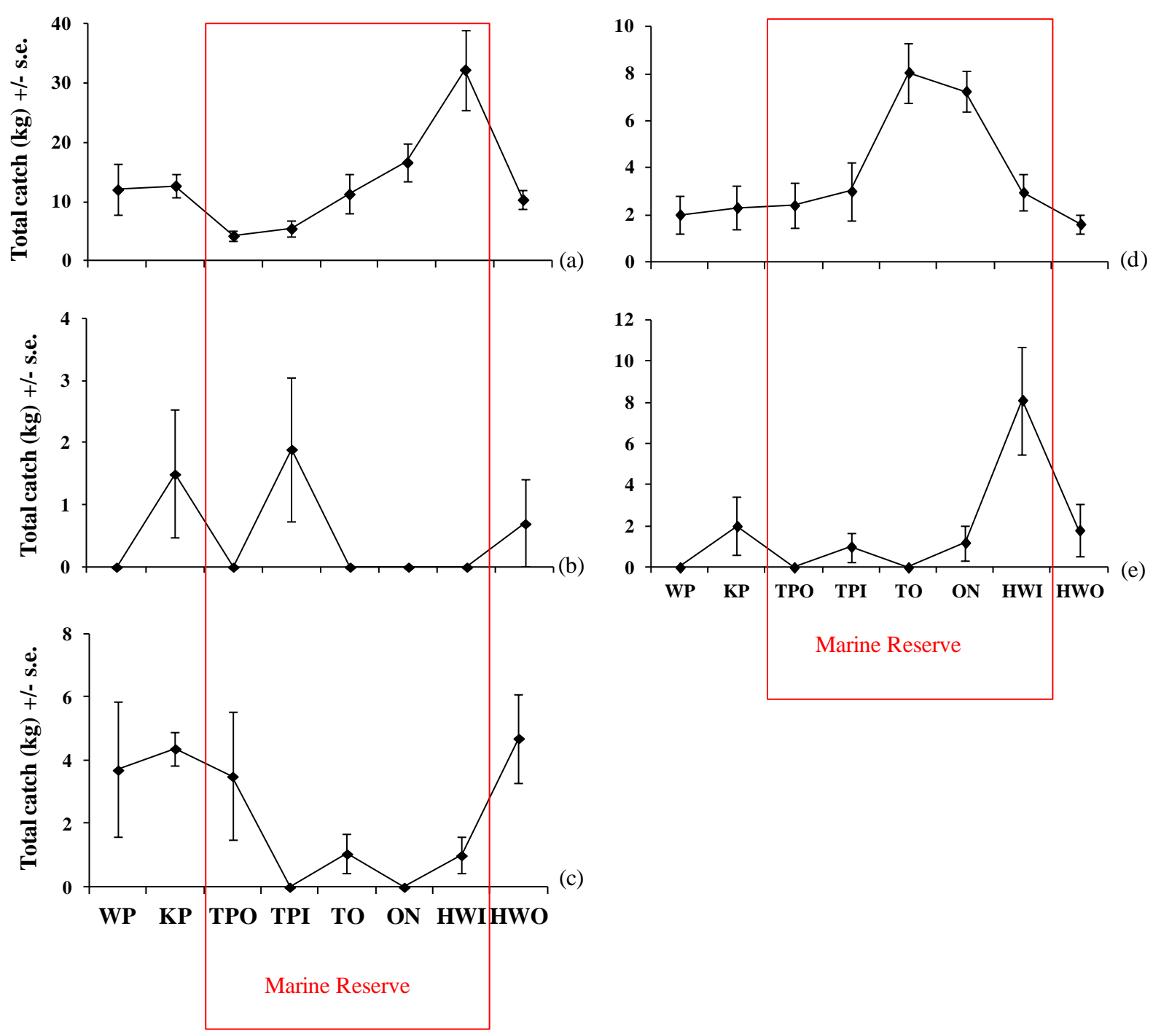

Figure 5.9: Mean Catch Per Unit Effort (CPUE) expressed as $\mathrm{kg}$ per pot lifted between different sites among season from Winter 2010 to Summer 2010. (a) Winter 2010, (b) Summer 2011, (c) Winter 2011, (d) Spring 2011 and (e) Summer 2012. The sites outside of the reserve were (from the south to the north of Kapiti Island), WP: West Point, KP: Kaiwharawhara Point, TPO: Trig Point outside and HWO: Hole in the wall outside. The four sites inside the reserve were: TPI: Trig Point inside, TO: Te Oneroa, ON: Onepoto and HWI: Hole in the wall inside. 


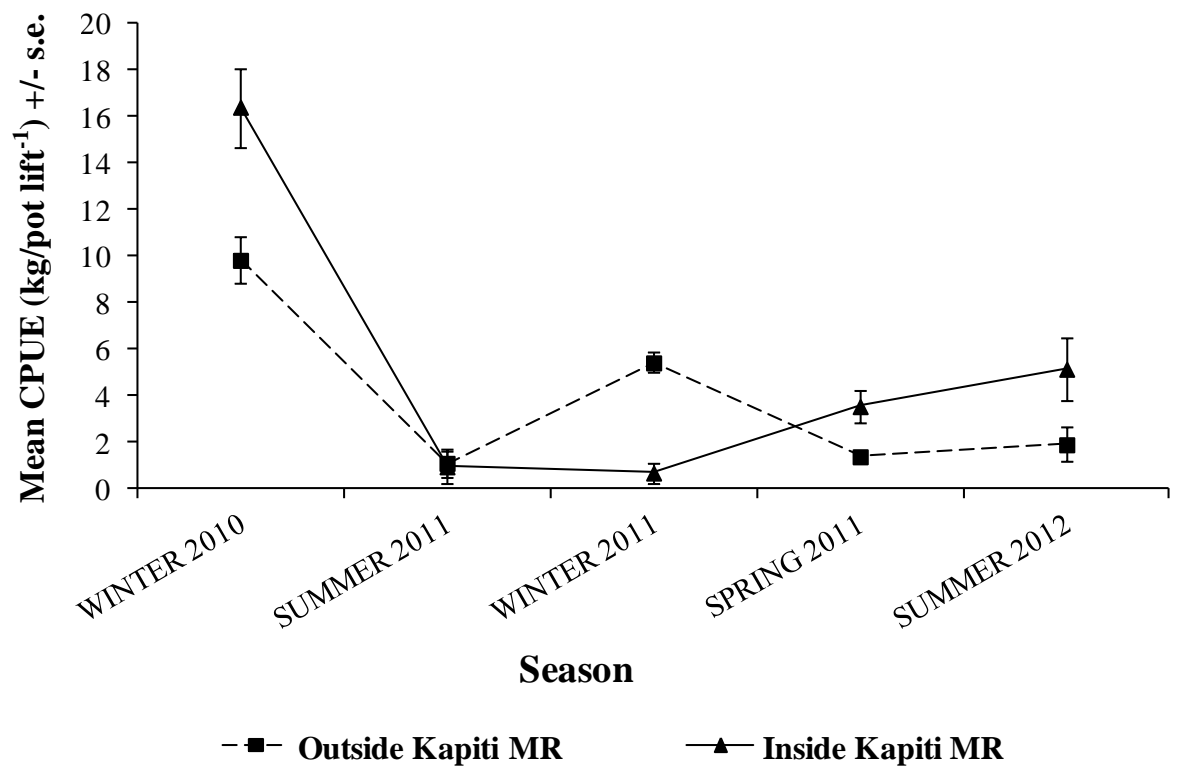

Figure 5.10: Mean CPUE (kg rock lobster per pot lift; males and females pooled) in three different seasons from 2010 to 2012. The graph shows the catch inside and outside of Kapiti Marine Reserve.

\subsubsection{Historical commercial Catch Per Unit Effort versus current Catch Per Unit Effort}

In Taputeranga MR the CPUE collected during this study both inside and outside the MR was significantly different from the historical commercial fisheries data (inside: PERMANOVA, pseudo- $F=12.488, \mathrm{p}<0.001$; outside: PERMANOVA, pseudo- $F=40.057, \mathrm{p}<0.001$ ) (Table 5.2). The average CPUE from this study was twice as high as the commercial CPUE (1998 to 2005) (Fig. 5.11a).

At KMR, however, the difference between my CPUE data and the commercial CPUE was significantly different only inside the MR (PERMANOVA, pseudo-F=3.1017, $\mathrm{p}=0.049$ ). The average CPUE at KMR from this study was 1.93 times higher than the commercial CPUE (1998 to 2005) (Fig 5.11b).. 
Table 5.2: PERMANOVA results between data source origin (origin; two levels: commercial and data collected in this study), and 'Season' (with three levels were Summer, Winter and Spring). Data from inside and outside were run independently. The analysis was based on similarity matrices calculated using Bray-Curtis coefficients. NP: Number of permutations.

\begin{tabular}{|c|c|c|c|c|c|c|}
\hline \multirow{2}{*}{$\begin{array}{c}\text { INSIDE } \\
\text { Source }\end{array}$} & \multicolumn{6}{|c|}{ Taputeranga MR } \\
\hline & df & SS & MS & Pseudo-F & $\mathbf{p}$ & NP \\
\hline Origin & 1 & 9150.9 & 9150.9 & 12.488 & $0.0001 *$ & 9943 \\
\hline Season & 2 & 10276 & 5138.1 & 7.0116 & $0.0003 *$ & 9962 \\
\hline OriginxSeason & 2 & 8974.4 & 4487.2 & 6.1235 & $0.0004 *$ & 9965 \\
\hline
\end{tabular}

\begin{tabular}{rccccc}
\hline \multicolumn{6}{c}{ Kapiti MR } \\
\hline df & SS & MS & Pseudo-F & p & NP \\
\hline 1 & 3373.9 & 3373.9 & 3.1017 & $0.049^{*}$ & 9954 \\
2 & 4519.6 & 2259.8 & 2.0775 & 0.0893 & 9950 \\
2 & 5024.7 & 2512.4 & 2.3097 & 0.0567 & 9941 \\
\hline
\end{tabular}

\begin{tabular}{|c|c|c|c|c|c|c|}
\hline \multirow{2}{*}{$\begin{array}{c}\text { OUTSIDE } \\
\text { Source }\end{array}$} & \multicolumn{6}{|c|}{ Taputeranga MR } \\
\hline & df & SS & MS & Pseudo-F & $\mathbf{p}$ & NP \\
\hline Origin & 1 & 29103 & 29103 & 40.057 & $0.0001 *$ & 9949 \\
\hline Season & 2 & 5443.4 & 2721.7 & 3.7461 & $0.0096 *$ & 9948 \\
\hline OriginxSeason & 2 & 3326.7 & 1663.4 & 2.2894 & 0.0645 & 9935 \\
\hline
\end{tabular}

\begin{tabular}{rrrrrr}
\hline \multicolumn{5}{c}{ Kapiti MR } \\
\hline df & SS & \multicolumn{1}{c}{ MS } & Pseudo $-\mathbf{F}$ & \multicolumn{1}{c}{ p } & NP \\
\hline 1 & 1513 & 1513 & 1.6618 & 0.177 & 9956 \\
2 & 13281 & 6640.7 & 7.2936 & $0.0001 *$ & 9954 \\
2 & 16071 & 8035.7 & 8.8258 & $0.0001 *$ & 9953 \\
\hline
\end{tabular}

Season also played an important role in CPUE except outside the MR in KMR (Table 5.3). The seasonal variation followed a different pattern in my study compared to commercial data. In my study, CPUE was higher in Spring, especially inside the TMR, but commercial CPUE remained relatively constant over the seasons (Fig. 5.3a). At KMR only Winter showed higher CPUE inside and outside of the reserve compared with commercial CPUE data (Fig. $5.3 b)$. 


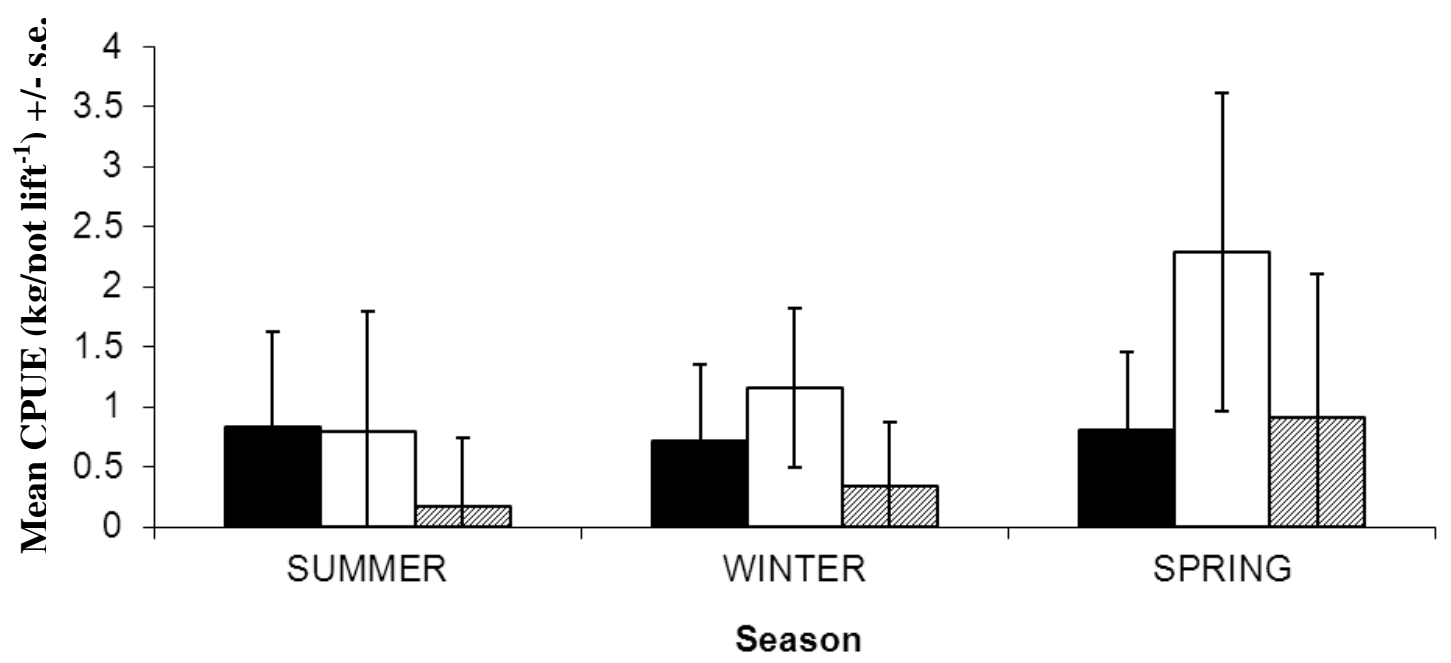

-915 aTMR inside aTMR outside

(a)

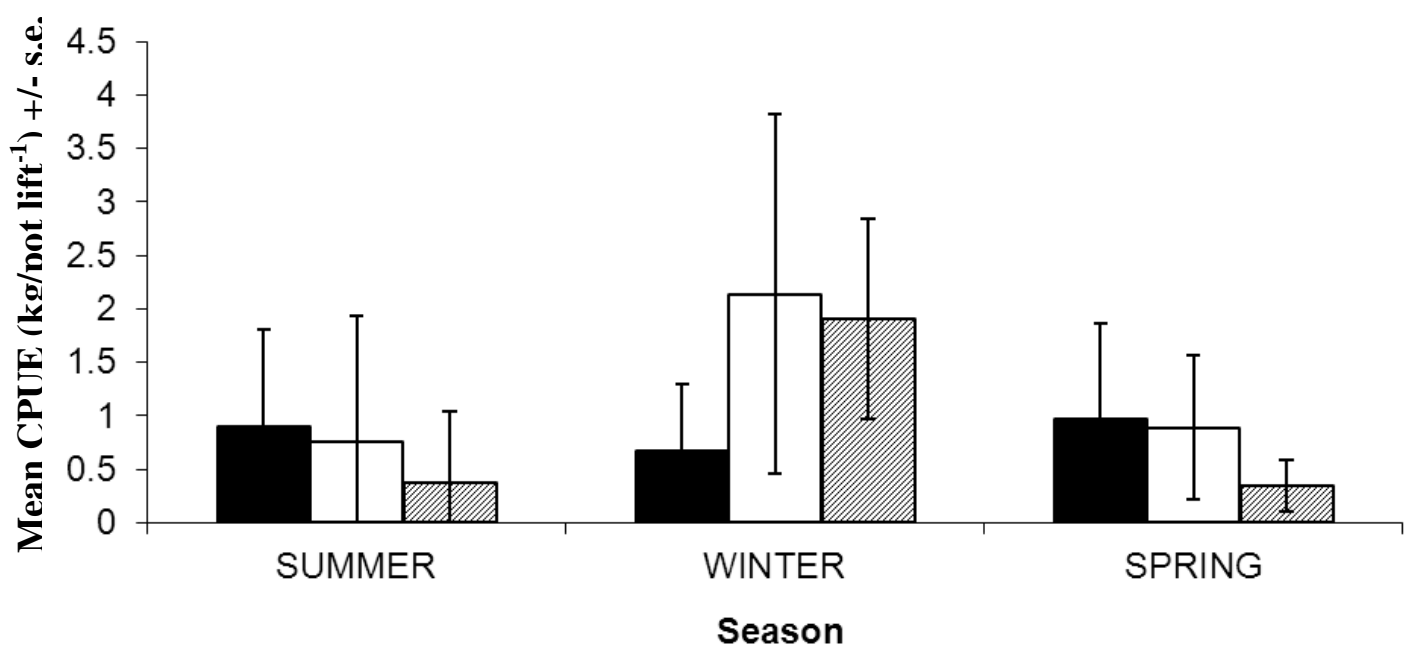

घ934 aKMR inside øKMR outside

(b)

Figure 5.11: Mean Catch Per Unit Effort (CPUE) expressed as kg per pot lifted between different seasons from 1989 to 2005. (a) Comparison between mean CPUE between area 915 (Wellington South coast) and data from Taputeranga MR inside/outside. (b) Comparison between mean CPUE between area 934 (Kapiti coast) and data from Kapiti MR inside/outside. The 915/934 data were pooled between years and separated between season. Data from this study were separated between inside and outside of the reserve, and then separated per season. 
Table 5.3: Pair-wise comparisons between research and historical commercial catch data for three seasons (Summer, Winter, and Spring) Data from inside and outside each MR were analysed separately. NP: Number of permutations.

\begin{tabular}{|c|c|c|c|c|c|c|c|}
\hline & \multirow[b]{2}{*}{ Season } & \multicolumn{3}{|c|}{ Taputeranga } & \multicolumn{3}{|c|}{ Kapiti } \\
\hline & & $\mathbf{t}$ & $\mathbf{p}$ & $\mathbf{N P}$ & $\mathbf{t}$ & $\mathbf{p}$ & $\mathbf{N P}$ \\
\hline \multirow[t]{3}{*}{ Inside } & Summer & 2.7173 & $0.0019 *$ & 9948 & 1.7049 & 0.0615 & 9875 \\
\hline & Winter & 2.5489 & $0.0073^{*}$ & 9940 & 2.5378 & $0.0032 *$ & 9942 \\
\hline & Spring & 3.2655 & $0.0006^{*}$ & 9939 & 0.55401 & 0.7305 & 9071 \\
\hline \multirow[t]{3}{*}{ Outside } & Summer & 5.4463 & $0.0001 *$ & 9948 & 1.7734 & 0.05 & 9874 \\
\hline & Winter & 3.1121 & $0.0006^{*}$ & 9951 & 4.0289 & $0.0001 *$ & 9949 \\
\hline & Spring & 2.6833 & $0.002 *$ & 9948 & 1.8123 & 0.0523 & 9080 \\
\hline
\end{tabular}

\subsubsection{Rock lobster morphometric indices}

Mean values of all five morphometric indices were greater inside both reserves compared to outside. In addition, mean values of all 5 morphometric indices for inside KMR and outside KMR were greater than for inside TMR and outside TMR, respectively (Table 5.4). Significant differences between inside and outside were observed for TMR for carapace length, carapace width, tail length, tail width and weight. However, KMR showed significant differences in carapace length, carapace width between inside and outside of the reserve (Table 5.5). 
Table 5.4: Average size for carapace length, carapace width, tail length, tail width and weight for rock lobsters caught inside and outside of Taputeranga and Kapiti MR (mean \pm s.e.).

\begin{tabular}{|c|c|c|c|c|}
\hline & \multicolumn{4}{|c|}{ Marine Reserve } \\
\hline & \multicolumn{2}{|c|}{ Taputeranga } & \multicolumn{2}{|c|}{ Kapiti } \\
\hline & Inside & Outside & Inside & Outside \\
\hline Carapace length (mm) & $111.41 \pm 3.9$ & $104.22 \pm 3.3$ & $133.02 \pm 4.7$ & $117.11 \pm 5.3$ \\
\hline Carapace width (mm) & $70.11 \pm 2.9$ & $65.05 \pm 2.3$ & $82.03 \pm 3.6$ & $72.92 \pm 4.2$ \\
\hline Tail length (mm) & $127.22 \pm 3.7$ & $116.22 \pm 3.5$ & $145.84 \pm 4.4$ & $132.98 \pm 5.7$ \\
\hline Tail width (mm) & $63.11 \pm 3.03$ & $59.84 \pm 2.3$ & $78.20 \pm 3.11$ & $72.45 \pm 4.2$ \\
\hline Weight (gr) & $860.11 \pm 17.1$ & $669.64 \pm 13.2$ & $1360.63 \pm 27.51$ & $982.71 \pm 19.7$ \\
\hline
\end{tabular}

Table 5.5: Two-tailed $t$-test for a comparison of morphometric indices between lobsters from inside and outside two MRs. Significant results are shown in bold.

\begin{tabular}{lrrrrr}
\cline { 2 - 3 } & \multicolumn{3}{c}{ Marine Reserves } \\
\cline { 2 - 3 } \cline { 5 - 6 } \cline { 5 - 6 } \cline { 5 - 6 } \cline { 5 - 6 } Carapace length & $\mathbf{0 . 0 0 2}$ & 265 & & T.032 & 118 \\
Carapace width & $\mathbf{0 . 0 0 0 1}$ & 265 & & $\mathbf{0 . 0 2 7}$ & 118 \\
Tail length & $\mathbf{0 . 0 0 0 1}$ & 92.7 & & 0.103 & 64.9 \\
Tail width & $\mathbf{0 . 0 2 2}$ & 265 & & 0.33 & 87.5 \\
Weight & $\mathbf{0 . 0 0 0 1}$ & 265 & & 0.082 & 65.9 \\
\hline
\end{tabular}

In the TMR, the mean carapace width increased with wide varienace over the sampling period (2010-2012) (Fig. 5.12). In summer 2010 the mean carapace width was $60.6 \mathrm{~mm}$ ( \pm $3.3 \mathrm{~mm}$ s.e.), by then end of Spring 2011 (last season with captures inside) the mean carapace width was $69.8 \mathrm{~mm}( \pm 2.7 \mathrm{~mm}$ s.e.). Similar results were found for the size of the tail widths, which increased from $56.2 \mathrm{~mm}( \pm 2.5 \mathrm{~mm}$ s.e. $)$ in summer 2010 to $66.5 \mathrm{~mm}( \pm 2.4 \mathrm{~mm}$ s.e. $)$ by Spring 2011. In addition, outside the reserve the tail wide had increased around $5 \mathrm{~mm}$ (mean size) from summer $2010(58.5 \mathrm{~mm} \pm 2.4 \mathrm{~mm}$ s.e. $)$ to summer $2012(64.5 \pm 2.4 \mathrm{~mm}$ s.e.) (Fig. 5.13). 

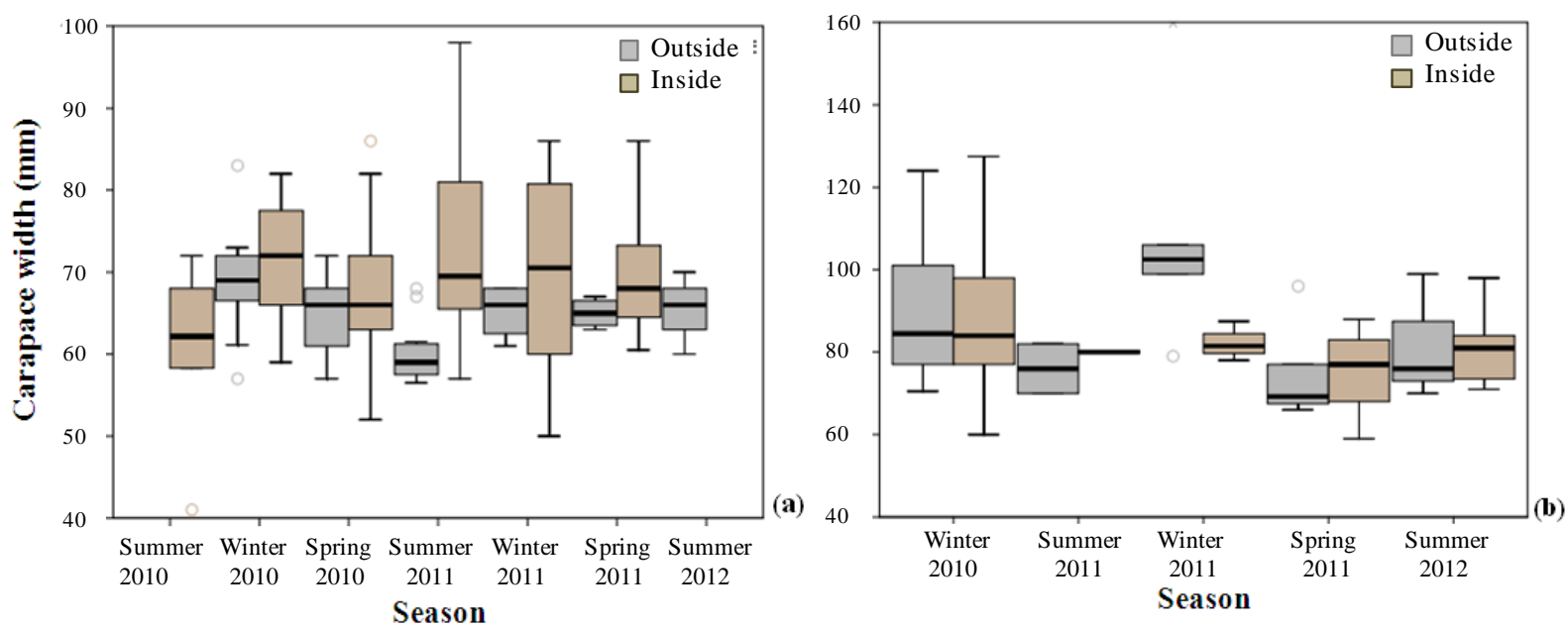

Figure 5.12: Box plots for rock lobster caught inside and outside Taputeranga and Kapiti Marine Reserves respectively (male and female data were pooled). Box plots show the median interquartile range (box) for carapace width $(\mathrm{mm})$ between different seasons and years. (a) Taputeranga Marine Reserve and (b) Kapiti Marine Reserve.
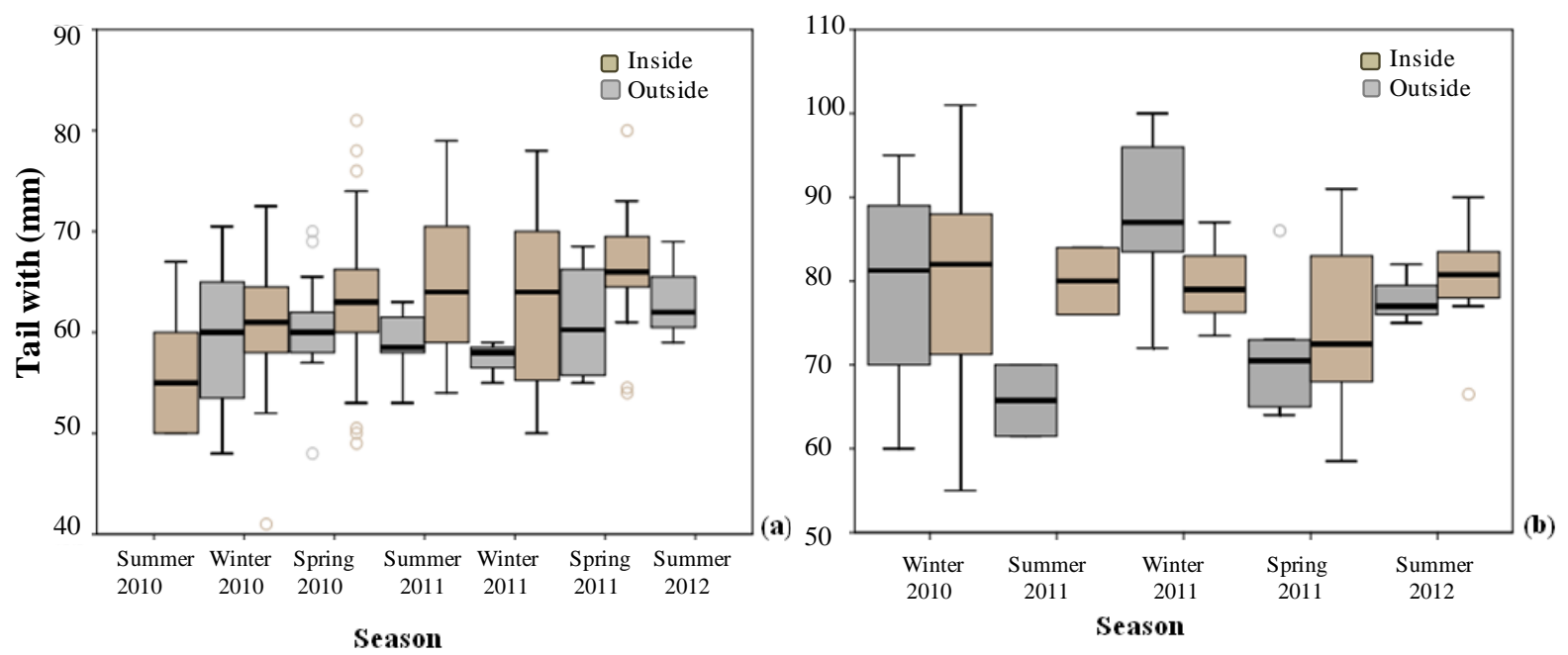

Figure 5.13: The box plots for rock lobster caught inside and outside of Taputeranga and Kapiti Marine Reserve, respectively (males and females data were pooled). Box plots show the median interquartile range (box) for tail width $(\mathrm{mm})$ between different season and years. (a) Taputeranga Marine Reserve and (b) Kapiti Marine Reserve.

At the TMR the size frequency histograms for male and female RLs revealed that the majority of males and females inside and outside of the reserve were larger than the minimum legal size (MLS - tail width MLS for females is $60 \mathrm{~mm}$ and for males is $54 \mathrm{~mm}$ ). Inside the reserve $86.8 \%$ of females and $91.2 \%$ of males were larger than MLS, while only $56 \%$ of females and $83 \%$ of males outside of the reserve were larger than MLS. In the 
KMR, all RL caught (100\%) within and outside the reserve were larger than MLS (Fig. 5.14 a-h \& 5.15a, b).

Over time (from Summer 2010 to Summer 2012) the size frequency histograms were markedly right skewed for males and females inside the TMR (Fig. 5.14 a-h \&5.15a, b).

\subsubsection{Sex ratio}

The total ratio of males to females caught inside TMR was $1: 1.7$. However, the sex ratio outside the reserve recorded more females outside compared with the males caught. The sex ratio outside was approximately 1:1.4 males to females.

This ratio varied seasonally, with more males in winter both inside and outside of the reserves, where the sex ratio was 3:1 males to females. In Spring more males were found inside TMR (2.3:1 males to females), whilst more females were found outside of the reserve (1:2 males to females).

At KMR the sex ratio of RLs caught inside the reserve was 1:2.8 males to females. Outside the reserve the sex ratio was 3:1 males to females. There were fluctuations in the sex composition of the catches between seasons, but no consistent pattern was evident. 

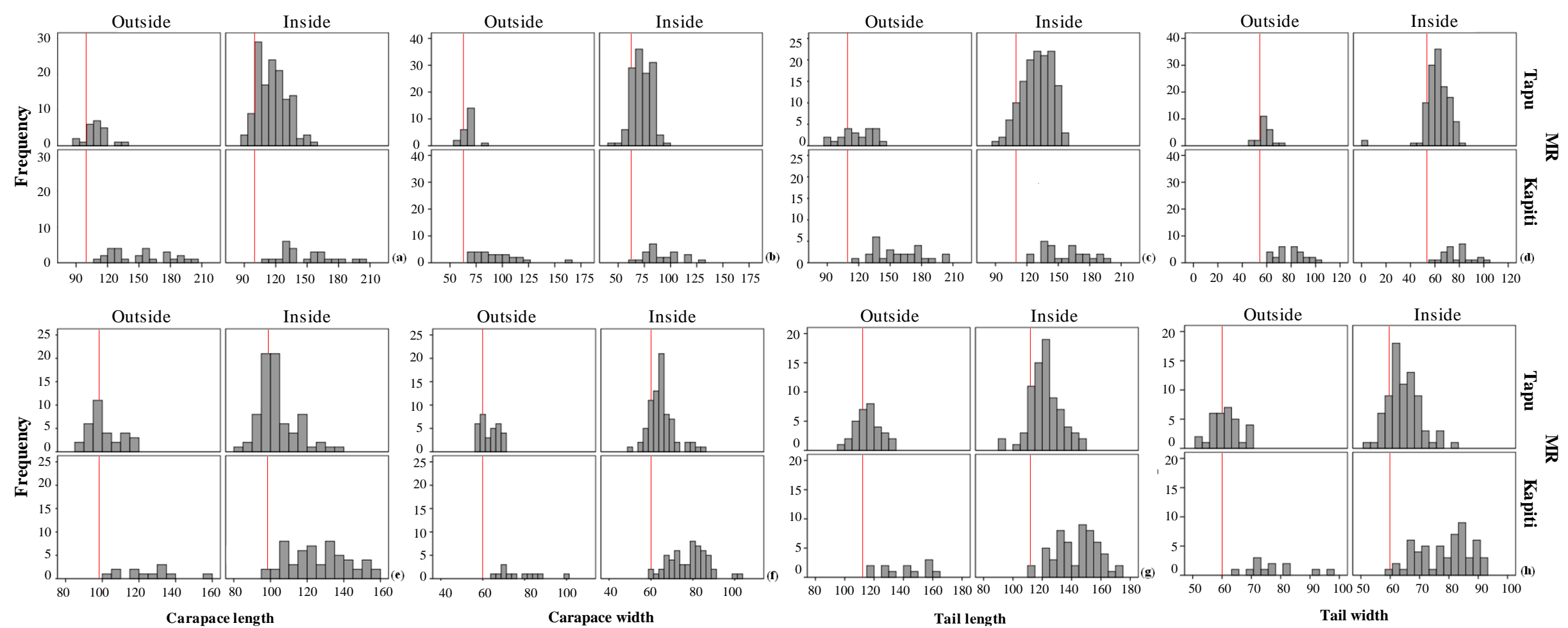

Figure 5.14: Size frequency histograms (\% frequency) for male and female rock lobsters surveyed on the Wellington south coast and Kapiti Island within and outside Taputeranga and Kapiti MRs. Figures from a-d show male data, and from e-h are the female data. The measures are carapace length, carapace width, tail length and tail width. Vertical red lines are the minimum legal sizes equivalent to $54 \mathrm{~mm}$ TW for males and $60 \mathrm{~mm}$ TW for females. 

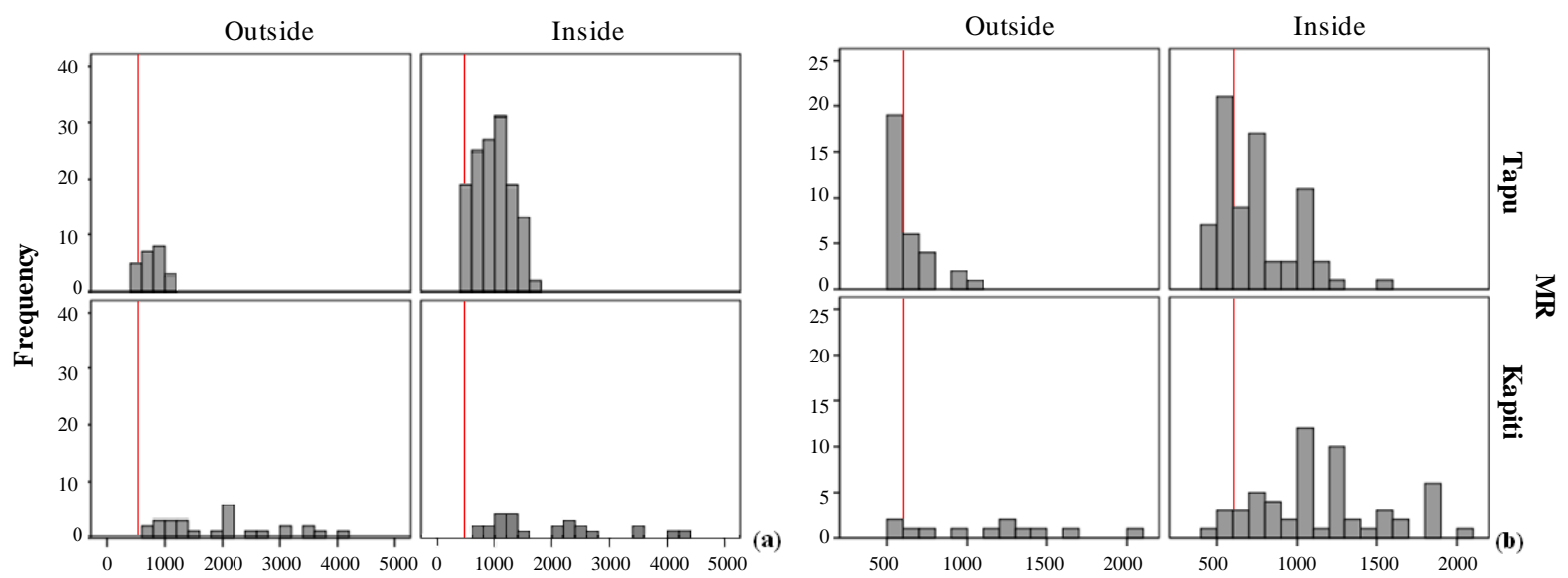

Figure 5.15: Weight frequency histograms ( $\%$ frequency) for male (a) and female (b) rock lobsters surveyed at Wellington south coast and Kapiti Island within and outside Taputeranga and Kapiti MR. The measure is weight of rock lobster caught. Vertical red lines are the minimum legal sizes for either sex. 


\subsection{Discussion}

In this study I investigated how rock lobsters (RLs) (Jasus edwardsii) have responded to the protection afforded by two marine reserves (MRs) in New Zealand (Taputeranga and Kapiti) by comparing data from different sites (inside and outside MRs) and seasons from 2010 to 2012. I compared data from historical catches in the RL fishing sites and catch data from inside of MRs and examined temporal variability.

RLs are responding positively to protection, with higher abundance (CPUE) inside the MRs compared to outside. This effect was more noticeable at the Taputeranga MR (TMR) which is one of the newest MRs established in New Zealand (August 2008) than at Kapiti MR (KMR - established in May 1992). At TMR protection appears to have had a strong and significant positive effect on RL in terms of abundance, biomass and size. The majority of RLs were caught inside the reserve (78\%). Significant differences between inside and outside the TMR were found, with 3.1 times higher biomass inside the MR compared to outside. In addition, heavier rock lobsters were found inside the reserve. These results indicate that TMR is allowing the local RL population to rebuild. These results are similar to other studies on lobsters as well as on other invertebrates and fish species inside marine protected areas (see Davis, 1977; Warner et al., 1977; Bertelsen et al., 2000; Davidson, 2001a,b; Goñi et al., 2001; Halpern, 2002; Davidson, 2004; Cox and Hunt, 2005; Pande et al., 2008).

\section{Rock lobster population increases}

The recovery of the RL population in TMR appears to have occurred very quickly. When my study began (January, 2010), the TMR had been closed to fishing for less than 2 years (August 2008). While a full population recovery may take longer, several studies report similar rapid increases in marine populations. For example, Halpern and Warner (2002) reviewed $80 \mathrm{MRs}$ and found that higher average biomass, size and diversity in reserves can occur within 1-3 years. In the late 1990s, other authors (including Roberts, 1995; Russ and Alcala, 1998) found that MRs in tropical regions can show positive responses in biodiversity in less than 2 years. In addition, heavily targeted species (such as RLs) are more likely to respond quickly when fishing is removed, because fishing is the main negative factor affecting population size and demography (Polacheck, 1990; Carr and Reed, 1993; Rowley, 
1994, Halpern and Warner, 2002; Pande and Gardner, 2009; Pande et al., 2008; Diaz Guisado et al., 2012). In temperate marine reserves like New Zealand (as well as Australia), other studies have found that RLs can respond positively and quickly in terms of size and biomass (see Babcock et al., 1999; Edgar and Barrett, 1999; Kelly et al., 2000; Davidson et al., 2002; Freeman, 2008). Therefore as predicted by Pande and Gardner (2009), there was an increase in the mean size of RLs; however, I also found an increase in mean biomass and mean abundance. Two meta-analyses carried out in New Zealand (Pande et al., 2008 and Diaz Guisado et al., 2012) showed that RLs were, on average, more abundant inside than outside MRs. Similar responses of other types of spiny lobster species have also been reported in response to protection, such as the European spiny lobster Palinurus elephas in the Mediterranean (Goñi et al., 2001) and the Caribbean spiny lobster Panulirus argus (Davis, 1977; Warner et al., 1977; Bertelsen et al., 2000; Cox and Hunt, 2005).

The biomass caught in terms of CPUE ( $\mathrm{kg} \mathrm{pot}^{-1}$ lifted) inside both MRs was generally higher than outside, although only significant differences were reported at TMR. At the TMR biomass was 3.1 times higher inside the reserve compared to outside, while at KMR it was 1.36 times higher. However, both these CPUE values are lower than those reported from other MRs. For example, Freeman (2008) found that in Te Tapuwae o Rongokako MR (Gisborne, New Zealand) CPUE was 46 times higher inside the MR four years after MR establishment. Other RL studies have found higher CPUE inside of reserves (see MacDiarmid and Breen, 1992; Babcock et al., 1999; Kelly et al., 2000; Davidson et al., 2002; Kelly et al., 2002; Shears et al., 2006; Freeman et al., 2012). In the case of the KMR, the difference in the biomass between inside and outside the reserve was not significant. This could be because the surrounding areas at KMR are not as heavily fished for RLs as they are for other fish species (i.e., blue cod, snapper and kingfish) for the following reasons: (1) because KMR is located around Kapiti Island making it more difficult to access to the KMR ;(2) because old MRs like KMR are predicted to supply 'trophy-sized' fish to recreational fishers through spillover process across boundaries from marine reserves (Bohnsack, 1996; Roberts et al., 2001), KMR contains bigger RLs, and divers and fishers prefer smaller RLs ('size reason') because they are considered to be of better quality (i.e., tastier) than the bigger ones (fishers pers.com.), therefore, KMR is not heavy targeted as other places in Wellington South Coast, 3) emigration from the KMR is high thus depressing biomass inside and increasing it outside, and 2) beuse poaching of RL inside the MR is high because it is on the seaward side of the island and thus hard to police. 


\section{A gradient of rock lobsters with increasing distance from the centre of MRs}

Another finding at TMR was that the highest biomass was recorded in the centre of the reserve and decreased toward the MR boundaries, then decreased even more outside the reserve. Other studies have reported similar results for RLs (see Kelly et al., 2000; Kelly et al., 2002; Kellner et al. 2007; Freeman, 2008) and also for other species including blue cod and snapper (Denny et al., 2004; Pande et al., 2008; Diaz Guisado et al., 2012). This reduction is most probably explained by a combination of fishing effort and RL movements. The fishing effort at TMR (including commercial, recreational and customary fishing - as well as diving) was relocated mainly outside the boundaries of the reserve. In addition, there is a general perception that MRs can enhance fisheries outside their boundaries leading to a 'fishing the line' strategy (Kelly et al., 2000). The loss of fishing grounds (due to the MR designation), added to the location of TMR along the city's coast, has resulted in the TMR's boundaries being popular fishing grounds. This intense fishing effort may explain the decrease in biomass and abundance and lead to RLs avoiding cross boundary movements between inside and outside of the MR (Davis, 1977; Blonder et al., 1992; Eggleston and Dahlgren, 2001; Kelly and McDiarmid, 2003; Shears et al., 2006). Another potential reason about highest biomass in the centre at TMR could be because the biggest reef is mainly located inside and at the boundaries of the reserve, where there is an Island called Taputeranga Island, which creates excellent refuges for RLs (adults and juveniles) at the centre of the TMR.

Other factors could also be affecting RL population distribution around the TMR and KMR. The size and shape of marine reserves have been considered as important factors in RL distribution, because the MR size is related to the RL home range (MacDiarmid, 1991; MacDiarmid et al., 1991), and MR shape (i.e. perimeter-to-area ratio) has to include appropriate shelter areas, habitats (including for reproduction) and food (Schonewald-Cox and Bayless, 1986; Cox et al., 1997; Acosta, 2002; Cox and Hunt, 2005). These have been described as important factors for other Palinurid species like Panulirus argus, Panulirus guttatus, Panulirus homarus, Panulirus marginatus and Homarus gammarus (Berry and Smale, 1980; Howard, 1980; Addison, 1986; Herrnkind and Butler, 1986; Davis and Dodrill, 1989; Polovina et al., 1995; Butler and Herrnkind, 1997; Eggleston and Dahlgren, 2001; Wynne and Cote, 2007). The high habitat complexity around Kapiti Island may affect RL distribution. Stewart and MacDiarmid (2003) found at Kapiti Island that RLs were more numerous on the western side of the island (at the same sampling sites used in this study), 
which was explained by the high complexity of reef structures compared with the other side of the island. In addition, Kapiti is an area with low puerulus settlement compared with other areas the North Island of New Zealand, which may lead to a slower recovery of RL population in Kapiti Island than elsewhere in NZ (Stewart and MacDiarmid, 2003).

\section{Historical catches versus current catches}

Because I used the same historical fishing grounds for my research, the historical commercial catch CPUE, this made it possible to make comparions between historical commercial catch CPUE data and my CPUE data collected between 2010 - 2012. Comparison of historical commercial catch CPUE data and my CPUE data collected between 2010-2012 inside TMR showed a higher mean CPUE in this study compared to historical data, with the greatest difference being in winter and spring when the highest catches were recorded. However, catches outside the reserve showed a similar or lower mean CPUE compared to the historical data. Moreover, the patterns of seasonal variation my catch found in the TMR are very similar to the historical commercial catches. Similar results were found by Kelly et al. (2002) at the Cape Rodney to Okakari Point MR in northern NZ who identified a fishing peak from winter to spring and then a decline in summer. However, at Gisborne in north-eastern NZ (Te Tapuwae o Rongokako MR), Freeman (2008) found a different pattern, whereby CPUE declined in winter, and peaked in summer. The highest mean CPUE inside the TMR may indicate that the RL population is building well within the reserve

At the KMR, the average CPUE was higher than historical data with only summer and winter catches outside the reserve being similar to the historical data pattern. In contrast, CPUE from inside the MR showed the opposite pattern to the historical data, where the lowest catch was in winter inside the reserve. However, seasonal catches per year did not show any clear pattern. It is possible that these seasonal differences are because there are differences in local processes between the MRs that are regulating RL seasonal catchability, such as water temperature and salinity which affect population dynamics (Punt et al., 1997; Freeman, 2008). The other important point that should be considered is that the historical commercial data from the KMR includes the complete RL934 area, which is a larger area than my study area. This may explain in part the discrepancies observed between my data and the historical data. 


\section{Seasonal movements}

Despite being described as a species with high site fidelity, RLs show seasonal movements between inshore and offshore environments that can exceed $5 \mathrm{~km}$ (up to $12 \mathrm{~km}$ ) in New Zealand (MacDiarmid et al., 1991; Kelly et al., 1999; Kelly, 2001; Gardner et al., 2003; Barrett et al., 2009). These seasonal movements are thought to be related to moulting, reproduction and feeding cycles (MacDiarmid et al., 1991; Kelly et al., 1999; Kelly, 2001; Freeman, 2008; Barrett et al., 2009; Freeman et al., 2012). However, Freeman (2008) considered these seasonal movements as not consistent over regional spatial scales. Therefore, it is important to determine how these movements at local scale are, for a good understanding of the dynamics RLs stocks and their management. In my study I found a lower number of RLs in the middle of February, this might be explained by migration offshore at the TMR started ( $50 \mathrm{~m}$ deep). In mid-April RL catchability increased again, suggesting this is when they move back inshore. At KMR this return of RL was generally two weeks earlier than at the TMR. Because these movement patterns were consistent through the course of this study, it suggests that these seasonal movements are more related to mate and moult. In northern New Zealand, MacDiarmid (1991) and Kelly et al. (1999) found that males moved offshore to feed and then for mating in July, they then moved inshore to moult in October - November. Later on, Freeman (2008) found on the coast north of Gisborne that in August and September tagged males moved offshore (43 m deep) to moult, and then in February tagged males came back inshore, where they remained until next moulting. Therefore, there are not clear patterns of seasonal movement of RLs at bigger than local scales and more studies are needed to better understand RLs movement behaviour.

\section{Sex ratio effects}

It is important to consider the sex ratio when assessing MR effectiveness. This is because fishing not only impact the biomass and abundance of RLs but also the sex ratio (Frusher and Hoening, 2001; Freeman, 2008). In New Zealand and Australia, due to the fishing regulations and seasonal movement, the RL fishery is sometimes biased towards males and sometimes towards females (Prescott et al., 1997; Breen et al., 2005; Freeman, 2008). In New Zealand the fisheries regulations state that berried females and soft-shelled RLs have to be returned to the water. In addition, there are different sex-specific minimum legal sizes (tail width MLS for males is $54 \mathrm{~mm}$, for females is $60 \mathrm{~mm}$ ). Therefore these regulations have a biasing effect 
on the sex ratios of fished RL populations. Because all fishing activities are banned in MRs it is expected that the sex ratio will recover to its natural state (Freeman, 2008). Both outside and inside the TMR the sex ratio was biased toward females (i.e. fewer males than females). This might reflect that the fishery located in the surrounding areas is mainly male biased (selecting more males rather than females during fishing seasons). Similar results were reported by Sullivan (2004) and Freeman (2008), who found a male-biased fishery in Gisborne. Also, another factor impacting male to female sex ratios is the slower growth of females after reaching sexual maturity relative to males thus exposing males to fishing pressure sooner than females.

Both size and sex ratio are very important in group structure having implications for the reproductive potential of RL populations (MacDiarmid and Butler, 1999; MacDiarmid and Kittaka, 2000; MacDiarmid et al., 2000; Freeman, 2008). For example, a large number of large males means it is more likely than females will be successfully fertilizes due to females preferentially mating with large males (MacDiarmid and Butler, 1999; Davidson et al., 2002; Cox and Hunt, 2005). Therefore, bigger, more abundant RLs and with an even sex ratios are likely to produce more egg output within MRs, which can then potentially be exported to adjacent fisheries (see MacDiarmid and Butler, 1999; Bertelsen and Cox, 2001; Cox and Hunt, 2005).

\section{Conclusions}

This study reports how RLs are responding positively to protection in two MRs in the Wellington region in terms of abundance and biomass. However, in order to better understand RL responses to MRs closure, it is important to conduct more studies in terms of cross boundary movement of RLs, especially around MRs where the fishing effort is concentrated near the boundaries. In this study I showed how within both MRs (TMR and KMR) RL populations are rebuilding with higher CPUE than in areas outside and higher than historical catches.. At the TMR higher RLs abundance were found, meanwhile at KMR bigger RLs were found. While the overall abundance, biomass and morphometric characteristics inside MRs are showing more, bigger and larger RLs, RLs outside of the reserve are not performing as the same as inside of the MRs. For example, at both MRs 
different seasonal catchability were found which means that RLs should be managed differently depending of their seasonality at local scales rather than consider general restrictions for recreational fishers, and regional restriction for commercial fisher as is currently. This should consider close seasons for specific times such as reproductive periods, in order to ensure higher and successful of reproduction rates, by diminishing the RLs stress level.

This study helps to create a more complete understanding of RLs along the Wellington South Coast inside and outside of MRs. In addition, this provides insights into the effectiveness of MRs (despite this is not the main goal in New Zealand), as well as better understanding of RLs populations dynamics that maybe lead to better management and protection. 


\section{Chapter 6.General Discussion}

This discussion is divided into three sections: 1) Methodological limitations, which highlights the strengths and weaknesses of the methodologies I used in each chapter; 2) Discussion and Perspectives, which outlines the findings and new insights from my study and considers new avenues for future research; and (3) Recommendations, which describes a new framework for establishing and managing MRs, reducing time and cost, and increasing public participation in MR establishment and management.

\subsection{Methodological limitations}

Here I identify and discuss the main challenges faced in conducting this research in order to support future research in this area. In chapter 2, the first challenge was data gathering. The challenge to estimate the pre-establishment cost was a result of the scarcity of available information. My study, as well as that of McCrea-Strub et al. (2011), found that there is very little financial data collected for reserve establishment, and that the main information resources are grey literature and personal communications. Therefore, I had to define a list of assumptions that would allow me to make my calculations. These assumptions mean my estimates may not reflect the true costs. However, the methodology applied is likely to be applicable to other MRs/MPAs, or any process that would require a cost calculation. In the case of New Zealand, cost information is managed by government agencies. Despite this information being in the public record, the process and time to obtain it depends on staff time availability. Also the information when obtained often provided a low level of detail. Similar to budgeting practices in other countries, in New Zealand (see Green et al., 2012) conservation budgets come from central and local government. The conservation budget for protected areas is normally divided amongst different protected areas, and the level of priority of each protected areas determines the amount of money spent. For that reason MR managers could only provide an estimation of spending across cost categories (for example operational and salary components). Therefore, for this research I only got an estimation of spending. 
Although government department budgets are very limited at present, a potential solution could be that the government could manage an online public database that could be updated year by year, which might support future spending at each MR or other MRs. In addition, such an initiative may help to create a more transparent system in terms of public budgets. Although the proposed solution requires a significant financial investment, the government should consider it within their conservation priorities, because by creating this database, the complete process of MRs establishment would be faster and cheap to run and manage over the longer-term.

To develop the questionnaires used in chapter 3 and 4 I faced similar challenges. While it is true that questionnaires were critically important to collect the information necessary to develop those chapters, the design (type of questionnaire to be used), pre-testing and application requires four main components that have to be taken into account. The four components are: (1) Good topic knowledge. The questionnaire has to contain all the information and the area attributes necessary to describe the locations (in this case MR attributes) (Tait et al., 2009). (2) Be well defined. It has to be clear, short and precise. One of the problems in my research was the length of my first survey. Despite a good response rate, it could have been improved if the questionnaire was shorter, with fewer and narrower questions. (3) Time investment. A well-managed research topic, plus a well-defined questionnaire, helps to dramatically reduce the time invested. (4) Funding. To determine what types of questionnaire one will use is an important factor that will guide how much money to invest. In this research, I used a face-to-face questionnaire in chapter 3, but later on I used an Internet questionnaire in chapter 4. Although the first questionnaire was long and expensive, I found that the face-to-face questionnaire was a good approach to reach people for the first time to introduce the research and invite them to participate. Also, the topic was related to personal opinions, and therefore a face-to-face questionnaire provided the trust levels needed to get reliable answers to these types of questions (for questions see Appendices A and B). Moreover, I found that many people who took part in the first survey also participated in the second questionnaire (online). The questionnaire is a fundamental tool in social research and it has to be designed carefully to ensure reliable results (Tait et al., 2009). Also, it is important to consider the cost (money and time) to be invested in different types of questionnaires, which is an important point in research (see Berrens et al., 2003; Evans and Mathur, 2005; Marta-Pedroso et al., 2007; Fleming and Bowden, 2009; Tait et al., 2009). 
The main challenge encountered in chapter 5 was the unpredictable weather conditions at the study locations. Weather is always a key element of fieldwork, especially in the marine environment; however, the sampling methodology used can help to reduce the time wasted due to inclement weather. Despite some days of planned fieldwork being cancelled due to bad weather, in many cases it was still possible to go out due to the type of sampling method used. Therefore, I consider the use of rock lobster pots as an appropriate methodology to answer all the questions in this chapter. It is to be noted, however, that rock lobster pot catches can be biased because the catchability can change with rock lobster pot design, bait, 'soak' times as well as with the season, water temperature, visibility, rock lobster life cycles (MacDiarmid et al., 1991; Kelly et al., 1999; Kelly, 2001; Ziegler et al., 2002a, b \& 2003; Freeman, 2008; Barrett et al., 2009; Freeman et al., 2009, 2012). In my study, I tried to minimize all of these biases. I fished the same seasons for a two year period and used the same fishing grounds and soak time. In addition, in order to be as conservative as possible through time, I used the same rock lobster pots for my whole research, and the bait used was the same as that used by commercial fishermen. Freeman (2008) used a similar approach in her research to reduce the biases produced by the same factors. Other survey methods have been used to assess rock lobster responses to protection, but the use of rock lobster pots has advantages over the other methods such as a baited underwater video technique and underwater visual census (conducted by divers). The advantages are mainly in terms of time, cost and efficiency in places where weather conditions are difficult or unpredictable.

\subsection{Discussion and perspectives}

In my study I aimed to assess the impact and effectiveness of marine reserves in New Zealand by using socio-economic and biological evaluations. Moreover, these results serve as an opportunity to examine some aspects of governance of MRs in New Zealand. Each chapter in this thesis contains key components of this assessment, which together provides a detailed picture about MR performance in New Zealand.

Assessing the effectiveness and the impact of marine protected areas (MPAs) and marine reserves (MRs) remains one of the biggest challenges in marine conservation. Even with recent technologies and research developments, gaining a better understanding of MPAs and MRs is still difficult, because their effects are felt both inside the protected areas and beyond their boundaries (Claudet, 2011). Therefore, any new MPA establishment will have an effect 
not only within the MPA area, but also on the surrounding area, potentially modifying human well-being. These effects can be positive or negative, direct or indirect - for example, direct positive benefits exist by enhancing harvested populations beyond the MPA's boundaries (Kellner et al., 2007; Gell and Roberts, 2003; Halpern et al., 2010). Effects are even more significant when full no-take MPAs are established, such as MRs in New Zealand. From an economic perspective, MRs can be considered a public investment in marine conservation, so to determine how this investment affects society's well-being is an important question in resource management (Alban et al., 2011). By answering this question it should be possible to improve current conservation practices and increase the understanding and knowledge about how well MPAs are performing based on the proposed goals (Pomeroy et al., 2004). However, socio-economic and ecological fields are often ignored in most MPA assessments, or are not a priority, as is generally the case in New Zealand. Such oversights might occur because such evaluations are not a requirement under current legislation or because of funding shortfalls (see Bruner et al., 2003, Balmford et al., 2004, McCrea-Strub et al., 2011). To ignore one or more of these critical components in MRs management will provide an incomplete or biased view about MRs effects. This may produce an under/over-valuation of MPA effectiveness. Although the main goal of MRs in New Zealand is for scientific purposes (MR Act, 1971), for this reason, this research recognized and used biological and socioeconomic methods to build and increase our understanding of NZ MRs. In addition, my study provided new insights and avenues for potential future research.

New Zealand has different motives that underlie the establishment of MRs compared to other countries. Ecosystem preservation, fisheries management and the development of educational and recreational opportunities are the most commonly cited reasons for MR establishment (Alban et al., 2011). The first of these 'ecosystem preservation' is explicit in the MR Act (1971) as '...marine reserves for the purpose of preseverving them in natural state as he habitat of marine life for scientific stutudy.', but my research found that the public think more than this one reason that lead the MRs creation in New Zealand. Therefore, from a public point of view, MRs in New Zealand are pursuing simultaneous objectives, despite this not being actually explicit in the current MR legislation. It is importatt to recognise and understand the different motives for what people are thinking for MRs establishment, because form these motives would depend the future societal value of MRs, as well as the MRs success. 
MPA 'effectiveness' refers to how well MPAs are achieving the objectives for which they were established (Pomeroy et al., 2004). Nevertheless, I would include motives as part of MR effectiveness in New Zealand as well. This is because motives are closely linked to the types of benefits that society is expecting from MPAs, then through motives, MRs goals should be determined. This is critical to gain social recognition of MRs (Sanchirico, 2000; Carter, 2003; Pomeroy et al., 2004; Christie \& Pollnac, 2011; Alban et al, 2011). It is important that MR managers can identify and determine whether it is possible to achieve the goals that should be created from specific motives in the proposed MR area. Therefore, MR goals should be realistic and specific to each MR in order to prevent false expectations that might affect the benefits perceived by the society. For example, I found that even though MRs are good tools to protect marine environments, people could not see any direct benefits for themselves at either of my study sites (MRs). This could be because people's perceptions and expectations of MRs are out of line with the true objective of MRs in New Zealand, or simply because the benefits are not obvious to them. This disconnect might be resolved by strengthening the relationship between the public and other stakeholders and conservation managers, particularly through better information and relationship building. This will help ensure long term success (Christie \& Pollnac, 2011).

One way to assess MR effectiveness is to look at the impact (for example biological, social, economic and/or cultural) of the designation of a MR (Alban et al, 2011). Concerning the impact, identification of costs and benefits produced by MRs is one approach that may be used. In my study, I found four main costs that were associated with MRs: pre-establishment, establishment, management and displacement. The first cost (pre-establishment) is basically the one that is required for MR establishment and without it the MR would not progress. In my study the pre-establishment process of one of the MRs was analysed (TMR) and it took a long time (> 17 years). During this time almost 50\% of the costs were covered by nongovernmental and volunteer labour. The amount of free time and persistence demonstrated the high level of commitment to the MR by local stakeholders. Christie \& Pollnac (2011) explain that a high level of commitment to MPAs is not only based on the ecological and social benefits and equitable distribution of the benefits expected, but on the process by which these outcomes are generated. It was clear that the Taputeranga MR case took much longer due to conflicts amongst different groups (for more details see Gardner \& Bell, 2008). Lack of funding was also a key element for this delay, because the formal process required extensive documentation and information on why a MR should be established. The MR 
establishment showed power and capacity of those who worked on it, creating major influences that resulted in successful MR establishment. During the pre-establishment process individual and collective motives guided the process until the establishment of the MR, but these motives were not included in my study. They would however, be a valuable contribution to the present work if investigated further.

For TMR the pre-establishment process responsibilities were shared, as well as the costs amongst governmental and non-governmental organisations in order to produce something expected to be beneficial to everyone and to future generations. The current legal framework supporting the creation of MRs in New Zealand, the MR Act, 1971 (today under revision) is a positive example of good governance during the pre-establishment process, where participatory planning, compliance and commitment were key elements to success (similar examples can be found in Pomeroy, 2004; Christie \& Pollnac, 2011; Hoffman et al., 2012). However, in the following steps (establishment and managing of the MR) the good governance principle declined dramatically. This is because a government agency took full responsibility for the management of the MR, being the sole decision-making and management body. Therefore, the New Zealand government covers the human and financial resources of these two stages. It is important to highlight that my study (refer to Chapter 4) showed that the majority of people agreed to contribute in monetary terms when they were asked about a hypothetical conservation fund for each MR. Even though the respondents do not have any responsibility for the MRs, there is a collective willingness to contribute/participate in MRs. In this case the respondents were showing their willingness to contribute through a payment, because they were asked specifically for it. Therefore, my research has shown that people would like to contribute and/or participate more actively in MRs, which is an important opportunity that the government should consider.

With respect to governance, in no-take areas that are only managed by government institutions, members of the general public and stakeholders in the MRs are confined to exercise their responsibility of respect and follow the no-take rules in the protected areas. However, general users cannot make or influence decisions regarding MRs (the MR process in NZ involves the proponents making a formal application whose details may be changed by various Ministers), removing any opportunity to participate in MR management, which is a key aspect of good governance. To avoid the situation of no-take areas with no public participation in the MR's management, a new international framework called ecosystem- 
based management was implemented for MPA management (POC, 2003; USCOP, 2004), which promised to maintain ecosystem structure and function, by delivering the ecosystem goods and services that society enjoys, alongside the trade-offs required to meet multiple management goals, improve and/or achieve better ecosystem and conservations outcomes and including active participation and involvement of stakeholders in the MPA management decision-making (Ruckelshaus et al., 2008; Halpern et al., 2010; Alban, 2011; Christie \& Pollnac, 2011; Fraschetti et al., 2011 and references therein). In New Zealand a new policy entitled the MPA Policy was launched in 2006. The MPA Policy tries to integrate the roles and responsibilities of MPA management across a range of central and local government agencies, attempting to create a more integrated consultation process at the regional scale for MPA establishment. However, this process lacks public participation and as such cannot be viewed as an example of good governance. The MPA policy is mainly about government agenciy participation from the planning stages, referring to the general public as groups of interest in marine biodiversity in a general way, without providing any specific formal relationship between the public and government organizations. Therefore, the MPA policy is moving the MR establishment process from a bottom-up process, which was guided by the MR Act, to a top-down process leaving aside its local participation. Good governance (effective and cohesive) and direct public participation are crucial to secure the environmental outcomes that will provide benefits to the wider society (Borrini-Feyeradbend et al., 2006; Lockwood \& Kothari, 2006; The World Bank, 2006). International experience with marine coastal management approaches have demonstrated that top-down processes are inadequate (see Myers and Worm, 2003; Pauly et al., 2003; Castilla et al., 2007). For that reason the latest research as well as many agencies across the world have decided to shift towards bottom-up governance of local resources, through the use a co-management policy framework, where responsibility is shared among locals, governments and fishers. Such a process has been demonstrated to be more successful that top-down policies (Sandersen and Koester, 2000; Pauly et al., 2003; Berkes, 2004; Gelcich et al., 2007).

Due to the legal requirement to minimise or prevent direct point sources of anthropogenic stress in MRs in New Zealand, most sources of anthropogenic stress are banned and this can cause conflict amongst users. At both study sites (Kapiti and Taputeranga MRs) I found that these conflicts were reduced after the establishment of MRs (refer to chapter 3). Although most conflicts were reduced over time, at TMR the conflict with the rock lobster fishermen (RLF) continued, although it has reduced a little. This is because at TMR the RLF were the 
most affected group as fishing was re-allocated in order to maintain their level of catches (refer to chapter 2). This re-allocation occurred in two ways, (1) to areas beyond the MR that were originally fished, and (2) to the MR boundaries ('fishing the line'). The MR establishment generated negative externalities for the RLF (Boncoeur et al., 2011), because it increased their fishing costs (operational cost), along with the number of hours at sea, as well as reducing the fishable area, with the consequence that the fishing yield might be reduced (Holland, 2000; Goñi et al., 2011). Boncoeur et al. (2011) explained that fishermen's decisions about re-allocation can be influenced by their perceptions of higher relative rents, resource knowledge allocation and species prices and harvesting costs. Based on the information gathered in my research and that by Boncoeur et al. (2011) I suggest that there are still economic benefits for the RL fishery, through the establishment of TMR. However, further analysis is needed, comprising more details about motives and perceptions that may explain fisher behaviour after being re-allocated, although there is currently very little literature on this topic (Hilborn, 2006; Boncoeur et al., 2011; Goñi et al., 2011). Another valuable extension to the present study would be to investigate how MRs affect the profitability of those fishers displaced due to its establishment, and the impact at different economic scales (e.g. local, regional, national). Results from my study, combined with the proposed research would give new insights that can be applied to bioeconomic models to explain MPA effectiveness for fisheries because this requires a realistic description of microeconomic behaviours through time and space. To understand this spatial distribution of fishing effort is crucial (Holland, 2000; Holland et al., 2004; Valcic, 2009; Boncoeur et al., 2011).

While it is true that MRs have negative consequences for fishermen in terms of closing an area to fishing activity, it is equally true that MRs can generate multiple benefits, from which fishermen can be compensated through time. One MR benefit is the potential for enhanced harvested populations beyond the MR boundaries (Gell \& Roberts, 2003; Kellner et al., 2007; Halpern et al., 2010). This can occur by spillover (net emigration of adults and juveniles across borders) or by the export of pelagic eggs and larvae (Allison et al., 1998; Gell \& Roberts, 2003; Schnier, 2005). At both of my study sites, I found that the RL populations responded positively and quickly to protection in terms of abundance and biomass; RLs inside the MRs were bigger and more abundant than outside (e.g., Pande et al. 2008; Diaz Guisado et al. 2012). Hence, the RL populations are re-building quickly inside the MRs, and this might directly benefit adjacent fished areas by spillover, because spillover primary 
involves the emigration of large individuals (Goñi et al., 2011). However, whilst no definitive conclusion can be drawn at this stage because RL capture benefits to fishermen were not assessed, additional research areas for focus include understanding and providing evidence of the benefits that MRs are contributing to the surrounding fisheries, as well as research in biomass export and egg and larvae export (Goñi et al., 2011). At the moment these areas are poorly developed (especially in New Zealand), and could be the next step in fisheries research, but not only for RLs, also for other species of economic importance.

My research also identified other negative impacts of MR establishment that have affected the general public in the surrounding areas. This was mainly obvious at the newest reserve (TMR), where feelings of loss of property rights emerged. For example, different extractive activities cannot be conducted in these areas anymore. However, despite the cost and negative impacts that the MRs produced, people generally had positive attitudes to MRs. This was identified through people's perceptions that stated that since MR establishment the biodiversity had become more interesting, and people have become more educated in terms of environmental issues. Based on Vaughan \& Hogg (2002), where they describe that attitudes are constructed based on a utility rather than an object produced by a person, then in this study I found that respondents perceive that benefits outweigh the problems and costs. Smith et al. (1996) explain that positive attitudes enable people to maximise the probability of having a positive experience while minimising aversive ones, thus by increasing public participation, support for MRs could be increased and reduce further societal costs. This could be achieved by organising regular guided visits to the MRs, by taking people to areas inside and outside the reserve so they make their own judgments, giving public seminars where MR attributes can be shown, and by having MR education projects at schools and local communities.

Another important finding from my research is the recognition of multiple values and benefits provided from MRs to human well-being, including use and non-use values. Despite numerous studies showing benefits from MRs in many forms (for example Pande et al. 2008; Diaz-Guisado et al. 2012 and references therein), not many publications have recognised the non-use MR values at the local (small) scale. Macroscale valuations do not provide the same level of detail as at the microscale, which could lead to many values being under-represented or not included. This generally includes those values related to non-use values (option values, bequest values and existence values), such as cultural and religious values. MRs can be 
considered as a public investment by society (Alban et al. 2011) therefore it is important to determine the utility level of MRs to society, which was determined through the economic valuation in my study.

In conclusion, MRs are an important tool to protect biodiversity. The two MR case studies that I used (Taputeranga and Kapiti) showed that the benefits and values provided to society are greater than the costs and negative impacts produced. In addition, users and stakeholders expect that these benefits and values perceived may increase over time, especially if MR management could become more participative. Therefore, this research was able to provide new insights that will help in the future of conservation and MRs, by improving the level of information for better decision making, which is described in the section below.

\subsection{Recommendations}

The process for MR establishment and management in New Zealand can be divided into three phases (based in the MR Act, 1971): (1) Pre-establishment, which is divided into two stages, the non-statutory and subsequently the statutory phase. (2) Establishment, which is about the MR being set up, and (3) Management, which includes the MR plan and monitoring, where public participation in management is limited. However, with the new Marine Protected Area Policy (MPA policy) launched in 2006, MRs will be part of a suite of conservation tools entitled Marine Protected Areas (MPAs) that will be implemented through the MPA Policy. Therefore, for MRs the non-statutory process as it used to be (pre-establishment) was removed, and has been replaced with the MPA Policy. However, MRs will remain managed under the MR Act (1971), which at the moment is very rigid with respect to the public community involvement in the MR management.

From this point forward I will be using 'MPAs' as a term referring to MPA as: MRs, National Park and other conservation areas under the Reserve Act 1977 that could be established in New Zealand under the MPA Policy.

The aim of the MPA policy is to develop a nationally consistent approach to classify nearshore areas (and offshore as well) within a series of biogeographic regions and develop suitable MPAs (Fig. 6.1a). This classification is coordinated nationally by the Department of Conservation (DOC) and the Ministry of Primary Industries (MPI) via expert workshops that 
include all relevant stakeholders as observers only (MPA Policy Implementation Plan - Ref. 102). From this process a classification approach and protection standard was developed. At the same time an inventory of all current MPAs was created to identify gaps in the current MPA network, to determine which management tools currently protect habitats and ecosystems and if these meet the protection standards (Fig. 6.1b). Prioritisation for establishing new MPAs was then carried out on a bioregional basis. This was accomplished through the use of marine protection planning forums (MPPFs) within each biogeographic region or ecologically discrete MPA planning unit (Fig 6.1c). The MPPFs also involve Tāngata whenua (Māori - 'people of the land'), regional councils, marine biodiversity interest groups, and users and stakeholders who use marine areas and may be affected by MPAs. During the MPPFs, DOC and MPI provide the forums with information, advice and logistic tools; meanwhile the MPPFs' chairperson provides facilitation and guidance to obtain a consensus on where new MPAs should be established. This process aims to follow Planning Principle 4 in the MPA policy, that 'MPA establishment will be undertaken in a transparent, participatory, and timely manner'. However, what is described in the MPA Policy document as the way to reach that principle (transparent, participatory, and timely manner) appears to be by informing the public about the decision making process (Planning Principle 4. Ref. 88), through a written report after the MPPFs is finished (Planning Principle 4. Ref. 90). After this process is finished, the statutory process is required to implement the proposed MPA.

The final stage of the MPA policy and implementation plan is concerned with monitoring and evaluation of MPAs, but this process is still being developed (Fig. 6.1d).

Despite the new MPA Policy trying to make the whole MPA establishment process more integrative by allowing regional consultation with specific groups, the MPA policy does not specifically mention public participation in the process: as such, public participation seems very limited or not as fully developed. This situation with limited public participation may create conflicts between local community and decision-makers. Consequently, from what is stated in the MPA Policy, it seems that this process and decision making moves New Zealand marine conservation away from what is considered to be a good governance policy, effectively making MPA establishment a top-down process. However because the MPA policy does not clearly state how the public can participate, it appears that people are only involved once the decisions have been made by the government 


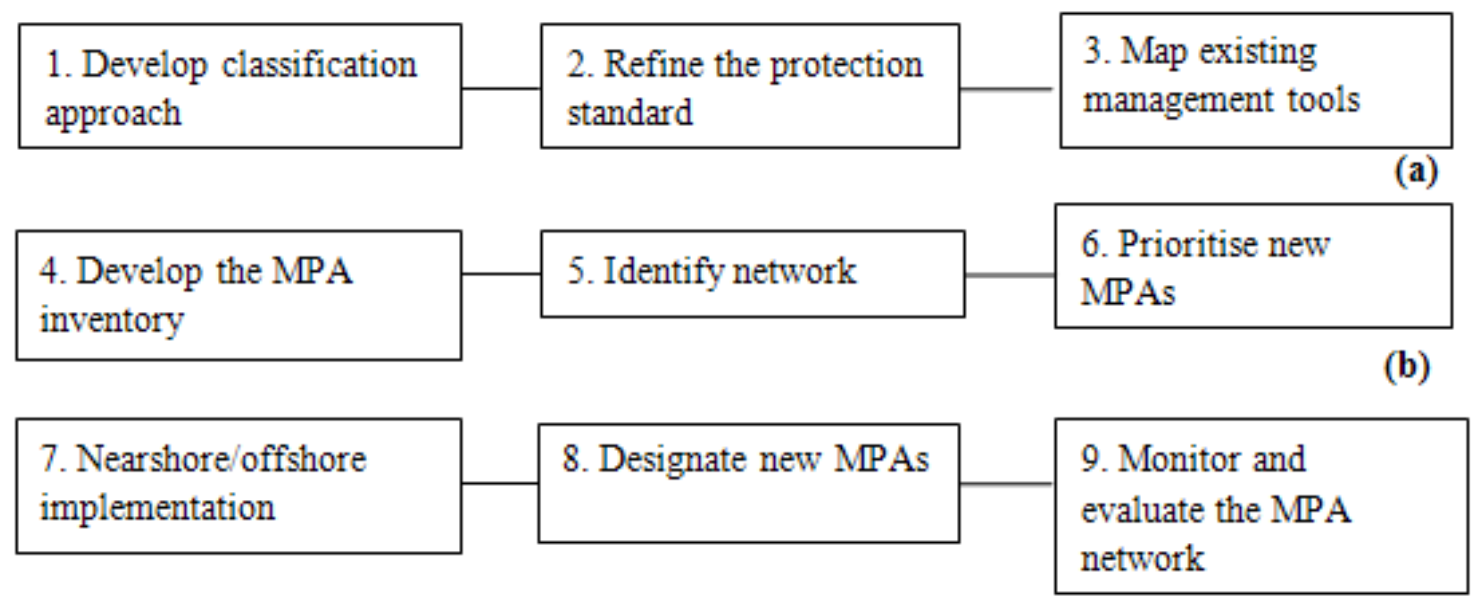

(c)

(d)

Figure 6.1: MPA Policy Implementation Plan. (a) Stage one: Preparation for implementation, (b) Stage two: Strategic analysis, (c) Stage three: Development of an MPA network and, (d) Stage four: Monitoring and evaluation. (Figure from the MPA Policy \& Implementation Plan, 2005).

In addition, the MPA Policy mainly considers biological aspects of MPAs, and does not consider directly spiritual, social (including cultural, educational, and others), economic (tourism, fisheries, others) and governance (empowerment) aspects. To not consider all these aspects in conservation will likely make conservation less effective, especially over the longterm.

I propose that a 'MPA Policy Guideline' is necessary to clarify and avoid all potential misunderstandings that consequently could delay the MPA establishment process. This 'MPA Policy Guideline' should be clear and easy to follow, recognising MPA values, with all terms being defined, and with clear statements about public participation.

From the information and results gathered during my research, I propose two main changes to improve the current MPA Policy: (1) divide this whole process into five phases. While the increase from four to five phases may appear to increase the length of the process, this is not the case, (2) move to a balance between top-down and bottom-up process, led by locals and stakeholders, with government guidance and support. My five phase process will attempt to reduce the time and costs associated with each phase, and increase the public participation 
from the beginning of the process to the MPA establishment and management. Moreover, this approach tries to integrate the four important aspects of conservation: social, economic, environmental and governance. Such an approach will be suitable for coastal MPAs (such as the MRs used in my study) located in or close to urban areas and could be easily adapted for different types of protected areas in and outside of New Zealand such as large offshore MRs, for example the Kermadecs, Auckland Islands.

It is important to highlight that the basis of this new approach is to develop strategic and formal alliances between government and key groups, including central government (in this case represented by DOC), local government (e.g. city and regional councils), research providers, fisheries stakeholders in order to minimise time and costs, and to maximise knowledge (including traditional knowledge) input and gain for decision making. This alliance would be not only beneficial to MPA establishment, but also other conservation projects that could come after the MPA establishment, for example related to species/communities monitoring, effectiveness assessment, MPA connectivity, and others.

The proposed framework is shown in Figure $6.2(\mathrm{a}, \mathrm{b}, \mathrm{c}, \mathrm{d}$ and e), where phase I and phase II constitute the pre-establishment process. Phase III is when the MR is gazetted, then phase IV is concerned with monitoring, and phase $\mathrm{V}$ includes an overall assessment of $\mathrm{MR}$ effectiveness.

Phase I: This phase is marked by determining the motives to create an MPA in a specific place, and by identifying the goals of the MPA.

The motivation for the MPA could come from two sources: (1) the government and (2) stakeholders and users (including researchers). The government's motivation should be based on the goals of the MR Act and/or MPA Policy (depending on the conservation tool to be used), and be in line with national, local and/or international agreements. The stakeholders' and users' motivations could be, for example, to protect a very specific area due its high value to them. Therefore, stakeholders' and users' motives will generate perceptions, attitudes and expectations about the future MPA that are important to take into account. The key step in this phase is that the government's, stakeholders' and users' motivations should be overlapping in order to create a shortlist of MPA goals. I suggest that the way to coordinate and integrate both motivations (government and people) is by using the ecosystem services context, which is based on human well-being by protecting the environment. This approach can protect not only habitats as the MPA Policy suggests, but also protects other 
types of levels (species, communities, social interests, etc.). Rees et al. (2012) note that '...this approach can transfer the complexity of the marine ecosystems functions into marine ecosystems services broadening the inclusion of range of values into decision-making for marine conservation.' (for information on ecosystems services please refer to Chapter 4).

In circumstances where MPA designation is being driven by the government as a result of the MPA Policy (Fig. 6.1b), then those areas to be protected should be treated as follows. The potential sites should be mapped (stage two MPA policy), and the central and local government agencies (represented by DOC and the regional council respectively) should identify stakeholders, users and experts from the respective area. If the expert is located outside the city, then the government should take responsibility for paying travel costs (because the process is driven by the government). Then, the local agency should explain their reasons for proposing an MPA and should ask this newly formed group of stakeholders, users and experts to form a formal MPA team to lead the process. Under these circumstances, operational costs should be covered by the government.

If these people do not want to take part in this process, then the government agency would have three options: (1) quit the project, (2) look for alternative arguments to convince them, or (3) try to form a new team of people.

If the MPA idea comes from the local community and/or stakeholders then they should approach DOC to conduct the steps above, starting with the creation of the MPA team.

Once the team is formed, it is necessary to examine the motivation of the government and the people to find common ground to help set the MPA's goals. Therefore MPA goals should integrate three main perspectives: national (The New Zealand Biodiversity Strategy), local (The New Zealand Coastal Policy Statement) and the general public (collective motivations). Based on the MPA goals, research would then be needed. Therefore it would be necessary to understand different aspect of MPAs: environmental, socio-economic, such as potential uses of the MPA, and expectations of the MPA. This would include interviews, surveys and focus groups. After the different motivations are explored, it would be important to define which one of the MPA tools is most appropriate (such as MRs, wildlife refuge, or management reserves, etc.). In addition, information should be collected to establish the biological, oceanographic, geologic and environmental features of importance at the proposed MPA. To reduce time and cost, bibliographical analysis and expert panels could be used. It is important to highlight that expert panels not only include researchers, but also include groups such as 
fishers and iwi, who have local and traditional knowledge. Based on the MPA's goals plus all the collected information, one complete MPA report (RP) should be written.

Whether the initial idea for the MPA is from government or stakeholders and users, the route to MPA establishment is a mixture of bottom-up and top-down process, with high public participation. In both cases, stakeholders and users would be leading the process, with the government represented by DOC and local council, as the MPA Team requires.

After the MR goals are determined as 'term of reference' and the RP is written, in order to validate the complete project public consultation through a public meeting should take place. This meeting should be organised by the MPA Team. In this meeting special emphasis should be placed on whether the goals truly represent what people and government are expecting. Also, during this meeting any modifications should be included by public agreement. If there is little public support, two options are available; one is to quit the MPA project, the other is to go back to the previous stage and check for potential solutions, in order to improve current goals. This process from start to finish should be between 7-12 months in duration. If after this period there is no consensus, then the MPA team should give the best available options (including the level of disagreement) to the government, and the government will decide what is best for the proposed area as a mandatory order. One fair option is to consider compensation methods if the government considers it to be necessary. For example, if a specific number of commercial fishers will be displaced due to the new MPA establishment, then the government can decide to pay an amount of money (previously established) as compensation for this decision. Therefore, if there is no consensus after the 7-12 month establishment period, then people should be aware about the reasons and consequences of this disagreement.

Because the government will have the complete background of the current project, then the government should decide in a period no longer than 3- 5 months.

Once the MPA goals are determined and the project accepted (by people or the government), then the process should move to phase II.

It is important to highlight that the whole of phase $\mathrm{I}$ is co-funded by government, NGOs, private funds and volunteers. This phase should not take longer than 7-12 months if there is agreement at the first instance, however, if there is disagreement this process should not be longer than 2 years and a half years. 


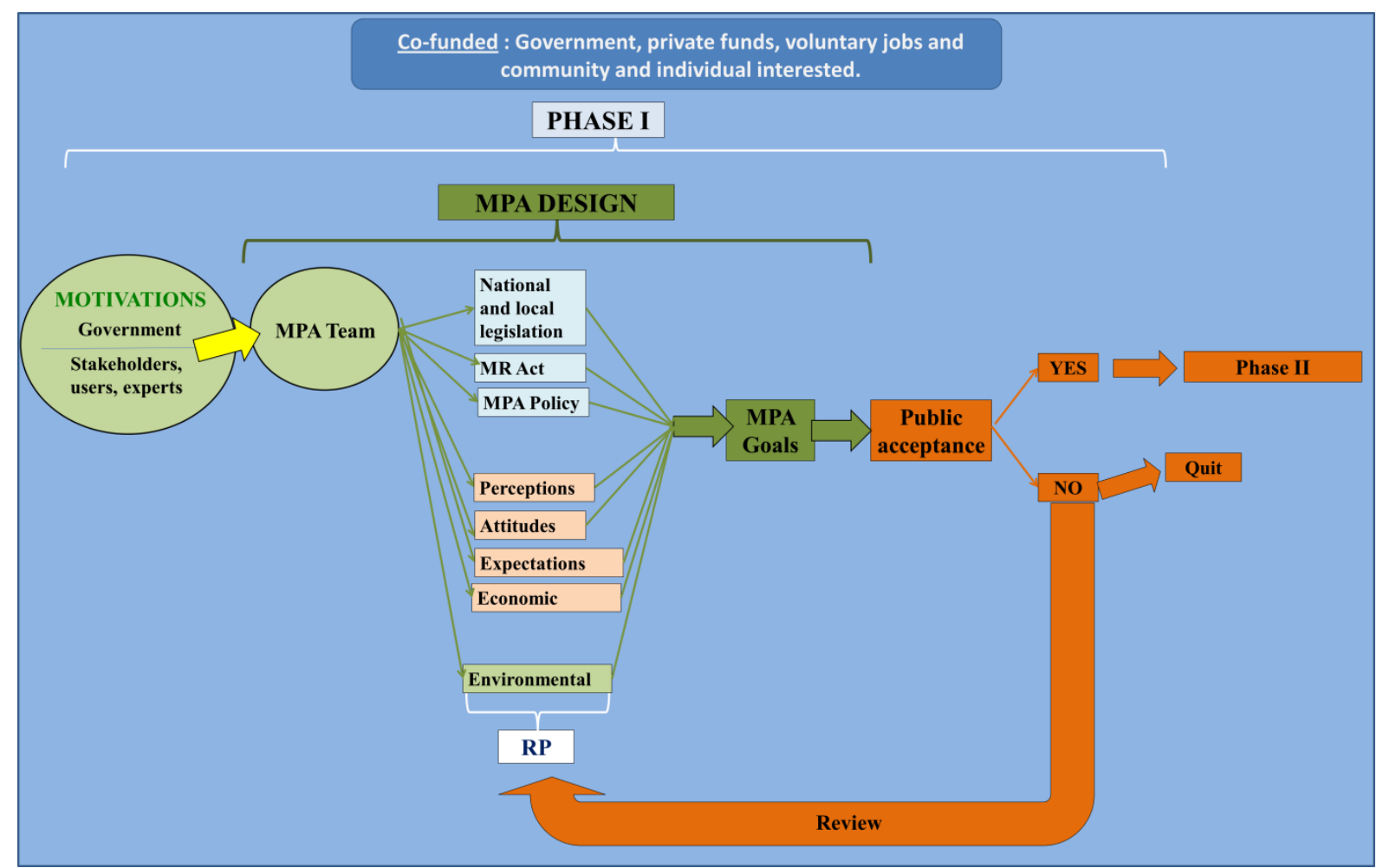

Figure 6.2a: Schematic including a new set of recommendations related to the establishment, management and on-going monitoring of marine reserves in New Zealand. The figure describes Phase I.

Phase II: Once the potential MPA is validated during the public consultation period or by government, then government should provide funding to the MPA Team for phase II. This government contribution will permit a multidisciplinary analysis that should be carried out by the expert members of the MPA team or under contract from external experts as required. This analysis should include the expected benefits, costs and the creation of two databases with environmental and socio-economic information. This database should be based on the information from the RP, and consider control areas/sites as well. I will call this 'Data Base (DB)'. The difference between the RP and DB is that the RP is based on a literature review as well as the expert panels opinion, whereas the DB is compiled from data collected with a methodology that could permit future multi-year, such as BACI, comparisons by including different aspects of MPA (environmental and socio-economics). Several authors (e.g. Russ, 2002; Pande \& Gardner, 2008; Osenberg et al., 2011; Moland et al., 2012) agree that the before-after control-impact (BACI) design is the best way to assess effects of protection, but very few MPAs have been surveyed before their establishment in sufficient detail (multi-site, multi-year) to permit this sort of analysis. Without such information it is impossible to quantify how effective the MPA will be at various times in the future. Then, with information 
from the DB the most important aspects and gaps identified in RP should be filled or completed (for example, the identification of key species, habitats, commercial species, socio-economic expectations, etc.).

When all of this information is collected and analysed, the proposal has to be written. It should include a formal role for, and participation of the future MPA committee, which should be established at this point in order to create a co-management structure with the government. The MPA committee will be responsible for permitting issues in the MPA (to conduct research, activities, business opportunities, and MPA projects, etc.). In addition, the proposal should establish a management (co-management) structure and monitoring plans. As soon as the draft is ready, it should be presented to the public in order to make this process as transparent and participative as possible. This presentation must be explained in a way that will enable everyone to understand, with time for questions and discussions. In order to expedite the process, focus groups could be used. A facilitator will conduct these meetings or focus groups with the knowledge to drive it in a way to achieve the main goal of it, and avoid redundant discussions.

In the case that the public disagrees with the proposal, in the same meeting potential solutions or changes should be discussed during the public consultation, and later included in the final proposal. If at the end of the meeting they do not find solutions, then an appendix with the most common issues should be added.

The final proposal should be written (including an appendix if necessary) by the MPA Team. In the case that the MPA Team lacks the knowledge, an external consultant can be contracted. The money to pay this external contractor should come from the same budget at the beginning of phase II.

Where possible, the proposal should be submitted for peer-review prior to the start of the statutory process in order to support the approval of the MPA proposal. With the final proposal written and validated, the MR project will be able to move to phase III. Phase II should take no longer than 7-12 months. 


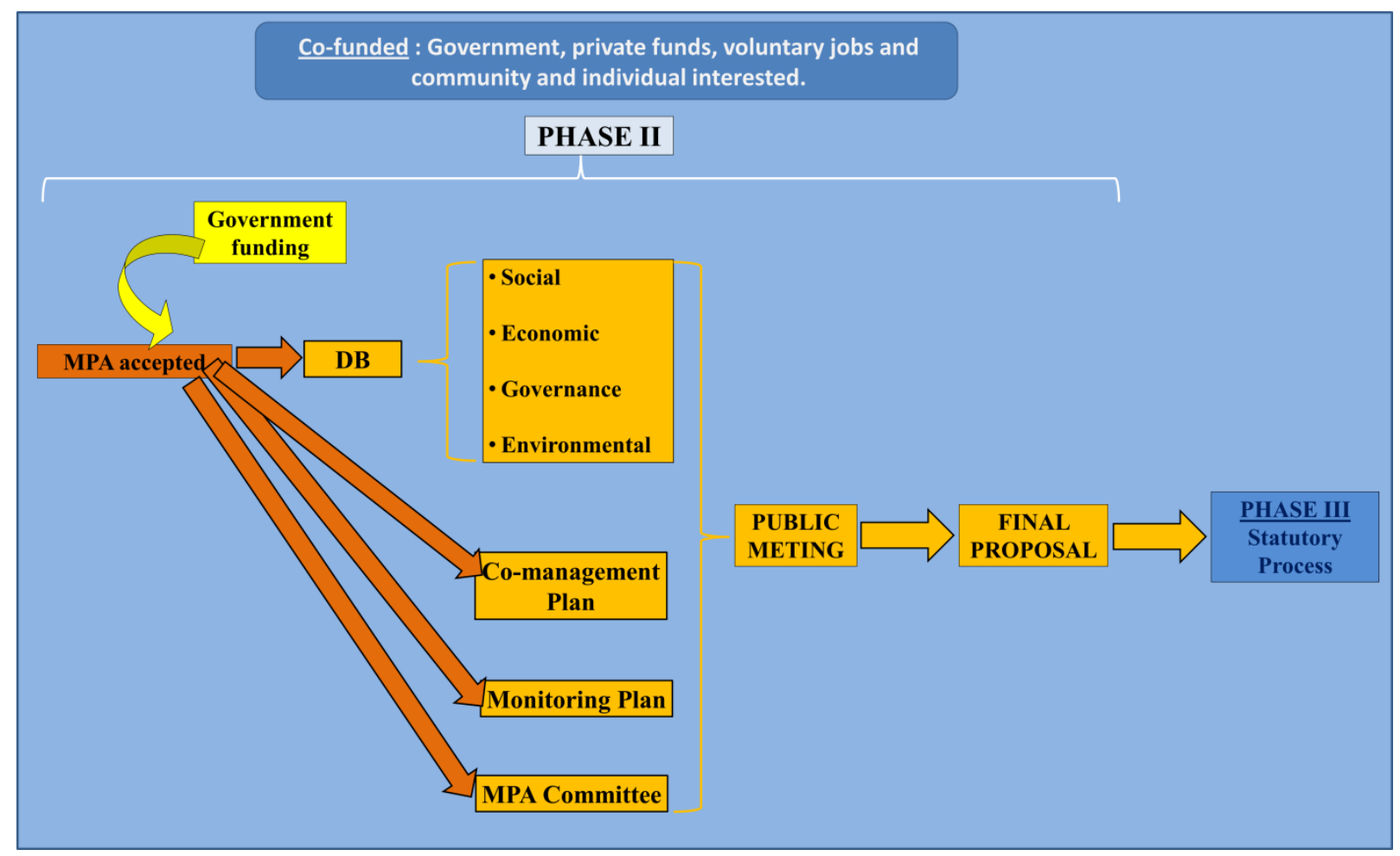

Figure 6.2b: Schematic including a new set of recommendations related to the establishment, management and on-going monitoring of marine reserves in New Zealand. The figure describes Phase II.

Phase III: This phase starts when the final proposal is moving into the statutory process. Because the prior phases already contain extensive information gathering and consultation processes, this phase should be quicker than the current process.

After the statutory process is finished the MPA should be gazetted and implemented.

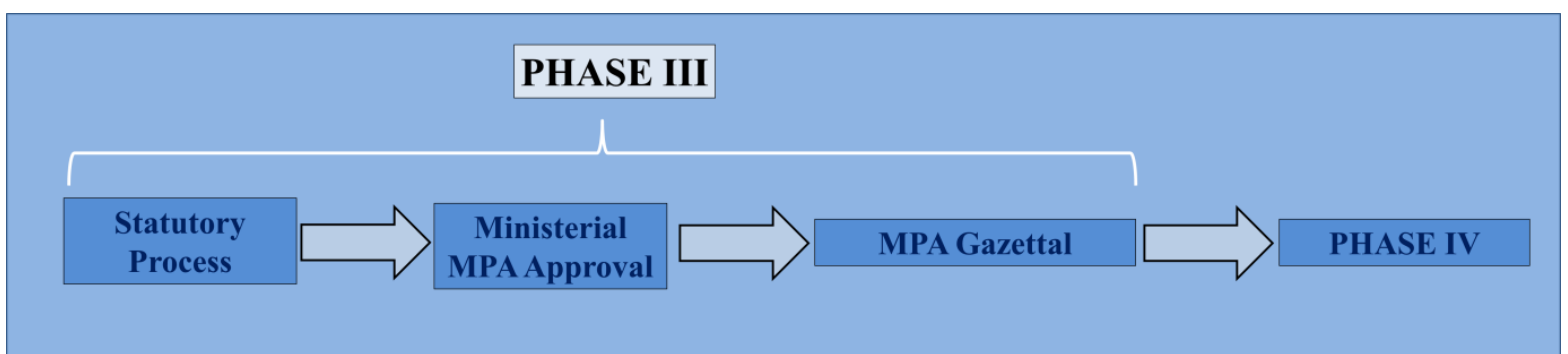

Figure 6.2c: Schematic including a new set of recommendations related to the establishment, management and on-going monitoring of marine reserves in New Zealand. The figure describes Phase III.

Phase IV: There should be two main priorities at this stage: (1) to form a MPA Committee, (2) the co-management plan should start to work. The co-management plan and the MPA committee should be running within one year. The monitoring plan should reflect the initial 
goals of the MPA. Based on the MPA goals and proposal information, specific indicators should also be determined, which should include environmental, socio-economic and governance (for indicator development see Pomeroy et al., 2004). By using the new indicators, the first monitoring should be carried out in year 1 after the MPA establishment, and be compared with the before situation (pre-establishment), in order to generate initial results. This should be discussed and compared with the monitoring plan by the government and the MPA committee in order to obtain feedback, which should be included in the final document.

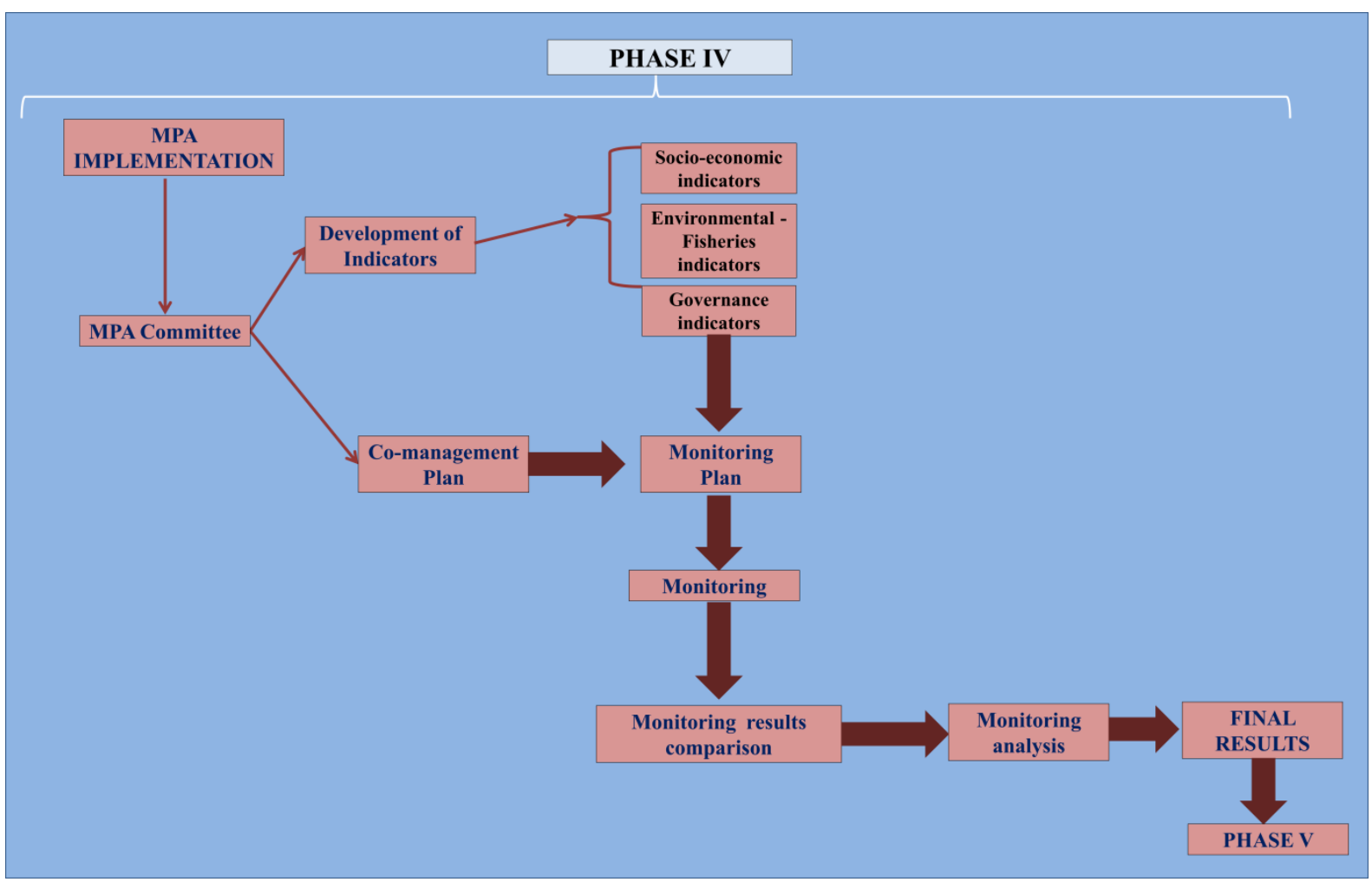

Figure 6.2d: Schematic including a new set of recommendations related to the establishment, management and on-going monitoring of marine reserves in New Zealand. The figure describes Phase IV.

Phase V: The government and the MPA Team should release documents at regular intervals to share data with the public. If a public document is too difficult to be launched and published, public meetings could be held as well. The public must be given the opportunity to express comments and opinions on the document before final conclusions are made. This opportunity needs to be done within a specific timeframe (e.g., 1 or 2 months). After, the timeframe has passed, and then final conclusions should be incorporated. In the case that the final conclusions indicate that the current MPA is effective with respect to meet the MPA 
goals proposed. However, if the results show that the MPA has not met its goals, then it is important to look for potential causes. One of the aims is to share MPA findings because it is important to include public feedback to help to look for potential causes as well as potential solutions. Solutions that come from the general public will be more easily accepted by them, so consequently they should be included in the monitoring plans if this necessary or possible.

Phases IV and V should be carried out every year (if possible), in order to permit effective monitoring of MPA performance and be more accurate with respect MPA effectiveness results.

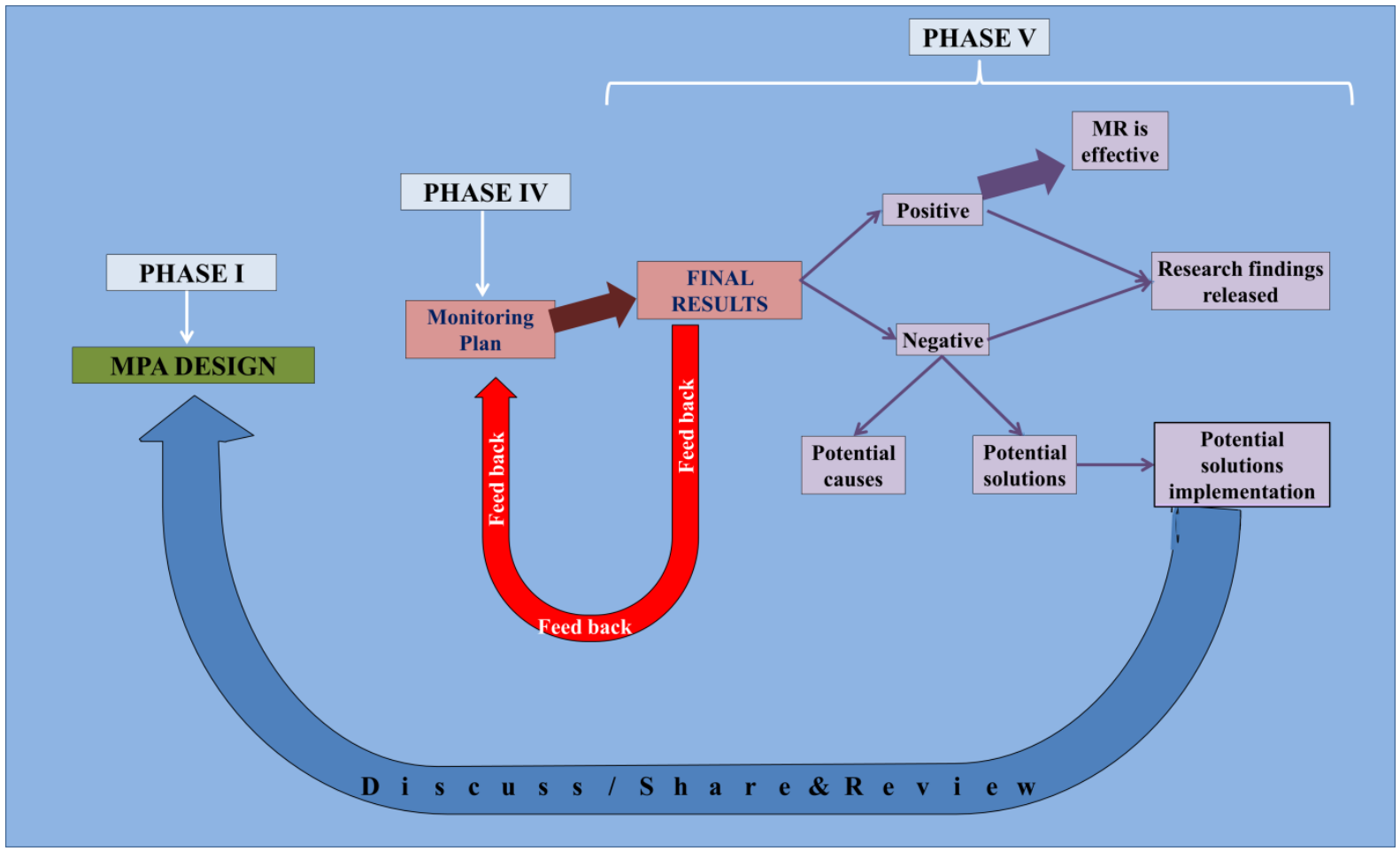

Figure 6.2e: Schematic including a new set of recommendations related to the establishment, management and on-going monitoring of marine reserves in New Zealand. The figure describes Phase V.

Finally, I would like to summarise all the information provided in this set of recommendations, in five main points:

1. In order to protect biodiversity and public interests, the current MR Act (1971) needs to be a more flexible conservation tool. It should allow for the establishment of areas based on a mixture of components (not only for scientific research) as explained above. 
2. Policies and legislation should establish clear timeframes in each process/stage, in order to avoid long delays, which only increase the cost in terms of money, time and effort.

3. Policies and legislation should establish clear solutions in those cases without consensus after deadlines. Also, compensation methods should be considered for the most affected people by the conservation resolutions.

4. The current MPA Policy is still not clear. It lacks clear statements about public participation and definitions, as well as containing incongruences on the terminology used throughout the document. There is not clarity about how to approach and conduct this process either. Therefore, it is necessary to create a 'step by step guide', which should contain easy instructions to follow for decision-makers and stakeholders.

5. It is necessary to include and establish community participation and responsibility as a formal role in MPAs. For this to happen, this role should be explicitly described in the New Zealand legislation.

\section{Conclusions}

Although the TMR was established in a similar way to my recommendations, the majority of MRs and MPAs (e.g. marine parks, and areas of significant conservation values) have been designated piecemeal and lack structure and a systematic method to set them up, from the idea to establish and manage them. While it is true that the TMR process shows a good example of governance during the non-statutory process by following the guidelines of the MR Act (1971), and then the public participation dramatically decreased. Despite the fact that TMR was not established under complete public agreement, several consultation processes were held making the process more participative (which was not usual in the old MRs), but excessively long (more than 15 years). The current MPA policy tries to reduce this time by trying to be as efficient as possible during the process of public engagement. Consultation only happens once the MPA tool has been decided, but this late consultation can take several years to achieve. Therefore, neither a bottom-up process nor a top-down process by themselves will reduce the time, cost, and effort of MPA designation. My recommendation use a mix and balance between bottom-up and top-down processes where clear timeframes are established. If such timeframes cannot be met by consensus then clear and decisive steps 
forward are suggested. Also I suggested using a different approach of MPA goal definition, which considers ecosystem services, rather than habitat as the current policy.

If New Zealand wants to continue scaling-up (create more) MRs or any MPAs, then the country should make the MPA process more integrative and participative, because conservation decisions affect not only biodiversity, but also the human community in terms of social, economic and governance issues.

This approach presented here is an insight that could be useful to include within the current MPA Policy and potentially improve it. It also attempts to minimise the time and costs involved in MPA formation from the pre-establishment stages, by creating effective and formal alliances between different groups of stakeholders. In addition, this approach is driven by the people, and supported by the government. Therefore, my recommendations aim to increase the level of commitment and empowerment to MPAs through co-management. Increasing public participation and commitment is crucial to maintain ecosystem structure and making MPAs more effective in the long term. 


\section{Bibliography}

Abesamis, R.A. \& Russ, G.R. 2005. Density-dependent spillover from a marine reserve: long-term evidence. Ecological Applications 15: 1798-1812

Abbott, J.K. \& Hayne, A.C. 2012. What are we protecting? Fisher behaviour and the unintended consequences of spatial closures as a fishery management tool. Ecological Applications 22: 762-777.

Acosta, C.A. 2002. Spatially explicit dispersal dynamics and equilibrium population sizes in marine harvest refuges. J Mar Sci 59:458-468

Adams, W. M., \& D. Hulme. 2001. If community conservation is the answer in Africa, what is the question? Oryx 35:193-200

Adams, V.M., Pressey, R.L., Naidoo, R. 2010. Opportunity costs: who really pays for conservation? Bioogical Conservation. 143, 439-448.

Addison, J. T. 1986. Density-dependent mortality and the relationship between size composition and fishing effort in lobster populations. Canadian Journal of Fisheries andAquatic Science, 43, 2360-2367

Alban, F., Appéré, G. \& Boncoeur, J. 2006. Economic analysis of marine protected areas.A literature review. EMPAFISH Project.

Alban, F., Boncoeur, J. \& Roncin, N. 2011. Assessing the impact of marine protected areas on society's well-being: an economic perspective. In: Marine Protected Areas A Multidisciplinary Approach. Claudet, J. (Ed.) Published by Centre National de la Recherche Scientifique (CNRS), Paris.

Alder, J., Zeller, D., Pitcher, T. \& Sumaila, R. 2002. A method for evaluating marine protected area management.Coastal Management 30: 121-131

Alexander, S. E. 2000. Resident attitudes towards conservation and black howler monkeys in Belize: the Community Baboon Sanctuary. Environmental Conservation 27: 341-350

Allison, G.W., Lubchenco, J. \& Carr, M.H. 1998. Marine reserves are necessary but no sufficient for marine conservation. Ecological Applications 8: S79-S92

Amirnejad. H., Khalilian, P.P. \& Assareh, M. 2006. Determine the value of protection and promenade Forest Park Si Sangan Noshahr using willingness to pay people. J. Nat. Resour. Constr.: 4- 72.

Anderlini, V.C., Wear, R.G. \& Haddon, M. 1992. A review of marine biological and ecological information for the Moa Point Area.Coastal Marine Research Unit. CMRU Report No 21. Victoria University of Wellington.

Armstrong, C. 2007. A note on the ecological-economic modelling of marine reserves in fisheries.Ecological Economics 62: 242 - 250 
Arin, T. \& Kramer, RA.2002. Diver's willingness to pay to visit marine sanctuaries: an explanatory study.Ocean \& Coastal Management 45: 171 -183

Arrow, K., Solow, R., Portney, P. R., Leamer, E. E., Radner, R.\& Schuman, H. 1993. Report of the NOAA panel on contingent valuation', Federal Register, Vol. 58, pp. 4601-4614

Asafu-Adjaye, J. \& Tapsuwan, S. 2008. A contingent valuation study of scuba diving benefits: Case study in Mu Ko Similan Marine National Park, Thailand. Tourism Management 29: $1122-1130$

Asah, S.T., Bengston, D.N., Wendt, K. \& Nelson, K.C. 2012. Diagnostic reframing of intractable environmental problems: Case of a contested multiparty public land-use conflict. Journal of Environmental Management 108: 108-119

Austen, M.C., Malcolm, S.J., Frost, M., Hattam, C., Mangi, S., Stentford, G., Benjamins, S., Burrows, M., Butenschön, M., Duck, C., Johns, D., Merino, G., Mieszkowska, N., Miles, A., Mitchell, I.\& Smyth, T. 2011. Marine. In: The UK National Ecosystem Assessment Technical Report. UK National Ecosystem Assessment.UNEP-WCMC, Cambridge.

Babcok, R.C., Kelly, S., Shears, N.T., Walker, J.W. \& Willis, T.J. 1999. Changes in community structure in temperate marine reserves. Mar. Ecol. Prog. Ser. 189: 125-134

Babcock, R. C., Phillips, J. C., Lourey, M., \& Clapin, G. 2007. Increased density, biomass and egg production in an unfished population of Western Rock Lobster (Panulirus cygnus) at Rottnest Island, Western Australia. Marine and Freshwater Research 58: 286-292.

Ballantine, W.J. 1991. Marine reserves for New Zealand. Leigh Laboratory Bulletin No. 25. University of Auckland. Auckland, New Zealand.

Ballantine, W.J. \& Langlois, T.J. 2008. Marine reserves: the need for systems. Hydrobiologia 606: $35-44$

Balmford, A. \& Whitten,T. 2003. Who should pay for tropical conservation, and how could the costs be met? Oryx 37: 238-250.

Balmford, A., R.E., Green \& Jenkins, M. 2003. Measuring the changing state of nature. Trends Ecol. Evol. 18: 326-330.

Balmford, A., Gravestock, P., Hockley, N. McClean, C. \& Roberts, C. 2004.The worldwide costs of marine protected areas. PNAS 101: $9694-9697$

Balmford .A., Bennun L., ten Brink B., Cooper D., Côté I. M., Crane P., Dobson A., Dudley N., Dutton I., Green R. E., Gregory R. D., Harrison J., Kennedy E.T., Kremen C., Leader-Williams N., Lovejoy T. E., Mace G., May R., Mayaux P., Morling P., Phillips J., Redford K., Ricketts T. H., Rodríguez J. P., Sanjayan M., Schei P. J., van Jaarsveld A. S. \& Walther B. A. 2005. The Convention on Biological Diversity's 2010 Target. Science 307: 212 -213 
Banzhaf, H.S., D. Burtraw, D. Evans, \& A. Krupnick. 2006. Valuation of natural resource improvements in the Adirondacks. Land Economics 82:445-464

Barber, C.V., Miller, K.R. \& Boness, M. (Eds.). 2004. Securing protected areas in the face of global change: Issues and strategies, IUCN. Gland and Cambridge.

Barbier, E.E., Burgess, J.C. \& Folke, C. 1994. Paradise Lost? The ecological economics of biodiversity, Earthscan, London.

Barrett, N.S., Buxton, C.D. \& Edgar, G.J. 2009. Changes in invertebrate and macroalgal populations in Tasmanian marine reserves in the decade following protection. Journal of Experimental Marine Biology \& Ecology 345: 141-157

Bartholomew, A., Bohnsack, J.A., Smith, S.G., Ault, J.S., Harper, D.E. \& McClellan, D.B. 2008. Influence of marine reserve size and boundary length on the initial response of exploited reef fishes in the Florida Keys National Marine Sanctuary, USA. Landscape Ecology 23: 55-65

Bateman, I.J. \& Turner, R.K. 1993.Valuation of environment, methods and techniques: the contingent valuation method. In: Kerry Turner R, editor. Sustainable environmental economics and management: principles and practice. London: Belhaven Press; p. 12091.

Bateman, I. J., Carson, R. T., Day, B., Hanemann, M., Hanley, N., Hett, T., Jones-Lee, M., Loomes, G., Mourato, S., Ozdemiroglu, E., Pearce, D. W., Sugden, R. \& Swanson, J. 2002. Economic Valuation with Stated Preference Techniques: A Manual. Edward Elgar, Cheltenham.

Bateman, I., Mace, G.M., Fezzi, C., Atkinson, G. \& Turner, K. 2011. Economic analysis for ecosystem service assessments. Environmental and Resource Economics 48: 177-218

Battershill, C.N., Murdock, R.C., Grange, K.R., Singleton, R.J., Arron, E.S., Page, M.J. and Oliver, M.D. 1993. A survey of the marine habitats and communities of Kapiti Island.New Zealand Oceanographic Institute, Wellington, New Zealand. A report prepared for the Department of Conservation.

Baxter, A.S. 1987a. Kapiti Island subtidal ecological survey. Ministry of Agriculture and Fisheries Central Fisheries Management Area Internal Report 87/2. Ministry of Agriculture and Fisheries, Wellington, New Zealand.

Baxter, A.S. 1987b. Kapiti Island marine recreational survey. Ministry of Agriculture and Fisheries Internal Report 87/3. Ministry of Agriculture and Fisheries, Wellington, New Zealand.

Beaumont, N.J., Austen, M.C., Atkins, J.P., Burdon, D., Degraer, S., Dentinho, T.P., Derous, S., Holm, P., Horton, T., van Ierland, E., Marboe, A.H., Starkey, D.J., Townsend, M. \& Zarzycki, T. 2007. Identification, definition and quantification of goods and services 
provided by marine biodiversity: Implications for the ecosystem approach. Marine Pollution Bulletin 54: 253 - 265

Beaumont, N.J., Austen, M.C., Mangi, S.C. \& Townsend, M. 2008.Economic valuation for the conservation of marine biodiversity. Marine Pollution Bulletin 56: 386 - 396

Beca-Carter, H.. 1980. Moa Point wastewater treatment plant and outfall study: study of wastewater treatment and disposal into Cook Strait for Wellington City Corporation. Unpublished Report. Beca Carter Hollings and Ferner Ltd, Caldwell Connell Engineers Pty Ltd, Wellington.

BenDor, T., Scheffran, J. \& Hannon, B. 2009. Ecological and economic sustainability in fishery management: A multi-agent model for understanding competition and cooperation. Ecological Economics 68: 1061 - 1073

Bennett, A.T. 1988. Getaways to powerlessness: Incorporating Hispanic deaf and families into formal schooling. Disability, Handicap and Society 3: 119-151

Berkes F. 2004. Rethinking community based conservation. Conservation Biology 18: 62130 .

Berrens, R., Bohara, A., Jenkins-Smith, H., Silva, C. \& Weimer, D. 2003. The advent of Internet surveys for political research: A comparison of telephone and Internet samples. Political Analysis 11: 1-22

Berry, P. F., \& Smale, M. J. 1980. An estimate of production and consumption rates in the spiny lobster Panulirus homarus on a shallow littoral reef off the Natal Coast, South Africa. Marine Ecology Progress Series 2: 337-343.

Bertelsen, R.D., Hunt, J.H. \& Muller, R. 2000. Spiny lobster spawning potential and population assessment: a monitoring programme for the south Florida fishing region. Report to National Marine Fisheries Service MARFIN. Florida Marine Research Institute, Marathon, FL.

Bertelsen, R.D. \& Cox, C. 2001. Sanctuary roles in population and reproductive dynamics of Caribbean spiny lobster. In: Kruse GH, Bez N, Booth A, Dorn MA and 6 others (Eds.) Spatial processes and management of marine populations. University of Alaska Sea Grant College Program, AK-SG- 01-02, Fairbanks, AK, p 591-605

Bishop, J. T. 1999. Valuing forests: A Review of method and application in developing countries. International Institute for Environment and Development (IIED). 53-67. London: WC1 ODD, U.K.

Bliem, M. \& Getzner, M. 2010.Willingness to pay for river restoration: Differences across time and scenarios. Working paper, unpublished manuscript. Available at: http://www.econbiz.de/en/search/detailed-view/doc/willingness-to-pay-for-river- 
$\underline{\text { restoration-differences-across-time-and-scenarios-bliem- }}$

$\underline{\text { markus/10009242841/?no_cache }=1}$

Blonder, B. I., Hunt, J. H., Forcucci, D.\& Lyons, W. G. 1992. Effects of recreational and commercial fishing on spiny lobster abundance at Looe Key National Marine Sanctuary. In 'Proceedings of the 41st Annual Gulf and Caribbean Fisheries Institute Meeting, St. Thomas, U. S. V. I., November, 1988'. (Eds G. T. Waugh, M. H. Goodwin, and S. M. Kau.) pp. 487-91. (Gulf and Caribbean Fisheries Institute: Charleston, South Carolina, USA.) .

Brauer, I., Müssner, R., Marsden, K., Oosterhuis, F., Rayment, M., Miller, C. \& Dodoková, A. 2006. The use of market incentives to preserve biodiversity.Final Report. A Project Under the Framework Contract for Economic Analysis ENV.G.1/FRA/2004/0081. EcoLogic, July, 2006.

Breen, P.A. \& Kim, S.W. 2006.Development of an operational management procedure (decision rule) for CRA 4.New Zealand Fisheries Assessment Report 2006/53.46 p.

Bruner, A., Hanks, J. \& Hannah, L. 2003. How Much Will Effective Protected Area Systems Cost? Presentation to the Vth IUCN World Parks Congress, 8-17 September: Durban, South Africa.

Bohnsack, J.A. 1993. Marine reserves: They enhance fisheries, reduce conflicts and protect resources. Oceanus 36: 63-71

Bohnsack, J.A. 1998. Application of marine reserves to reef fisheries management.Aust. J. Ecol. 23: 298-304

Bohnsack, J.A. 1996. Maintenance and recovery of reef fishery productivity. In: Reef fisheries. Polunin N.V.C. \& Roberts C.M. (Eds.) Published by Chapman \& Hall, London, UK.

Bohnsack, J.A. \& Ault, J.S. 1996. Management strategies to conserve marine biodiversity.Oceanography 9: 73-82

Borrini-Feyerabend, G., Johnston, J. \& Pansky, D. 2006. Governance of protected areas. In: Managing Portected Areas: A global guide. Lockwood, M., Worboys, G. \& Kothari, A. (Eds.).IUCN.Earthscan, Cromwell Press, Trowbridge, London.

Boncoeur, J., Thébaud, O. \& Alban, F. 2011. Bioeconomic analysis of marine protected area fisheries effects.In: Marine Protected Areas A Multidisciplinary Approach. Claudet, J. (Ed.) Published by Centre National de la Recherche Scientifique (CNRS), Paris.

Broad, K. \& Sanchirico, J.N. 2008. Local perspectives on marine reserve creation in the Bahamas.Ocean Coast Manage 51: 763-771.

Bruner, R., Gullison, E. \& Balmford, A. 2004. Financial costs and shortfalls of managing and expanding protected-area systems in developing countries. Bioscience 54: 1119-1126 
Bruner, D., Michael Mc. \& Santore, R. 2008. Hand in the Cookie Jar: An Experimental Investigation of Equity-based Compensation and Managerial Fraud. Southern Economic Journal 75: 261-78.

Buchsbaum, R., Pederson, J. \& Robinson, W. E. 2005. The Decline of Fisheries Resources in New England: Evaluating the Impact of Overfishing, Contamination, and Habitat Degradation. MITSea Grant College Programme Publication No. 05-5.

Butardo-Toribio, M.Z., Alino, P.M. \& Guiang, E.S. 2009. Cost-benefit study of marine protected areas: implications on financing and institutional needs. The Philippine Agricultural Scientist 92: 153-69

Butler, M.J.IV. \& Herrnkind, W.F. 1997. A test of recruitment limitation and the potential for population enhancement of Caribbean spiny lobsters in Florida. Canadian Journal of Fisheries and Aquatic Sciences 54: 452-63

Camargo, C., Maldonado, J.H., Alvarado, E., Moreno-Sánchez, R., Mendoza, S., Manrique, N., Mogollón, A., Osorio, J.D., Grajales, A. \& J.A. Sánchez. 2009. Community involvement in management for maintaining coral reef resilience and biodiversity in southern Caribbean marine protected areas. Biodiversity Conservation 18: 935-956

Cameron, T., Poe, G., Ethier, R. \& Schulze, W. 2002. Alternative Nonmarket ValueElicitation Methods: Are underlying preferences the same? Journal of Environmental Economics and Management 44: 391-425

Campbell, S.J., Hoey, A.S., Maynard, J., Kartawijaya, T., Cinner, J. et al. 2012. Weak compliance undermines the success of no-take zones in a large government-controlled marine protected area. PLoS One 7: e50074.

Carr, M.H. \& Reed, D.C. 1993. Conceptual Issues Relevant to Marine Refuges: Examples from Temperate Reef Fish. Canadian Journal of Fisheries and Aquatic Science 50: 2019- 2028

Carter, D.W. 2003. Protected areas in marine resource management: another look at the economics and research issues.Ocean and Coastal Management 46: 439-456

Carter, T., 2006. Vegetated roofs for urban ecosystem remediation: performance and policy in the Tanyard Branch Watershed. Ph.D. Dissertation, Institute of Ecology, University of Georgia, Athens, GA.

Carter, L. 2008. Below low tide - A seabed in motion. In: The Taputeranga marine reserve. J. Gardner \& J.J. Bell (Eds.) Second Edition. First Edition Ltd. Wellington, New Zealand.

Castilla, J.C. 1986. ¿Sigue existiendo la necesidad de establecer Parques y Reservas Marítimas en Chile? Ambiente y Desarrollo 2: 53-63

Castilla, J.C. 1976. Parques y Reservas Marítimas Chilenas - Necesidad de creación, probables localizaciones y criterios básicos. MedioAmbiente 2: 70-8 
Castilla, J.C., Gelcich. S. \& Defeo, O. 2007. Successes, lessons and projections from experience in marine benthic invertebrate artisanal fisheries in Chile. In: McClanahan T, Castilla JC, editors. Fisheries management: progress toward sustainability. Oxford: Blackwell Publishing.

CBD (Convention on Biological Diversity). 2010. 2010 Biodiversity Target. Available at <https://www.cbd.int/2010-target/>

Christie, P. \& Pollnac, R. 2011. Social dynamics of scaling-up marine protected area declarations and management. In: Marine Protected Areas A Multidisciplinary Approach. Claudet, J. (Ed.) Published by Centre National de la Recherche Scientifique (CNRS), Paris.

Cinti, A., Shaw, W. \& Torre, J. 2010. Insights from the users to improve fisheries performance: Fisher's knowledge and attitudes on fisheries policies in Bahia de Kino, Gulf of California, Mexico. Marine Policy 34: 1322-1334

Claudet, J. 2011. Marine Protected Areas A Multidisciplinary Approach. Published by Centre National de la Recherche Scientifique (CNRS), Paris.

Cole, R. \& Jackson, B. 1989. Marine survey of Wellington's south coast. Unpublished report to the Department of Conservation, Wellington, New Zealand.

Conrad, J. 1999. The bioeconomics of marine sanctuaries. Journal of Bioeconomics 1: 205217

Cooper, P. Poe, G.L. \& Batemans, I.J. 2004. The structure of motivation for contingent values: A case study of lake water quality. Ecological Economics 50: 69-82

Costanza, R., d'Arge R., de Groot, R., Farber, S., Grasso, M., Hannon, B., Limburg, K., Naeem, S., O'Neill, R.V., Paruelo, J., Raskin, R.G., Sutton, P. \& van den Belt, M. 1997. The value of the world's ecosystem services and natural capital. Nature 387: 253 - 260

Costanza, R. \& Kubiszewski, I., 2012. The authorship structure of “ecosystem services" as a transdisciplinary field of scholarship. Ecosystem Services 1, 16-25

Cotsilinis, M.E. 1999. Intertidal community responses following the decommissioning of a sewer outfall: Owhiro Bay, Wellington, December 1994 - March 1996 Thesis - M.Sc. in Zoology, Victoria University of Wellington.

Cowley, P.D., Brouwer, S. L. \& Tilney, R. L. 2002. The role of the Tsitsikamma National Park in the management of four shore-angling fish along the south-eastern cape coast of South Africa. S. Afr. J. Mar. Sci. 24: 27-36

Cox, C., Hunt, J.H., Lyons, W.G. \&Davis, G.E. 1997. Nocturnal foraging of the Caribbean spiny lobster, Panulirus argus, at offshorereefs of Florida, USA. Mar Freshw Res 48:671-680. 
Cox, C. \& Hunt, J.H. 2005. Change in size and abundance of Caribbean spiny lobsters Panulirus argusin a marine reserve in the Florida Keys National Marine Sanctuary, USA. Marine Ecology Progress Series 294: 227-239

Craw, M. \& Cocklin, C. 1997. Social impact assessment for Te Whanganui-A-Hei Marine Reserve. Unpublished Consultancy report to Department of Conservation.

Cruz-Trinidad, A., Geronimo, RC., Cabral, RB. \& Aliño, PM. 2011. How much are the Bolinao-Anda coral reef worth? Ocean \& Coastal Management 54: 696 - 705

Daily, G.C., Soderqvist, T., Aniyar, S., Arrow, K., Dasgupta, P., Ehrlich, P.R., Folke, C., Jansson, A., Oansson, J.B., Kautsky, N., Levin, S., Lubchenco, J., Maler, K.G., Simpson, D., Starrett, D., Tilman, D.\& Walker, B. 2000. The value of nature and the nature of value. Science 289: 395-396.

Davis, G.E. 1977. Effects of recreational harvest on a spiny lobster, Panulirus argus, population. Bull Mar Sci 27: 223-236.

Davidson, R.J. 2001a. Changes in population parameters and behaviour of blue cod (Parapercis colias; Pinguipedidae) in Long Island-Kokomohua Marine Reserve, Marlborough Sounds, New Zealand. Aquat Conserv 11: 417-435

Davidson, R.J. 2001b. Changes in population parameters and behaviour of blue cod (Parapercis colias; Pinguipedidae) in Long Island - 435 Lokomohua Marine Reserve, Marlborough Sounds, New Zealand. Aquat.Conserv. Mar. Freshw. Ecosyst.11: 417

Davidson, R. J., Villouta, E., Cole, R. G., \& Barrier, R. G. F. 2002. Effects of marine reserve protection on spiny lobster (Jasus edwardsii) abundance and size at Tonga Island Marine Reserve, New Zealand. Aquatic Conservation: Marine and Freshwater Ecosystems 12: 213-227

Davidson, R.J. 2004. Long Island-Kokomohua Marine Reserve, Queen Charlotte Sound: 1992-2003. Survey and Monitoring Rep No. 343, Department of Conservation, Nelson, Accessed on 22nd August 2012 http://doc.govt.nz/upload/documents/conservation/marine-and-coastal/marineprotected-areas/report-on-monitoring.pdf

Davis, G. E., \& Dodrill, J. W. 1989. Recreational fishery and population dynamics of spinylobsters, Panulirus argus, in Florida Bay, Everglades National Park, 1977-1980. Bulletin of Marine Science 44: 78-88.

Day, J.C. 2002. Zoning-lessons fromtheGreatBarrierReefMarinePark.Ocean \& Coastal Management 45: 139-56. 
De Lacy, T. \& Whitmore, M. Toursim and recreation. In: Managing Portected Areas: A global guide. Lockwood, M., Worboys, G. \& Kothari, A. (Eds.). IUCN. Earthscan, Cromwell Press, Trowbridge, London.

Dean, S., Gadsby, P., Hall, S., Thomas, A. \& Wharfe, C. 2005. Evaluation and Comparison of the Management Efficacy for TeWhanganui-A-Hei and Kapiti Marine Reserves.

Decker, D. J., Brown, T. L., \& Siemer, W. F. 2001. Human Dimensions of Wildlife Management in North America. (The Wildlife Society:Bethesda, MD.).

DEFRA (Department for Environment Food and Rural Affairs). 2007. An introductory guide to valuing ecosystem services.Defra Publications, London, UK. Available at: www.defra.gov.uk

Denny, C.M., Willis, T.J. \& Babcock, R.C. 2004. Rapid recolonisation of snapper Pagrus auratus: Sparidae within an offshore island marine reserve after implementation of notake status. Marine Ecology and Progress Series 272: 183-190

Department of Conservation (DOC). 1998. Kapiti marine reserve conservation management plan. Wellington Conservancy.Department of Conservation, Wellington, New Zealand.

Department of Conservation (DOC). 2006. The value of conservation. What does conservation contribute to the economy? Available in $<$ http://www.doc.govt.nz/upload/documents/conservation/value-ofconservation.pdf $>$.Retrieved 2010-07-21.

Department of Conservation. 2007. Taputeranga Marine Reserve.Brochure.

Department of Conservation (DOC). 2008a. Available in

$<$ http://www.doc.govt.nz/>. Retrieved 2010-07-21.

Department of Conservation.2008b. Tonga Island Marine Reserve.Informative brochure. Available at:http://www.doc.govt.nz/upload/documents/conservation/marine-andcoastal/marine-protected-areas/tonga-island-marine-reserve-web.pdf Retrieved on $\underline{09 / 10 / 2012 .}$

Devine - Wright, P. 2005. Beyond NIMBYism: towards an integrated framework for understanding public perceptions of wind energy. Wind Energy 8: 125-139.

Diaz-Guisado, D., Cole, R.G., Davidson, R.J., Freeman, D.J., Kelly, S., Macdiarmid, A., Pande, A., Stewart, R., Struthers, C. \& Bell, J.J. 2012. Comparison of methodologies to quantify the effects of age and area of marine reserves on the density and size of targeted species. Aquatic Biology 14: 185-200

Dimitrakopoulos, P.G., Jones, N., Iosifides, T., Florokapi, I., Lasda, O., Paliouras, F. \& Evangelinos, K.I. 2010. Local attitudes on protected areas: Evidence from three Natura 2000 wetland sites in Greece. Journal of Environmental Management 91: 1847-1854. 
Dugan, J.E. \& Davis, G.E. 1993. Applications of Marine Refugia to Coastal Fisheries Management.Canadian Journal of Fisheries and Aquatic Sciences 50: 2019-2042

Durrant, J.O. \& Shumway, J.M. 2004. Attitudes towards wilderness study areas: a survey of six southeastern Utah counties. Environmental Management 33: 271-283

Dziegielewska, D., 2009. Total economic value. In: Tietenberg, T., Niggol Seo, S. (Eds.), Encyclopedia of Earth. Environmental Information Coalition, National Council for Science and the Environment, Washington, D.C. Available at http://www.eoearth.org/article/Total_economic_value

Edgar, G. J., \& Barrett, N. S. 1999. Effects of the declaration of marine reserves on Tasmanian reef fishes, invertebrates and plants. Journal of Experimental Marine Biology and Ecology 242: 107-144.

Eddy, T.D., Pande, A. \& Gardner, J.P.A. In review. Assessing Marine Reserve Effects When All Sites are not Equal: Reef Fishes at Kapiti Marine Reserve, New Zealand. PLOSONE.

Eddy, T.D., Pitcher, T.J., MacDiarmid, A.B., Byfield, T.T., Jones, T., Tam. J,, Bell, J.J. \& Gardner, J.P.A. In revision. The ecosystem effects of fishing: past, present and future at the Taputeranga Marine Reserve, New Zealand. PLoSONE.

Eddy, T.D., Gardner, J.P.A. \& Bell, J.J. 2008. A Status Report on the Biological and Physical Information for Wellington's South Coast with Monitoring Recommendations for the Taputeranga Marine Reserve. New Zealand Department of Conservation Report.

Eddy, T.D. 2011. Marine Reserves as Conservation and Management Tools: Implications for Coastal Resource Use. PhD Thesis.Victoria University of Wellington, New Zealand.

Eggleston, D.B. \& Dahlgren, C.P. 2001. Distribution and abundance of Caribbean spiny lobsters in the Key West National Wildlife Refuge: relationship to habitat features and impact of an intensive recreational fishery. Mar. Freshwater Res. 52: 1567-76

Egoh, B.N., O’Farrell, P.J., Charef, A., Gurney, L.J., Koellner, T., bi, H.N., Egoh M. \& Willmen, L. 2012. An African account of ecosystem service provision: Use, threats and policy options for sustainable livelihoods. Ecosystem Services 2: 71-81

Emerton, L. \& Bos, E. 2004. Value: counting ecosystems as water infrastructure. IUCN, Gland, Switzerland and Cambridge, UK.

Enderby, J. \& Enderby, T. 2006. A guide to New Zealand's Marine Reserves.

Evans, J.R. \& Mathur, A. 2005. The value of online surveys.Emerald 15: 195 - 219

Faasen, H. \& Watts, S. 2007. Local community reaction to the 'no-take' policy on fishing in the Tsitsikamma National Park, South Africa. Ecological Economics 64: 36-46

Farber, S.C., Costanza, R., Childers, D.L., Erickson, J. Gross, K., Grove, M., Hopkinson, C.S., Kahn, J., Pinceti, S., Troy, A., Warren, P. \& Wilson, M. 2006. Linking ecology and economics in ecosystem management. BioScience 56: 121-132 
Fiallo, E. A., \& S. K. Jacobson.1995. Local communities and protected areas: attitudes of rural residents toward conservation and Machalilla National Park, Ecuador. Environmental Conservation 22: 241-249.

Fleming, C. M. \& Bowden, M. 2009.Web-based surveys as an alternative to traditional mail methods.Journal of Environmental Management 90: 284-292

Follesa, M.C., Cuccu, D., Cannas, R. \& Cau, A. 2007. On the growth of the European spiny lobster, Palinurus elephas from Sardinian waters (central western Mediterranean Sea). New Zealand Journal of Marine and Freswater Reseacrh 41: 377- 383

Follesa, M.C., Cuccu, D., Cannas, R., Cabiddu, S., Murenu, M., Sabatini,A., et al. 2008. Effects of marine reserve protection on spiny lobster (Palinurus elephas Fabr.,1787) in a central western Mediterranean area. Hydrobiologia 606: 63-68

Forcada, A., Valle, C., Bonhomme, P., Criquet, G., Cadiou, G., Lenfant, P \& Sanchez Lizaso, J.L. 2009. Effects on gradients of fish biomass across marine protected area boundaries. Marine environmental research 66: 536 - 547

Forest \& Bird. 2008. Forest \& Bird condemns 40\% rise in sea lion quota. Available in $<$ http://forestandbird.colo.onesquared.net/what-we-do/publications/mediareleases/forest-bird-condemns-40-rise-in-sea-lion-quota.Retrieved 2010-07-21.

Forest \& Bird. 2011. Marine Reserves - FAQ. Available at $<$ http://www.forestandbird.org.nz/campaigns/we-love-marine-reserves/marine-reservesfaq $>$ Retrieved on $10^{\text {th }}$ February, 2013.

Fort, R., Rosenman, R. \& Budd, W. 1993. Perception costs and NIMBY. Journal of Environmental Management 38: 185-200

FOTMR (Friends of Taputeranga Marine Reserve). 2001. Meet the Trustees. Available at: http://taputeranga.org.nz/the-trust/meet-the-trustees/ Retrieved on $16^{\text {th }}$ November, 2012.

Francour, P., Doussan, I., Sartoretto, S., Martin, G., Harmelin, J.-G. \& Pollard, D. 2005. Guide de création d'un espace marin protégé en Méditerranée : aspects juridique, biologique et écologique. Les Actes, Parc National de Port-Cros: France.

Fraschetti, S., Giangrande.A., Terlizzi, A., Della Tommasa, L., Miglietta, M.P. \& Boero, F. 2002. Spatio-temporal variation of hydroids and polychaetes associated with Cystoseira amentacea (Fucales, Phaeophyceae): a regional scale approach. Mar. Biol. 140: 949957

Fraschetti, S., Terlizzi, A., Bussotti, S., Guarnieri, G., D’Ambrosio, P. \& Boero, F. 2005. Conservation of Mediterranean seascapes: analyses of existing protection schemes. Mar Environ Res 59:309-332 
Francini-Filho, R.B. \&Moura, R.L. 2008. Evidence for spillover of reef fishes from a no-take marine reserve: an evaluation using the before-after control - impact (BACI) approach. Fisheries Research 93: 346-356

Fraschetti, S., Claudet, J. \& Grorud-Colvert, K. 2011. Transitioning from single-sector management of marine resources to ecosystem-based management: what can marine protected areas offer? In: Marine Protected Areas A Multidisciplinary Approach. Claudet, J. (Ed.) Published by Centre National de la Recherche Scientifique (CNRS), Paris.

Frazee, S.R., Cowling, R.M., Pressey, R.L., Turpie, J.K. \& Lindenberg, N. 2003.Estimating the costs of conserving a biodiversity hotspot: a case-study of the Cape Floristic Region, South Africa.Biol. Conserv. 112: 275-290

Freeman, D. 2008. The ecology of spiny lobster (Jasusedwardsii) on fished and unfished reefs.PhD Thesis. The university of Auckland.ResearchSpace@ Auckland

Freeman, D.J., MacDiarmid, A.B., \& Taylor, R.B. 2009. Habitat patches that cross marine reserve boundaries: consequences for the lobster Jasus edwardsii. Marine Ecology Progress Series 388: 159-167.

Freeman, D.J., Breen, P.A., \& MacDiarmid, A.B. 2012. Use of a marine reserve to determine the direct and indirect effects of fishing on growth in a New Zealand fishery for the spiny lobster Jasus edwardsii. Canadian Journal of Fisheries and Aquatic Sciences 69: 894-905.

Frusher, S. D., \& Hoenig, J. M. 2001.Impact of lobster size on selectivity of traps for southern rock lobster (Jasus edwardsii). Canadian Journal of Fisheries and Aquatic Science 58: 2482-2489

Gaddis, S.E. 1998. How to design online surveys. Training \& Development 52: 67-71

Gardner, C., Frusher, S., Haddon, M., \& Buxton, C. 2003. Movements of the southern rock lobster Jasus edwardsii in Tasmania, Australia. Bulletin of Marine Science 73: 653-671

Gardner, J. and Bell, J.J. (Eds). 2008. The Taputeranga Marine Reserve. First Edition Publishers, Wellington, New Zealand.

Gardner, J.P.A, \&Struthers, C.D. 2013. Comparisons among survey methodologies to test for abundance and size of a highly targeted fish species. Journal of Fish Biology 82: 242262.

Gelcich, S., Edwards-Jones, G., Kaiser, M.J. \& Watson, E. 2005a. Using discourses for policy evaluation: the case of marine common property rights in Chile. Society and Natural Resources 18: 377-391 
Gelcich, S., Edwards-Jones, G. \& Kaiser, M.J. 2005b. Importance of attitudinal differences among artisanal fishers with respect to comanagement and conservation of benthic resources. Conservation Biology 19: 865-875

Gelcich, S., Kaiser, M. J., Castilla, J. C. \& Edwards-Jones, G. 2008. Engagement in comanagement of marine benthic resources influences environmental perceptions of artisanal fishers. Environmental Conservation 35: 36-45

Gelcich, S., Edwards-Jones, G. \& Kaiser, M.J. 2007. Heterogeneity in fishers harvesting behaviour under a Territorial user rights policy. Ecological Economics 6: 246-54.

Gell, F.R. \& Roberts, C.M. 2002. The Fishery Effects of Marine Reserves and Fishery Closures, WWF-US.Available in <http://www.worldwildlife.org/oceans/fishery_effects.pdf> Retrieved 2010-07-21.

Gell, F.R. \& Roberts, C.M. 2003. Benefits beyond boundaries: the fishery effects of marine reserves. Trends in Ecology and Evolution 18: 448 - 455

Gerber, L. R., L. W. Botsford, A. Hastings, H. P. Possingham, S. D. Gaines, S. R. Palumbi, \& Andelman, S. 2003. Population models for marine reserve design: a retrospective and prospective synthesis. Ecological Applications 13: S47-S64

Gillespie, S. 2011. Rainfall Characterisation for Central Queensland associated with Tropical Cyclones Crossing the Queensland Coast. C\&R Consulting (4)

Gillespie, R. \& Bennett, J. 2011. Non use economic values of marine protected areas in the south-west marine area. Working paper.

Goh, A. 2008. Human impact: past and present. In: The Taputeranga marine reserve. J. Gardner \& J.J. Bell (Eds.) Second Edition. First Edition Ltd. Wellington, New Zealand.

Goñi, R., Renones, O. \& Quetglas, A. 2001. Dynamics of a protected Western Mediterranean population of the European spiny lobster Palinurus elephas (Fabricius, 1787) assessed by trap surveys. Marine and Freshwater Research 52: 1577-1587

Goñi, R.,Hilborn, R., Díaz, D., Mallol, S. \& Alderstein, S. 2010. Evidence of biomass export from six WesternMediterranean marine protected area as measured from artisanal fisheries. Marine Ecology and Progress Series 366: 159-174

Goñi, R., Badalamenti, F. \& Tupper, M.H. 2011. Effects of marine protected areas on adjacent fisheries: evidence from empirical studies. In: Marine Protected Areas AMultidisciplinary Approach. Claudet, J. (Ed.) Published by Centre National de la Recherche Scientifique (CNRS), Paris.

Gravestock, P., Roberts, C.M. \& Bailey, A. 2008. The income requirements of marine protected areas. Ocean \& Coastal Management 51: 272 - 283

Green, P.E., Tull, D.S. \& Albaum, G. 1988. Research for marketing decisions. Prentice-Hall, Inc. New Jersey, USA. 
Green, J.M.H., Burgess, N.D., Green, R.E., Madoffe, S.S., Munishi, P.K.T., Nashanda, E., Kerry Turner, R. \& Balmford, A. 2012. Estimating management costs of protected areas: A novel approach from the Eastern Arc Mountains, Tanzania. Biological Conservation 150, 5-14

Greenstreet, S. P. R., Fraser H. M. , Piet G. J. 2009. Using MPAs to address regional-scale ecological objectives in the North Sea: modelling the effects of fishing effort displacement. ICES Journal of Marine Science 66: 99-100

Hall, K. 2003. What is bioprospecting and what are our international commitments?, Background paper for Ministry of Economy Development, Wellington. Available at < www.med.govt.nz/ers/nat-res/bioprospecting/general-information/what-is/what-is.pdf> Retrieved on $2^{\text {nd }}$ February, 2012

Halpern, B.S. 2002. The impact of marine reserves: do reserves work and does reserve size matter? Ecological Applications 13 Supplement: S117-S137

Halpern, B. S. \& Warner R. R. 2002. Marine reserves have rapid and lasting effects. Ecology Letters 5: 361-366

Halpern, B.S. 2003. The impact of marine reserves: do reserves work and does reserve size matter? Ecol. Applic. 13: S117-S137

Halpern, B.S., S.D. Gaines, \& R.R. Warner. 2004. Confounding effects of the export of production and the displacement of fishing effort from marine reserves. Ecological Applications 14: 1248-1256

Halpern, B.S., Lester, S.E. \& McLeod, E. 2010. Placing marine protected areas onto ecosystem-based management seascapes. Proceedings of the National Academy of Sciences of the United States of America 107: 312-317

Hannesson, R. 2002. The economics of marine reserves.Natural Resource Modelling 15: 273-290

Hardin, G. 1968. The Tragedy of the Commons.Science 162: 1243-1248

Hastings, A. \& Botsford, L.W. 1999. Equivalence in yield from marine reserves and traditional fishery management. Science 284: 1537-1538

Hearnshaw, E.J., Cullen, R. \& Hughey, F.D. 2010. Ecosystem Services Review of Water Storage Projects in Canterbury: The Opihi River Case. Lincoln University, New Zealand.

Heck, N., Dearden, P., McDonald, A. \& Carver, S. 2011. Developing MPA performance indicators with localstakeholders' input in the Pacific Rim National Park Reserve, Canada.Biodivers Conserv 20: 895-911

Herrnkind, W. F., \& Butler, M. J. 1986. Factors regulating postlarval settlement and juvenile microhabitat use by spiny lobsters Panulirus argus. Marine Ecology Progress Series 34: 23-30. 
Hilborn, R. \& Walters, C. 1992. Quantitative fisheries stock assessment: choice, dynamics and uncertainty.Kluwer Academic Publishers, Boston.

Hilborn, R., Stokes, K. Maguire, J.J., Smith, A.D.M., Botsford, L.W., Mangel, M., Orensanz, J., Parma, A., Rice, J., Bell, J.. Cochrane, K.L., Garcia, S., Hall, S.J., Kirkwood, G.P., Sainsbury, K., Stefansson, G.\& Walters, C. J. 2004. When can marine reserves improve fisheries management? Ocean and Coastal Management 47/3-4:197-205

Hilborn, R. 2006. Faith-based fisheries.Fisheries 31: 554-555

Hoagland, P., Kaoru, Y. \& Broadus, J.M. 1995.A methodological review of net benefit evaluation for marine reserve. World Bank, Environmental Economics Series, Paper $\mathrm{n}^{\mathrm{o}}$ 027

Hoevenagel, R. 1994. The contingent valuation method: scope and validity, Vrije Universiteit, Amsterdam.

Hoffman, B., Roeger,S., Stolton,S. \&Wise, P. 2012. Australia: Dhimurru, looking after one land and sea. In:Dudley,N. \&Stolton,S. (Eds.). Protected Landscapes and Wild Biodiversity, Values of Protected Landscapes and Seascapes Series volume 3, IUCN and GIZ, Gland, Switzerland.

Holmes, G. 2013. Exploring the relationship between local support and the success of protected areas. Conservation and Society 11: 72-82

Holland, D.S. 2000. A bioeconomic model of marine sanctuaries on Georges Bank.Canadian Journal of Fisheries and Aquatic Sciences 56: 253-264

Holland, D.S., Sanchirico, J.N., Curtis, R.E. \& Hicks R.L. 2004. An introduction to spatial modelling in fisheries economics.Marine Resource Economics 19: 1-6

Horta e Costa, B., Batista, M.I., Gonçalves, L., Erzini, K., Caselle, J.E., et al. 2013. Fishers' Behaviour in Response to the Implementation of a Marine Protected Area. PLoS ONE 8(6): e65057

Howard, A. E. 1980. Substrate controls on the size composition of lobster (Homarus gammarus) populations. J. Cons. int. Explor. Mer. 39: 130-133.

Howarth, R.B. \& Farber, S. 2002. Accounting for the value of ecosystem services. SPECIAL ISSUE: The Dynamics and Value of Ecosystem Services: Integrating Economic and Ecological Perspectives. Ecological Economics 41: 421-429

Hut, L. 2008. Economic Impact Analysis of the Cape Rodney Okakari Point (Leigh) Marine Reserve on the Rodney District. Investigation number 4052. A report prepared for the Department of Conservation. Available at $<$ http://www.marinenz.org.nz/documents/leigh eco impact.pdf $>$ Retrieved on $20^{\text {th }}$ November, 2009.

Hutchings, J.A. 2000. Collapse and recovery of marine fishes. Nature 406: 882-885 
Hutchings, J.A. \& Myers, R.A. 1994. What can be learned from the collapse of a renewable resource? Atlantic cod, Gadusmorhua, of Newfoundland and Labrado. Can. j. fish aquat. sci. 51: 2126-2146

Hutton T., Mardle S., Pascoe S.\& Clark R. A. 2004. Modelling fishing location choice within mixed fisheries: English North Sea beam trawlers in 2000 and 2001. ICES Journal of Marine Science 61:1443-145

Ilieva, J., Baron, S. \& Healey, N.M. 2002. Online surveys in marketing research: pros and cons. International Journal of Marketing Research 44: 361-76

Institute on Governance (Canada). 2002. Available at <www.iog.ca $>$ Retrieved on $25^{\text {th }}$ September, 2012.

IUCN, The Nature Conservancy \& The World Bank. 2004. How much is an ecosystem worth? Assessing the economic value of conservation.The International Bank for Reconstruction and Development/The World Bank. Washington, DC.

Jackson, N.B. 2003. Opinions to spare? Click here. New York Times, July 3, p. G1.

Jacobson, S. K., M. McDuff, \& M. Monroe 2006. Conservation Education and Outreach Techniques. Oxford University Press, U.K.

James, M.R. 1976. A study of molluscan macrofauna on different rock types in the Cook Strait area. Thesis - BSc (Hons.), Victoria Universety of Wellington.

James, A.N., Green, M.J.B.\& Paine, J.R. 1999. A Global Review of Protected Area Budgets and Staff.World Conservation Monitoring Centre, Cambridge, United Kingdom.

Jenkins, M. 2003. Prospects for Biodiversity. Science 302: 1175-1177

Jentoft, S. \& B. McCay. 1995. User participation in fisheries management: lessons drawn from international experiences. Marine Policy 19: 227-246

Jones, P.J.S. 2008. Fishing industry and related perspectives on the issues raised by no-take marine protected area proposals. Marine Policy 32:749-58.

Kahneman, D. \& Knetsch, JL. 1992. Valuating public goods: The purchase of moral satisfaction. Journal of Environmental Economics and Management $22: 57$ - 70

Kapoor I. 2001. Towards participatory environmental management? Journal of Environmental Management 63: 269-79.

Kellner, J.B., Tetreault, I., Gaines, S. D. \& Nisbet, R. M. 2007. Fishing the line near marine reserves in single and multispecies fisheries. Ecological Applications 17:1039-1054

Kelly, S. 2001. Temporal variation in the movement of the spiny lobster Jasus edwardsii. Marine and Freshwater Research 52: 323-331. 
Kelly, S., MacDiarmid, A. B., \& Babcock, R. C. 1999. Characteristics of spiny lobster, Jasus edwardsii, aggregations in exposed reef and sandy areas. Marine and Freshwater Research 50: 409-416.

Kelly, S., Scott, D., MacDiarmid, A.B. \& Babcock, R.C. 2000. Spiny lobster, Jasus edwardsii, recovery in New Zealand marine reserves. Biol. Conserv 92:359-369.

Kelly, S., Scott, D., \& MacDiarmid, A. B. 2002. The value of a spillover fishery for spiny lobsters around a marine reserve in northern New Zealand. Coastal Management 30: 153-166.

Kelly, S. \& McDiarmid, A.B. 2003. Movement patterns of mature spiny lobster, Jasus edwardsii, from a marine reserve. New Zealand Journal of Marine and Freshwater Research 37: 149-158.

Kettles, H. \& Hughes, P. 2009. Wellington marine information CD. Published by the Department of Conservation's Wellington Hawke's Bay Conservancy. New Zealand.

Kettunen, M. \& Brink, P. 2006. Value of biodiversity: documenting EU examples where biodiversity loss has led to the loss of ecosystem services. Final Report for the European Commission. Institute for European Environmental Policy IEEP, Brussels, Belgium.

Kikuchi, R. \& Gerardo, R. 2009. More than a decade of conflict between hazardous waste management and public resistance: A case study of NIMBY syndrome in Souselas (Portugal). Journal of Hazardous Materials 172: 1681-1685.

Kniivilä, M. 2006. Users and non-users of conservation areas: Are there differences in WTP, motives and the validity of responses in CVM surveys? Ecological Economics 59: 530 - 539

Kollmuss, A., \& J. Agyeman. 2002. Mind the Gap: why do people act environmentally and what are the barriers to pro-environmental behavior? Environmental Education Research 8:239-260.

Kramer, D. L., \& Chapman, M. R. 1999. Implications of fish home range size and relocation for marine reserve function. Environmental Biology of Fishes 55: 65-79.

Kriström, B., \&Boman, M. 2000. Valuing the multiple functions of forests. URL: http://www.sekon.slu.se/\%7Ebkr/palo.PDF [March10, 2003]

Langford, I. \& Bateman, I. 1993. Welfare Measures for Contingent Valuation Studies: Estimation and Reliability, Cetnre for Social and Economic Research on the Global Environment.

Lédée, E. J.I.., Sutton, S. G.., Tobin, R. \& De Freitas, D. M. 2012. Responses and adaptation strategies of commercial and charter fishers to zoning changes in the Great Barrier Reef Marine Park. Marine Policy 36: 226-234. 
Leslie, H., Ruckelshaus, M., Ball, I.R., Andelman, S., \& Possingham, H.P. 2003. Using siting algorithms in the design of marine reserves networks. Ecological Applications 13: S185-S198

Lester, S.E,. Halpern, B.S., Grorud-Colvert, K., Lubchenco, J., Ruttenberg, B.I., Gaines, S.D., Airame, S. \& Warner, R.R. 2009. Biological effects within no-take marine reserves: a global synthesis. Marine Ecology Progress Series. 384:33-46.

Likert, R. 1932. A technique for the measurement of attitudes.Archives of Psychology 22: 4453

Lockwood, M., Kothari, A. \& Worboys, G. (Eds.). 2006. Managing Protected Areas: a Global Guide. IUCN. Earthscan, Cromwell Press, Trowbridge, London.

McAlpine, K.G. \& Wotton, D.M. 2009. Conservation and the delivery of ecosystem services.A literature review.Department of Cnservation Report, New Zealand. Available at <http://www.doc.govt.nz/documents/science-andtechnical/sfc295entire.pdf $>$ Retrieved on $10^{\text {th }}$ February, 2013.

MacDiarmid, A. B. 1991. Seasonal changes in depth distribution, sex ratio and size frequency of spiny lobster Jasus edwardsii on a coastal reef in northern New Zealand. Marine Ecology Progress Series 70: 129-141.

MacDiarmid, A. B., \& Breen, P. A. 1992. Spiny lobster population change in a marine reserve. Paper presented at the Second International Temperate Reef Symposium, Auckland.

MacDiarmid, A. B., \& Butler, M. J. 1999. Sperm economy and limitation in spiny lobsters. Behavioural Ecology and Sociobiology 46: 14-24

MacDiarmid, A. B., \& Kittaka, J. 2000. Breeding. In B. F. Phillips \& J. Kittaka (Eds.), Spiny lobsters: Fisheries and culture. Oxford: Blackwells

MacDiarmid, A. B., Hickey, B., \& Maller, R. A. 1991. Daily movement patterns of the spiny lobster Jasus edwardsii (Hutton) on a shallow reef in northern New Zealand. Journal of Experimental Marine Biology and Ecology 147: 185-205.

MacDiarmid, A. B., Stewart, R., \& Oliver, M. 2000. Mate choice in rock lobsters. Seafood New Zealand, August, 38-39.

MacDiarmid, A.B., McKenzie, A., Sturman, J., Beaumont, J., Mikaloff-Fletcher, S., Dunne, J. 2012. Assessment of anthropogenic threats to New Zealand marine habitats. New Zealand Aquatic Environment and Biodiversity Report 93: 255 p.

Mangi, S.C. \& Austen, M.C. 2008. Perceptions of stakeholders towards objectives and zoning of marine-protected areas in southern Europe.Journal for Nature Conservation $16: 271-80$.

Mardle S.\& Hutton T. 2004. Measuring the effects of distance to fishing grounds in location choice modelling. In: Anrooy R., De Young C., editors. Report of the Sixteenth Annual 
Conference of the European Association of Fisheries Economists. FAO Fisheries Report, 739.

Marine Protected Areas Policy (MPA Policy). 2005. Marine Protected Areas Policy and Implementation Plan. Published by Department of Conservation and Ministry of Fisheries. Available at <www.biodiversity.govt.nz>

Marta-Pedroso, C., H. Freitas, \& T. Domingos. 2007. Testing the survey mode effect on contingent valuation data quality: A case study of web based versus in-person interviews. Ecological Economics 62: 388-398

Mascia, M.B., 2004. Social dimensions of marine reserves. In: Sobel, J., Dahlgren, C. (Eds.), Marine Reserves: A Guide to Science, Design, and Use. Island Press, Washington, DC.

Mascia, M.B. \& Claus, C.A. 2009. A property rights approach to understanding human displacement from protected areas: the case of marine protected areas. Conserv. Biol. $23,16-23$

.Mascia, M.B., Claus, C.A., Naidoo, R. 2010. Impacts of marine protected areas on fishing communities. Conserv. Biol. 24, 1424-1429

McCartney, A. 2006. The Social Value of Seascapes in the Jurien Bay Marine Park: An Assessment of Positive and Negative Preferences for Change. Journal of Agricultural Economics 57: 577-594

McClanahan, T.R. 1999. Is there a future for coral reef parks in poor tropical countries? Coral Reefs 18: 321-325

McClanahan, T.R. \& Mangi, S. 2000. Spillover of exploitable fishes from a marine park and its effect on the adjacent fishery. Ecol Appl 10: 1792-1805.

McClanahan, T., Davies, J., \& Maina, J. 2005. Factors influencing resource users and managers' perceptions towards marine protected area management in Kenya. Environmental Conservation 32: 42-49

McClanahan, T.R., Cinner, J.E., Maina, J., Graham, N.A.J., Daw, T.M., Stead, S.M., Wamukota, A., Brown, K., Ateweberhan, M., Venus, V.and Polunin, N.V.C. 2008. Conservation action in a changing climate. Conserv.Lett. 1:53-59

McCrea-Strub, A., Zeller, D., Sumaila, U.R., Nelson, J., Balmford, A. \& Pauly, D. 2011. Understanding the cost of establishing marine protected areas. Marine Policy 35: 1-9

McFadden, D.1994. Contingent valuation and social choice.American Journal of Agricultural Economics 76: 689-708.

McGregor, K. 2007. Spillover from marine reserves: A systematic literature review and population model for queen conch using Gladden Spit Marine Reserve, Belize, as a case study. Msc, Thesis. Imperial College Conservation Science (ICCS). 
Mendonça, M.J.C., Sachsida, A. \& Loureiro, P.R.A. 2003. A study on the valuing of biodiversity: the case of three endangered species in Brazil. Ecological Economics 46: 9-18

Michener, H. A., DeLamater, J. D. \& Myers, D. J. 2004. Social Psychology (Australia: Thompson Wadsworth).

Millennium Ecosystem Assessment (MEA). 2005. Ecosystems and Human Well-being: Synthesis. Island Press, Washington, DC.

Miller, R. J. 1994. Why are there so many American lobsters? The Lobster Newsletter 7: 1415

McKoy, J. 1968. A survey of three rocky shores on Kapiti Island - Easter 1968. Unpublished report, Zoology Department, Victoria University of Wellington. Appendix in: Baxter, A.S. (1987). Kapiti Island subtidal ecological survey.

Ministry of Fisheries. 2010. New Zealand rock lobster fisheries public consultation document on proposals to review sustainability measures and other management controls for 1 april 2011. Government Report. http://www.fish.govt.nz/NR/rdonlyres/5B0A0FC17846-4C1F-B6AC-B79EAC2B0E3A/0/Rock_Lobster_Initial_Advice.pdf Accessed on 22nd August 2012

Ministry of Tourism. 2012. The Facts - Tourism in New Zealand. Available in < http://www.tourismnewzealand.com/developing-nz-tourism/about-the-tourismindustry/the-facts-tourism-in-new-zealand/> Retrieved 2013-01-24.

Ministry for Primary Industry. 2012. Rock Lobster Catch Limit

Changes.http://www.mpi.govt.nz/news-resources/news/rock-lobster-catch-limitchanges.Accessed on $7^{\text {th }}$ August 2012.

Moberg, F., \& C. Folke. 1999. Ecological Goods and Services of Coral Reef Ecosystems. Ecological Economics 29: 215-33

Mmopelwa, G., Kgathi, D.L \& Molefhe, L. 2007. Tourists' perceptions and their willingness topay for park fees: A case study of self drive and clients for mobile tour operators in Moremi Game Reserve, Botswana. Tourism Management 28: 1044-1056

Moore, J., Balmford, A., Allnutt, T. \& Burgess, N. 2004. Integrating costs into conservation planning across Africa. Biological Conservation. 117: 343-350.

Murawski, S., Rago, P., \& Fogarty, M. 2004. Spillover effects from temperate marine protected areas. American Fisheries Society Symposium 42: 167-184.

Moreno, C.A. \& P.S., Rubilar. 1997. Densidad de poblaciones protegidas en reservas marinas: Cambios en el tiempo y eventual efecto de la explotación. Estudios Oceanológicos 16: $41-50$ 
Moritz, C. \& Faith, D.P. 1998. Comparative phylogeography and the identification of genetically divergent areas for conservation. Molecular Ecology 7: 419 - 429

Murray, S.N., Ambrose, R.F., Bohnsack, J.A., Botsford, L.W., Carr, M.H., Davis, G.E., Dayton, P.K., Gotshall,D., Gunderson, D.R., Hixon, M.A., Lubchenco, J., Mangel, M., MacCall, A., McArdle, D.A., Ogden,J.C., Roughgarden, J., Starr, R.M., Tegner, M.J. \& Yoklavich, M.M. 1999. No-take reservenetworks: sustaining fishery populations and marine ecosystems. Fisheries 24: 11-25

Musall, F. D. \& Kuik, O. 2011. Local acceptance of renewable energy-A case study from southeast Germany. Energy Policy 39: 3252-3260. doi: 10.1016/j.enpol.2011.03.017

Myers, R.A., Hutchings, J.A. \& Barrowman, N.J. 1997. Why do fish stocks collapse? The example of cod in eastern Canada. Ecological Applications 7: 91-106

Myers, R. A. and Worm, B. 2003. Rapid worldwide depletion of predatory fish communities. Nature 423: 280-283

NABIS. 2012. Internet mapping of New Zealand's marine environment, species distributions and fisheries management. Available at <http://www.nabis.govt.nz/Pages/default.aspx $>$

Naidoo, R., Balmford, A., Ferraro, P.J., Polasky, S., Ricketts, T.H., Rouget, M. 2006. Integrating economic costs into conservation planning. Trends Ecol. Evol. 21: 681687.

Napier, V., Branch, G. \& Harris, J. 2005. Evaluating conditions for successful comanagement of subsistence fisheries in Kwa Zulu-Natal, South Africa. Environmental Conservation 32: 165-177

National Research Council (NRC). 2001. Marine Protected Areas: Tools for Sustaining Ocean Ecosystem. National Academy Press, Washington, D.C.

NOAA. 2011. NOAA's Climate Prediction Center: La Niña is back. http://www.noaanews.noaa.gov/stories2011/20110908_lanina.html Accessed on 22nd August 2012

NRC (National Research Council). 2001. Marine Protected Areas: Tools for Sustaining Ocean Ecosystem. National Academy Press; Washington, DC.

Nunes, P.A.L.D., van den Bergh J.C.J.M. \& Nijkamp, P. 2003. The Ecological Economics of Biodiversity: Methods and Policy Applications, Edward Elgar Publishing, Cheltenham.

NZRLIC (New Zealand Rock Lobster Industry Council). 2012. Current issues. Rock lobster fisheries decisions. Available at http://www.nzrocklobster.co.nz/rl-currentissues Retrieved on 21st November, 2012 .

Ojea, E. \& Loureiro, M.L. 2010. Valuing the recovery of overexploited fish stocks in the context of existence and option values. Marine Policy 34: 514-521 
O’Neill, J. 1993. Ecology, policy and politics: Human well-being and the natural world. London: Routledge.

Pagiola, S., von Ritter, K., \& Bishop, J. 2004. Assessing the economic value of ecosystem conservation. The world bank environment department. Environment Department Paper number 101.

Palumbi, S.R. 2000. The ecology of marine protected areas.In M. Bertness, M. Hixon, and S. Gaines (Eds.), Marine Community Ecology.Sinauer Press, Sunderlan, Mass.

Pande, A. 2001. Evaluating biological change in New Zealand marine reserves.Thesis - Ph.D. in Zoology, Victoria University of Wellington.

Pande, A., MacDiarmid, A.B., Smith, P.J., Davidson, R.J., Cole, R.G., et al. 2008. Marine reserves increase the abundance and size of blue cod and rock lobster. Marine Ecology Progress Series 366: 147-158

Pande, A \& Gardner, J.P.A. 2009. A baseline biological survey of the proposed Taputeranga Marine Reserve (Wellington, New Zealand): spatial and temporal variability along a natural environmental gradient. Aquatic Conservation-Marine and Freshwater Ecosystems.

Pande, A \& Gardner, J.P.A. 2012. The Kapiti Marine Reserve (New Zealand): Spatial and temporal comparisons of multi-species responses after 8 years of protection. New Zealand Journal of Marine and Freshwater Research 46: 71-89.

Pandolfi, J. M., Bradbury, R. H., Sala, E., Hughes, T. P., Bjorndal, K. A., Cooke, R. G., Mcardle, D., Mcclenachan, L., Newman, M. J. H., Paredes, G., Warner, R. R. \& Jackson, J. B. C. 2003. Global Trajectories of the Long-Term Decline of Coral Reef Ecosystems. Science 15: 955 - 958

Patterson, M., \&Cole, A. 1999. Assessing the Value of New Zealand's Biodiversity.School of Resource and Environmental Planning, Massey University.

Pascale, J.M., Doyle, P., Chan, A. \& Griffiths, J. 2004. Using Field Experiments to Improve. Instrument Design: The SIPP Methods Panel Project.

Pauly, D., Christensen, V., Dalsgaard, J., Froese, R. \&Torres Jr. F. 1998. Fishing down marine food webs. Science 279: 860-863

Pauly, D., Christensen, V., Guénette, S., Pitcher, T.J., Sumaila, U.R., Walters, C.J., Watson, R. \& Zeller, D. 2002. Towards sustainability in world fisheries. Nature 418: 689-695

Pauly, D., Alder, J., Bennett, E., Christensen, E.V., Tyedmers, P. \& Watson, R. 2003. The future for fisheries. Science 302:1359-61

Pearce, D.W. and Moran, D. 1994. The Economic Value of Biological Diversity. Earthscan, London. 
Perrings, C.K.G., Mäler, C., Folke, C.S. \&Holling, B.O. 1995. Biodiversity Loss. Economic and Ecological Issues.Cambridge University Press, Cambridge and New York.

Pezzack, D. S. 1992. A review of lobster (Homarus americanus) landing trends in the Northwest Atlantic 1947-1986. J. North. Atl. Fish. Sci. 14: 115-127

Pezzey, J.C.V., Roberts, C.M. \& Urdal, B.T. 2000. A simple bioeconomic model of a marine reserve.Ecological Economics, forthcoming.

Pimentel, D., Wilson, C., McCullum, C., Huang, R., Dwen, P., Flack, J., Tran, Q., Saltman, T., \&Cliff, B. 1997. Economic and environmental benefits of biodiversity. Bioscience 47: 747-757

Pew Oceans Commission (POC). 2003. America's Living Oceans: Charting a Course for Sea Change. Arlington (VA): POC.

Pita, C., Pierce, G. J. \& Theodossiou, I. 2010. Stakeholders' participation in the fisheries management decision-making process: Fishers' perceptions of participation. Marine Policy 34: 1093 - 1102

Polacheck, T. 1990. Year around closed areas as a management tool.Nat. Resource Modeling 4: $327-353$

Polasky, S., Camm, J.D. \& Garber-Yonts, B. 2001. Selecting biological reserves costeffectively: an application to terrestrial vertebrate conservation in Oregon. Land Econom. 77: 68-78.

Polovina, J. J., Haight, W. R., Moffitt, R. B., \& Parrish, F. A. 1995. The role of benthic habitat, oceanography and fishing on the population dynamics of the spiny lobster, Panulirusmarginatus (Decapoda, Palinuridae), in the Hawaiian archipelago. Crustaceana 68: 203-212

Pomeroy, R.S., Parks, J.E., \& Watson, L.M. 2004. How is your MPA doing? A guidebook of natural and social indicators for evaluating marine protected area management effectiveness. Gland, Switzerland: IUCN.

Pouliquen-Young, O. 1997. Evolution of the system of protected areas in Western Australia. Environmental Conservation 24: 168-181

Pradhan N. C.\& Leung P. 2004. Modelling trip choice behaviour of the longline fisheries in Hawaii. Fisheries Research 68:209-224

Rassweiler, A., Costello, C., Siegel, D.A. 2012. Marine protected areas and the value of spatially optimized fishery management. PNAS 109, 11884-11889.

Rauwald, K.S. \& Moore, C.F. 2002. Environmental attitudes as predictors of policy support across three countries. Environment \& Behavior 34: 709-39 
Ready, R.., Fisher, A., Guignet, D., Stedman, R. \&Wang, J. 2006. A pilot test of a new stated preference valuation method: Continuous attribute-based stated choice. Ecological Economics 59: 247-255

Rees, S.E., Attrill, M.J., Austen, M.C., Mangi, S.C., Richards, Jo.P. \& Rodwell, L.D. 2010. Is there a win-win sceneario for marine nature conservation? A case study of Lyme Bay, England. Ocean \& Coastal Management 53:135-145

Rees, S.E., Austen, M.C., Attrill, M.J. \& Rodwell, L.D. 2012. Incorporating indirect ecosystem services into marine protected area planning and management. International Journal of Biodiversity Science, Ecosystem Services \& Management 8: 273-285

Restrepo, J.D., Zapata, P., Díaz, J.M., Garzón-Ferreira, J. \&García, C.B. 2006. Fluvial Xuxes into the Caribbean Sea and their impact on coastal ecosystems: the Magdalena River, Colombia. Global Planet Change 50: 33-49

Richardson, E.A., Kaiser, M.J. \& Edwards-Jones, G. 2005. Variation in fishers' attitudes within an inshore fishery: implications for management. Environmental Conservation 32: $213-225$

Roberts, C.M. \&Polunin, N.V.C. 1991. Are marine reserves effective in the management of reef fisheries? Reviews in Fish Biology and Fisheries 1: 65-91

Roberts, C.M. 1995. Rapid build-up of fish biomass in a Caribbean marine reserve. Conservation Biology 9: 815-826

Roberts, C.M. 1998. Sources, sinks, and the design of marine reserve networks. Fisheries 23:16-19

Roberts, C.M. \&Hawkins, J.P. 2000. Fully-protected Marine Reserves: A Guide, WWF Endangered Seas Campaign, Washington, DC and University of York. Available in www.panda.org/resources/publications/water/mpreserves/mar_dwnld.htm>Retrieved 2010-07-21.

Roberts, C., Bohnsack, J.A., Gell, F., Hawkins, J.P., \& Goodridge, R. 2001. Effects of Marine Reserves on Adjacent Fisheries. Science 294: 1920-1923

Robertson, B. \& Stevens, L. 2007. Kapiti, southwest, south coasts and Wellington Harbour: risk assessment and monitoring recommendations. Report prepared for Greater Wellington Regional Council. Wriggle Ltd, Nelson.

Rogers, A. 2011. Is choice modeling really necessary? Public versus expert values for marine reserves in Western Australia.Paper presented at the 55th Australian Agricultural and Resource Economics Society annual conference, Melbourne Australia, 10th - 13th February 2009.

Rojas-Nazar, U., Gaymer, C.F., Squeo, F.A., Garay-Flühmann, R \& Lopez, D. 2012. Combining information from benthic community analysis and social studies to establish 
no-take zones within a multiple uses marine protected area. Aquatic Conservation: Marine and Freshwater Ecosystems 22: 74-86

Rowley, R.J. 1994. Marine reserves in fisheries management. Aquatic Conservation: Marine and Freshwater Ecosystems 4: 233-254

Ruckelshaus, M., Klinger, T., Knowlton, N., \& Demaster, D.P. 2008. Marine ecosystembased management in practice: scientific and governance challenges. Bioscience 58: 563

Russ, G.R. 2002.Yet another review of marine reserves as reef fishery management tools. In Coral Reef Fishes: Dynamics and Diversity in a Complex Ecosystem (Sale, P.F., ed.), Academic Press.

Russ, G.R. \& Alcala, A.C. 2004. Marine reserve benefits local fisheries. Ecological Applications 15:597-606

Russell, M.K. 2004.Population biology of paua (Haliotis iris and Haliotis australis) along the Wellington South Coast, New Zealand.Thesis - M.Sc.In Marine Biology, Victoria University of Wellington.

Russ, G. \& Alcala, A. 1998. Natural fishing experiments in marine reserves 1983-93: community and trophic responses. Coral Reefs 17: 383-397

Ryan, R.J. 1995. Claims-making and rhetoric in the contest between conservation and recreation. The Case of the The Wainui Marine Reserve Proposal. Msc. Thesis. Lincoln University, New Zealand.

Saengsupavanich, C., Seenprachawong, U., Gallardo, W.G., Shivakoti, G.P. 2008. Portinduced erosion prediction and valuation of a local recreational beach. Ecological Economics 67: 93-103.

Saengsupavanich, C. 2012. Unwelcome environmental impact assessment for coastal protection along a 7-km shoreline in Southern Thailand. Ocean \& Coastal Management 61: 20-29

Sale, P. F., \& Kritzer, J. P. 2003. Determining the extent and spatial scale of population connectivity: Decapods and coral reef fishes compared. Fisheries Research 65: 153172.

Sanchirico, J.N. 2000. Marine protected areas as fishery policy: A discussion of potential cost and benefits. Discussion paper No 00-23. Washington, DC: Resource for the Future.

Sanchirico, J.N., Cochran, K.A. \& Emerson, P.M. 2002. Marine Protected Areas: Economic and social implications. Washington, D.C.: Resource for the future, Discussion Paper 02-06. 
Sandersen, H.T. \& Koester, S. 2000. Comanagement of tropical coastal zones: the case of the Soufrie`re marine management area, St Lucia, WI. Coastal Management 28:87-97

Sattout, E.J., Talhouk, S.N. \& Caligari, P.D.S. 2007. Economic value of cedar relics in Lebanon: An application of contingent valuation method for conservation. Ecological Economics 61: 315 - 322

Schaefer, M.B. 1954. Some aspects of the dynamics of populations important to the management of commercial marine fisheries. Bulletin of the Inter-American Tropical Tuna Commission 1: 27-56

Schnier, K.E. 2005. Biological 'Hot Spots' and Their Effect on Optimal Bioeconomic Marine Reserve Formation. Ecological Economics 52: 453-468

Schonewald-Cox, C. M. \& Bayless, J. W. 1986. The boundary model: a geographical analysis of design and conservation of nature reserves. Biolgical Conservation 38, 305-322.

Sethi, S.A. 2007. Poaching and the Performance of Marine Reserves as Ocean Management Tools.Msc. Thesis. University of Washington, New Zealand.

Shears, N.T. \&Babcock R.C. 2004.Quantitative classification of New Zealand's shallow subtidal reef communities. Report to Department of Conservation, Science and Research Unit, October 2004.

Shears, N.T., Grace, R.V., Usmar, N.R., Kerr, V. \& Babcock, R.C. 2006. Long-term trends in lobster populations in a partially protected vs. no-take Marine Park. Biological Conservation, 132, 222-231.

Shipp, R.L. 2003. A perspective on marine reserves as a fishery management tool. Fisheries Management 28: 10-21

Simon, G.L., Bumpus, A.G. \& Mann, P. 2012. Win-win scenarios at the climatedevelopment interface: Challenges and opportunities for stove replacement programs through carbon finance. Global Environmental Change 22: 275-287

Smith, E.R., Fazio, R.H. \& Cejka, M.A. 1996. Accessible attitudes influence categorization of multiple categorizable objects. Journal of Personality and Social Psychology 71: $888-898$

Smith, M.D. \& Wilen, J.E. 2003. Economic impacts of marine reserves: the importance of spatial behavior. Journal of Environmental Economics and Management 46:183-206.

Smith, M.D., Lynham, J., Sanchirico, J.N. \& Wilson, J.A. 2012. Political economy of marine reserves: Understanding the role of opportunity costs. Proceedings of the National Academy of Sciences of the United States of America 107: 18300-18305.

Solomon, J. 2007. An evaluation of collaborative resource management and the measurement of illegal resource use in a Ugandan national park.Phd Thesis. University of Florida, USA. 
Soulé, M. 1991. Conservation: Tactics for a constant crisis. Science 253 744-750

Spalding, M., L. Fish, \& Wood, L. 2008. Toward representative protection of the world's coasts and oceans-progress, gaps, and opportunities. Conservation Letters 1: 217-226

Spash, C.L. 2006. Non-economic motivation for contingent values: Rights and attitudinal beliefs in the willingness to pay for environmental improvements. Land Economics 82: $602-622$

Spurgeon, D. 1997. Canada's Cod Leaves Science in Hot Water. Nature 386: 107

Stamieszkin, K., Wielgus, J. \& Gerber, L.R. 2009. Management of a marine protected area for sustainability and conflict resolution: Lessons from Loreto Bay National Park (Baja California Sur, Mexico). Ocean \& Coastal Management 52: 449-458

Stelzenmüller, V., Maynou, F., Bernard, G., Cadiou, G., Camilleri, M., Crec'hriou, R., Criquet, G., Dimech, M., Esparza, O., Huggins, R., Lenfant, P. \& Pérez-Ruzafa, A. 2008. Spatial assessment of fishing effort around European marine reserves: implications for successful fisheries management. Marine Pollution Bulletin 56: 201826.

Stevens, T.H., Echeverria, J., Glass, R.J., Hager, T., \& More, T.A. 1991. Measuring the existence value of wildlife: what do CVM estimates really show? Land Economics 67: 390400.

Stevens, L., Robertson, B. \& Robertson, B. 2004. Broad scale habitat mapping of sandy beaches and river estuaries - Wellington Harbour and South Coast. Report for Greater Wellington the Regional Council. Cawthron Report No. 913. Cawthron Institute, Nelson, New Zealand.

Stevenson, T.C., Tissot, B.N. \& Walsh, W.J. 2013. Socioeconomic consequences of fishing displacement from marine protected areas in Hawaii. Biological Conservation 160: $50-58$

Stewart R. A. \&MacDiarmid A. B. 2003. A survey of Kaimoana at Kapiti Island 1999 and 2000.National Institute of Water and Atmospheric Research Ltd. Wellington, New Zealand.

Stobart, B., Warwick, R., Gonzalez, C. et al. 2009. Long-term and spillover effects of a marine protected area on an exploited fish community. Marine Ecology and Progress Series 384: 47-60

Sumaila, U.R. 1998. Protected marine reserves as fisheries management tools: A bioeconomic analysis. Fisheries Res. 37: 287 - 296

Sumaila, U.R., \& Armstrong C.W. 2006. Distributional and efficiency effects of marine protected areas: A study of the Northeast Atlantic cod fishery. Land Economics 82: 321-332 
Swanson, 1995 In: T.M. Swanson, Editor, The Economics and Ecology of Biodiversity Decline, Cambridge University Press, Cambridge and New York.

Tacchoni, L. 2000. Biodiversity and Ecological Economics: Participation, Values and Resource Management. Earthscan, London and Sterling.

Tait, P.R., Bicknell, K \& Cullen, R. 2009. Web-based surveys and sample frame bias in a choice experiment. Paper presented at the 53rd Australian Agricultural and Resource Economics Society annual conference, Cairns Australia, 10th - 13th February 2009.

Taylor, N. \& Buckenham, B. 2003. Social impacts of marine reserves in New Zealand. Published by Department of Conservation, New Zealand.

Taylor, S.J. \& Bogdan, R. 1986.Introducción a los métodos cualitativos de investigación: la búsqueda de significados. Buenos Aires, Paidós.

TEEB. 2010. The Economics of Ecosystems and Biodiversity: Mainstreaming the Economics of Nature: A Synthesis of the Approach, Conclusions and Recommendations of TEEB.

The New Zealand Treasury. 2012. Budget 2012 Information Release. Release document, June 2012. Available at $<$ www.treasury.govt.nz/publications/informationreleases/budget/2012> Retrieved on 5th February, 2013

The World Factbook. 2011. Available at: https://www.cia.gov/library/publications/the-worldfactbook/geos/nz.html Retrieved on 5th October, 2012.

Trippel, E. 1995. Age at Maturity as a Stress Indicator in Fisheries. Bioscience 45: 768 - 769

Tsuge, T. \&Washida, T. 2003. Economic valuation of the Seto Inland Sea using an Internet CV survey. Marine Pollution Bulletin 47: 230-236

Turner, R.K., Paavola, J., Cooper, P., Farber, S., Jessamy, V. \& Georgiou, S. 2003. Valuing nature: lessons learned and future research directions. Ecol. Econ. 46: 493-510.

Turner, M. \& Weninger, Q. 2005. Meetings with costly participation: An empirical analysis. Rev. Econ. Stud. 72: 247-268

Turpie, J.K. 2003. The existence value of biodiversity in South Africa: how interest, experience, knowledge, income and perceived level of threat influence local willingness to pay. Ecological Economics 46: 199/216

United States of America Commission Ocean Policy. 2004. An Ocean Blueprint for the 21st Century Final Report of the U.S. Commission on Ocean Policy. Available in < http://oceancommission.gov/documents/full_color_rpt/welcome.html> Retrieved 201007-21.

University of Auckland. 1974. Maui Development Environmental Study. Report on Phase I (1974). Report prepared for Shell, B.P. and Todd Oil Services Ltd. Shell, B.P., Todd, Auckland. 
University of Auckland. 1982. Maui Development Environmental Study. Report on Phase II (1977-1981). Report prepared for Shell, B.P. and Todd Oil Services Ltd. Shell, B.P., Todd, Auckland.

US Commission on Ocean Policy (USCOP). 2004. An Ocean Blueprint for the 21 st Century. Washington (DC): USCOP.

Vadnjal, D. \& O'Connor, M. 1994. What is the value of Rangitoto Island? Environmental Values 3: $369-380$

Valcic, B. 2009. Spatial policy and the behavior of fishermen. Marine Policy 33: 215- 222

Vaughan, G.M. \& Hogg, M.A. 2002. Introduction to social psychology. Pearson Education Australia Pty Limited.

van Schaik, C.P. \& Kramer, R.A. 1997. Toward a new protection paradigm. In Kramer, R.A., van Schaik, C.P. \& Johnson, J. (Eds.) Last stand, protected areas and the defence of tropical biodiversity, Oxford University Press, New York.

Venkatachalam, L. 2004. The contingent valuation method: a review. Environmental Impact Assessment Review 24: 89-124

Voora, V. \& Thrift, C. 2010. Using Emergy to value ecosystem goods and services.International Institute, for Sustainable Development. Available at <http://www.iisd.org/pdf/2010/using_emergy.pdf $>$ Retrieved on $10^{\text {th }}$ February, 2013.

Wallmo, K. \&Edwards, S. 2008. Estimating Non-market Values of Marine Protected Areas: A Latent Class Modeling Approach. Marine Resource Economics 23: 301-323

Walsh, R. G., Loomis, J. B., \& Gillman, R. A. 1984. Valuing option, existence, and bequest demand for wilderness. Land Economics 60: 14-29.

Warner, R.E., Combs, C.L. \&Gregory, D.R. Jr. 1977. Biological studies of the spiny lobster, Panulirus argus (Decapoda: Palinuridae) in south Florida. Proc 29th Gulf Carib Fish Inst 29:166-183

Weisbrod, B.A. 1964. Collective-consumption services of individual consumption goods. Quarterly Journal of Economics 78: 471-477

Wells, S. \& S. Mangubhai. 2005. A Workbook for Assessing Management Effectiveness of Marine Protected Areas in the Western Indian Ocean. IUCN Eastern African Regional Programme, Nairobi, Kenya.

Wells, S., Burgess, N. \& Ngusaru, A. 2007. Towards the 2012 marine protected area targets in eastern Africa. Ocean \& Coastal Managment 50: 67-83

Western, D. 1994. Ecosystem conservation and rural development: the case of Amboseli. In: Western, D. Wrigth, R.M. \& Strum, S. (Eds.) Natural conncetions: perpesctives in community-based conservation. Covelo CA: Island Press. 
Wilcox, C. \& Pomeroy, C. 2003. Do commercial fishers aggregate around marine reserves? Evidence from Big Creek Marine Ecological Reserve, Central California North. American Journal of Fisheries Management 23: 241-50.

Wilkie, D.S., Carpenter, J.F. \& Zhang, Q. 2001. The under - financial of protected areas in the Congo basin: so many parks and so little willingness-to-pay. Biodiversity and Conservation 10: 691- 701

Wilson, A. \&Laskey, N. 2003. Internet-based marketing research: a serious alternative to traditional research methods. Marketing Intelligence \& Planning 21: 79-84

Willis, T.J. \& Roberts, C.D. 1996. Recolonisation and recruitment of fishes to intertidal rockpools at Wellington, New Zealand. Environmental Biology of Fishes 47: 329-343

Willis, T.J., Millar, R.B. \&Babcock, R.C. 2003. Protection of exploited fishes in temperate regions: high density and biomass of snapper Pagrus auratus (Sparidae) in northern New Zealand marine reserves. J. Appl. Ecol. 40: 214-227

Williams, E., Firn, J.R., Kind, V., Roberts, M. \& McGlashan, D. 2003. The value of Scotland's ecosystem services and natural capital. European Environment 13: 67-78.

Winckel, P.R., Vrijling, J.K., van de Graaff, J. 2008. Developing a building policy for the erosion zone. Solutions to some key (Dutch) questions. Coastal Engineering 55: 79-92

Wolfenden, J., Cram, F. \& Kirkwood, B. 1994. Marine reserves in New Zealand: A survey of community reactions. Ocean \& Coastal Management 25: 31-51

Wolsink, M. 2000. Wind power and the NIMBY-myth: institutional capacity and the limited significance of public support. Renewable Energy 21: 49-64.

Vreugdenhil D. 2003. Modeling the financial needs of protected area systems: An application of the "Minimum Conservation System" design tool. Paper presented at the Fifth World Parks Congress; 8-17 September 2003, Durban, South Africa

Wright, I.C., Pallentin, A., MacKay, K., Gardner, J. Byfield, T. \& Orpin, A. 2007. Wellington south coast marine reserve nearshore habitat mapping poster. Published by the Department of Conservation. View poster on DOC website.

Wynne, S. P. \& Cote, I. M. 2007. Effects of habitat quality and fishing on Caribbean spotted spiny lobster populations. Journal of Applied Ecology 44: 488-494.

Xu, J., Chen, L., Lu, Y. \& Fu, B. 2006. Local people's perceptions as decision support for protected area management in Wolong Biosphere Reserve. Journal of Environmental Management 78: 362-372

Ziegler, P. E., Frusher, S. D., \& Johnson, C. R. 2003. Space-time variation in catchability of southern rock lobster Jasus edwardsii in Tasmania explained by environmental, physiological and density-dependent processes. Fisheries Research 61: 107-123. 
Ziegler, P. E., Frusher, S. D., Johnson, C. R., \& Gardner, C. 2002a. Catchability of the southern rock lobster Jasus edwardsii, I. Effects of sex, season and catch history. Marine and Freshwater Research 53: 1143-1148.

Ziegler, P. E., Johnson, C. R., Frusher, S. D. \& Gardner, C. 2002b. Catchability of the southern rock lobster Jasus edwardsii. II Effects of size. Marine and Freshwater Research 53: 1149-1159. 


\title{
Appendices
}

\section{Economic, social and biological evaluation of two marine reserves within New Zealand}

By

Ursula A. Rojas Nazar

\author{
A thesis submitted to \\ Victoria University of Wellington \\ In fulfilment of the requirements for the degree of \\ Doctor of Philosophy in Marine Biology.
}

Victoria University of Wellington 2012

VICTORIA UNIVERSITY OF WELLINGTON

Te Whare Wānanga o te Ūpoko o te Ika a Māui

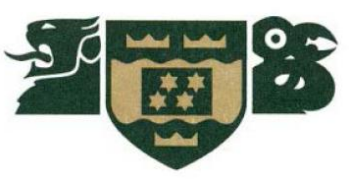




\section{Appendix A}

Glossary - Chapter II 
a) Iwi community (Māori people): Iwi means extended kinship group, tribe of indigenous people belonging to Aotearoa, New Zealand. (adapted form www.maoridictonary.co.nz)

b) The Wellington Tenths : The Wellington Tenths and administer the Reserved Lands on behalf of the land owners and have pursued Waitangi Tribunal claims on behalf of ngaiwi o Taranakimai Te Upoko o te Ika since 1987’.

'The objective of the Wellington Tenths Trust as being: to maintain and develop the reserves to the best financial and social benefit of the descendants of the original owners. Therefore the managing Trustees must look at investments and projects in a holistic way - incorporating cultural, social, spiritual and financial considerations in their decision making. Another responsibility of the Trust is to up hold the Mana Whenua status in the region. This means that the Tenths are involved in many different projects and activities in the Wellington region'. (Cited from http://www.tekau.maori.nz/WellingtonTenthsTrust/AboutUs.aspx)

c) Marine Bioblitz is a concept for promoting urban biodiversity and public awareness. It is designed as a scientific endeavour that is also an educational event, incorporates elements of a festival and above all is a celebration of local biodiversity. A Bioblitz aims to bring together scientists from a range of organisations and the general public, in a race against time to see how many species can be found and identified in a biological survey of an urban area or park over a 24 hour period'. (Cited from www.marinebioblitz.wellington.net.nz/)

d) New Zealand jobs salary guides atInternet:

- http://www.roberthalf.co.nz/EMEA/New\%20Zealand/Channel\%20Descriptors $\underline{\text { /rh-nz(en)/PDFs/technology-it-salary-guide-2012-new-zealand.pdf }}$

- http://www.seek.co.nz/jobs-resources/?cid=sk:main:nz:tab:tools

- http://www.trademe.co.nz/jobs/salaryguide?gclid=CLPOtov76LMCFQQcpQodfSgAVg

- http://www2.careers.govt.nz/jobs-database/whats-happening-in-the-jobmarket/who-earns-what/

- http://www.hays.net.nz/salary-guide/ 
e) Mana whenua mana moana status: Refers to the Traditional Māori land and sea tenure. Territorial rights, power from the land (mana) and sea (moana)- power associated with possession and occupation of tribal land. The tribe's history and legends are based in the lands they have occupied over generations and the land provides the sustenance for the people and to provide hospitality for guests" (adapted from www.maoridictionary.co.nz).

f) The CRA 4 quota management area (QMA) defines a rock lobster fishery which covers the southern half of North Island of New Zealand, extending from Hawke's Bay on the central east coast into Cook Strait, past Wellington and ending in the South Taranaki Bight on the lower west coast of North Island' (Breen at al., 2009) 
Appendix B

Surveys used to gather social information on chapter III 


\title{
Information Sheet for a Study of "Socio-economic evaluation of Marine Reserves in New Zealand"
}

\author{
Researcher: Ursula A. Rojas Nazar, School of Biological Sciences, Victoria University \\ of Wellington
}

My name is Ursula Rojas and I am a PhD student at Victoria University of Wellington under the supervision of Dr James Bell, Dr Jonathan Gardner, and Prof Ross Cullen (Lincoln University). This study forms part my doctoral research in the School of Biological Studies at Victoria University of Wellington. The main goal of this is to assess the economic value of the marine environment, to improve decision-making and improve public policies for marine conservation in NZ.

To achieve my purpose I am gathering information on social, biological and economic aspects of marine reserves surrounding the North Island of New Zealand. I have selected Taputeranga MR in the Wellington region for my study. My research includes local and regional data obtained from fishermen (commercial and recreational), the local population (people who live around the MRs), tourism (visitors and general public), local businesses (including cafés, dive shops etc) and other relevant government agencies. To collect all the information I require for my studies of these MRs I will use questionnaires, particularly focused on the cost and benefits related to protection, goals/aims, staffing, recurrent income and expenditure.

I am would like to invite you to take part in this study. For that I would like to know if you are able to participate and share your experiences and knowledge by answering the following questionnaire. The questionnaire will be conducted by a qualified interviewer. It will take approximately 25 minutes.

The results of this research will form part of my $\mathrm{PhD}$ thesis and may also be published in scientific journals or as part of presentations at scientific meetings. 
Please note that your participation is entirely voluntary and ethics approval has been granted for this study. If you do not wish to proceed, or you decide not to answer the questions in the questionnaire, you can choose to stop at any time or leave a blank answer. Should any participants feel the need to withdraw from the research, they may do so without question at any time before the data is analysed. Just let me know at the time.

In addition, it is important to mention that any information provided by you would be considered confidential and will be used with your consent only for academic purposes.

If you require any further information, please do not hesitate to contact me or my supervisor by e-mail or phone number.

Thanks for your collaboration.

Ursula Rojas Nazar

$\mathrm{PhD}$ Student in Marine Conservation

e-mail: ursula.rojasnazar@staff.vuw.ac.nz

Phone: 021-02501176
James J. Bell

Primary Supervisor

james.bell@vuw.ac.nz

04-463 5233-extn-8104

Centre for Marine Environmental and Economic Research

School of Biological Sciences,

Victoria University of Wellington,

Po Box 600,

Wellington,

New Zealand.

$$
>\langle())^{\circ}>
$$




\section{VICTORIA UNIVERSITY OF WELLINGTON}

\section{CONSENT TO PARTICIPATION IN RESEARCH}

\section{Title of project: "Socio-economic evaluation of Marine Reserves in New Zealand"}

I have been given and have understood an explanation of this research project. I have had an opportunity to ask questions and have them answered to my satisfaction. I understand that I may withdraw myself (or any information I have provided) from this project (before data collection and analysis is complete) without having to give reasons or without penalty of any sort.

I understand that any information I provide will be kept confidential to the researcher and the supervisors, the published results will not use my name, and that no opinions will be attributed to me in any way that will identify me.

I understand that the data I provide will not be used for any other purpose or released to others without my written consent.

I understand that the data will form part of a PhD thesis and may also be published in scientific journals or as part of presentations at scientific meetings.

I would like to receive a summary of the results of this research when it is completed.

I agree to take part in this research.

Signed:

Name of participant: Date:

(Please print clearly) 


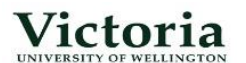
Te Whare Wananga
o te Upoko o te Ika a Mâui

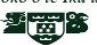

\section{"Socio-economic evaluation of Marine Reserves in New}

\section{Zealand"}

\section{LOCAL COMmunity QUESTIONNAIRE}

Interviewer to say: Good morning/afternoon/evening. My name is Ursula Rojas Nazar; I am from Victoria University of Wellington. I am assessing the economic and social value of the marine reserves located at Island Bay, called Taputeranga MR to improve decision-making and public policies on marine conservation in NZ. You was agree to participate in my research by answering the following questionnaire, which will take around 10 minutes. All the information provided by you is confidential (your name will not be associated with the answers) and will only be used with your consent for academic research purposes. This questionnaire has been reviewed by the Victoria University of Wellington Human Ethics Committee, and is used with their permission.

The following questions relate to where you live and your knowledge about the Taputeranga MR/ Kapiti MR. For that read the questions and then select the most appropriate answer for you. The first part is related to your fishing background (if any), and then we will talk about the Taputeranga/Kapiti MR.

\section{Local community background}

1. Do you own this property, or are you renting it?
a) Own
b) Rent full time
c) Holiday let

2. How long have you resided in this area?

day(s)/ month(s)/year(s)

3. Why have you chosen to live in this area? Please select the most important three (3) only.
a) Close to shops
b) Easy transport to work/school
c) Beautiful seas and landscape
d) Popular place
e) Safe place
f) Away from the inner city
g) Taputeranga/Kapiti MR
h) Other 


\section{Marine Reserve Knowledge}

1. Do you know what a marine reserve is?

a) Yes

b) No (if you do not, please read Appendix I at the and of the questionnaire, then go to question 3)

2. Can you describe in only a few words, what are the main goal(s) of a marine reserve?

3. Do you consider Marine Reserves to be a useful tool to protect the marine environment?
a) Yes
b) No
c) I don't know

4. Is marine conservation in general an important issue for you?
a) Yes, why?
b) No, why?
c) I don't know

5. Do you know about the existence of the Taputeranga/Kapiti marine reserves?
a) Yes
b) No (If you do not, please read Appendix II at the end of the questionnaire, there you will find a brief explanation. Then go to question 7 )

6. What was your position regarding the proposal to create a marine reserve at Island Bay/Kapiti coast?
a) I agreed with it
b) I disagreed with it
c) I didn't care 
7. I will show you a list of activities; First, can you tell me which activities (if any) you are currently conducting in the Taputeranga marine reserve?. Next, can you indicate with a tick if you know which activities are permitted and prohibited inside the marine reserve?(for the last question use the complete list)

\begin{tabular}{|l|l|l|l|l|}
\hline Activity & You & Permitted & Prohibited & Unsure \\
\hline Walking & & & & \\
\hline $\begin{array}{l}\text { Sitting in the car on the beach and } \\
\text { observing the environment }\end{array}$ & & & & \\
\hline Surfing & & & & \\
\hline Biking & & & & \\
\hline Playing & & & & \\
\hline Rockpooling & & & & \\
\hline Sitting on or near to the beach & & & & \\
\hline Recreational fishing & & & & \\
\hline Commercial fishing & & & & \\
\hline Picnicking & & & & \\
\hline Sunbathing & & & & \\
\hline Beach-combing & & & & \\
\hline Running & & & & \\
\hline Conducting research & & & & \\
\hline Swimming & & & & \\
\hline Boating & & & & \\
\hline Water skiing & & & & \\
\hline Boogie boarding & & & & \\
\hline Surf rescue & & & & \\
\hline Motor-biking & & & & \\
\hline Collecting fire wood & & & & \\
\hline Snorkelling & & & & \\
\hline Surfcasting & & & & \\
\hline Diving & & & & \\
\hline DOC activities & & & \\
\hline Shellfish collecting & & & \\
\hline Wind-surfing & & & \\
\hline Collecting seaweed & & & \\
\hline Education & & & \\
\hline
\end{tabular}


8. The following table describes some features of the Taputeranga/Kapiti marine reserve. With respect to the Marine Reserve how important is each of these features to you? Please rank them on a scale 1-5 where 5 is the most important and $\mathbf{1}$ is the least important.

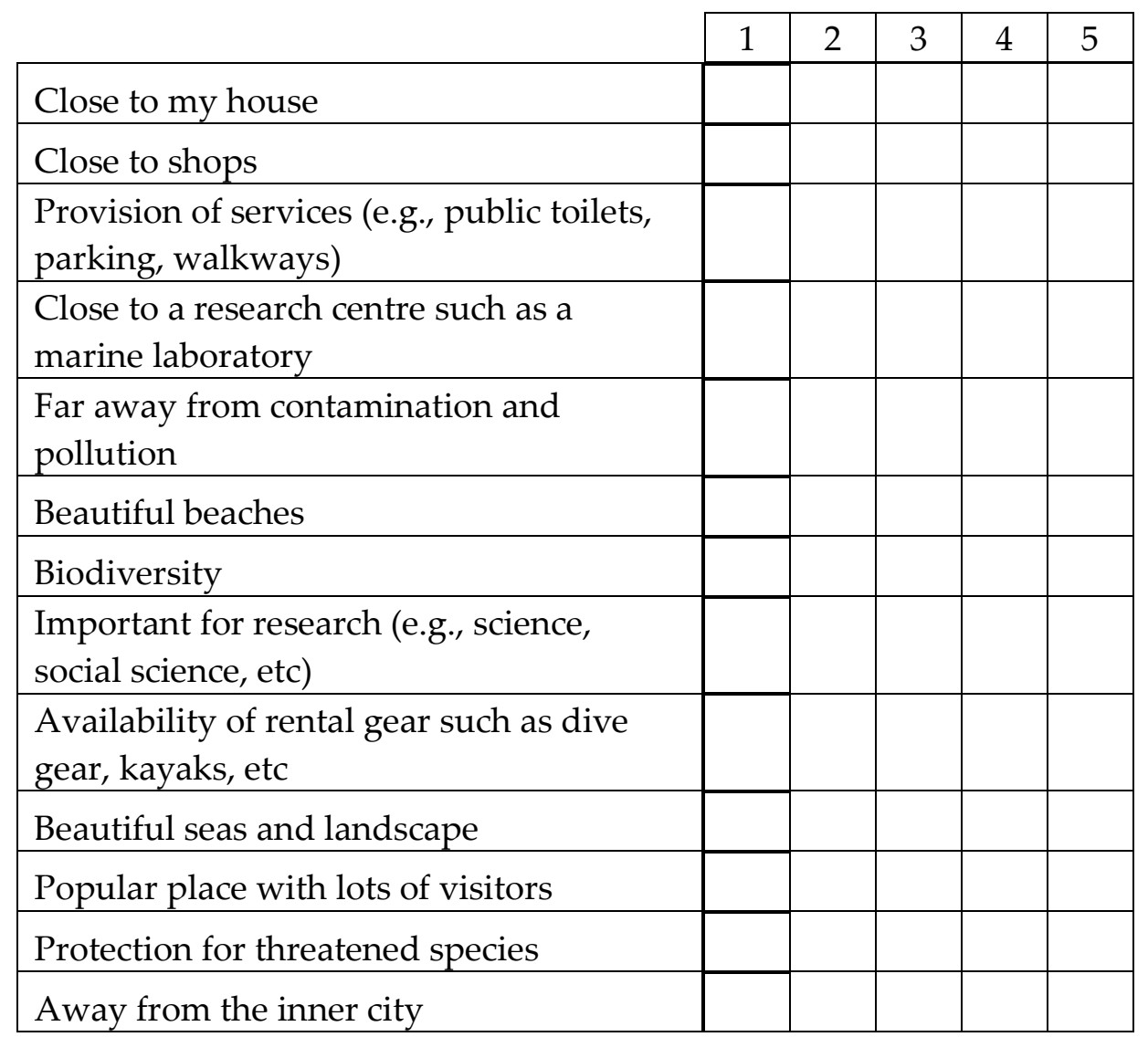

\section{Establishment Process of the Marine Reserve}

1. Did you participate in the Taputeranga/Kapiti Marine Reserve establishment process (for example participated in the consultation process, answered surveys, attended public meetings, attended meetings with key user groups or individual users)?

a) Yes (please explain what the participation was)

b) No (go to question 4 )

2. What was your initial reaction to the establishment of the Taputeranga/Kapiti marine reserve in/or close to your suburb?
a) Supported establishment
b) Opposed establishment
c) I didn't care
d) I wasn't here 
3. Has your opinion about the Marine Reserve changed since that time?

a) Yes (why?)

b) No

4. From your perspective, do you think the establishment of the Taputeranga/Kapiti Marine Reserve was a good decision?
a) Yes, better that expected (why?)
b) No (why?)
c) I don't care

\section{Perception and satisfaction levels}

1. Has the establishment of the Taputeranga/Kapiti marine reserve caused you or your family any issues (e.g., quality of life, economic loss, etc,)?
a) $\mathrm{No}$
b) Yes

Problems

2. Are you aware of any other issues that have arisen following the establishment of the Taputeranga/Kapiti marine reserve?
a) No (go to question 4)
b) Yes

Problems

3. In your judgment, who is responsible for resolving the problems identified in the previous two question(s)? It is possible to choose more than one (These answers are in relation to question 1 and/or 2)
a) Local residents
b) Department of Conservation
c) Local Council
d) Royal Forest and Bird Protection Society of NZ
e) Ministry of Fisheries
f) Universities
g) NIWA
h) Police

Other (specify)

4. Overall, has the creation of the Taputeranga/Kapiti marine reserve had a positive effect, negative effect or no effect on your life? Why?
a) Positive
b) Negative
c) No change

Reasons: 
5. Do you feel that you have benefited from the establishment of the marine reserve with respect to the following categories:

\begin{tabular}{|l|l|l|l|l|}
\hline & Negative & $\begin{array}{c}\text { Same before } \\
\text { and after the } \\
\text { establishment }\end{array}$ & Positive & $\begin{array}{c}\text { I don't } \\
\text { know }\end{array}$ \\
\hline $\begin{array}{l}\text { Your overall economic } \\
\text { state }\end{array}$ & & & & \\
\hline Your wealth level & & & & \\
\hline Your health & & & & \\
\hline Your families wellbeing & & & & \\
\hline Leisure time & & & & \\
\hline Work & & & & \\
\hline Overall well-being & & & & \\
\hline
\end{tabular}

6. If this marine reserve did not exist would you still be living here?
a) Yes
b) Likely
c) Unlikely
d) No

7. Can you state your satisfaction level with respect to the Taputeranga/Kapiti marine reserve in these different aspects?

\begin{tabular}{|l|l|l|l|l|l|}
\hline & $\begin{array}{c}\text { Very } \\
\text { satisfied }\end{array}$ & Satisfied & Dissatisfied & $\begin{array}{c}\text { Very } \\
\text { dissatisfied }\end{array}$ & Unsure \\
\hline Biodiversity protection & & & & & \\
\hline Litter on beach and in the water & & & & & \\
\hline Education opportunities & & & & & \\
\hline $\begin{array}{l}\text { Local participation in } \\
\text { management }\end{array}$ & & & & & \\
\hline Biodiversity recovery & & & & & \\
\hline $\begin{array}{l}\text { MR surveillance/policing (e.g. by } \\
\text { DoC Ranger) }\end{array}$ & & & & & \\
\hline
\end{tabular}

8. Have you noticed any changes in terms of the marine flora and fauna since the MR was established?
a) No
b) I don't know
c) Yes (ask if it is possible to describe this change)

9. Have you noticed any changes in terms of human usage of the area since the MR was established?
d) No
e) I don't know
f) Yes (ask if it is possible to describe this change) 
10. If the Taputeranga/Kapiti MR were disestablished, what do you think would be the implications for the environment? and for you personally?

11. Who do you think should pay for the management of the marine reserve?

12. When I say "Taputeranga/Kapiti marine reserve", what is the first word that comes into your mind? Can you explain why you thought of this word?

Word:

Reasons:

13. Do you have other comments before finishing this section of the interview? 


\section{Demographic Information}

Interviewer says: These last few questions will help us to understand how well our sample represents the study area in the Wellington city/ Kapiti Coast areas. Your answers are strictly confidential, and will only be used for statistical and academic purposes. You will not be identified in any way.

\begin{tabular}{|l|l|l|}
\hline Gender & Age & $\begin{array}{l}\text { Highest education level } \\
\text { completed: }\end{array}$ \\
\hline a) M & a) $<20 \mathrm{yr}$ & a) Primary complete \\
b) F & b) $21-30 \mathrm{yr}$ & b) Secondary complete \\
c) $31-40 \mathrm{yr}$ & c) & Trade/technical qualification \\
d) $41-50 \mathrm{yr}$ & d) & Degree/professional qualification \\
e) $51-60 \mathrm{yr}$ & e) & Other (specify) \\
f) $>61$ yr & \\
\hline Taputeranga MR & Kapiti MR \\
\hline a) Owhiro Bay & a) & Kaitawa \\
b) Happy Valley & b) & Kena Kena \\
c) Island Bay & c) & Maungakotukutuku \\
d) Houghton Bay & d) & Otaki Forks \\
e) Lyall Bay & e) & Otaki \\
f) Moa Point & f) & Otaihanga \\
g) Breaker Bay & g) & Paraparaumu Beach North \\
h) Other (specify) & h) & Paraparaumu Beach South \\
i) & Paraparaumu Central \\
j) & Paekakariki \\
k) & Raumati Beach \\
& l) & Raumati South \\
m) & Waikanae Beach \\
n) & Waikanae East \\
o) & Waikanae Park \\
p) & Waikanae West \\
q) & Other (specify) \\
\hline
\end{tabular}

THANK YOU 


\section{Interviewer says:}

I would like to thank you for agreeing to answer these questions, and taking part in this interview. I wish to repeat that all the information provided by you is confidential and will only be used for academic purposes.

We will continue with this study for two more years, therefore I would like to ask you if you would like to take part in future surveys in this study

a) No

b) Yes

Would you like to have a copy of the results from this survey?

a) No

b) Yes

*If the person is agreeing to participate in future surveys or would like to have a copy of the results, please ask next question, otherwise finish with the questionnaire.

Please can you give me your contact information?

Name:

Address:

Contact phone:

E-mail:

\section{Again thank you very much for your time.}




\section{Victoria Te Whare Wānanga te Üpoko o te Ika a Mãu} 50菌圈果

\section{“Socio-economic evaluation of Marine Reserves in New Zealand"}

\section{VISITOR QUESTIONNAIRE}

Interviewer to say: Good morning/afternoon/evening. My name is Ursula Rojas Nazar; I am from Victoria University of Wellington. I am assessing the economic and social value of the marine reserves located at Island Bay, called Taputeranga MR to improve decision-making and public policies on marine conservation in NZ. You was agree to participate in my research by answering the following questionnaire, which will take around 10 minutes. All the information provided by you is confidential (your name will not be associated with the answers) and will only be used with your consent for academic research purposes. This questionnaire has been reviewed by the Victoria University of Wellington Human Ethics Committee, and is used with their permission.

The following questions relate to where you live and your knowledge about the Taputeranga MR/ Kapiti MR. For that read the questions and then select the most appropriate answer for you. The first part is related to your fishing background (if any), and then we will talk about the Taputeranga/Kapiti MR.

\section{Spending}

Interviewer says: the following questions relate to your trip to.... (Taputeranga MR/ Kapiti MR). For this purpose I will read questions with alternative answers. Please select the most appropriate answer for you.

1. Where is your main place of residence?

a) New Zealand

City

Suburb b) Elsewhere

Country

City

2. By which means of transport did you get here?

* If you travelled in a car, please state the engine size
a) Car
(cc)
b) Bus
c) Van
d) Campervan
e) Motorcycle
f) Bicycle
g) Other, please specify 
3. How many people travelled with you today in the same vehicle, please state their relationship to you, age and sex of the people (including you)

\begin{tabular}{|l|l|l|}
\hline Number & Relationship & Sex \\
\hline & & \\
\hline & & \\
\hline & & \\
\hline & & \\
\hline
\end{tabular}

4. How long have you been coming to this area?
a) First visit
b) $1-12$ months
c) $1-5$ years
d) $5-10$ years
e) >10 years
f) I live here (If yes, go to section II)

5. If this is not your first visit, how often do you normally come here?
a) 1-2 times per year
b) 3-4 times per year
c) 5-9 times per year
d) 10 times or more per year

6. How long are you planning to stay in the area of the marine reserve?
a) hours
b) 1 day
c) $2-3$ days
d) 4 - 5 days
e) 1 week
f) 2 weeks
g) More than 2 weeks

7. What are the reasons for visiting this area during your trip? Please select the most important three (3) only.
i) Close to my house
j) Equipment rentals
k) Accommodation
1) Shopping
m) Easy access from our house/place rented
n) Beautiful seas and landscape
o) Popular place
p) Safe place
q) Away from the inner city 

r) Taputeranga/Kapiti MR
s) Boating
t) Fishing
u) Diving
v) Collecting seaweed
w) Other (specify)

8. Have you or will you purchase or rent items such as food, equipment, accommodation in the area surrounding the MR?
a) Yes purchase
b) No purchase
c) Yes rent
d) No rent

9. Which type of items have you/will you purchase or rent to use at the Marine reserve? And how much do you spend? (for example food, retail items, gear rental) (Please indicate with a check $P$ for Purchase or $R$ for Rent)

\begin{tabular}{|l|l|l|l|}
\hline Item & & & N.Z.\$ \\
\hline & $\mathbf{P}$ & $\mathbf{R}$ & \\
\hline & $\mathbf{P}$ & $\mathbf{R}$ & \\
\hline & $\mathbf{P}$ & $\mathbf{R}$ & \\
\hline
\end{tabular}

\section{Marine Reserve knowledge}

1. Do you know what a marine reserve is?
a) Yes
b) No (if you do not, please read Appendix I at the end of the questionnaire, then go to question 3)

2. Can you describe in only a few words, what are the main goal(s) of a marine reserve?

3. Do you consider Marine Reserves to be a useful tool to protect the marine environment?
a) Yes
b) No
c) I don't know

4. Is marine conservation in general an important issue for you?
a) Yes, why?
b) No, why?
c) I don't know

5. Do you know about the existence of the Taputeranga/Kapiti marine reserves? 

a) Yes
b) No (If you do not, please read Appendix II at the end of the questionnaire, there you will find a brief explanation. Then go to question 7 )

6. What was your position regarding the proposal to create a marine reserve at Island Bay/Kapiti coast?
a) I agreed with it
b) I disagreed with it
c) I didn't care

7. I will show you a list of activities; First, can you tell me which activities (if any) you are currently conducting in the Taputeranga marine reserve?. Next, can you indicate with a tick if you know which activities are permitted and prohibited inside the marine reserve?(for the last question use the complete list)

\begin{tabular}{|l|l|l|l|l|}
\hline Activity & You & Permitted & Prohibited & Unsure \\
\hline Walking & & & & \\
\hline $\begin{array}{l}\text { Sitting in the car on the beach and } \\
\text { observing the environment }\end{array}$ & & & & \\
\hline Surfing & & & & \\
\hline Biking & & & & \\
\hline Playing & & & & \\
\hline Rockpooling & & & & \\
\hline Sitting on or near to the beach & & & & \\
\hline Recreational fishing & & & & \\
\hline Commercial fishing & & & & \\
\hline Picnicking & & & & \\
\hline Sunbathing & & & & \\
\hline Beach-combing & & & & \\
\hline Running & & & & \\
\hline Conducting research & & & & \\
\hline Swimming & & & & \\
\hline Boating & & & & \\
\hline Water skiing & & & & \\
\hline Boogie boarding & & & & \\
\hline Surf rescue & & & & \\
\hline Motor-biking & & & & \\
\hline Collecting fire wood & & & & \\
\hline Snorkelling & & & & \\
\hline Surfcasting & & & & \\
\hline Diving & & & & \\
\hline DOC activities & & & & \\
\hline Shellfish collecting & & & & \\
\hline Wind-surfing & & & \\
\hline Collecting seaweed & & & \\
\hline Education & & & \\
\hline
\end{tabular}


8. The following table describes some features of the Taputeranga/Kapiti marine reserve. With respect to the Marine Reserve how important is each of these features to you? Please rank them on a scale 1-5 where 5 is the most important and $\mathbf{1}$ is the least important.

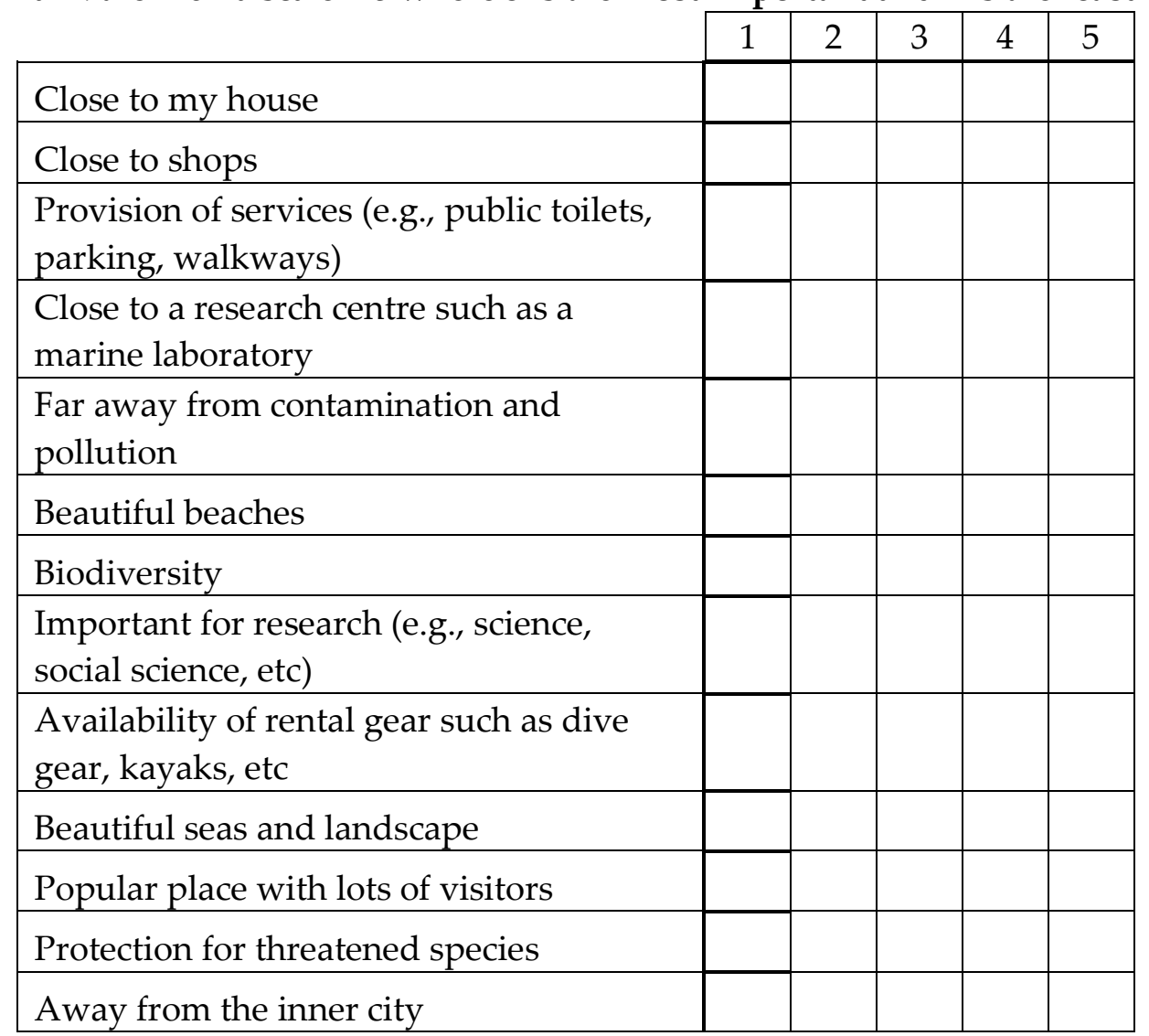

\section{Perception and satisfaction levels}

1. From your perspective, do you think the establishment of Taputeranga/Kapiti Marine Reserve was a good decision in this area?
a) Yes (Ask why)
b) No (Ask why)
c) I don't care
d) I don't know

2. Is the Taputeranga/Kapiti marine reserve what you expected it to be before you came here?
a) Yes, better than expected (Ask why)
b) No (Ask why)
c) I am not sure

3. Can you identify any problem(s) with the establishment the Taputeranga/Kapiti marine reserve?
c) No (go to question 5$)$
d) I don't know (go to question 5)
e) Yes

Problems 
4. In your judgment, who is responsible for resolving the problems identified in the previous two question(s)? It is possible to choose more than one (Please be clear if the answers are in relation to question 3)
i) Local residents
j) Department of Conservation
k) Local Council
1) Royal Forest and Bird Protection Society of NZ
m)Ministry of Fisheries
n) Universities
o) NIWA
p) Police
q) Other (specify)

5. Do you feel that you have benefited from the establishment of the marine reserve in terms of the following categories:

\begin{tabular}{|l|l|l|l|l|}
\hline & Negative & $\begin{array}{l}\text { Same before } \\
\text { and after the } \\
\text { establishment }\end{array}$ & Positive & $\begin{array}{c}\text { I don't } \\
\text { know }\end{array}$ \\
\hline $\begin{array}{l}\text { Your overall economic } \\
\text { state }\end{array}$ & & & & \\
\hline Your wealth level & & & & \\
\hline Your health & & & & \\
\hline Your families wellbeing & & & & \\
\hline Leisure time & & & & \\
\hline Work & & & & \\
\hline Overall well-being & & & & \\
\hline
\end{tabular}

6. If the Taputeranga/Kapiti marine reserve did not exist would you have still come here today?
e) Yes
f) Likely
g) Unlikely
h) No

7. Can you state your satisfaction level with respect to the Taputeranga/Kapiti marine reserve in these different aspects?

\begin{tabular}{|l|l|l|l|l|l|}
\hline & $\begin{array}{c}\text { Very } \\
\text { satisfied }\end{array}$ & Satisfied & Dissatisfied & $\begin{array}{c}\text { Very } \\
\text { dissatisfied }\end{array}$ & Unsure \\
\hline Biodiversity protection & & & & & \\
\hline Litter on beach and in the water & & & & & \\
\hline Education opportunities & & & & & \\
\hline Local participation in management & & & & & \\
\hline Biodiversity recovery & & & & & \\
\hline $\begin{array}{l}\text { MR surveillance/policing (e.g. by } \\
\text { DoC Ranger) }\end{array}$ & & & & & \\
\hline
\end{tabular}


8. Have you noticed any changes in term of the marine flora and fauna since the MR was established?
g) No
h) I don't know
i) Yes (ask if it is possible to describe this change)

9. Have you noticed any changes in terms of human usage of the area since the MR was established?
a) $\mathrm{No}$
b) I don't know
c) Yes (ask if it is possible to describe this change)

10. If the Taputeranga/Kapiti MR were to be disestablished, what do you think would be the implications for the environment? and for you personally?

11 Who do you think should pay for the management of the marine reserve?

12. When I say "Taputeranga/Kapiti marine reserve", what is the first word that comes into your mind? Can you explain why you thought of this word?

Word:

Reasons:

13. Do you have other comments before finishing this section of the interview? 


\section{Demographic Information}

Interviewer says: These last few questions will help us to understand how well our sample represents the study area in the Wellington city/ Kapiti Coast areas. Your answers are strictly confidential, and will only be used for statistical and academic purposes. You will not be identified in any way.

\begin{tabular}{|c|c|c|}
\hline Gender & Age & $\begin{array}{l}\text { Highest education level } \\
\text { completed: }\end{array}$ \\
\hline $\begin{array}{l}\text { a) } M \\
\text { b) } F\end{array}$ & $\begin{array}{l}\text { a) }<20 \mathrm{yr} \\
\text { b) } 21-30 \mathrm{yr} \\
\text { c) } 31-40 \mathrm{yr} \\
\text { d) } 41-50 \mathrm{yr} \\
\text { e) } 51-60 \mathrm{yr} \\
\text { f) }>61 \mathrm{yr}\end{array}$ & $\begin{array}{l}\text { a) Primary complete } \\
\text { b) Secondary complete } \\
\text { c) Trade/technical qualification } \\
\text { d) Degree/professional qualification } \\
\text { e) Other (specify) }\end{array}$ \\
\hline \multicolumn{2}{|c|}{ Taputeranga MR } & Kapiti MR \\
\hline \multicolumn{2}{|c|}{$\begin{array}{l}\text { a) Owhiro Bay } \\
\text { b) Happy Valley } \\
\text { c) Island Bay } \\
\text { d) Houghton Bay } \\
\text { e) Lyall Bay } \\
\text { f) Moa Point } \\
\text { g) Breaker Bay } \\
\text { h) Other (specify) }\end{array}$} & $\begin{array}{ll}\text { a) } & \text { Kaitawa } \\
\text { b) } & \text { Kena Kena } \\
\text { c) } & \text { Maungakotukutuku } \\
\text { d) } & \text { Otaki Forks } \\
\text { e) } & \text { Otaki } \\
\text { f) } & \text { Otaihanga } \\
\text { g) } & \text { Paraparaumu Beach North } \\
\text { h) } & \text { Paraparaumu Beach South } \\
\text { i) } & \text { Paraparaumu Central } \\
\text { j) } & \text { Paekakariki } \\
\text { k) } & \text { Raumati Beach } \\
\text { l) } & \text { Raumati South } \\
\text { m) } & \text { Waikanae Beach } \\
\text { n) } & \text { Waikanae East } \\
\text { o) } & \text { Waikanae Park } \\
\text { p) } & \text { Waikanae West } \\
\text { q) } & \text { Other (specify) }\end{array}$ \\
\hline
\end{tabular}




\section{Interviewer says:}

I would like to thank you for agreeing to answer these questions, and taking part in this interview. I wish to repeat that all the information provided by you is confidential and will only be used for academic purposes.

We will continue with this study for two more years, therefore I would like to ask you if you would like to take part in future surveys in this study
c) No
d) Yes

Would you like to have a copy of the results from this survey?
c) No
d) Yes

*If the person is agreeing to participate in future surveys or would like to have a copy of the results, please ask next question, otherwise finish with the questionnaire.

Please can you give me your contact information?

Name:

Address:

Contact phone:

E-mail:

\section{Again thank you very much for your time.}




\section{Victoria \\ Te Whare Wānanga te Üpoko o te Ika a Mãui

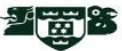
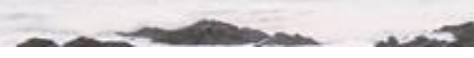

\section{"Socio-economic evaluation of Marine Reserves in New Zealand"}

\section{FISHERMEN QUESTIONNAIRE}

Interviewer to say: Good morning/afternoon/evening. My name is Ursula Rojas Nazar; I am from Victoria University of Wellington. I am assessing the economic and social value of the marine reserves located at Island Bay, called Taputeranga MR to improve decision-making and public policies on marine conservation in NZ. You was agree to participate in my research by answering the following questionnaire, which will take around 10 minutes. All the information provided by you is confidential (your name will not be associated with the answers) and will only be used with your consent for academic research purposes. This questionnaire has been reviewed by the Victoria University of Wellington Human Ethics Committee, and is used with their permission.

The following questions relate to where you live and your knowledge about the Taputeranga MR/ Kapiti MR. For that read the questions and then select the most appropriate answer for you. The first part is related to your fishing background (if any), and then we will talk about the Taputeranga/Kapiti MR.

\section{Fisher Background}

1. What type of fishing are you involved in?
a) Commercial Fishing
b) Recreational Fishing
c) Traditional customary (Maori) harvest

Specify

2. How long have you been a commercial/recreational/customary fisher?

.............. year(s)

3. What species do you target and what other species (if any) do you catch/fish? And can you indicate what kind of fishing method(s) that you use?

\begin{tabular}{|c|c|c|}
\hline Target species & Other species & Method \\
\hline & & \\
\hline & & \\
\hline & & \\
\hline
\end{tabular}


4. Where are your current landing points?

\begin{tabular}{|c|c|c|}
\hline Point & Location & City/Province/Region \\
\hline & & \\
\hline & & \\
\hline & & \\
\hline
\end{tabular}

5. Which means of transport do you use to get from your house to begin your fishing?

* If you travelled in a car, please state your engine size
a) Car (cc)
b) Bus
c) Van
d) Campervan
e) Motorcycle
f) Bicycle
g) Other, please specify

\section{Marine Reserve knowledge}

1. Do you know what a marine reserve is?
a) Yes
b) No (if you do not, please read Appendix I at the end of the questionnaire, then go to question 3)

2. Can you describe in only a few words, what are the main goal(s) of a marine reserve?

3. Do you consider Marine Reserves to be a useful tool to protect the marine environment?
a) Yes
b) No
c) I don't know

4. Is marine conservation in general an important issue for you?
a) Yes, why?
b) No, why?
c) I don't know

5. Do you know about the existence of the Taputeranga/Kapiti marine reserves?
a) Yes
b) No (If you do not, please read Appendix II at the end of the questionnaire, there you will find a brief explanation. Then go to question 7 )

6. What was your position regarding the proposal to create a marine reserve at Island Bay/Kapiti coast?
a) I agreed with it
b) I disagreed with it
c) I didn't care 
7. I will show you a list of activities; First, can you tell me which activities (if any) you are currently conducting in the Taputeranga marine reserve?. Next, can you indicate with a tick if you know which activities are permitted and prohibited inside the marine reserve?(for the last question use the complete list)

\begin{tabular}{|l|l|l|l|l|}
\hline Activity & You & Permitted & Prohibited & Unsure \\
\hline Walking & & & & \\
\hline $\begin{array}{l}\text { Sitting in the car on the beach and } \\
\text { observing the environment }\end{array}$ & & & & \\
\hline Surfing & & & & \\
\hline Biking & & & & \\
\hline Playing & & & & \\
\hline Rockpooling & & & & \\
\hline Sitting on or near to the beach & & & & \\
\hline Recreational fishing & & & & \\
\hline Commercial fishing & & & & \\
\hline Picnicking & & & & \\
\hline Sunbathing & & & & \\
\hline Beach-combing & & & & \\
\hline Running & & & & \\
\hline Conducting research & & & & \\
\hline Swimming & & & & \\
\hline Boating & & & & \\
\hline Water skiing & & & & \\
\hline Boogie boarding & & & & \\
\hline Surf rescue & & & & \\
\hline Motor-biking & & & & \\
\hline Collecting fire wood & & & & \\
\hline Snorkelling & & & & \\
\hline Surfcasting & & & & \\
\hline Diving & & & & \\
\hline DOC activities & & & \\
\hline Shellfish collecting & & & \\
\hline Wind-surfing & & & \\
\hline Collecting seaweed & & & \\
\hline Education & & & \\
\hline
\end{tabular}


8. The following table describes some features of the Taputeranga/Kapiti marine reserve. With respect to the Marine Reserve how important is each of these features to you? Please rank them on a scale 1-5 where 5 is the most important and $\mathbf{1}$ is the least important.

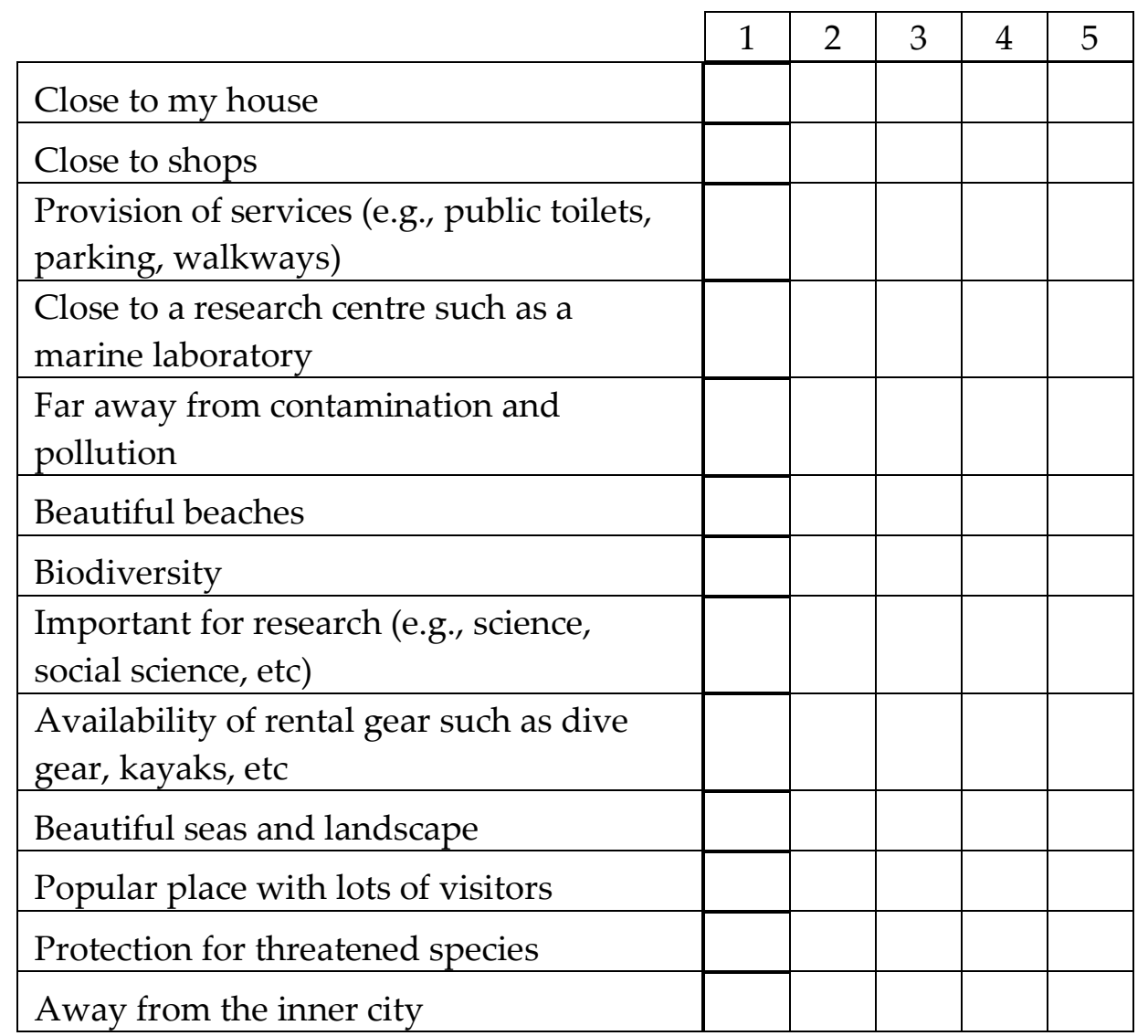

\section{Establishment Process of the Marine Reserve}

1. Did you participate in the Taputeranga/Kapiti Marine Reserve establishment process (for example participated in the consultation process, answered surveys, attended public meetings, attended meetings with key user groups or individual users)?

a) Yes (ask what the participation was)

b) No (go to question 4)

2. What was your initial reaction to the establishment of the Taputeranga/Kapiti marine reserve?
a) Supported establishment
b) Opposed establishment
c) I didn't care

3. Has your opinion about the Marine Reserve changed since that time?
a) Yes (Ask why)
b) No 
4. From your perspective, do you think the establishment of the Taputeranga/Kapiti Marine Reserve was a good decision?

a) Yes, better that expected (Ask why)

b) No (Ask why)

c) I don't care

\section{Fishermen relationship with the Taputeranga/Kapiti Marine} Reserve

1. Did you fish in the area which is currently the Taputeranga/Kapiti marine reserve before the establishment of the Marine Reserve?

\section{a) Yes}

b) No

2. Before the marine reserve was established, did you target and catch the same species and use the same fishing method(s) that you currently use? (If interviewee chooses b, $c$ or $d$ go to question 3)

a) Yes, same species and method(s)

b) Changed species, but same method(s)

c) Changed method(s), but same species

d) No

3. This question depends on the answer on question 2. If the interviewee chooses answer $b$, then ask question 3.1. If interviewee chooses answer c, then ask question 3.2. However, if the interviewee chooses answer $c$, ask 3.1 and 3.2.

3.1. What species did you target and catch in the area that is now the marine reserve?

3.2. Can you indicate what kind of fishing method(s) that you used for these species?

\begin{tabular}{|l|l|l|}
\hline Target species & Other species & Method \\
\hline & & \\
\hline & & \\
\hline & & \\
\hline
\end{tabular}

4. Are your current landing points the result of the establishment of the marine reserve?
a) Yes
b) No, they are the same

5. Do you think that the establishment of the Taputeranga/Kapiti marine reserve has changed the cost for you to go fishing?
a) Yes
b) No (go to section $V$ ) 
6. Can you estimate the percentage increase in the cost of fishing for you? $\%$

7. Can you estimate how much more these changed costs are in dollars?

\begin{tabular}{|c|c|c|c|c|}
\hline & $\begin{array}{c}\text { Unit } \\
\text { (day/month/annual) }\end{array}$ & $\begin{array}{l}\text { Rec. } \\
\text { Fish. }\end{array}$ & $\begin{array}{l}\text { Comm. } \\
\text { Fish. }\end{array}$ & $\begin{array}{l}\text { Custom. } \\
\text { Harv. }\end{array}$ \\
\hline \multicolumn{5}{|c|}{ Fixed Cost } \\
\hline \multicolumn{5}{|c|}{ Fishing gear } \\
\hline \multicolumn{5}{|l|}{ Dive gear } \\
\hline \multicolumn{5}{|c|}{$\begin{array}{l}\text { Boat maintenance (e.g. painting, } \\
\text { engine overhaul) }\end{array}$} \\
\hline \multicolumn{5}{|c|}{ Car maintenance } \\
\hline \multicolumn{5}{|c|}{ Material and supplies } \\
\hline \multicolumn{5}{|c|}{ Full time staff cost } \\
\hline \multicolumn{5}{|c|}{ Quota } \\
\hline \multicolumn{5}{|l|}{ Others (specify) } \\
\hline \multicolumn{5}{|c|}{ Variable Cost } \\
\hline \multicolumn{5}{|l|}{ Engine Repairs } \\
\hline \multicolumn{5}{|l|}{ Boat preparation } \\
\hline \multicolumn{5}{|l|}{ Administration } \\
\hline \multicolumn{5}{|l|}{ Office expenses } \\
\hline \multicolumn{5}{|l|}{ Selling expenses } \\
\hline \multicolumn{5}{|c|}{$\begin{array}{l}\text { General maintenance (e.g. } \\
\text { cleaning) }\end{array}$} \\
\hline \multicolumn{5}{|c|}{ Taxes } \\
\hline \multicolumn{5}{|c|}{$\begin{array}{l}\text { Licences fees (e.g. operation, } \\
\text { navigation, etc) }\end{array}$} \\
\hline \multicolumn{5}{|c|}{ Boat insurance } \\
\hline \multicolumn{5}{|l|}{ Car Insurance } \\
\hline \multicolumn{5}{|c|}{ Part time staff } \\
\hline \multicolumn{5}{|c|}{$\begin{array}{l}\text { Other services (e.g. lunch, extra- } \\
\text { transport) }\end{array}$} \\
\hline \multicolumn{5}{|c|}{ Boat fuel } \\
\hline \multicolumn{5}{|l|}{$\begin{array}{l}\text { Car fuel } \\
\text { Boat oil }\end{array}$} \\
\hline \multicolumn{5}{|l|}{ Car oil } \\
\hline Others (specify) & & & & \\
\hline
\end{tabular}




\section{Perceptions \& Satisfaction Levels}

1. Has the establishment of the Taputeranga/Kapiti marine reserve caused you or your family any problems (e.g., quality of life, economic loss, etc,)?
a) No
b) Yes - Problems

2. Are you aware of any other problems that have arisen after the establishment the Taputeranga/Kapiti marine reserve?

a) No (go to question 4)

b) Yes - Problems

3. In your judgment, who is responsible for resolving the problems identified in the previous two question(s)? It is possible to choose more than one (Please be clear if the answers are in relation to question 1 and/or 2)
a) Local residents
b) Department of Conservation
c) Local Council
d) Royal Forest and Bird Protection Society of NZ
e) Ministry of Fisheries
f) Universities
g) NIWA
h) Police
i) Other (specify)

4. Do you feel that you have benefited from the establishment of the marine reserve with respect to the following categories:

\begin{tabular}{|l|l|l|l|l|}
\hline & Negative & $\begin{array}{c}\text { Same before } \\
\text { and after the } \\
\text { establishment }\end{array}$ & Positive & $\begin{array}{c}\text { I don't } \\
\text { know }\end{array}$ \\
\hline $\begin{array}{l}\text { Your overall economic } \\
\text { state }\end{array}$ & & & & \\
\hline Your wealth level & & & & \\
\hline Your health & & & & \\
\hline Your families wellbeing & & & & \\
\hline Leisure time & & & & \\
\hline Work & & & & \\
\hline Overall well-being & & & & \\
\hline
\end{tabular}


5. If this marine reserve was open to commercial/recreational fishing again, would you return to your activities in this area?
a) Yes
b) Likely
c) Unlikely
d) No

6. Can you state your satisfaction level with respect to the Taputeranga/Kapiti marine reserve in these different aspects?

\begin{tabular}{|l|l|l|l|l|l|}
\hline & $\begin{array}{c}\text { Very } \\
\text { satisfied }\end{array}$ & Satisfied & Dissatisfied & $\begin{array}{c}\text { Very } \\
\text { dissatisfied }\end{array}$ & Unsure \\
\hline Biodiversity protection & & & & & \\
\hline Litter on beach and in the water & & & & & \\
\hline Education opportunities & & & & & \\
\hline Local participation in management & & & & & \\
\hline Biodiversity recovery & & & & & \\
\hline $\begin{array}{l}\text { MR surveillance/policing (e.g. by } \\
\text { DoC Ranger) }\end{array}$ & & & & & \\
\hline
\end{tabular}

7. Have you noticed any changes in terms of the marine flora and fauna since the MR was established?
a) No
b) I don't know
c) Yes (ask if it is possible to describe this change)

8. Have you noticed any changes in terms of human usage of the area since the MR was established?
a) No
b) I don't know
c) Yes (ask if it is possible to describe this change)

9. If the Taputeranga/Kapiti MR were to be disestablished, what do you think would be the implications for the environment? and for you personally?

Environment:

Personal:

10. Who do you think should pay for the management of the marine reserve?

11. When I say "Taputeranga/Kapiti marine reserve", what is the first word that comes into your mind? Can you explain why you thought of this word?

Word:

Reasons 
12. Do you have other comments before finishing this section of the interview?

\section{Demographic Information}

Interviewer says: These last few questions will help us to understand how well our sample represents the study area in the Wellington city/ Kapiti Coast areas. Your answers are strictly confidential, and will only be used for statistical and academic purposes. You will not be identified in any way.

\begin{tabular}{|c|c|c|}
\hline Gender & Age & $\begin{array}{l}\text { Highest education level } \\
\text { completed: }\end{array}$ \\
\hline $\begin{array}{l}\text { a) } \mathrm{M} \\
\text { b) } \mathrm{F}\end{array}$ & $\begin{array}{l}\text { a) }<20 \mathrm{yr} \\
\text { b) } 21-30 \mathrm{yr} \\
\text { c) } 31-40 \mathrm{yr} \\
\text { d) } 41-50 \mathrm{yr} \\
\text { e) } 51-60 \mathrm{yr} \\
\text { f) }>61 \mathrm{yr}\end{array}$ & $\begin{array}{l}\text { a) Primary complete } \\
\text { b) Secondary complete } \\
\text { c) Trade/technical qualification } \\
\text { d) Degree/professional qualification } \\
\text { e) Other (specify) }\end{array}$ \\
\hline \multicolumn{2}{|c|}{ Taputeranga MR } & Kapiti MR \\
\hline $\begin{array}{l}\text { a) Owhi } \\
\text { b) Happy } \\
\text { c) Island } \mathrm{x} \\
\text { d) Hought } \\
\text { e) Lyall B } \\
\text { f) Moa Po } \\
\text { g) Breake } \\
\text { h) Other ( }\end{array}$ & $\begin{array}{l}\text { iro Bay } \\
\text { Valley } \\
\text { Bay } \\
\text { on Bay } \\
\text { ay } \\
\text { int } \\
\text { r Bay } \\
\text { specify) }\end{array}$ & $\begin{array}{ll}\text { a) } & \text { Kaitawa } \\
\text { b) } & \text { Kena Kena } \\
\text { c) } & \text { Maungakotukutuku } \\
\text { d) } & \text { Otaki Forks } \\
\text { e) } & \text { Otaki } \\
\text { f) } & \text { Otaihanga } \\
\text { g) } & \text { Paraparaumu Beach North } \\
\text { h) } & \text { Paraparaumu Beach South } \\
\text { i) } & \text { Paraparaumu Central } \\
\text { j) } & \text { Paekakariki } \\
\text { k) } & \text { Raumati Beach } \\
\text { l) } & \text { Raumati South } \\
\text { m) } & \text { Waikanae Beach } \\
\text { n) } & \text { Waikanae East } \\
\text { o) } & \text { Waikanae Park } \\
\text { p) } & \text { Waikanae West } \\
\text { q) } & \text { Other (specify) }\end{array}$ \\
\hline
\end{tabular}




\section{Interviewer says:}

I would like to thank you for agreeing to answer these questions, and taking part in this interview. I wish to repeat that all the information provided by you is confidential and will only be used for academic purposes.

We will continue with this study for two more years, therefore I would like to ask you if you would like to take part in future surveys in this study
e) No
f) Yes

Would you like to have a copy of the results from this survey?
e) No
f) Yes

*If the person is agreeing to participate in future surveys or would like to have a copy of the results, please ask next question, otherwise finish with the questionnaire.

Please can you give me your contact information?

Name:

Address:

Contact phone:

E-mail:

\section{Again thank you very much for your time.}




\section{"Socio-economic evaluation of Marine Reserves in New Zealand"}

\section{LOCAL BUSINESS QUESTIONNAIRE}

Interviewer to say: Good morning/afternoon/evening. My name is Ursula Rojas Nazar; I am from Victoria University of Wellington. I am assessing the economic and social value of the marine reserves located at Island Bay, called Taputeranga MR to improve decision-making and public policies on marine conservation in NZ. You was agree to participate in my research by answering the following questionnaire, which will take around 10 minutes. All the information provided by you is confidential (your name will not be associated with the answers) and will only be used with your consent for academic research purposes. This questionnaire has been reviewed by the Victoria University of Wellington Human Ethics Committee, and is used with their permission.

The following questions relate to where you live and your knowledge about the Taputeranga MR/ Kapiti MR. For that read the questions and then select the most appropriate answer for you. The first part is related to your fishing background (if any), and then we will talk about the Taputeranga/Kapiti MR.

\section{Local Business background}

1. What type of business do you have?(Can be more than one)
a) Teaching diving courses
b) Dive charters
c) Maintaining dive equipment
d) Sales of dive equipment
e) Dive equipment rental
f) Fishing charters
g) Rent boats
h) Sell boats
i) Boat maintenance
j) Tourist trips
k) Clothing retail
1) Dairy/supermarket
m) Petrol station
n) Motel/hotel
o) Camping
p) Takeaway food/restaurant/café
q) Other 
3. How many people do you employ during the year within your business?

Permanent full time

Permanent part time

Can you tell me what the seasonal months are for your business?

\begin{tabular}{|l|l|l|l|l|l|}
\hline January & February & March & April & May & June \\
\hline July & August & September & October & November & December \\
\hline
\end{tabular}

4. How much do you pay the workers per hour?

\begin{tabular}{|ll|}
\hline Permanent full time & $\$ / \mathrm{hr}$ \\
Permanent part time & $\$ / \mathrm{hr}$ \\
\hline
\end{tabular}

5. Why have you chosen to locate your business in this area? Please select the most important three (3) only.
a) Good business location, close to many customers
b) Property prices or rentals
c) Easy transport to work
d) Beautiful seas and landscape
e) Popular place
f) Safe place
g) Away from the inner city
h) Family business
i) Taputeranga/Kapiti MR
j) Others (specify)

\section{Economic Benefits}

1. Has your business revenue changed in any way since the establishment of the Taputeranga/Kapiti marine reserve?

a) Since the start of the marine reserve my business revenue has increased

b) No, it is the same (go to question 4)

c) Since the start of the marine reserve my business revenue has decreased

2. Please estimate the percentage increase or decrease in your business revenue since the Taputeranga/Kapiti marine reserve was established.

$$
\%
$$

3. What do you think are the main reasons for this increase/decrease in your business revenue? 
4. Do you think the Taputeranga/Kapiti marine reserve has attracted more visitors into the area?
a) Yes
b) No (go to question 9 )

5. Please estimate the number of visitors in this area during winter and summer?

\begin{tabular}{|l|l|}
\hline Winter (June, July and August) & Summer (December, January and February) \\
\hline & \\
\hline
\end{tabular}

6. Does your business receive any financial gain from this increase in the number of visitors?

a) Yes

b) No (go to section III)

7. Please estimate this increase in percentage

\begin{tabular}{|r|}
\hline$\%$ Winter \\
\hline$\%$ Summer \\
\hline
\end{tabular}

8. Can tell me how much your business revenue is during winter (June, July and August) and summer (December, January and February)

Winter

Summer

\section{Marine Reserve knowledge}

1. Do you know what a marine reserve is?
a) Yes
b) No (if you do not, please read Appendix I at the and of the questionnaire, then go to question 3)

2. Can you describe in only a few words, what are the main goal(s) of a marine reserve?

3. Do you consider Marine Reserves to be a useful tool to protect the marine environment?
a) Yes
b) No
c) I don't know

4. Is marine conservation in general an important issue for you?
a) Yes, why?
b) No, why?
c) I don't know 
5. Do you know about the existence of the Taputeranga/Kapiti marine reserves?

a) Yes

b) No (If you do not, please read Appendix II at the and of the questionnaire, there you will find a brief explanation. Then go to question 7 )

6. What was your position regarding the proposal to create a marine reserve at Island Bay/Kapiti coast?

a) I agreed with it

b) I disagreed with it

c) I didn't care

7. I will show you a list of activities; First, can you tell me which activities (if any) you are currently conducting in the Taputeranga marine reserve?. Next, can you indicate with a tick if you know which activities are permitted and prohibited inside the marine reserve?(for the last question use the complete list)

\begin{tabular}{|l|l|l|l|l|}
\hline Activity & You & Permitted & Prohibited & Unsure \\
\hline Walking & & & & \\
\hline $\begin{array}{l}\text { Sitting in the car on the beach and } \\
\text { observing the environment }\end{array}$ & & & & \\
\hline Surfing & & & & \\
\hline Biking & & & & \\
\hline Playing & & & & \\
\hline Rockpooling & & & & \\
\hline Sitting on or near to the beach & & & & \\
\hline Recreational fishing & & & & \\
\hline Commercial fishing & & & & \\
\hline Picnicking & & & & \\
\hline Sunbathing & & & & \\
\hline Beach-combing & & & & \\
\hline Running & & & & \\
\hline Conducting research & & & & \\
\hline Swimming & & & & \\
\hline Boating & & & & \\
\hline Water skiing & & & & \\
\hline Boogie boarding & & & & \\
\hline Surf rescue & & & & \\
\hline Motor-biking & & & & \\
\hline Collecting fire wood & & & & \\
\hline Snorkelling & & & & \\
\hline Surfcasting & & & & \\
\hline Diving & & & & \\
\hline DOC activities & & & \\
\hline Shellfish collecting & & & \\
\hline Wind-surfing & & & \\
\hline Collecting seaweed & & & \\
\hline Education & & & \\
\hline
\end{tabular}


8. The following table describes some features of the Taputeranga/Kapiti marine reserve. With respect to the Marine Reserve how important is each of these features to you? Please rank them on a scale 1-5 where 5 is the most important and $\mathbf{1}$ is the least important.

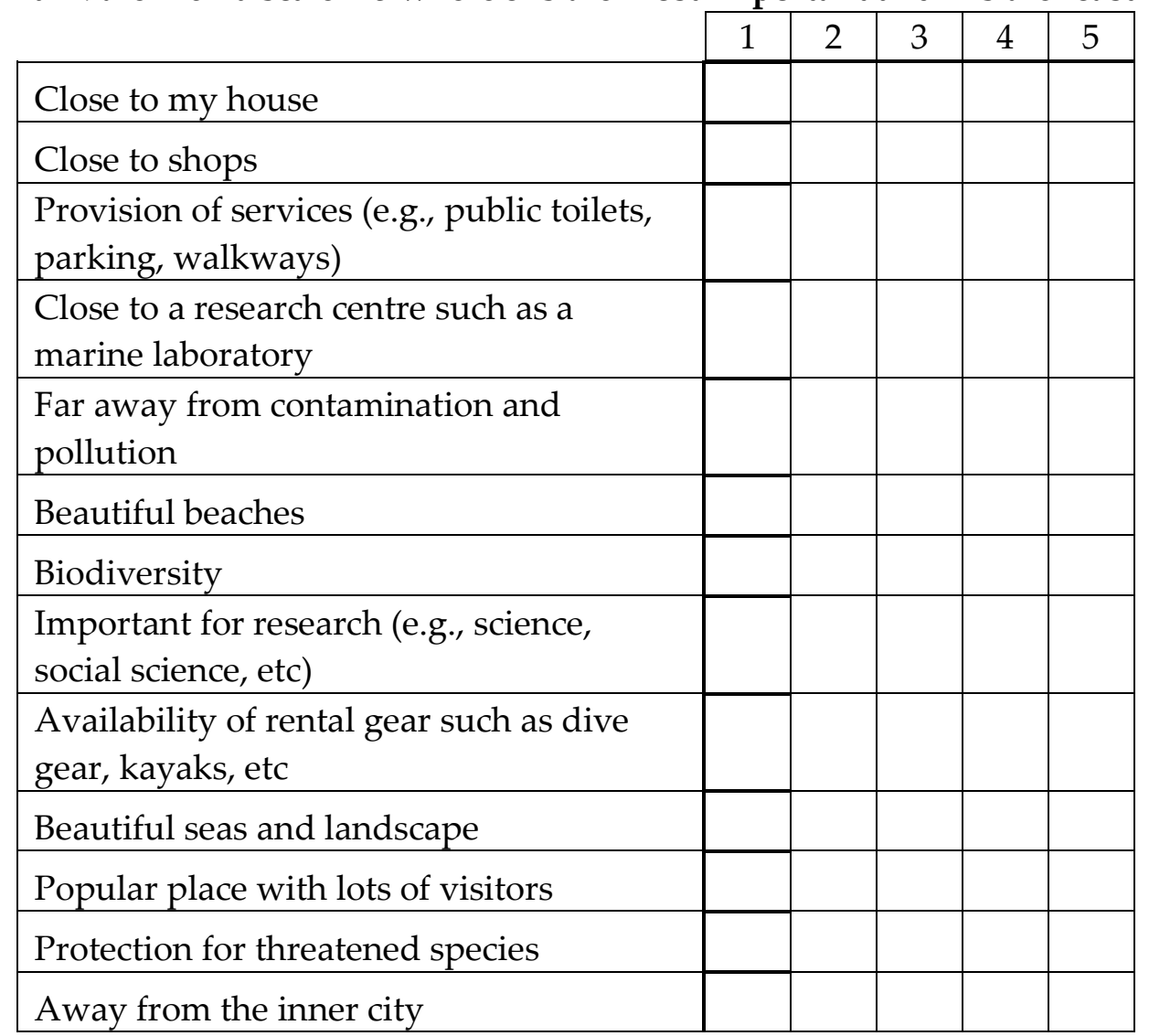

\section{Establishment Process of the Marine Reserve}

1. Did you participate in the Taputeranga/Kapiti Marine Reserve establishment process (for example participated in the consultation process, answered surveys, attended public meetings, attended meetings with key user groups or individual users)?

a) Yes (ask what the participation was)

b) No (go to question 4)

2. What was your initial reaction to the establishment of the Taputeranga/Kapiti marine reserve in/or close to your suburb?
a) Supported establishment
b) Opposed establishment
c) I didn't care
d) I wasn't here

3. Has your opinion about the Marine Reserve changed since that time?
a) Yes (why?)
b) No 
4. From your perspective, do you think the establishment of the Taputeranga/Kapiti Marine Reserve was a good decision?
a) Yes, better that expected (why?)
b) No (why?)
c) I don't care

\section{Perception and satisfaction levels}

1. Has the establishment of the Taputeranga/Kapiti marine reserve caused you or your family any issues (e.g., quality of life, economic loss, etc,)?
c) No
d) Yes

Problems

2. Are you aware of any other issues that have arisen following the establishment of the Taputeranga/Kapiti marine reserve?

f) No (go to question 4)

g) Yes

Problems

3. In your judgment, who is responsible for resolving the problems identified in the previous two question(s)? It is possible to choose more than one (These answers are in relation to question 1 and/or 2)
r) Local residents
s) Department of Conservation
t) Local Council
u) Royal Forest and Bird Protection Society of NZ
v) Ministry of Fisheries
w) Universities
x) NIWA
y) Police

Other (specify)

4. Overall, has the creation of the Taputeranga/Kapiti marine reserve had a positive effect, negative effect or no effect on your life? Why?
d) Positive
e) Negative
f) No change

Reasons: 
5. Do you feel that you have benefited from the establishment of the marine reserve with respect to the following categories:

\begin{tabular}{|l|l|l|l|l|}
\hline & $\begin{array}{l}\text { Negativ } \\
\text { e }\end{array}$ & $\begin{array}{l}\text { Same before and } \\
\text { after the } \\
\text { establishment }\end{array}$ & Positive & I don't know \\
\hline Your overall economic state & & & & \\
\hline Your wealth level & & & & \\
\hline Your health & & & & \\
\hline Your families wellbeing & & & & \\
\hline Leisure time & & & & \\
\hline Work & & & & \\
\hline Overall well-being & & & & \\
\hline
\end{tabular}

6. If this marine reserve did not exist would you still be living here?
i) Yes
j) Likely
k) Unlikely
1) $\mathrm{No}$

7. Can you state your satisfaction level with respect to the Taputeranga /Kapiti marine reserve in these different aspects?

\begin{tabular}{|l|l|l|l|l|l|}
\hline & $\begin{array}{c}\text { Very } \\
\text { satisfied }\end{array}$ & Satisfied & Dissatisfied & $\begin{array}{c}\text { Very } \\
\text { dissatisfied }\end{array}$ & Unsure \\
\hline Biodiversity protection & & & & & \\
\hline Litter on beach and in the water & & & & & \\
\hline Education opportunities & & & & & \\
\hline $\begin{array}{l}\text { Local participation in } \\
\text { management }\end{array}$ & & & & & \\
\hline Biodiversity recovery & & & & & \\
\hline $\begin{array}{l}\text { MR surveillance/policing (e.g. by } \\
\text { DoC Ranger) }\end{array}$ & & & & & \\
\hline
\end{tabular}

8. Have you noticed any changes in terms of the marine flora and fauna since the MR was established?
j) No
k) I don't know
1) Yes (ask if it is possible to describe this change)

9. Have you noticed any changes in terms of human usage of the area since the MR was established?
m) No
n) I don't know
o) Yes (ask if it is possible to describe this change)

10. If the Taputeranga/Kapiti MR were disestablished, what do you think would be the implications for the environment? and for you personally? 
11. Who do you think should pay for the management of the marine reserve?

12. When I say "Taputeranga/Kapiti marine reserve", what is the first word that comes into your mind? Can you explain why you thought of this word?

Word:

Reasons:

13. Do you have other comments before finishing this section of the interview?

\section{Demographic Information}

Interviewer says: These last few questions will help us to understand how well our sample represents the study area in the Wellington city/ Kapiti Coast areas. Your answers are strictly confidential, and will only be used for statistical and academic purposes. You will not be identified in any way.

\begin{tabular}{|c|c|c|}
\hline Gender & Age & $\begin{array}{l}\text { Highest education level } \\
\text { completed: }\end{array}$ \\
\hline $\begin{array}{l}\text { a) } \mathrm{M} \\
\text { b) } \mathrm{F}\end{array}$ & $\begin{array}{l}\text { a) }<20 \mathrm{yr} \\
\text { b) } 21-30 \mathrm{yr} \\
\text { c) } 31-40 \mathrm{yr} \\
\text { d) } 41-50 \mathrm{yr} \\
\text { e) } 51-60 \mathrm{yr} \\
\text { f) }>61 \mathrm{yr}\end{array}$ & $\begin{array}{l}\text { a) Primary complete } \\
\text { b) Secondary complete } \\
\text { c) Trade/technical qualification } \\
\text { d) Degree/professional qualification } \\
\text { e) Other (specify) }\end{array}$ \\
\hline \multicolumn{2}{|c|}{ Taputeranga MR } & Kapiti MR \\
\hline \multicolumn{2}{|c|}{$\begin{array}{l}\text { a) Owhiro Bay } \\
\text { b) Happy Valley } \\
\text { c) Island Bay } \\
\text { d) Houghton Bay } \\
\text { e) Lyall Bay } \\
\text { f) Moa Point } \\
\text { g) Breaker Bay } \\
\text { h) Other (specify) }\end{array}$} & $\begin{array}{ll}\text { a) } & \text { Kaitawa } \\
\text { b) } & \text { Kena Kena } \\
\text { c) } & \text { Maungakotukutuku } \\
\text { d) } & \text { Otaki Forks } \\
\text { e) } & \text { Otaki } \\
\text { f) } & \text { Otaihanga } \\
\text { g) } & \text { Paraparaumu Beach North } \\
\text { h) } & \text { Paraparaumu Beach South } \\
\text { i) } & \text { Paraparaumu Central } \\
\text { j) } & \text { Paekakariki } \\
\text { k) } & \text { Raumati Beach } \\
\text { l) } & \text { Raumati South } \\
\text { m) } & \text { Waikanae Beach } \\
\text { n) } & \text { Waikanae East } \\
\text { o) } & \text { Waikanae Park } \\
\text { p) } & \text { Waikanae West } \\
\text { q) } & \text { Other (specify) }\end{array}$ \\
\hline
\end{tabular}

THANK YOU 


\section{Interviewer says:}

I would like to thank you for agreeing to answer these questions, and taking part in this interview. I wish to repeat that all the information provided by you is confidential and will only be used for academic purposes.

We will continue with this study for two more years, therefore I would like to ask you if you would like to take part in future surveys in this study

1. No

2. Yes

Would you like to have a copy of the results from this survey?

g) No

h) Yes

*If the person is agreeing to participate in future surveys or would like to have a copy of the results, please ask next question, otherwise finish with the questionnaire.

Please can you give me your contact information?

Name:

Address:

Contact phone:

E-mail:

\section{Again thank you very much for your time.}


Appendix C

Surveys used to gather information on chapter IV 


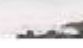

\section{Taputeranga Marine Reserve}

Hello, my name is Ursula Rojas Nazar; I am a student at Victoria University of Wellington. This survey is part of my PhD entitled 'Socio-economic evaluation of marine reserves in New Zealand'. The general goal of this survey is to evaluate some aspects of the management of the Taputeranga marine reserve. The results of my study will help to improve decision-making and public policies on marine conservation in New Zealand. In addition, the results obtained from this study may help to improve the state of marine reserves in New Zealand.

Are you willing to participate in my research by completing a simple questionnaire? It will take around 15 minutes.

All the information provided by you is confidential (your name will not be associated with the answers) and will only be used with your consent for academic research purposes. This questionnaire has been reviewed and approved by the Victoria University of Wellington Human Ethics Committee.

TE WHARE WXNANGA O TE OPOKO O TE IKAAMÃU 59:

\section{CONSENT TO PARTICIPATION IN RESEARCH}

\section{Title of project: "Socio-economic evaluation of Marine Reserves in New Zealand"}

I have been given and have understood an explanation of this research project. I have had an opportunity to ask questions and have them answered to my satisfaction. I understand that I may withdraw myself (or any information I have provided) from this project (before data collection and analysis is complete) without having to give reasons or without penalty of any sort.

I understand that any information I provide will be kept confidential to the researcherandthe supervisors, the published results will not use my name, and that no opinions will be attributed to me in any way that will identify me.

I understand that the data I provide will not be used for any other purpose or released to others without my written consent.

I understand that the data will form part of a PhD thesis and may also be published in scientific journals or as part of presentations at scientific meetings.

I agree to take part in this research.

I Would you like to take part of this study by answering the following questions:

Y Yes

No 


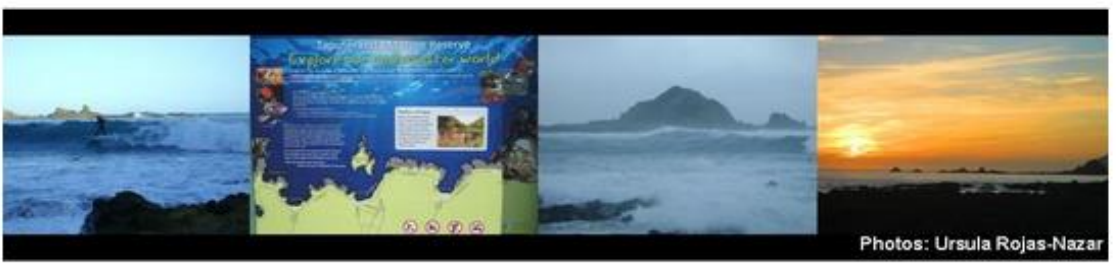

Taputeranga Marine Reserve

Marine Reserves are established in New Zealand under the marine reserves Act (1971). The Act is in place "... for the purpose of preserving the marine environment, as marine reserves for the scientific study of marine life, in areas of New Zealand that contain underwater scenery, natural features, or marine life, of such distinctive quality, or so typical, or beautiful, or unique, that their continued preservation is in the national interest."

The Taputeranga marine reserve is one of the newest in New Zealand, and was established in August 2008. It is located on Wellington's south coast and is the first marine reserve in Cook Strait. Taputeranga MR is 855 hectares in size, the 15th largest marine reserve in New Zealand.

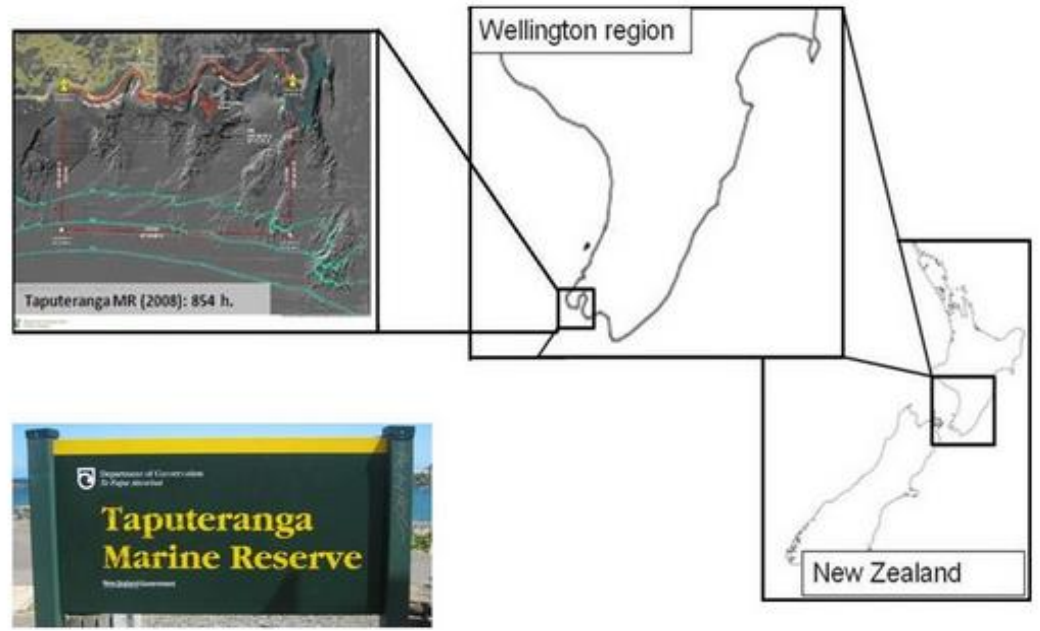

There are two reasons this area was selected to be a marine reserve:

(a) The Taputeranga marine reserve is considered to be unique as it is the only marine reserve in cook Strait. The reserve is likely to contributes animal lawae and plant spores to, and share migratory animals with the national network of marine reserves. For these reasons conservation of the area is extremely important for the scientific study of marine life.

(b) To gain public support for the creation of a marine reserve on Wellington's south coast, and to enable Wellingtonians. New Zealanders and overseas visitors to benefit from the enhanced recreational, commercial, and educational opportunities that will be generated by a marine reserve located on the coastline of the capital city.

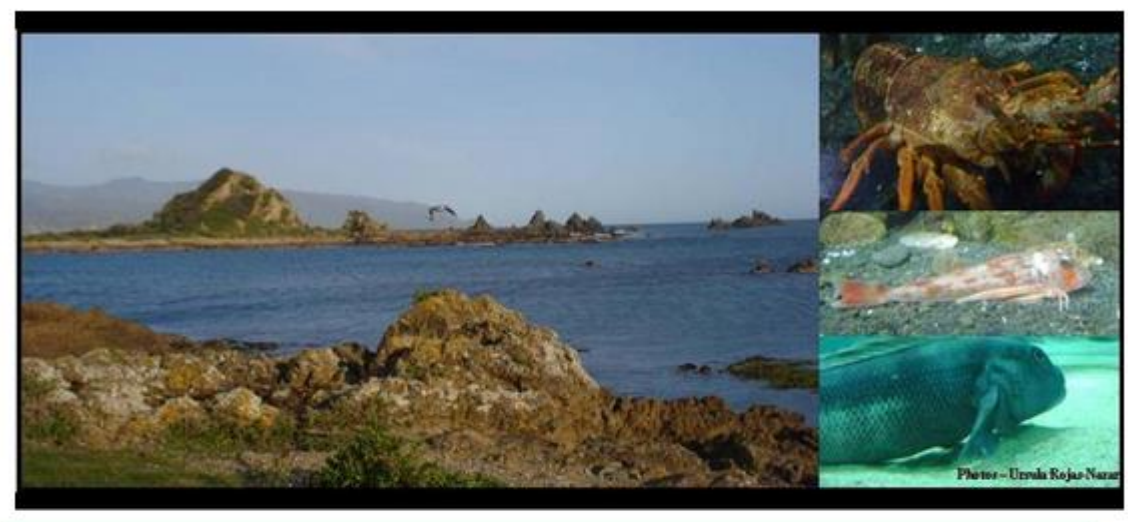




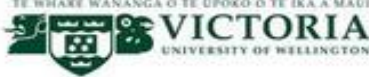

\section{Taputeranga Marine Reserve biodiversity}

The Taputeranga marine reserve includes many valuable commercial species, such as paua, rock lobster, paddle crab, blue cod, blue moki, tarakihi and butterfish. At the same time theTaputeranga marine reserve supports a huge diversity of species that play an important role in the ecosystem. For example, the marine reserve contains around 370 species of macroalgae, echinoderms (including sea-stars, star-fish, brittle stars, sea cucumber and kina), and molluscs (such as, scallops and sea slugs. In addition, the Taputeranga marine reserve has around 50 species of fish, found rock pools to deep waters. The Taputeranga marine reserve is visited by many other species, including dolphins, big sharks and orcas.

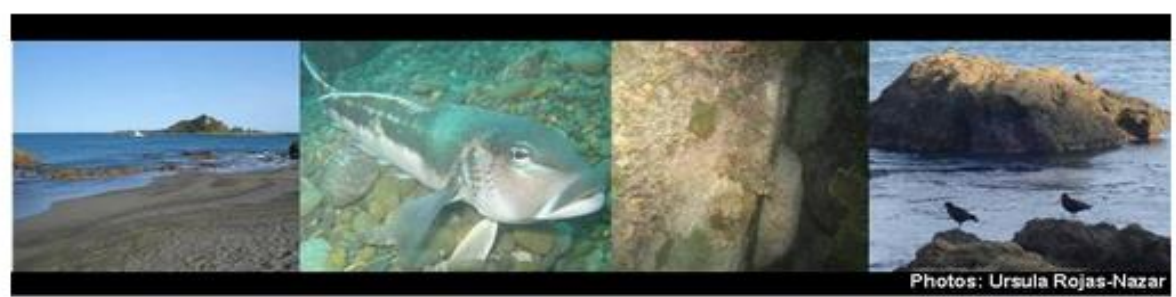

Taputeranga marine reserve's direct and indirect uses

Many activities are conducted by people in the marine reserve. Activities such as walking on the coast, observing the environment, surfing, rock pooling, snorkelling, SCUBA diving and boating are the most common. There are also some public services in the marine reserve including two boat ramps, one located in Island Bay, and the other is in Owhiro Bay, in front of the marine reserve at The Sirens Rocks is the Victoria University Coastal Ecology Laboratory (VUCEL), while the Marine Education centre is located in Island Bay which has numerous aquariums with marine life.

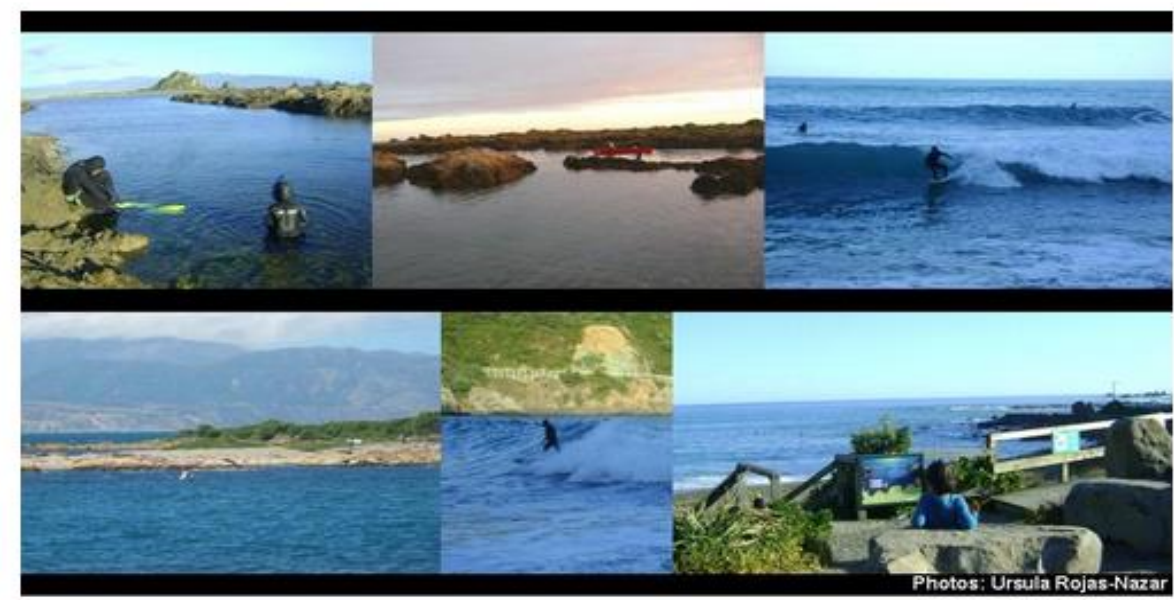

\section{Taputeranga Marine Reserve issues}

Several issues have become apparent since the marine reserve was established. On occasions, the beaches and the sea have been contaminated with pollutants from an outfall and a storm drain in Owhiro Bay and Houghton Bay. These outfalls affect animals, plants and habitats in this area, and may also affect the quality of life of local residents. Moreover, this problem affects visitors and particularly people who enjoy aquatic sports in the area. Another issue is the accumulation of large heaps of kelp (which is natural) and rubbish (which is a man-made problem) on the beach, both of which some people find offensive. Since the marine reserve was established, DoC receives several calls a week to report illegal activities inside the marine reserve, with paua and crayfish poaching the most common activities reported. Another issue is some local people feel there is not enough local involvement in the management of the marine reserve.

There are other activities which indirectly affect the marine reserve. A common harvesting tactic is to fish on the boundaries of the marine reserve, this is called 'fishing the line'. This tactic means that fishers (recreational, commercial and customary) fish more at the boundaries of the marine reserve. This is perfectly legal and reflects the increased size and abundance of animals inside the marine reserve and local knowledge about the movement of the fish and shellifish from inside to outside the area of the marine reserve. 


\section{Taputeranga Marine Reserve}

General questions

1. Have you heard of the Taputeranga marine reserve?

Yes

No

2. How many times have you visited the Taputeranga marine reserve?

None (please go to question 3 )

Once (please select $N / A$ on the following question, and then go to question 4)

2-4 times (please select N/A on the following question, and then go to question 4)

5 or more times (please select N/A on the following question, and then go to question 4)

3. Do you intend to visit the Taputeranga marine reserve in the future?

Yes (please select N/A on the following question, and then go to question 5)

No (please select N/A on the following question, and then go to question 5)

Likely (please select N/A on the following question, and then go to question 5)

Not sure (please select N/A on the following question, and then go to question 5)

N/A

4. What was the reason for your visit(s)? (Please tick A.LL relevant)

$\square$ Research

$\square$ Recreation (Please state your main activities here. E.g. kayaking, snorkelling, surting, boating, diving, etc.)

(r)

$\square$ Other (please state)

N/A

5. Had you previously heard all the information above regarding the Taputeranga marine reserve?

(O) Yes

No

6. Were you aware of the biodiversity in the Taputeranga marine reserve before you read the information above?

Yes

No

7. Do you think it was a good decision to establish the Taputeranga marine reserve?
O Yes
$\mathrm{C}^{\text {No }}$

8. Did the information provided above influence your answer to question number 7 ?

Yes (Please state how )
No (Please state why not)




\section{Marine Reserve: management}

Please read the following statements about marine reserves and indicate your level of agreement with each statement

Based on your understanding of the purpose of marine reserves in New Zealand, a marine reserve is successful when..?

\begin{tabular}{|c|c|c|c|c|c|c|}
\hline & $\begin{array}{l}\text { Strongly } \\
\text { disagree }\end{array}$ & Disagree & $\begin{array}{l}\text { Neither } \\
\text { agree nor } \\
\text { disagree }\end{array}$ & agree & $\begin{array}{l}\text { Strongly } \\
\text { agree }\end{array}$ & Unsure \\
\hline $\begin{array}{l}\text { Research is being conducted within the marine } \\
\text { reserve }\end{array}$ & & & & & & \\
\hline $\begin{array}{l}\text { Nobody is fishing at the boundaries of the marine } \\
\text { resenve }\end{array}$ & & & & & & \\
\hline $\begin{array}{l}\text { There is no poaching or illegal activities in the } \\
\text { marine resenve }\end{array}$ & & & & & & \\
\hline $\begin{array}{l}\text { Beaches in the marine resenve are not littered by } \\
\text { cigarettes, disposable nappies, assorted plastic. } \\
\text { latex products, etc }\end{array}$ & & & & & & \\
\hline $\begin{array}{l}\text { The marine resenve is valued and respected by } \\
\text { society }\end{array}$ & & & & & & \\
\hline $\begin{array}{l}\text { Fish populations in the marine resenve are } \\
\text { increasing in number } \& \text { size (e.g. crayfish, } \\
\text { butterfish, paua, kina, blue moki, tarakihi) }\end{array}$ & & & & & & \\
\hline $\begin{array}{l}\text { Wovld populations in the marine resenve are } \\
\text { increasing in number } \& \text { size (e.g. seaweeds, star- } \\
\text { fish, anemones, limpets) }\end{array}$ & & & & & & \\
\hline $\begin{array}{l}\text { The marine resenve is protecting a common marine } \\
\text { heritage }\end{array}$ & & & & & & \\
\hline $\begin{array}{l}\text { The marine reserve is visited by many people } \\
\text { during the year }\end{array}$ & & & & & & \\
\hline $\begin{array}{l}\text { Everyone in the region knows of the marine } \\
\text { resenve }\end{array}$ & & & & & & \\
\hline
\end{tabular}

Your satisfaction with Marime Reserves in New Zealand...

\begin{tabular}{|c|c|c|c|c|c|c|}
\hline & $\begin{array}{l}\text { Strongly } \\
\text { disagree }\end{array}$ & Disagree & $\begin{array}{l}\text { Neither } \\
\text { agree nor } \\
\text { disagree }\end{array}$ & agree & $\begin{array}{l}\text { Strongly } \\
\text { agree }\end{array}$ & Unsure \\
\hline 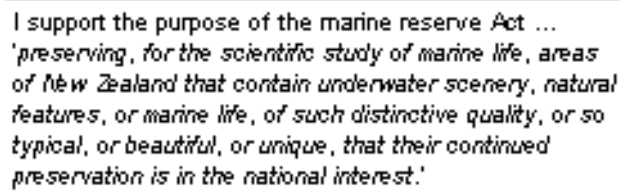 & & & & & & \\
\hline $\begin{array}{l}\text { I am satisfied with how marine reserves are managed in } \\
\text { New Zealand }\end{array}$ & & & & & & \\
\hline $\begin{array}{l}\text { I am satisfied with how marine resenves are performing } \\
\text { in New Zealand }\end{array}$ & & & & & & \\
\hline $\begin{array}{l}\text { I support the creation of more marine resenves in New } \\
\text { Zealand }\end{array}$ & & & & & & \\
\hline $\begin{array}{l}\text { I am satisfied with the restrictions that prohibit } \\
\text { commercial hanvesting from within marine resenves }\end{array}$ & & & & & & \\
\hline $\begin{array}{l}\text { I am satisfied with the restrictions that prohibit } \\
\text { recreational hanvesting from within marine reserves }\end{array}$ & & & & & & \\
\hline $\begin{array}{l}\text { I am satisfied with the restrictions that prohibit } \\
\text { customany hanvesting from within marine reserves }\end{array}$ & & & & & & \\
\hline
\end{tabular}




\begin{tabular}{|c|c|c|c|c|c|c|}
\hline & $\begin{array}{l}\text { Strongly } \\
\text { disagree }\end{array}$ & Disagree & $\begin{array}{l}\text { Neither } \\
\text { agree nor } \\
\text { disagree }\end{array}$ & agree & $\begin{array}{l}\text { Strongly } \\
\text { agree }\end{array}$ & Unsure \\
\hline 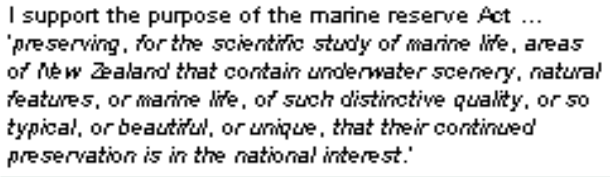 & & & & & & \\
\hline $\begin{array}{l}\text { I am satisfied with how marine reserves are managed in } \\
\text { New Zealand }\end{array}$ & & & & & & \\
\hline $\begin{array}{l}\text { I am satisfied with how marine reserves are performing } \\
\text { in New Zealand }\end{array}$ & & & & & & \\
\hline $\begin{array}{l}\text { I support the creation of more marine resenves in New } \\
\text { Zealand }\end{array}$ & & & & & & \\
\hline $\begin{array}{l}\text { I am satisfied with the restrictions that prohibit } \\
\text { commercial hanvesting from within marine resenves }\end{array}$ & & & & & & \\
\hline $\begin{array}{l}\text { I am satisfied with the restrictions that prohibit } \\
\text { recreational hanvesting from within marine resenves }\end{array}$ & & & & & & \\
\hline $\begin{array}{l}\text { I am satisfied with the restrictions that prohibit } \\
\text { customary harvesting from within marine resenves }\end{array}$ & & & & & & \\
\hline
\end{tabular}

Your perception of Taputeranga Marine Reserve ...

\begin{tabular}{l|ll}
\hline & $\begin{array}{c}\text { Neither } \\
\text { agree nor } \\
\text { disagree }\end{array}$ & $\begin{array}{c}\text { Strogly } \\
\text { agree } \\
\text { agree }\end{array}$ \\
\hline $\begin{array}{l}\text { Unce the establishment of the Taputeranga marine } \\
\text { resenve the abundance and size of the species in the } \\
\text { resenve has improved }\end{array}$
\end{tabular}

Your satisfaction with the Taputeranga Marime Reserve...

\begin{tabular}{|c|c|c|c|c|c|c|}
\hline & $\begin{array}{l}\text { Strongly } \\
\text { disagree }\end{array}$ & Disagree & $\begin{array}{l}\text { Neither } \\
\text { agree } \\
\text { nor } \\
\text { disagree }\end{array}$ & agree & $\begin{array}{l}\text { Strongly } \\
\text { agree }\end{array}$ & Unsure \\
\hline I am satisfied with how Taputeranga marine reserve was established & & & & & & 0 \\
\hline I am satisfied with the management of the Taputeranga marine resenve & & & & & & \\
\hline $\begin{array}{l}\text { I am satisfied with local participation in the management of Taputeranga } \\
\text { marine reserve }\end{array}$ & & & & & & \\
\hline $\begin{array}{l}\text { I am satisfied with surveillance and policing of the Taputeranga marine } \\
\text { reserve }\end{array}$ & & & & & & \\
\hline I am satisfied with how Taputeranga marine reserve looks and smells & & & & & & \\
\hline $\begin{array}{l}\text { I am satisfied with the information provided by the Department of } \\
\text { Consenvation about Taputeranga marine resenve }\end{array}$ & & & & & & \\
\hline $\begin{array}{l}\text { I am satisfied with the facilities (signs, seats, sea views) at the } \\
\text { Taputeranga marine reserve }\end{array}$ & & & & & & \\
\hline $\begin{array}{l}\text { I am satisfied with the information available on marine conservation } \\
\text { issues since the Taputeranga marine reserve was established }\end{array}$ & & & & & & \\
\hline $\begin{array}{l}\text { I am satisfied with how marine biodiversity is protected in the } \\
\text { Taputeranga marine reserve }\end{array}$ & & & & & & \\
\hline $\begin{array}{l}\text { I am satisfied with how property rights are respected at the boundaries of } \\
\text { the Taputeranga marine reserve }\end{array}$ & & & & & & \\
\hline $\begin{array}{l}\text { I am satisfied with the current boundaries of the Taputeranga marine } \\
\text { resenve }\end{array}$ & & & & & & \\
\hline I am supportive of the Taputeranga marine resenve & & & & & & \\
\hline
\end{tabular}




\section{Willingness to Pay (WTP) for conservation of Taputeranga marine reserve}

Assume that the New Zealand Government needs additional funds to manage Taputeranga marine reserve this is a hypothetical situation and there are no plans to introduce a lew). For the next questions please assume:

The Government proposes to introduce a 'new environmental levy'. The emironmental levy will be paid each year.

\section{Please consider how much vou can afford given vour current household income and personal expenses.}

Consider vou answer carefullv, because vour answer will help to improve decision-making and public policies on marine conservation in New Zealand.

1. Would you agree to contribute money for that purpose if all Wellington Region households were asked to contribute?

Yes (please select N/A on the following question, and then go to question 3)

No (go to question 2)

2. What is your main reason for NOT contributing? (Please tick one answer only)

I support the idea, but I cannot afford to pay based on my financial circumstances.

I pay income tax and GST and am opposed to any additional payments to central govemment.

I believe the Taputeranga Marine Resenve is already well managed.

I believe the govemment should seek funding from altemative sources.

I do not believe that paying such an amount will result in improved consenuation of theTaputeranga marine resenve.

Only people who will receive direct benefits from the existence of the Taputeranga marine resenve should pay for the fund

Consenvation is not an important issue for me.

I do not believe if I give my money to a govemment fund, it will be used for that purpose.

( N / $/ A$

3. What is the maximum amount that you (your household) are willing to pay each year to manage the Taputeranga marine reserve?

N.Z. $\$$

4. How should the funds that are collected by the environmental lewy be used at the Taputeranga marine reserve? Please rank the iterns on the list below for importance where 1 is the most important.

$\square$ Alocal education program about Taputeranga marine reserve
Help fund scientific research in the Taputeranga marine resenve
Help with the reduction of contamination in the Taputeranga marine reserve
$\begin{aligned} & \square \\ & \square\end{aligned}$ Mearing the beach of litter in the Taputeranga marine resenve
$\square$ Mre surveillance to prevent poaching or any illegal activities in the Taputeranga marine reserve
$\square$ More sunveillance to reduce fishing at the boundaries of theTaputeranga marine resenve
$\square$ Other (Please state):




\section{Demographic Information}

These last few questions will help us to understand how well our sample represents the study area in the Wellington south coast. Your answers are strictly confidential, and will only be used for statistical and academic purposes. You will not be identified in any way. Please place a tick beside the best responses to each question.

\section{Gender:}

Male
Female

\section{Age:}

Please state your age

3. Do you have any children?
O Yes
No

4. Highest education level completed:
Primany school
Secondary school
Tradertechnical qualification
Degree/professional qualification
Other (specify):

5. What is your current employment status?
Unemployed
Student
Employee
Self-employed
Retired
Homemakeriparents

6. What is your annual household income from all sources before tax?
(1) Less than $\$ 20,000$
- $\$ 20,001$ to $\$ 40,000$
C $\$ 40,001$ to $\$ 60,000$
( $\$ 50,001$ to $\$ 80,000$
C $\$ 80,001$ to $\$ 100,000$
More than $\$ 100,000$ 
7. Do you belong to any of the following group(s)? Please tick ALL that are relevant.

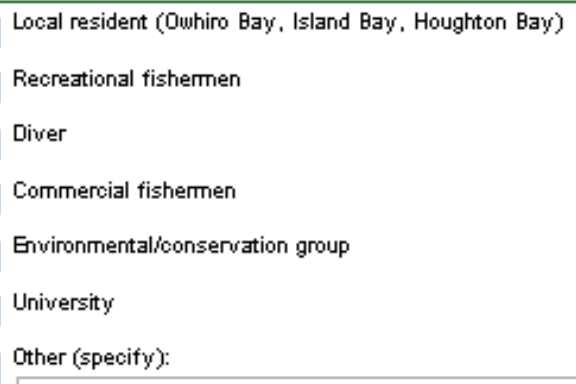

8. What is your postcode? if you don't know please go to http:/tools.nzpost.co.nz/tools/addresspostcode-finder

Postcode

9. The survey questions are easily understood
Strongly agree
Agree
Disagree
Strongly disagree

I would like to thank you for agreeing to answer these questions, and taking part in this interview. I wish to repeat that all the information provided by you is confidential and will only be used for academic purposes.

1. We will continue with this study for one more year, therefore i would like to ask you if you would like to take part in future surveys in this study
No
C Yes

2. Would you like to have a copy of the results from this survey?
No
Yes

*if you are agree to participate in future sumeys or would like to have a copy of the results, piease can you give me your contact information to contact you or send you the results required?

$\begin{array}{ll}\text { Name: } & \square \\ \text { Address: } & \square \\ \text { Contact phone: } & \square \\ \text { E-mail: } & \end{array}$

Again, many thanks for your time!

More information at: http:WWww.doc.govt.nz 


\section{Kapiti Marine Reserve}

Hello, my name is Ursula Rojas Nazar; I am a student at Victoria University of Wellington. This survey is part of my PhD entitled 'Socio-economic evaluation of marine reserves' in New Zealand. The general goal of this survey is to evaluate some aspects of the management of the Kapiti Marine Reserve. The results of my study will help to improve decision-making and public policies on marine conservation in New Zealand. In addition, the results obtained from this study may help to improve the state of marine reserves in New Zealand.

Are you willing to participate in my research by completing a simple questionnaire? It will take around 15 minutes.

All the information provided by you is confidential (your name will not be associated with the answers) and will only be used with your consent for academic research purposes. This questionnaire has been reviewed and approved by the Victoria University of Wellington Human Ethics Committee.

\section{CONSENT TO PARTICIPATION IN RESEARCH \\ Title of project: "Socio-economic evaluation of Marine Reserves in New Zealand"}

I have been given and have understood an explanation of this research project. I have had an opportunity to ask questions and have them answered to my satisfaction. I understand that I may withdraw myself (or any information I have provided) from this project (before data collection and analysis is complete) without having to give reasons or without penalty of any sort.

I understand that any information I provide will be kept confidential to the researcherandthe supervisors the published results will not use my name, and that no opinions will be attributed to me in any way that will identify me.

I understand that the data I provide will not be used for any other purpose or released to others without my written consent.

I understand that the data will form part of a PhD thesis and may also be published in scientific journals or as part of presentations at scientific meetings.

I agree to take part in this research.

I Would you like to take part of this study by answering the following questions:

Yes

No 


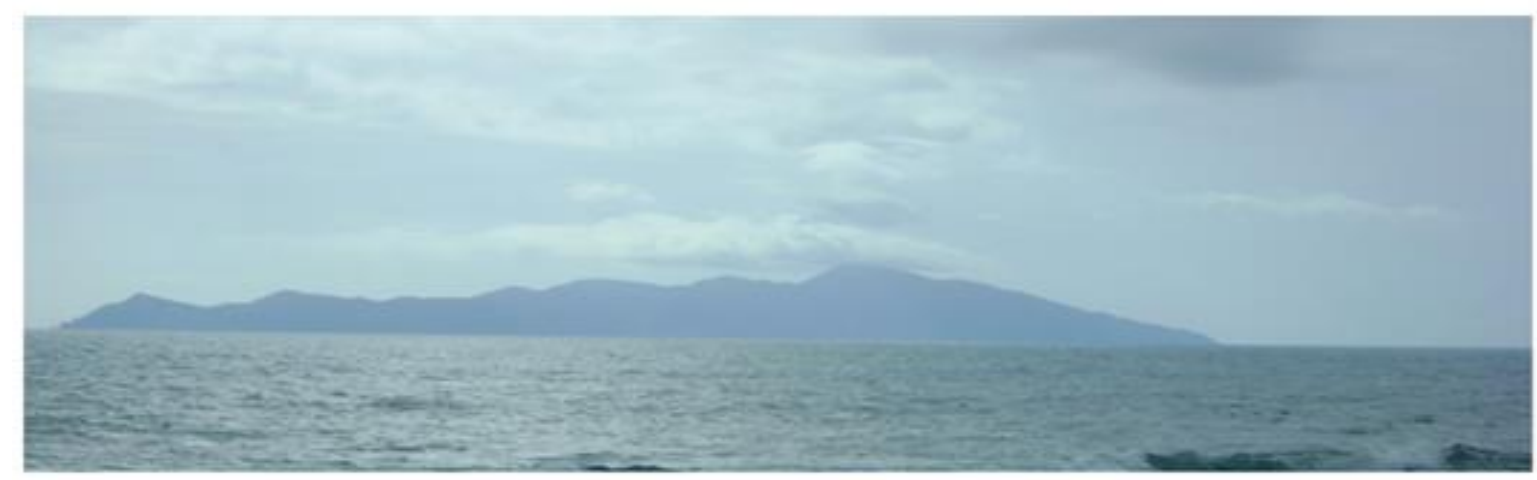

\section{Kapiti Marine Reserve}

Marine Reserves are established in New Zealand under the marine reserves Act (1971). The Act is in place "... for the purpose of preserving the marine environment, as marine reserves for the scientific study of marine life, in areas of New Zealand that contain underwater scenery, natural features, or marine life, of such distinctive quality, or so typical, or beautiful, or unique, that their continued preservation is in the national interest."

Kapiti marine reserve was established in 1992 on the Kapiti Coast, 30 kilometers north of Wellington city. It extends from a small portion on the North Island coast to Kapiti Island. Near the Kapiti marine reserve are several small towns, including Kapiti Beach, Raumati Beach and Waikanae Beach.

Kapiti marine reserve has a total area of 2167 ha. It's boundaries were a compromise, and do not include traditional fishing grounds at the northern end of the Island which continue to be fished.

Kapiti Marine Reserve protects a variety of habitats and areas of outstanding underwater scenery. Two major sea currents converge at Kapiti: a cold clear Southland current, and a turbid and saltier d'Urville current. This results in a fascinating overlap of marine plants and animals.

The reserve is made up of two areas east and west of Kapiti Island, which has been divided into distinct habitat zones. East of Kapiti Island is relatively sheltered, while west of the island is exposed to strong winds.

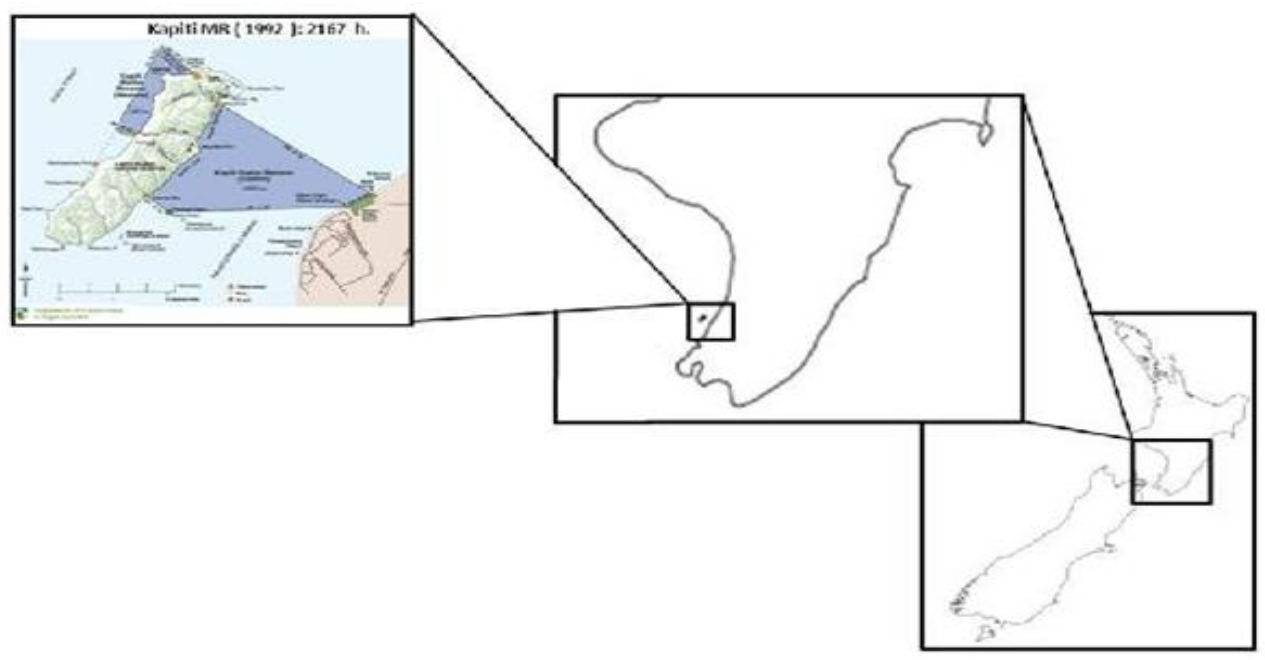




\section{Kapiti marine reserve biodiversity}

The main features of the marine reserve are three marine habitats, which support a rich variety of marine life (DoC, 2009).

The water depth in the channel east of Kapiti Island reaches up to $80 \mathrm{~m}$ deep and has strong currents. It provides a home to worms, shellfish, gurnard, and goatfish. In this habitat seaweed is uncommon. Narrow boulder-rock reefs with sandy patches just off the coast of the island are sheltered by the island but are still subject to strong currents. Seaweed and fish such as spotties, eagle rays, goatfish, blue cod and terakihi are common in this habitat. Rhodolith beds, which are unique to this region, are also found here. Rhodoliths are colorful marine algae that resemble coral.

The western reserve includes extensive reefs of large boulders that can been seen at low tide, from Tuteremoana (the highest point on the island) adjacent to the rocky headland. A wide diversity of marine plants and animals live in this habitat, including bryozoan beds, which are unique to the region Bryozoans are small animals that form moss like colonies which look like coral and attach themselves to rocks and seaweeds.

The Waikanae estuary and river mouth is also part of Kapiti marine reserve and provides a habitat for wading birds shellfish and whitebait.

The Kapiti marine reserve contains a lot of valuable commercial species such as paua, rock lobster, blue cod, snapper, kina, and butterfish. The marine reserve is constantly visited by many other species, some of which are very emblematic and amazing animals such as dolphins and big sharks.

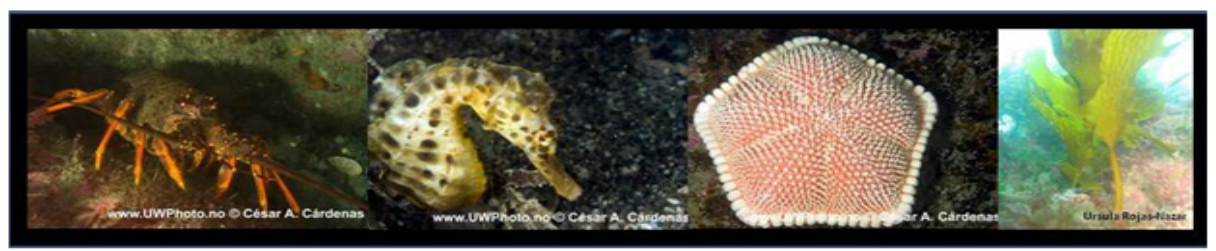

\section{Kapiti Marine Reserve's direct and indirect uses}

Many activities are conducted by people in the marine reserve as the weather allows. Activities such as walking on the coast, observing the environment, SCUBA diving, kayaking and boating are the most common

Since 1998 Kapiti marine reserve has been monitored by researchers from Victoria University of Wellington and Department of Conservation (DoC), in order to establish what differences existed in size and abundance of 34 key species (including algae, fish and invertebrates) between the reserve and control sites. Data are compared to that collected by NIWA in 1992 (prior to the establishment of the marine reserve) to determine what changes have occurred over time (DoC, 2010).

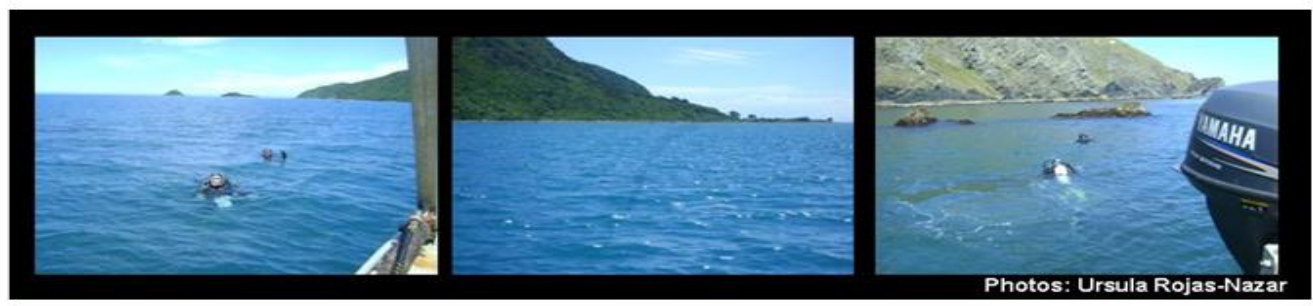

\section{Kapiti marine reserve issues}

Since the marine reserve was established, DoC has received many calls, to report illegal activities inside the marine reserve, with paua, kina and crayfish poaching, and netting being the most common activities reported.

There are other activities which indirectly affect the marine reserve. A common harvesting tactic is to fish on the boundaries of the marine reserve, this is called fishing the line. This tactic means fishermen (recreational, commercial and customary) fish more and on the boundaries of the marine reserves. This is perfectly legal and reflects the increased size and abundance of animals inside the marine reserve and local knowledge about the movement of the fish and shellfish outside the area of the marine reserve.

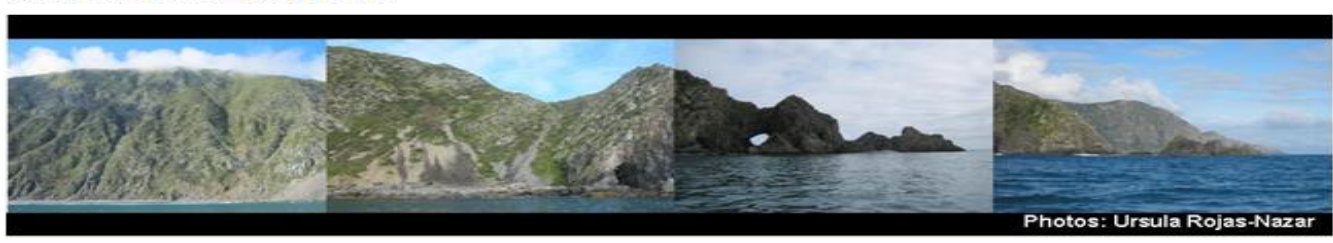




\section{Kapiti marine reserve}

\section{General questions}

1. Have you heard of the Kapiti marine reserve?

Yes

No

2. How many times have you visited the Kapiti marine reserve?

None (please go to question 3 )

Once (please select N/A on the following question, and then go to question 4)

2-4 times (please select N/A on the following question, and then go to question 4)

5 or more times (please select N/A on the following question, and then go to question 4)

3. Do you intend to visit the Kapiti marine reserve in the future?

- Yes (please select N/A on the following question, and then go to question 5 )

No (please select N/A on the following question, and then go to question 5 )

- Likely (please select N/A on the following question, and then go to question 5 )

Not sure (please select N/A on the following question, and then go to question 5)

N/A

4. What was the reason for your visit(s)? (Please tick ALL relevant)

[ Research

[7] Recreation (Please state your main activties here, E.g. kayaking, snorkeling, surfing, boating, diving, etc.)

Other (Please state)

NA

5. Had you previously heard all the information above regarding the Kapiti marine reserve?

Yes

(1) No

6. Were you aware of the biodiversity in the Kapiti marine reserve before you read the information above?
(1) Yes

No

7. Do you think it was a good decision to establish the Kapiti marine reserve?

Y) Yes

No

8. Did the information provided above influence your answer to question number $7 ?$

Yes (Please state how )

No (Please state why not) 


\section{0.}

\section{Marine Reserve: management}

Please read the following statements about marine reserves and indicate your level of agreement with each statement

Based on your understanding of the purpose of marine reserves in New Zealand, a marine reserve is successful when ...?

\begin{tabular}{l|l}
\hline Research is being conducted within the marine reserve & $\begin{array}{c}\text { Strongly } \\
\text { disagree }\end{array}$ \\
\hline $\begin{array}{l}\text { Nobody is fishing at the boundaries of the marine } \\
\text { reserve }\end{array}$ \\
$\begin{array}{l}\text { There is no poaching or illegal activities in the marine } \\
\text { reserve }\end{array}$ \\
$\begin{array}{l}\text { Beaches in the marine reserve are not littered by } \\
\text { cigarettes, disposable nappies, assorted plastic, latex } \\
\text { products, etc }\end{array}$ \\
$\begin{array}{l}\text { The marine reserve is valued and respected by society } \\
\text { disagree }\end{array}$
\end{tabular}

Your satisfaction with Marine Reserves in New Zealand..

\begin{tabular}{|c|c|c|c|c|c|c|}
\hline & $\begin{array}{l}\text { Strongly } \\
\text { disagree }\end{array}$ & Disagreed & $\begin{array}{l}\text { Neither } \\
\text { agree nor } \\
\text { disagree }\end{array}$ & agree & $\begin{array}{l}\text { Strongly } \\
\text { agree }\end{array}$ & Unsure \\
\hline $\begin{array}{l}\text { I support the purpose of the marine reserve Act... } \\
\text { 'preserving, for the scientific study of marine life, areas of } \\
\text { New Zealand that contain undenwater scenery, natural } \\
\text { features, or marine life, of such distinctive quality, or so } \\
\text { typical, or beautiful, or unique, that their continued } \\
\text { preservation is in the national interest.' }\end{array}$ & 0 & 0 & 0 & 0 & ○ & ○ \\
\hline $\begin{array}{l}\text { I am satisfied with how marine reserves are managed in New } \\
\text { Zealand }\end{array}$ & 0 & 0 & $\odot$ & ○ & ○ & $\odot$ \\
\hline $\begin{array}{l}\text { I am satisfied with how marine reserves are performing in } \\
\text { New Zealand }\end{array}$ & ○ & 0 & $\odot$ & ○ & $\odot$ & $\odot$ \\
\hline $\begin{array}{l}\text { I support the creation of more marine reserves in New } \\
\text { Zealand }\end{array}$ & 0 & ○ & 0 & ○ & $\odot$ & 0 \\
\hline $\begin{array}{l}\text { I am satisfied with the restrictions that prohibit commercial } \\
\text { harvesting from within marine reserves }\end{array}$ & $\odot$ & () & 0 & 0 & ○ & 0 \\
\hline $\begin{array}{l}\text { I am satisfied with the restrictions that prohibit recreational } \\
\text { harvesting from within marine reserves }\end{array}$ & 0 & 0 & 0 & 0 & ○ & $\odot$ \\
\hline $\begin{array}{l}\text { I am satisfied with the restrictions that prohibit customary } \\
\text { harvesting from within marine reserves }\end{array}$ & 0 & 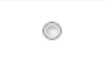 & $\odot$ & 0 & (2) & 0 \\
\hline
\end{tabular}

Your perception of Kapiti marine reserve ...

\begin{tabular}{|c|c|c|c|c|c|c|}
\hline & $\begin{array}{l}\text { Strongly } \\
\text { disagree }\end{array}$ & Disagree & $\begin{array}{l}\text { Neither } \\
\text { agree nor } \\
\text { disagree }\end{array}$ & agree & $\begin{array}{l}\text { Strongly } \\
\text { agree }\end{array}$ & Unsure \\
\hline $\begin{array}{l}\text { Since the establishment of the Kapiti marine reserve the } \\
\text { abundance and size of the species in the reserve has } \\
\text { improved }\end{array}$ & O & ○ & ○ & ○ & ○ & O \\
\hline $\begin{array}{l}\text { Since the establishment of the Kapiti marine reserve the } \\
\text { quantity of litter on the beach has reduced }\end{array}$ & $\odot$ & ○ & ○ & $\odot$ & ○ & ○ \\
\hline $\begin{array}{l}\text { The Kapiti marine reserve will conserve a portion of marine } \\
\text { biodiversity for future generations }\end{array}$ & O & O & O & O & $\odot$ & $\odot$ \\
\hline $\begin{array}{l}\text { The establishment of Kapiti marine reserve has helped to } \\
\text { reduce poaching }\end{array}$ & 0 & 0 & O & O & 0 & ○ \\
\hline $\begin{array}{l}\text { Due to the Kapiti marine reserve people have become more } \\
\text { aware of conservation issues }\end{array}$ & $\odot$ & 0 & $\odot$ & 0 & ○ & 0 \\
\hline The Kapiti marine reserve has reduced conflicts among users & 0 & ○ & ○ & ○ & O & ○ \\
\hline
\end{tabular}




\begin{tabular}{l}
\hline \\
\hline I am satis fied with how Kapiti marine reserve was established \\
I am satisfied with the management of Kapiti marine reserve \\
I am satis fied with local participation in the management of Kapti marine reserve \\
I am satisfied with survellance and policing of the Kapiti marine reserve \\
I am satisfied with how Kapiti marine reserve looks and smells \\
I am satisfied with the information provided by the Department of Conservation \\
about Kapti marine reserve \\
I am satisfied with the facilties (signs, seats, sea views) at the Kapiti marine \\
reserve \\
I am satis fied with the information available on marine conservation issues since \\
the Kapiti marine reserve was established \\
I am satisfied with how marine biodiversity is protected in the Kapiti marine \\
reserve \\
I am satis fied with how property rights are respected at the boundaries of the \\
Kapiti marine reserve \\
I am satisfied with the current boundaries of the Kapiti marine reserve \\
I am supportive of the Kapiti marine reserve
\end{tabular}

\section{Willingness to Pay (WTP) for conservation of Kapiti marine reserve}

Assume that the New Zealand Government needs additional funds to manage Kapiti marine reserve (this is a hypothetical situation and there are no plans to introduce a levy). For the next questions please assume:

The Government proposes to introduce a 'new environmental levy'. The environmental levy will be paid each year.

Please consider how much you can afford given your current household income and personal expenses.

Consider you answer carefully, because your answer will help to improve decision-making and public policies on marine conservation in New Zealand.

1. Would you agree to contribute money for that purpose if all Wellington Region households were asked to contribute?

\footnotetext{
Yes (please select N/A on the following question, and then go to question 3)

No (go to question 2)
}

2. What is your main reason for NOT contributing? (Please tick one answer only)
I support the idea, but I cannot afford to pay based on my financial circumstances.
- I pay income tax and GST and am opposed to any additional payments to central government.
- I believe Kapti marine reserve is aiready well managed.
I I believe the government should seek funding from aternative sources.
I I not believe that paying such an amount will resut in improved conservation of Kapti marine reserve.
Onily people who will receive direct benefts from the existence of Kapti marine reserveshould pay for the fund.
Conservation is not an important issue for me.
I Io not beleve if I give my money to a government fund, $\mathrm{k}$ will be used for that purpose.
(1) NA 
3. What is the maximum amount that you (your household) are willing to pay each year to manage Kapiti marine reserve?

N.S

4. How should the funds that are collected by the environmental levy be used at Kapiti marine reserve? Please rank the items on the list below for importance where 1 is the most important.
A local education program about Kapiti marine reserve
Help fund scientific research in Kapti marine reserve
Help with the reduction of contamination in Kapti marine reserve
Clearing the beach of Itter in Kapiti marine reserve
More surveillance to prevent poaching or any illegal activities in Kapti marine reserve
More surveillance to reduce fishing at the boundaries of Kapti marine reserve
Other (Please state):

\section{Demographic Information}

These last few questions will help us to understand how well our sample represents the study area in the Kapiti coast. Your answers are strictly confidential, and will only be used for statistical and academic purposes. You will not be identified in any way. Please place a tick beside the best responses to each question.

\section{Gender:}
(1) Male
Female

\section{Age:}

Please state your age

3. Do you have any children?
() Yes
○ No

4. Highest education level completed:
(1) Primary school
(-) Secondary school
() Trade/technical qualification
() Degree/professional qualification
Other (specify): 
3. What is the maximum amount that you (your household) are willing to pay each year to manage Kapiti marine reserve?

N.S.S

4. How should the funds that are collected by the environmental levy be used at Kapiti marine reserve? Please rank the items on the list below for importance where 1 is the most important.
A local education program about Kapiti marine reserve
Help fund scientific research in Kapti marine reserve
Help with the reduction of contamination in Kapti marine reserve
Clearing the beach of Itter in Kaptiti marine reserve
More surveillance to prevent poaching or any illegal activities in Kapti marine reserve
More surveillance to reduce fishing at the boundaries of Kapti marine reserve
Other (Please state):
5. What is your current employment status?
Unemployed
() Student
Employee
Self-employed
Retired
Homemaker/parents

6. What is your annual household income from all sources before tax?
Less than $\$ 20,000$
$\$ 20,001$ to $\$ 40,000$
$\$ 40,001$ to $\$ 60,000$
$\$ 60,001$ to $\$ 80,000$
$\$ 80,001$ to $\$ 100,000$
More than $\$ 100,000$

7. Do you belong to any of the following group(s)? Please tick ALL that are relevant.
Local resident (Raumati Beach, Kapiti coast, Paraparaumu, Waikane Beach)
Recreational fishermen
$\square$ Diver
Commercial fishermen
EnvironmentaVconservation group
University
Other (specify)

8. What is your postcode? if you don't know please go to http://tools.nzpost.co.nz/tools/address-postcodefinder/

Postcode

9. The survey questions are easily understood
Strongly agree
- Agree
Disagree
(2) Strongly disagree 
I would like to thank you for agreeing to answer these questions, and taking part in this interview. I wish to repeat that all the information provided by you is confidential and will only be used for academic purposes.

1. We will continue with this study for one more year, therefore I would like to ask you if you would like to take part in future surveys in this study
No
(- Yes

2. Would you like to have a copy of the results from this survey?
No

(1) Yes

*If you are agree to participate in future surveys or would like to have a copy of the results, please can you give me your contact information to contact you or send you the results required?

Name:
Address:
Contact phone:
E-mail:

Again, many thanks for your time!

More information at: http://www.doc.govt.nz 


\section{Appendix D}

\section{Education outcomes from the Experiencing Marine Reserves (EMR) programme by using the Taputeranga Marine Reserve}




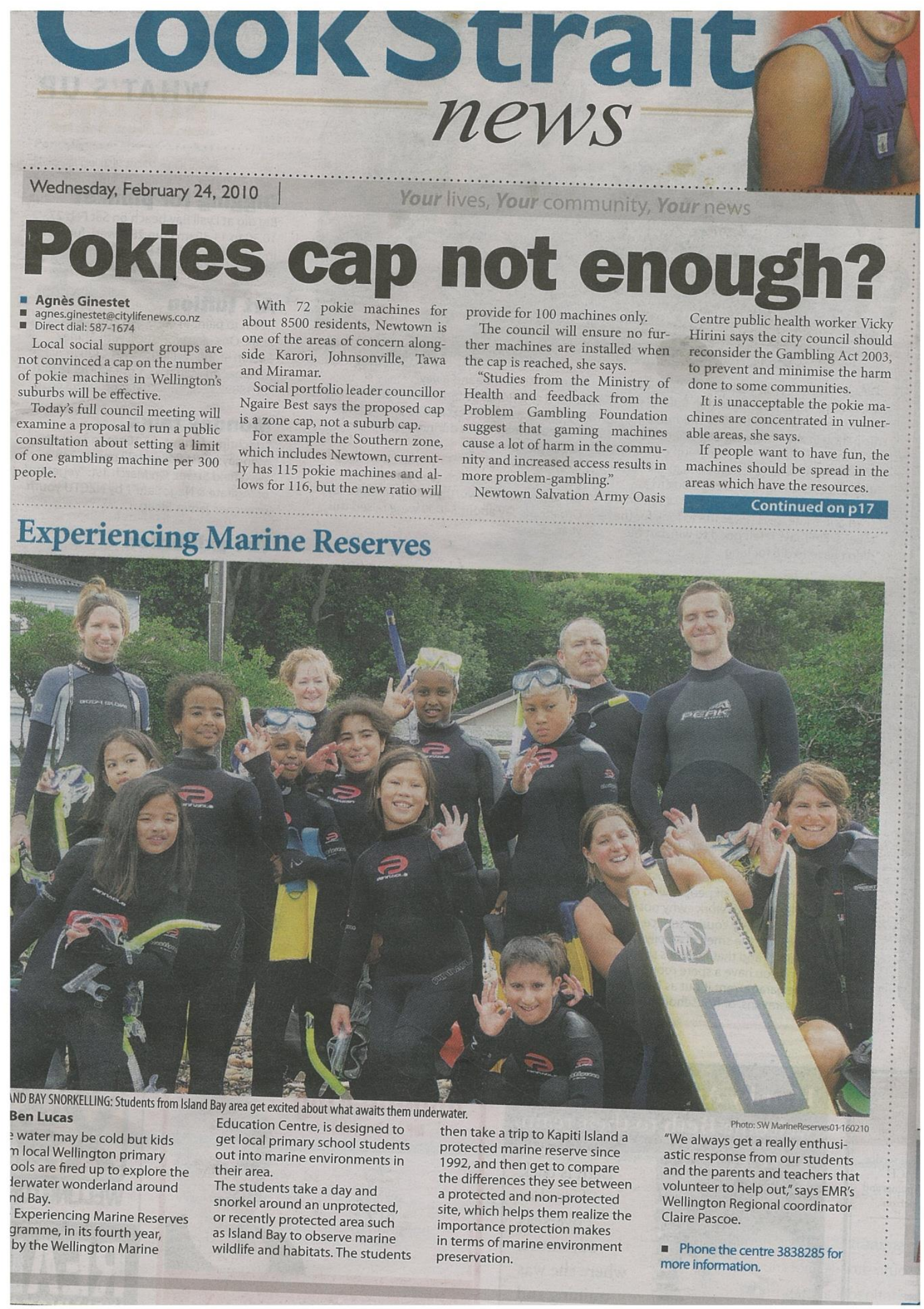

The EMR project as hot topic in the local news 


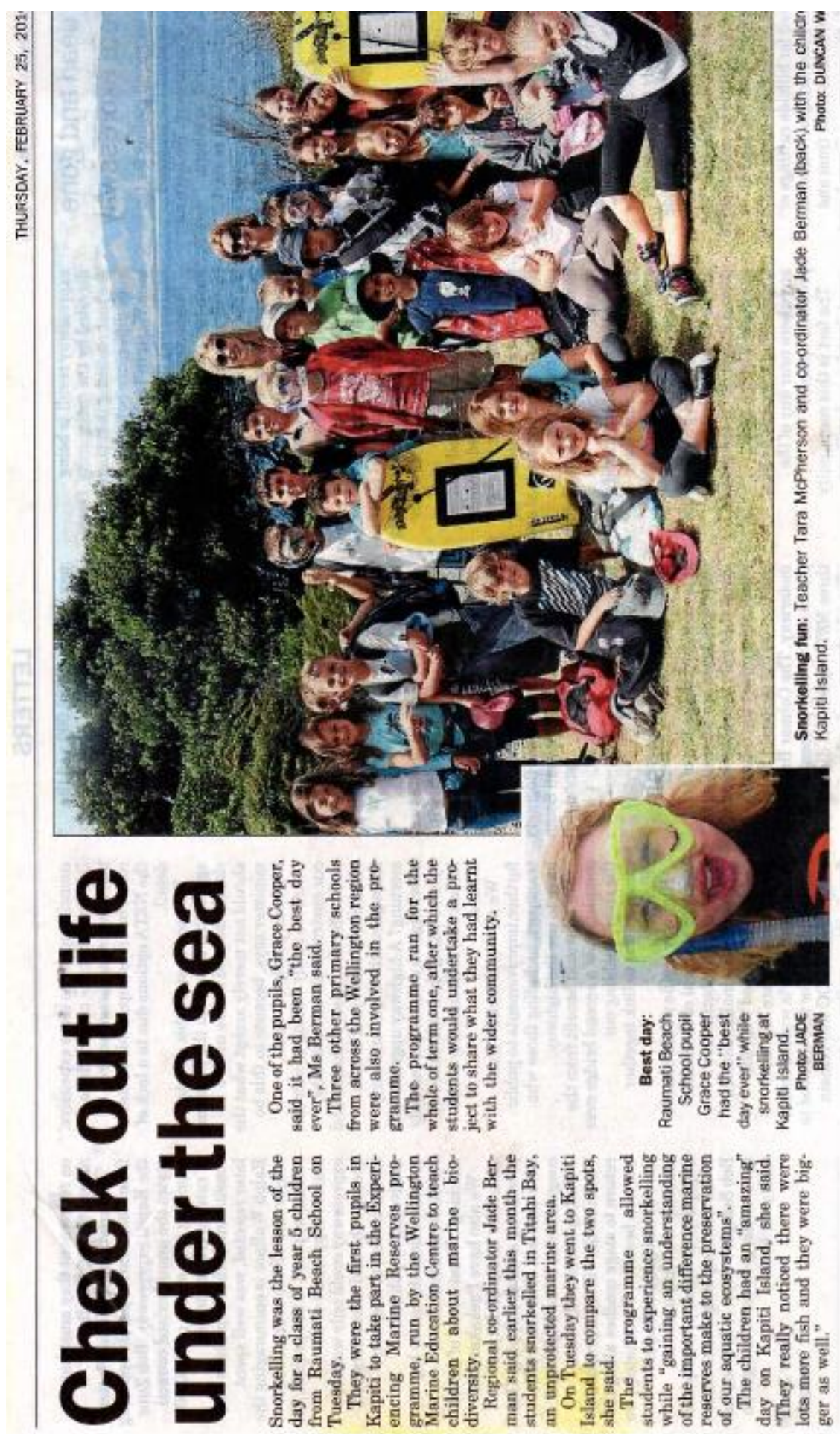




\title{
${ }^{m}$ Wellingtonian
}

\section{Children helping club with makeover}

\author{
The Wellingtonian Last updated 05:00 04/03/2010 \\ EMMA ALLEN
}

LIFE AQUATIC: Island Bay School pupils Ezra Moe-Jenkins, 9, left and Finn Meredith, 10 and Finn's mother Teresa Meredith study marine life off Island Bay beach.

Island Bay and Houghton Valley schools have joined forces with the Island Bay Marine Education Centre to give Islan Bay Surf Club a makeover.

The children are raising money by creating posters, models and bocklets to show what they have learned about the marine environment during trips to Island Bay.

The trips are part of the Experience Marine Reserves project that has been running four years. Berhampore and Raumati Beach schools are also involved in the project.

After the schoolchildren have been visited by marine experts, they are taken to a swimming pool to learn how to snork They then go to the Island Bay section of Taputeranga Marine Reserve, where they identify and count fish species.

They follow this with an action project, and Island Bay and Houghton Valley schools have decided their projects this $y$ will benefit the surf club.

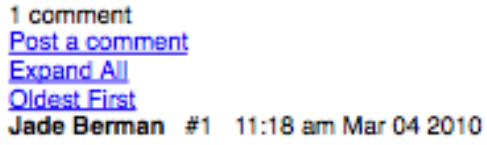

Correction to the above article - the Houghton Valley School are designing posters, comics and animations to raise awareness of marine reserves in their local community, not to raise money for the surf club. Last year Houghton Valle painted the new shark which is on the outside of the surf club as part of their projects through school.

Ad Feedback

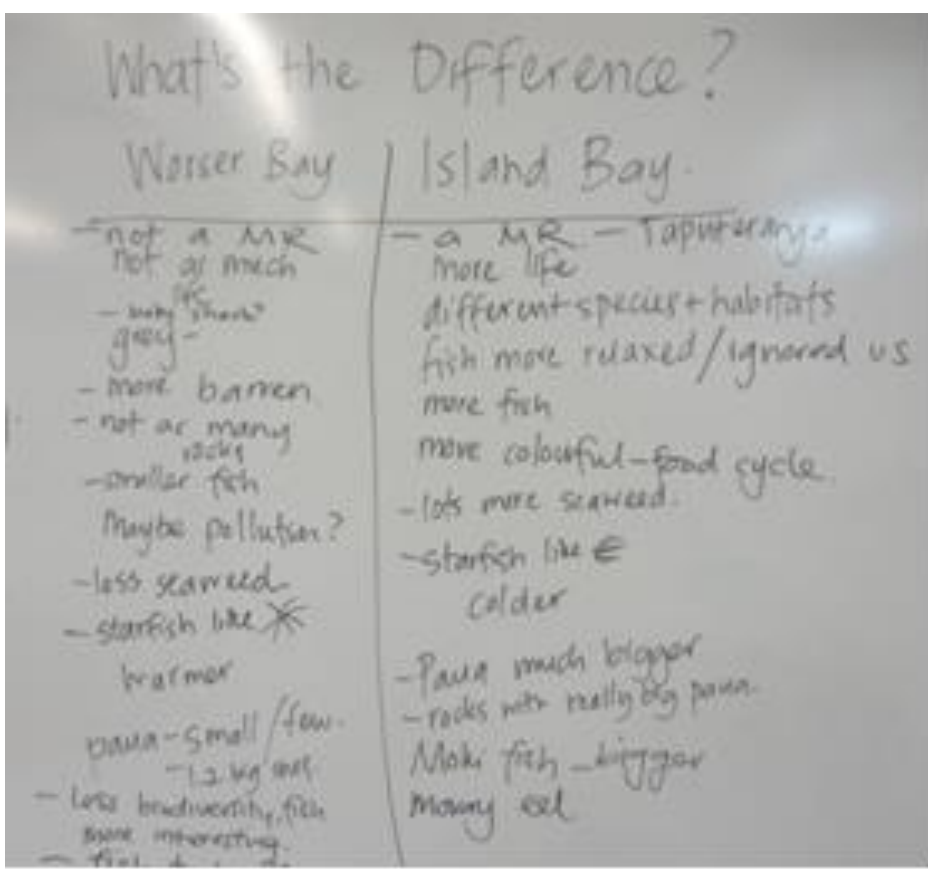

Students from the class had done a lot of work during their Inquiry journey and had lots of interesting ideas and observations about the difference between the two sites, and the difference marine protection can make. 


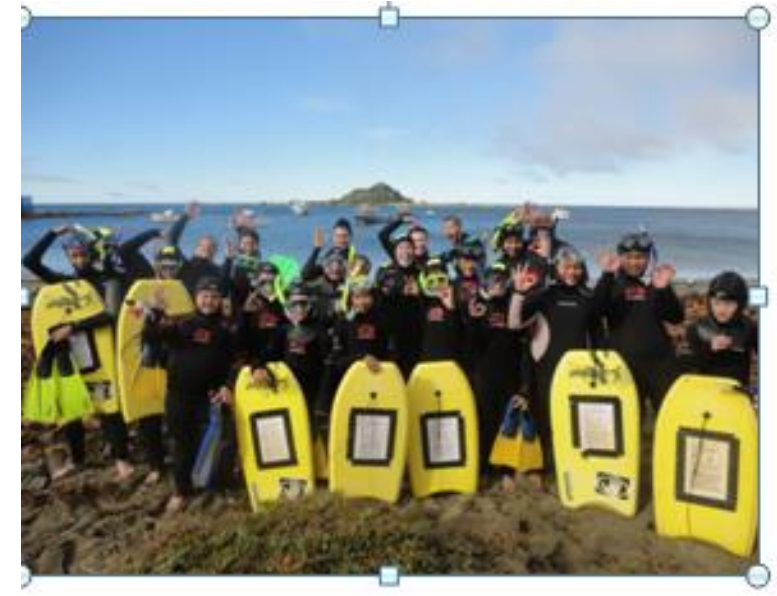

Year $7 / 8$ students at Taputeranga Marine Reserve

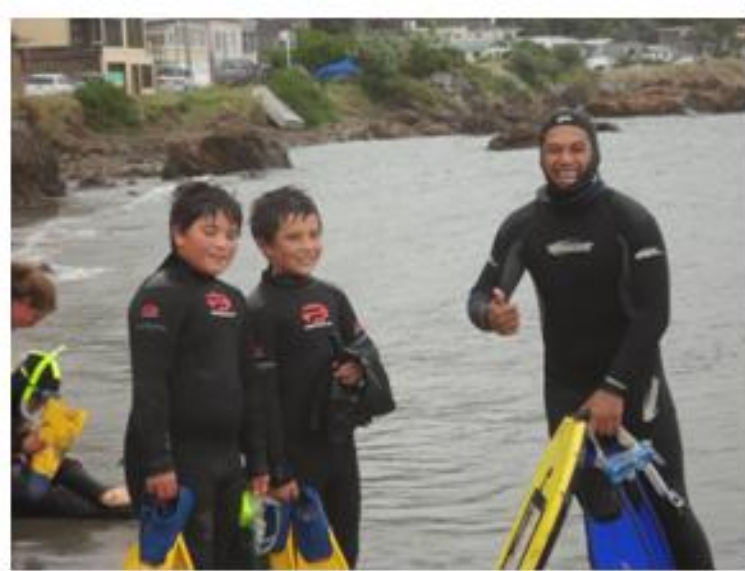

Eru, a community worker, with two students after their first ever snorkel

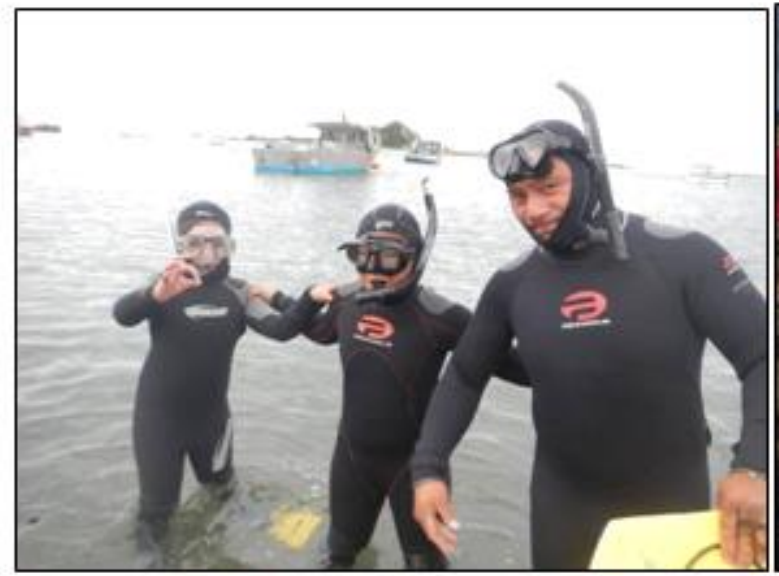

Parent volunteer Allan and students enter the water at Taputeranga.

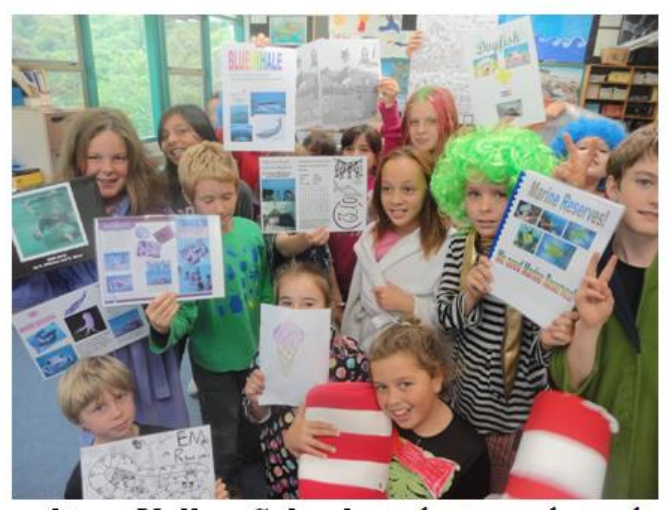

Houghton Valley School students undertook a range of different projects driven by the student's interests. The children created a websites, brochures which they distributed throughout the school, a book of photos of the experience was published and put into the school library. Posters and an EMR board game were also created. In addition the students undertook fundraising activities and have donated money to the Island Bay Marine Education Centre Aquarium, and \$231.50 to the Hectors Dolphin Trust. 


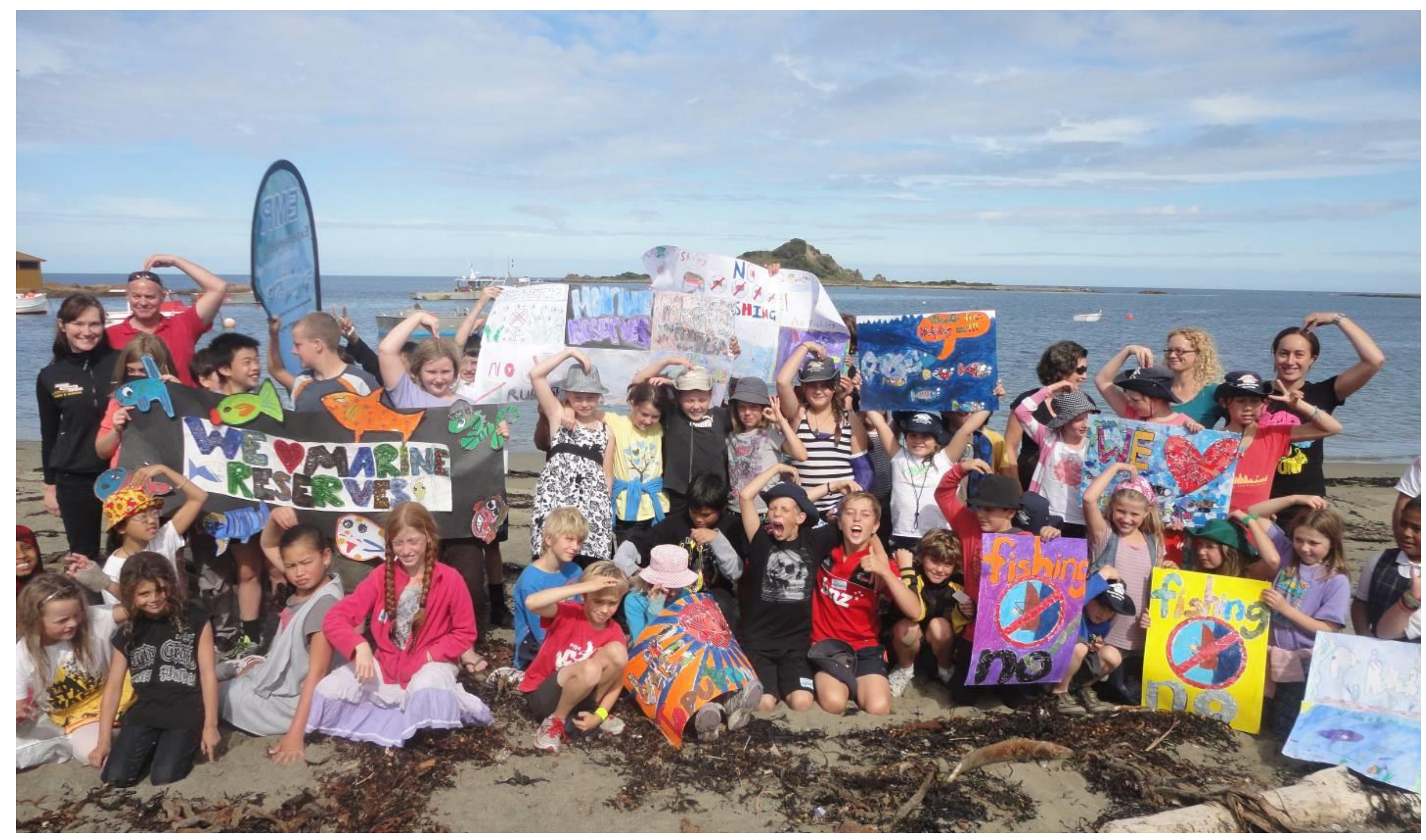

The EMR Project at Taputeranga Marine Reserve 
Appendix E

List with all researches and documents released by using Kapiti marine reserve and/or Taputeranga marine reserve. 


\begin{tabular}{cccc} 
MR Author $\quad$ Year & Name & $\begin{array}{c}\text { Type of } \\
\text { document }\end{array}$ & Publisher \\
\hline
\end{tabular}

Kapiti $\quad$ Maddren, N .
Battershill, C.N.,

Kapiti

K.R., Singleton, R.J., Arron, E.S., Page, M.J. \& Oliver, M.D.

Evaluating biological change in New Zealand marine reserves

A survey of marine habitats and communities of Kapiti Island

Monitoring of reef fish populations at Kapiti Island during aerial poisoning for rats, 1996.

Cole, R.G. \&

Singleton, R.J.

Pande, A.

National overview of biological monitoring in New Zealand's marine protected areas Department of Conservation,
Wellington, New Zealand.

stitute of Water and Atmospheric Research, Wellington (NIWA)
This research investigates the attitudes of recreational fishers to marine reserves, specifically the proposed Kapiti Island Marine Reserve, and how aspects of the recreation experience relate to these attitudes.

The Kapiti MR marine habitats and communities were surveyed and described. The aim of this study was to quantify the distribution and abundance of subtidal organisms around the Kapiti Island, and establish a database comparing community structure inside and outside reserves stretches of the Kapiti Island coast.

\section{Monitoring of reef fish populations at Kapiti Island.}

Taputeranga MR was monitored for three years prior the establishment . Kapiti MR was also monitored for the same time to establish what differences existed in size and abundance of key species between reserve and control sites.

Marine reserves, review, monitoring, ecological survey. This report provides a national overview of biological monitoring that has been undertaken or is in progress for 25 Marine Protected Areas and

Applications (MPAAs) in New Zealand-16 marine reserves (MR) and

the Sugar Loaf Islands Marine Park (SLIMPA) and 8 marine reserve applications (MRA). MPAAs have been established since 1975, however, most MPAA5 (22) have only been established or the applications lodged in the last 10 years.

NIWA's Video Ray Remotely Operated Vehicle (ROV) allowed for the underwater scenery and fish of the Kapiti Marine Reserve to be viewed on a television monitor on the boat. 
Continued from previous page

\begin{tabular}{|c|c|c|c|c|c|c|}
\hline MR & Author & Year & Name & $\begin{array}{c}\text { Type of } \\
\text { document }\end{array}$ & Publisher & Research Aim \\
\hline Kapiti & $\begin{array}{l}\text { Stewart, R.A. \& } \\
\text { MacDiarmid, A.B. }\end{array}$ & 2003 & $\begin{array}{l}\text { A Survey of Kaimoana at Kapiti Island, } 1999 \\
\text { and } 2000 .\end{array}$ & $\begin{array}{l}\text { Government } \\
\text { Report }\end{array}$ & $\begin{array}{l}\text { New Zealand Oceanographic } \\
\text { Institute NIWA, prepared for } \\
\text { DoC }\end{array}$ & $\begin{array}{l}\text { The aim of this study was to determine the response of selected } \\
\text { kaimoana species under different coastal management regimes with an } \\
\text { emphasis on rock lobster populations. Between January } 1999 \text { and } \\
\text { January 2000, dive surveys were completed at Kapiti Island in both the } \\
\text { reserve areas and the adjacent fished areas. }\end{array}$ \\
\hline Kapiti & $\begin{array}{l}\text { Shears, N.T. \& } \\
\text { Babcock, R.C. }\end{array}$ & 2004 & $\begin{array}{l}\text { Indirect effects of marine reserve protection } \\
\text { on New Zealand's rocky coastal marine } \\
\text { communities }\end{array}$ & $\begin{array}{l}\text { Government } \\
\text { Report }\end{array}$ & $\begin{array}{l}\text { Department of Conservation } \\
\text { (DoC) Science Internal Series } \\
192\end{array}$ & $\begin{array}{l}\text { Sea urchin barrens habitat, and algal community structure were } \\
\text { compared between reserve and non-reserve locations throughout New } \\
\text { Zealand to investigate the role of predators in controlling benthic } \\
\text { community structure. Kapiti MR was one of the MR sampled. }\end{array}$ \\
\hline Kapiti & Struthers, C.D. & 2004 & $\begin{array}{l}\text { Monitoring of blue cod (Parapercis co lias) } \\
\text { at Kapiti Marine Reserve, New Zealand,- a } \\
\text { comparison of survey methodologies }\end{array}$ & Master Thesis & $\begin{array}{l}\text { Thesis - Victoria University of } \\
\text { Wellington }\end{array}$ & $\begin{array}{l}\text { Temporal and spatial patterns of relative abundance and mean total } \\
\text { length (TL) of blue cod (Parapercis colias) were examined on the } \\
\text { western side of Kapiti Marine Reserve (KMR). }\end{array}$ \\
\hline Taputeranga & Manirakiza, A. & 2004 & $\begin{array}{l}\text { Proposed Wellington South Coast Marine } \\
\text { Reserve (Taputeranga Marine Reserve): } \\
\text { Towards Increasing Community Support }\end{array}$ & $\begin{array}{l}\text { Master Thesis - } \\
\text { VUW }\end{array}$ & $\begin{array}{l}\text { Thesis - Victoria University of } \\
\text { Wellington }\end{array}$ & $\begin{array}{l}\text { The aim of this research was to develop a set of community focussed } \\
\text { guidelines for the establishment of marine reserves in Wellington, based } \\
\text { on an in-depth understanding of the perceived impacts of the proposed } \\
\text { Taputeranga Marine Reserve on the community. }\end{array}$ \\
\hline Kapiti & $\begin{array}{l}\text { Harvey, A. } \\
\text { Woelkerling, W. } \\
\text { Farr, T. } \\
\text { Neill, K. } \\
\text { Nelson, W. }\end{array}$ & 2005 & $\begin{array}{l}\text { Biodiversity of crustose coralline algae in the } \\
\text { central NZ region }\end{array}$ & $\begin{array}{l}\text { Identification } \\
\text { guide }\end{array}$ & NIWA & $\begin{array}{l}\text { The priority of this research work, has been to develop a reliable and } \\
\text { durable reference, which can be used in fisheries and coastal } \\
\text { management, as well as in marine resource protection and conservation. }\end{array}$ \\
\hline Kapiti & $\begin{aligned} \text { Enderby, T. \& } & \text { Enderby, } \\
\text { J. } & \end{aligned}$ & 2006 & A guide to New Zealand's marine reserves & Book & New Holland Publishers & $\begin{array}{l}\text { This highly informative guide is written for tourists, outdoors } \\
\text { enthusiasts, divers, conservationists, students and scientists - anyone } \\
\text { with an interest in New Zealand's rich marine ecology. The book } \\
\text { contains an introduction to marine protected areas before covering each } \\
\text { reserve chapter by chapter, with maps, access details, activities and } \\
\text { facilities for visitors, as well as a mine of information on the wildlife } \\
\text { that can be encountered at each site. The appendices include a glossary, }\end{array}$ \\
\hline
\end{tabular}

list of species, further reading and index. 


\section{Continued from previous page}

\begin{tabular}{|c|c|c|c|c|c|c|}
\hline MR & Author & Year & Name & $\begin{array}{c}\text { Type of } \\
\text { document }\end{array}$ & Publisher & Research Aim \\
\hline Taputeranga & $\begin{array}{c}\text { Department of } \\
\text { Conservation (DoC) }\end{array}$ & 2007 & Taputeranga Marine Reserve & Brochure & Department of Conservation & Informative brochure about the Taputeranga Marine Reserve \\
\hline Kapiti & $\begin{array}{l}\text { Dave, A. \& Markby, J. } \\
\text { Department of } \\
\text { Conservation (DoC) }\end{array}$ & 2007 & Marine reserves: protecting our seas & $\begin{array}{c}\text { DVD } \\
\text { videorecording }\end{array}$ & $\begin{array}{l}\text { Department of Conservation } \\
\text { (DoC) by Liquid Action Films }\end{array}$ & $\begin{array}{c}\text { Documentary film about marine reserves in New Zealand. Twelve MRs } \\
\text { were analysed, and Kapiti MR was one of these. }\end{array}$ \\
\hline Kapiti & $\begin{array}{l}\text { Shears, N.T. and } \\
\text { Babcock R.C. }\end{array}$ & 2007 & $\begin{array}{l}\text { Quantitative description of mainland New } \\
\text { Zealand's shallow subtidal reef communities. }\end{array}$ & $\begin{array}{l}\text { Government } \\
\text { Report }\end{array}$ & $\begin{array}{l}\text { University of Auckland for } \\
\text { Department of Conservation }\end{array}$ & $\begin{array}{l}\text { In this study, surveys of shallow subtidal reef communities were carried } \\
\text { out at } 43 \text { locations ( } 247 \text { sites) throughout mainland New Zealand. } \\
\text { National and regional patterns in community structure are described, and } \\
\text { their relationships with environmental variables are investigated. }\end{array}$ \\
\hline Kapiti & $\begin{array}{l}\text { Pande, A., } \\
\text { MacDiarmid, A.B., Smith, } \\
\text { P.J., Davidson,R.J., } \\
\text { Cole, R.G., Freeman, D., } \\
\text { Kelly, S. \& } \\
\text { Gardner, J.P.A. }\end{array}$ & 2008 & $\begin{array}{l}\text { Marine reserves increase the abundance and } \\
\text { size of blue cod and rock lobster }\end{array}$ & Journal paper & $\begin{array}{l}\text { Marine Ecology Progress } \\
\text { Series }\end{array}$ & $\begin{array}{l}\text { Size and abundance data were compiled and collated for blue cod } \\
\text { Parapercis colias and rock lobster Jasus edwardsii from New Zealand } \\
\text { marine reserve (MR) studies for a meta-analysis to test the null } \\
\text { hypotheses that reserve status does not affect the size or abundance of } \\
\text { either species. Kapiti MR was one of the MRs analysed in this study. }\end{array}$ \\
\hline Taputeranga & $\begin{array}{ll}\text { Eddy, T., } & \text { Gardner, } \\
\text { J.P.A. \& } & \text { Bell, J.J. }\end{array}$ & 2008 & $\begin{array}{l}\text { A Status Report On the Biological and } \\
\text { Physical Information for Wellington's South } \\
\text { Coast with Monitoring Recommendations } \\
\text { for the Taputeranga Marine Reserve }\end{array}$ & $\begin{array}{l}\text { Government } \\
\text { Report }\end{array}$ & $\begin{array}{l}\text { Department of Conservation } \\
\text { (DoC) }\end{array}$ & $\begin{array}{l}\text { The aim of this report is to summarise information, particularly } \\
\text { highlighting research that is relevant to the monitoring of the } \\
\text { Taputeranga Marine Reserve (MR). It includes a spread sheet titled } \\
\text { "Marine Reserve Monitoring References" lists the studies that have } \\
\text { been conducted on the Wellington south coast indicating the species, } \\
\text { sites and methodologies used. }\end{array}$ \\
\hline Taputeranga & $\begin{array}{l}\text { Gardner, J.P.A. \& Bell, } \\
\text { J.J. (ed) }\end{array}$ & 2008 & The Taputeranga Marine Reserve & Book & $\begin{array}{c}\text { First Edition Publishers, } \\
\text { Wellington, New Zealand. } 534 \\
\text { pp. }\end{array}$ & $\begin{array}{l}\text { This highly impressive book has been edited by Jonathan Gardner, } \\
\text { Director of Victoria University's Centre for Marine Environmental \& } \\
\text { Economic Research with individual chapters contributed by experts in } \\
\text { their field. This comprehensive study is the only one of its kind and is } \\
\text { essential reading for all who are interested in the Taputeranga Marine } \\
\text { Reserve. }\end{array}$ \\
\hline
\end{tabular}


Continued from previous page

MR Author $\quad$ Year

Pande, A. \& Gardner, J.P.A.

Gardner, G.

Taputeranga

Friends of Taputeranga Issue 1, marine reserve

Banks, S.A. \&

Skilleter, G.A.

Taputeranga Berman J. \&

Bell

Bell 2010

Pérez-Matus, A. \& Shima,

Kapiti \&

Taputeranga

Barriball, L .

Mieszkowska, N . \&

Lundquist, C.J.

Taputeranga

Kapiti \&

Taputeranga
Eddy, T.D.

\section{Year}

Name

A baseline biological survey of the proposed

Taputeranga marine reserve (Wellington,

New Zealand): spatial and temporal variability along a natural environment

$$
\text { gradient }
$$

The Taputeranga Colouring-in Book

Taputeranga

Implementing marine reserve networks: A comparison of approaches in New South
Wales (Australia)and New Zealand

Spatial Variability of Sponge Assemblages on the Wellington South Coast, New Zealand

Journal paper

\section{The Open Marine Biology}

Journal

Disentangling the effects of macroalgae on the abundance of temperate reef fishes

Journal paper

Journal of Experimental Marine Biology and Ecology

\section{Master in Conservation -}

Egg diameter, body size, and individual variation in J. edwardsii

Biogeographical patterns in limpet abundance and assemblage composition in New Zealand

Marine reserves as conservation and resources use management tools: implications for coastal
Research Aim
This baseline data set was used to estimate temporal and spatia

variability in size and abundance of these taxa, and will be used to quantify taxon-specific changes in size and abundance once the MR is established

A great resource to encourage children to be aware of marine conservation issues. Based upon the new Taputeranga Marine Reserve located at Island Bay, Wellington.

It intends is to run and inform of newsletters on the Trust and more particularly, the Taputeranga Marine Reserve. The newsletters is one of the main means of reaching out to members of the Trust and to the wider community

It use TMR as an example of the establishment process of MRs in New Zealand.

The aim of this study was to provide baseline data for sponge biodiversity on the Wellington South Coast, New Zealand. Eighteen sites were qualitatively sampled resulting in the identification of 65 different sponge taxa.

In this study Taputeranga MR was one of the two sites selected in Wellington to manipulated macroalgal heterogeneity to determine the relative importance of different sources of habitat heterogeneity to the abundance of locally common reef fishes.

This study was conducted to test the relationship between egg size (diameter) and female body size, also to find whether Kapiti marine reserve and Taputeranga marine reserve in central New Zealand, do consequently contribute to larger eggs.

This paper documents the geographic distributions, abundances and assemblage patterns of intertidal limpets at 63 sites around the New Zealand coast, where Taputeranga is one of the sites.

This thesis has investigated the effects of human coastal resource use in New Zealand and Chile from social, economic and ecological, perspective through the use of different techniques by synthesising both quantitative and qualitative information sources. 
Continued from previous page

\begin{tabular}{|c|c|c|c|c|c|c|}
\hline MR & Author & Year & Name & $\begin{array}{c}\text { Type of } \\
\text { document }\end{array}$ & Publisher & Research Aim \\
\hline Taputeranga & Perea-Blázquez, A. & 2011 & $\begin{array}{l}\text { Interactions between Sponges and the Water } \\
\text { Column: Nutrient Utilisation and Feeding by } \\
\text { New Zealand } \\
\text { Subtidal Sponges }\end{array}$ & $\mathrm{PhD}$ Thesis & $\begin{array}{c}\text { Thesis - Victoria University of } \\
\text { Wellington }\end{array}$ & $\begin{array}{l}\text { The main goal of this research was to investigate the interactions } \\
\text { between sponges and the water column and how this varies in relation to } \\
\text { sponge characteristics, nutrient fluxes, seasonality and food supply. }\end{array}$ \\
\hline Taputeranga & $\begin{array}{l}\text { Friends of Taputeranga } \\
\text { marine reserve }\end{array}$ & $\begin{array}{l}\text { Issue 1, } \\
2011\end{array}$ & Taputeranga & $\begin{array}{l}\text { Community } \\
\text { newsletter }\end{array}$ & Taputeranga & $\begin{array}{l}\text { It intends is to run and inform of newsletters on the Trust and more } \\
\text { particularly, the Taputeranga Marine Reserve. The newsletters is one of } \\
\text { the main means of reaching out to members of the Trust and to the } \\
\text { wider community }\end{array}$ \\
\hline Taputeranga & $\begin{array}{l}\text { Friends of Taputeranga } \\
\text { marine reserve }\end{array}$ & $\begin{array}{l}\text { Issue } 1, \\
2011\end{array}$ & Taputeranga & $\begin{array}{l}\text { Community } \\
\text { newsletter }\end{array}$ & Taputeranga & $\begin{array}{l}\text { It intends is to run and inform of newsletters on the Trust and more } \\
\text { particularly, the Taputeranga Marine Reserve. The newsletters is one of } \\
\text { the main means of reaching out to members of the Trust and to the } \\
\text { wider community }\end{array}$ \\
\hline Taputeranga & $\begin{array}{l}\text { Friends of Taputeranga } \\
\text { marine reserve }\end{array}$ & $\begin{array}{l}\text { Issue } 2 \\
2011\end{array}$ & Taputeranga & $\begin{array}{l}\text { Community } \\
\text { newsletter }\end{array}$ & Taputeranga & $\begin{array}{l}\text { It intends is to run and inform of newsletters on the Trust and more } \\
\text { particularly, the Taputeranga Marine Reserve. The newsletters is one of } \\
\text { the main means of reaching out to members of the Trust and to the } \\
\text { wider community }\end{array}$ \\
\hline Taputeranga & $\begin{array}{l}\text { Friends of Taputeranga } \\
\text { marine reserve }\end{array}$ & $\begin{array}{l}\text { Issue 2, } \\
2011\end{array}$ & Taputeranga & $\begin{array}{l}\text { Community } \\
\text { newsletter }\end{array}$ & Taputeranga & $\begin{array}{l}\text { It intends is to run and inform of newsletters on the Trust and more } \\
\text { particularly, the Taputeranga Marine Reserve. The newsletters is one of } \\
\text { the main means of reaching out to members of the Trust and to the } \\
\text { wider community }\end{array}$ \\
\hline Taputeranga & $\begin{array}{l}\text { Friends of Taputeranga } \\
\text { marine reserve }\end{array}$ & $\begin{array}{c}\text { Issue 3, } \\
\text { August } \\
2011\end{array}$ & Taputeranga & $\begin{array}{l}\text { Community } \\
\text { newsletter }\end{array}$ & Taputeranga & $\begin{array}{l}\text { It intends is to run and inform of newsletters on the Trust and more } \\
\text { particularly, the Taputeranga Marine Reserve. The newsletters is one of } \\
\text { the main means of reaching out to members of the Trust and to the } \\
\text { wider community }\end{array}$ \\
\hline Taputeranga & $\begin{array}{l}\text { Friends of Taputeranga } \\
\text { marine reserve }\end{array}$ & $\begin{array}{l}\text { Issue } 4, \\
\text { October } \\
2011\end{array}$ & Taputeranga & $\begin{array}{l}\text { Community } \\
\text { newsletter }\end{array}$ & Taputeranga & $\begin{array}{l}\text { It intends is to run and inform of newsletters on the Trust and more } \\
\text { particularly, the Taputeranga Marine Reserve. The newsletters is one of } \\
\text { the main means of reaching out to members of the Trust and to the } \\
\text { wider community }\end{array}$ \\
\hline Kapiti & $\begin{array}{l}\text { Pande, A. \& Gardner, } \\
\text { J.P.A. }\end{array}$ & 2012 & $\begin{array}{l}\text { The Kapiti Marine Reserve (New } \\
\text { Zealand): spatial and temporal } \\
\text { comparisons of multi-species responses } \\
\text { after } 8 \text { years of protection }\end{array}$ & Journal paper & $\begin{array}{l}\text { New Zealand Journal of } \\
\text { Marine and } \\
\text { Freshwater Research }\end{array}$ & $\begin{array}{l}\text { In Kapiti MR macroalgal, macroinvertebrate and fish species were } \\
\text { surveyed for abundance and/or size at two sites inside and two outside } \\
\text { KMR and then conducted reservation status (inside vs outside KMR) } \\
\text { and temporal (1992 baseline vs } 1999 \text { 2000) tests to quantify biological } \\
\text { responses after } 8 \text { years of protection. }\end{array}$ \\
\hline
\end{tabular}


Continued from previous page

MR Author $\quad$ Year $\quad$ Name $\quad \begin{gathered}\text { Type of } \\ \text { document }\end{gathered}$ Publisher

Kapiti \&

Taputeranga

Neubauer, $\mathrm{P}$.

2012

Development and application of otolith based methods to infer demographic connections in a marine metapopulation

Perea-Blázquez, A.,

Taputerang

Davy, S.K. \& Bell, J.J

2012

Nutrient utilisation by shallow water temperate sponges in New Zealand

Estimates of Particulate Organic Carbon

A Perea-Blázquez, SK

Davy \& J J Bell

2012

Flowing from the Pelagic Environment to

the Benthos through Sponge Assemblages

Taputeranga

Berman, J.

Morelissen, B.

Gardner, J.P.A, \&

Struthers, C.D.
Patterns of temporal and spatial variability o sponge assemblages

Ecological Effects of Undaria pinnatifida (Harvey) Suringar and Nutrient-Enrichment

Comparisons among survey methodologies

to test for abundance and size of a highly targeted fish species
Journal paper

Hydrobiologia

This research investigated population connectivity of the common triplefin (Forsterygion lapillum) in Cook Strait, New Zealand, using chemical signatures contained within fish otoliths (ear stones). This study concentrate on likely connections between three local marine reserves: Kapiti Island (Kapiti coast), Long Island (Marlborough Sounds) and Taputeranga Marine Reserve (Wellington south coast).

This study investigated nutrient fluxes for several sponge species in order to estimate whether sponges were net producers or consume of nutrients from the water column, and how these patterns changed over time. Nutrient fluxes were examined at two sites located within the Taputeranga Marine Reserve on the south coast of Wellington, New Zealand.

Journal paper

This study examined the feeding activity of seven common sponge species from the Taputeranga marine reserve on the south coast of Wellington in New Zealand.

Thesis - Victoria University of Wellington

The primary goals of this thesis were to understand the spatial tempora pattern of sponge assemblage variation over a variety of scales and investigate suitable monitoring methods for sponge assemblages.

This thesis contributes to current gaps in knowledge in these areas for low-intertidal communities. Algal community dynamics and ecologica PhD Thesis Thesis - Victoria University of effects of the invasive kelp Undaria pinnatifida on low shores in the Wellington region, New Zealand, were examined, using field surveys and experiments.

Three sampling methods for estimating abundance and size of blue cod were compared inside and outside Kapiti Marine Reserve Two baited methods, baited underwater video (BUV) and experimental angling (EA), were more efficient and had lower levels of estimate variation than diver-based underwater visual census (UVC). 


\section{Continued from previous page}

\begin{tabular}{|c|c|c|c|c|c|c|}
\hline MR & Author & Year & Name & $\begin{array}{l}\text { Type of } \\
\text { document }\end{array}$ & Publisher & Research Aim \\
\hline $\begin{array}{l}\text { Kapiti \& } \\
\text { Taputeranga }\end{array}$ & Rojas Nazar, U.A. & In Progress & $\begin{array}{l}\text { A socio-economic evaluation of Marine } \\
\text { Reserves in New Zealand. }\end{array}$ & $\mathrm{PhD}$ Thesis & $\begin{array}{l}\text { Thesis - Victoria University of } \\
\text { Wellington }\end{array}$ & $\begin{array}{l}\text { The main goal of this research is to assess the economic value of the } \\
\text { marine environment, to improve decision-making and improve public } \\
\text { policies for marine conservation in NZ. }\end{array}$ \\
\hline Taputeranga & Diaz Guisado, D.E. & In Progress & $\begin{array}{l}\text { Effects of Marine Reserve protection on } \\
\text { adjacent non-protected populations in New } \\
\text { Zealand. }\end{array}$ & $\mathrm{PhD}$ Thesis & $\begin{array}{l}\text { Thesis - Victoria University of } \\
\text { Wellington }\end{array}$ & $\begin{array}{l}\text { The general aim of this research is to detect spillover (juvenile and adult } \\
\text { movement) from MRs to adjacent non-protected populations via the } \\
\text { detection of abundance gradients extending from reserves to fished } \\
\text { areas. }\end{array}$ \\
\hline Taputeranga & Byfield, T. & In Progress & $\begin{array}{l}\text { The Taputeranga Marine Reserve: Habitat } \\
\text { Mapping, ecosystem structure and } \\
\text { population connectivity }\end{array}$ & $\mathrm{PhD}$ Thesis & $\begin{array}{l}\text { Thesis - Victoria University of } \\
\text { Wellington }\end{array}$ & $\begin{array}{l}\text { Habitat Mapping, ecosystem structure of the Taputeranga Marine } \\
\text { Reserve }\end{array}$ \\
\hline $\begin{array}{l}\text { Kapiti \& } \\
\text { Taputeranga }\end{array}$ & Jones, $\mathrm{T}$. & In Progress & $\begin{array}{l}\text { Designing accurate and effective means of } \\
\text { monitoring marine ecosystems. }\end{array}$ & $\mathrm{PhD}$ Thesis & $\begin{array}{l}\text { Thesis - Victoria University of } \\
\text { Wellington }\end{array}$ & $\begin{array}{l}\text { This thesis consists of examining the effectiveness of marine monitoring } \\
\text { programmes at various marine reserves in New Zealand. Investigating } \\
\text { different methodologies for determining fish abundance at the Kapiti } \\
\text { Island marine reserve and developing a multispecies monitoring } \\
\text { approach for the Taputeranga Marine Reserve. }\end{array}$ \\
\hline $\begin{array}{l}\text { Taputeranga } \\
\text { \& Kapiti }\end{array}$ & Shima. J. & In Progress & $\begin{array}{l}\text { Investigation of the larval dispersal of } \\
\text { triplefin from the TMR to test the hypothesis } \\
\text { about larval dispersal from marine reserves. }\end{array}$ & $\begin{array}{c}\text { Research } \\
\text { project }\end{array}$ & $\begin{array}{l}\text { Victoria University of } \\
\text { Wellington }\end{array}$ & $\begin{array}{l}\text { The main goal was to sample larvae that potentially replenished the } \\
\text { reserve. We use otolith microchemistry to attempt to determine their } \\
\text { individual developmental histories (e.g., potentially, where they came } \\
\text { from, what developmental conditions they experienced, etc) }\end{array}$ \\
\hline Taputeranga & Shima. J. & In Progress & $\begin{array}{l}\text { Investigation of the larval dispersal of } \\
\text { triplefin from the TMR to test the hypothesis } \\
\text { about larval dispersal from marine reserves. }\end{array}$ & $\begin{array}{c}\text { Research } \\
\text { project }\end{array}$ & $\begin{array}{l}\text { Victoria University of } \\
\text { Wellington }\end{array}$ & $\begin{array}{l}\text { To evaluate how larvae with different developmental histories (e.g., } \\
\text { from different places, and/or that developed in favourable or } \\
\text { unfavourable conditions) interact with one another (e.g., whether fish } \\
\text { that settle in "good condition" do better when they are surrounded by } \\
\text { other fish that may be either more or fit or less fit). Because this study } \\
\text { will be conducting analyses of otolith microchemistry on sampled fish, } \\
\text { this study also (potentially) be able to evaluate patterns of larval } \\
\text { dispersal to- and from the reserve. }\end{array}$ \\
\hline
\end{tabular}

